\title{
The infinite alleles model revisited: a Gibbs sampling approach
}

\author{
Marc Manceau \\ July 22, 2021 \\ Department of Biosystems Science and Engineering, ETH Zürich, Basel, Switzerland \\ marc.manceau@ethz.ch
}

\begin{abstract}
The SARS-CoV-2 outbreak started in late 2019 in the Hubei province in China and the first viral sequence was made available to the scientific community on early January 2020. From there, viral genomes from all over the world have followed at an outstanding rate, reaching already more than $10^{5}$ on early May 2020, and more than $10^{6}$ by early March 2021. Phylodynamics methods have been designed in recent years to process such datasets and infer population dynamics and sampling intensities in the past. However, the unprecedented scale of the SARS-CoV-2 dataset now calls for new methodological developments, relying e.g. on simplifying assumptions of the mutation process.

In this article, I build on the infinite alleles model stemming from the field of population genetics to develop a new Bayesian statistical method allowing the joint reconstruction of the outbreak's effective population sizes and sampling intensities through time. This relies on prior conjugacy properties that prove useful both to develop a Gibbs sampler and to gain intuition on the way different parameters of the model are linked and inferred. I finally illustrate the use of this method on SARS-CoV-2 genomes sequenced during the first wave of the outbreak in four distinct European countries, thus offering a new perspective on the evolution of the sampling intensity through time in these countries from genetic data only.
\end{abstract}

Keywords : population genetics $\mid$ phylodynamics | infinite alleles $\mid$ coalescent $\mid$ prior conjugacy $\mid$

Gibbs sampling | 


\section{Contents}

1 Introduction 3

2 Model and notation 5

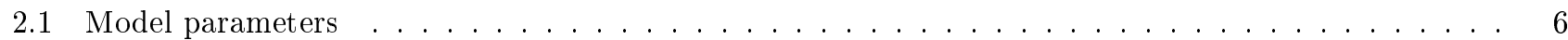

2.2 Past sampling and coalescent history . . . . . . . . . . . . . . . . . . . . . . . . . 6

2.3 Density of the full history $\ldots$. . . . . . . . . . . . . . . . . . . . . . . . 7

3 Inference method $\quad 7$

3.1 Observations and inference strategy . . . . . . . . . . . . . . . . . . . . . . 7

3.2 Prior conjugacy properties for parameters . . . . . . . . . . . . . . . . . . . . . . 9

$3.3 \quad$ Data augmentation with the past coalescent history . . . . . . . . . . . . . . . . . . . 10

3.4 Summary of the Gibbs sampler . . . . . . . . . . . . . . . . . . . . . . . . . . . . . 13

4 Numerical validation of the method 13

4.1 Past coalescent history . . . . . . . . . . . . . . . . . . . . . . . . . . 13

4.2 Simulation-based calibration . . . . . . . . . . . . . . . . . . . 14

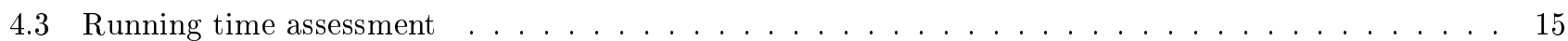

\begin{tabular}{|lll}
5 & Empirical application & 16
\end{tabular}

$5.1 \quad$ Data collection and preprocessing . . . . . . . . . . . . . . . . . . . . . 16

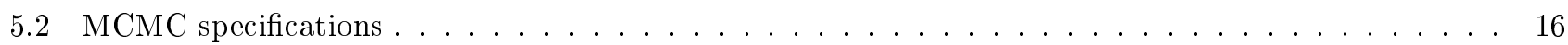

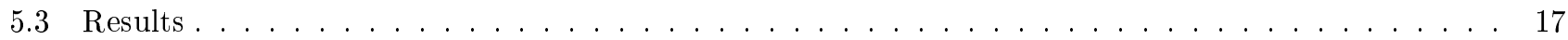

6 Discussion 19

A Details on the numerical method 25

B Case count data in the four countries

C Gibbs sampler code documentation 27

D Acknowledgements for data collection 28 


\section{Introduction}

The concept of descent with modification is central in modern biology, where biological entities evolving across various spatial and temporal scales (e.g. cells, individuals, species) can be seen as atomic particles carrying molecular sequences, that are passed on to their descent, while accumulating small gradual changes. As a result, the patterns of genetic differentiation obtained in a sample of particles depend on the underlying population dynamics, and can be analysed to retrieve information on this unobserved population dynamics. This is the aim shared by two related fields called population genetics and phylodynamics.

Population genetics and phylodynamics Molecular sequences are nowadays routinely being collected and analyzed throughout the tree of life, to address a wealth of biological questions, across fields such as ecology, anthropology, macroevolution, developmental biology, or epidemiology. In this manuscript, I focus on methods designed to investigate the population dynamics of a system through the analysis of genetic polymorphism. These methods have been applied across plenty of temporal and geographical scales, e.g. in ecology to study the population size trajectory of species (Parag et al. 2021), in epidemiology to estimate the prevalence of an infectious disease from sequences of pathogens sampled during an outbreak (Stadler et al. 2013), or in paleontology to study the species diversity trajectory of a clade over macroevolutionary time-scales (Morlon et al. 2011). While both fields address similar questions and may seem intertwined, their methodologies remained quite distinct, giving rise to two branches in the literature.

Population genetics approaches primarily aim at studying genetic variation within populations through time, based on genetic data. The recognition of the central influence of demography on genetic variation fostered the development of statistical methods aiming at inferring past demography from observed genetic polymorphism. The field has been very active since the beginning of the 70s, and most of the early theory is now digested in textbooks presenting the coalescent, with or without demography complications (Tavaré 2004; Hein et al. 2004, Durrett 2008). This early work relied on simplifying assumptions such as the infinite alleles or infinite sites models, when genetic data has been sampled at a single point in time. Elegant analytical developments of the probability distribution of summary statistics were derived, allowing one to investigate, e.g., population growth (Kuhner et al. 1998), population structure (Beerli and Felsenstein 1999), selection (McDonald and Kreitman 1991), or the presence of recombination Hudson 1983). Contemporary empirical applications usually deal with more complicated demography scenarios and samples taken at multiple points in time, and have thus adopted two different strategies. First, some studies rely on Principal Component Analysis or summary statistics that have been previously derived in very simple settings (Novembre et al. 2008). This approach is extremely fast and appropriate for an initial exploration of the dataset, still it lacks a quantitative aspect. Second, the rise of computational power fostered the development of Approximate Bayesian Computation to fit parameter-rich models using computationally intensive procedures (Skoglund et al. 2014 Kim et al. 2017).

Phylodynamics approaches stem from the field of phylogenetics, which aims at reconstructing the ancestral relationships between individuals, together with their evolutionary parameters, based on genetic data. In this field as well, researchers have acknowledged the key role of the demography in shaping the phylogenetic tree and hence the observed molecular patterns. This in turn promoted the rise of a subfield called phylodynamics, aiming at inferring the demography using molecular sequences, by integrating over precise phylogenetic relationships. The two main demography frameworks used in the field are (i) the coalescent, borrowed from Kingman (1982)'s work in population genetics and (ii) birth-death processes, relying on seminal results by Kendall (1948) and Nee et al. (1994). Compared to population genetics methods, there has been a cultural change towards more precise estimation relying on computationally intensive Bayesian inference methods. These methods rely on many superimposed model 
layers, among which e.g. models of clock evolution (Lepage et al. 2007), models of across-locus variation (Lartillot and Philippe 2004), and models of molecular substitution (Lanave et al. 1984). Moreover, phylodynamic methods have been developed to take into account serially sampled molecular data (Stadler 2010). Population dynamics has been modeled either in a coalescent framework using e.g. time-varying population size (Pybus and Harvey 2000 Drummond et al. 2002 Pybus et al. 2003), or in a birth-death framework, where the population is already free to fluctuate with constant birth and death rates, but larger variations can be allowed using time-varying parameters (Morlon et al. 2011; Stadler et al. 2013). As an alternative to time-dependent processes, some studies have attempted to introduce diversity-dependence processes in either a coalescent framework (Volz et al. 2009), or a birth-death framework (Etienne et al. 2012; Leventhal et al. 2013). Population structure can be modeled in a coalescent framework with discrete demes exchanging genes through migration (Ewing et al. 2004; Vaughan et al. 2014; Müller et al. 2017). In a birth-death process, structure is modeled using so-called multi-type birth-death processes, where different types are associated with different birth and death parameters, and individuals from a given type can either give birth to other types or directly change type (Maddison et al. 2007, Beaulieu and O'Meara 2016; Maliet et al. 2019, Barido-Sottani et al. 2020). Finally, methods have been developed to jointly consider occurrence and molecular data. In a coalescent framework, occurrences are assumed to be the result of a Poisson sampling process among the total population (Rasmussen et al. 2011 Parag et al. 2020). In a birth-death process, an individual can be sampled and sequenced at a given rate - in which case it appears in the tree - or sampled without being sequenced at another rate - in which case it is a simple occurrence (Vaughan et al. 2019; Gupta et al. 2020; Manceau et al. 2021).

Motivating example In this paper, I focus on inferring population dynamics for biological systems where (i) genetic polymorphism is sampled through time, and (ii) an ever increasing amount of sequences are being collected, challenging state-of-the-art methods for phylodynamic analysis.

The current SARS-CoV-2 pandemic provides the archetypal dataset that I propose to model. The outbreak survey started in late 2019, and the first viral genome was already published and made available for research on the 10th of January 2020. New sequences followed at an outstanding rate. By early May 2020, already more than $10^{5}$ viral sequences were available from across the world. A bit less than a year after, $10^{6}$ sequences have been reached before early March 2021. Developing statistical tools capable of keeping up with the pace of data acquisition thus represents a methodological challenge.

SARS-CoV-2 genomes have already been used to address a number of epidemiology-related questions, among which assessing the number and origins of introductions in a given locality (Gonzalez-Reiche et al. 2020; Lemey et al. 2020), the magnitude of super-spreading events (Li et al. 2020), or estimating the reproductive numbers of local outbreaks (Vaughan et al. 2020). Yet, phylogenetics/phylodynamics approaches do not scale well to large numbers of sequences and empirical applications typically require subsampling the original datasets.

The virus genome is approximately $3 \times 10^{4}$ nucleotides long, and its mutation rate, quite heterogeneous across the genome, has been estimated around 22 mutations per year per genome (Hadfield et al. 2018). As a result, new alleles and polymorphic sites of the genome have accumulated in the data at a slow pace. Together with the outstanding number of sequences, this rather slow mutation rate advocates for the use of simplifying assumptions of the mutation process.

The infinite alleles model Phylodynamic analyses generally assume a very realistic mutation process. Sequences have a finite number of sites, and each mutation hits a randomly chosen nucleotide, with a realistic substitution process ranging from the Jukes-Cantor to the Generalized Time Reversible model. Selection might even be modeled 
and nucleotides might have different mutation rates along the sequence. While these realistic models are very well designed to study fine-grain processes or processes happening over long timescales, they do not appear to be the best option to process large numbers of similar sequences. In this manuscript, I take a step back and aim at bringing back into fashion a simplifying assumption that has been traditionally considered in the early days of the neighbouring field of population genetics, namely the infinite alleles model. Under this model, each mutation hitting a sequence always creates a new allele never observed before. If we imagine that each sequence is a ball and an allele is a colour, genetic data thus simplifies as a sampling record of coloured balls through time, as illustrated in Figure 1 (Durrett 2008).

Analytical tractability is the main reason why the infinite alleles model is used nowadays. Following the past history of one genetic sequence backward in time, it can either (i) coalesce with another lineage that belongs to the same allele; or (ii) if it is the only representative of its allele, it can find the mutation that gave rise to it. Once this original mutation is found, everything else in the past is forgotten. The infinite alleles model was studied extensively during the golden age of population genetics, in combination with the coalescent model and for sequences sampled at a unique point in time. A closed-form analytical characterization of the probability distribution of the allele frequency spectrum in this setting exists, called Ewen's sampling formula (Ewens 1972).

The dynamics of the colour assemblage through time is informative of the underlying population dynamics that we are interested in inferring. I propose to work under a Bayesian framework, and to rely on population dynamics and sampling process assumptions similar to what has been recently used in phylodynamics. To ensure fast convergence of the Markov Chain Monte Carlo (MCMC) method that is used for inference, the model is (i) carefully built such that data augmentation can be performed efficiently, and (ii) relies on prior conjugacy properties and Gibbs sampling moves. This approach has been successfully applied to other phylogenetics methods before, and has shown a much faster convergence of MCMC methods relying on Gibbs sampling moves as compared to Metropolis-Hastings moves (Lartillot 2006). Further, prior conjugacy properties allow one to build a better intuition on the interactions between different parameters, which proves particularly convenient for the choice of prior distributions. As compared to state of the art phylodynamics methods, I aim at integrating over the unknown ancestral relationships more efficiently, with the hope to warrant dataset analysis on a larger scale.

Manuscript outline In Section 2, I introduce in more details the model assumptions, before turning to the inference strategy in Section 3. I then present in Section 4 some sanity checks and validate the inference method on simulated data. An empirical application in Section 5 illustrates the use of the method on the SARS-CoV2 sequences sampled during the first wave hitting Europe in 2020. Finally, I discuss in Section 6 the results of this paper as well as the future research challenges it opens. This manuscript is released along with the code implementing the method, and details on the implementation and use of the code are provided in Supp. Mat. C)

\section{Model and notation}

I build here on work by Parag et al. (2021) and Karcher et al. (2020), who both consider a sampling process on top of a coalescent model with piecewise-constant effective population sizes. The coalescent process is very conveniently described backward in time, and time will thus be, throughout the manuscript, the calendar time before present, in units of days for empirical applications, with $t=0$ at present and $t \rightarrow \infty$ in the past. 


\subsection{Model parameters}

The model is built around the following four key parameters.

First, the past effective population size is piecewise-constant on a partition of $(0,+\infty)$ into $p$ successive disjoint intervals $\left(\Delta_{j}^{(N)}\right)_{j=0}^{p-1}$ delimited by $0, \infty$, and the $p-1$ times $\left(t_{j}^{(N)}\right)_{j=1}^{p-1}$, i.e.

$$
N_{t}=\sum_{j=0}^{p-1} N_{j} \mathbb{1}_{\Delta_{j}^{(N)}}(t)
$$

where $\Delta_{j}^{(N)}=\left[t_{j}^{(N)}, t_{j+1}^{(N)}\right)$, with convention $t_{0}^{(N)}=0$ and $t_{p}^{(N)}=\infty$.

Second, following Parag et al. (2021), the past sampling intensity is also a piecewise-constant function, on a possibly different partition $\left(\Delta_{j}^{(S)}\right)_{j=0}^{p^{\prime}-1}$ of $(0, \infty)$, delimited by $0, \infty$, and the $p^{\prime}-1$ times $\left(t_{j}^{(S)}\right)_{j=1}^{p^{\prime}-1}$, i.e.

$$
S_{t}=\sum_{j=0}^{p^{\prime}-1} S_{j} \mathbb{1}_{\Delta_{j}^{(S)}}(t),
$$

where $\Delta_{j}^{(S)}=\left[t_{j}^{(S)}, t_{j+1}^{(S)}\right)$, with convention $t_{0}^{(S)}=0$ and $t_{p^{\prime}}^{(S)}=\infty$.

Last, the mutation rate $\mu$ and generation time $g$ are constant through time.

In a Bayesian framework, these parameters are random variables which are assigned prior distributions. The effective population sizes $\left(N_{j}\right)_{j=0}^{p-1}$ are assumed to be a priori distributed according to a Generalized Inverse Gaussian distribution, while the sampling intensities $\left(S_{j}\right)_{j=0}^{p^{\prime}-1}$ are assumed to be a priori distributed according to a Gamma distribution. Finally, the mutation rate $\mu$ and generation time $g$ are respectively a priori distributed according to a Gamma and Inverse-Gamma distribution. The choice of these prior distributions will be explained in Section 3 when discussing the posterior inference of these variables.

\subsection{Past sampling and coalescent history}

We assume that the sampling history is given by a Poisson Point Process (PPP) with rate

$$
\lambda_{t}^{(b)}:=S_{t} N_{t}
$$

generating the set of ordered sampling times $\mathcal{B}=\left(b_{i}\right)_{i=0}^{B-1}$ of all individuals. The total number of sampling events is denoted $B$, and individuals are numbered from 0 to $B-1$ in reverse birth time order. We will also call these sampling times the birth times of lineages when considering the history backward in time (hence the name $\mathcal{B}$ ). Lineages begin their backward-in-time journey as singletons $\{i\}$ where $i$ corresponds to the individual's number.

The past history of these lineages is further assumed to follow a standard coalescent with effective population size $N_{t}$, generation time $g$ and differentiation under an infinite alleles model with mutation rate $\mu$. That is, while there are $k_{t}$ lineages alive in the process, the next coalescent (resp. differentiation) event happens with rate,

$$
\begin{aligned}
& \lambda_{t}^{(c)}:=\left(\begin{array}{c}
k_{t} \\
2
\end{array}\right)\left(g N_{t}\right)^{-1} \\
& \lambda_{t}^{(d)}:=\mu k_{t} .
\end{aligned}
$$


When there is a coalescent event, two lineages $L_{i}$ and $L_{j}$, uniformly sampled among the $k_{t}$ living lineages at that time, are merged together in a unique lineage $L_{i} \cup L_{j}$. When there is a differentiation event, one of the $k_{t}$ living lineages is uniformly chosen to be killed. Forward in time, a coalescence corresponds to an individual giving birth to another individual, whereas a differentiation event corresponds to the acquisition of an original mutation responsible for the creation of an allele.

The past coalescent history thus generates in particular a partition of individuals into an allele partition $\mathcal{A}$ corresponding to the collection of all lineages killed by a mutation. It also generates the times at which differentiation and coalescent events, - jointly referred to as death events - happened in history. In order to record these, we take the following approach. Lineages are initially numbered with the same number as the individual's number it carries. Each coalescence involving two lineages numbered $j<i$ at time $t$ is considered to kill lineage $i$, and to keep living in lineage $j$ (see arrows on Fig. 11. By a slight abuse of language, we call such an event the death of individual $i$, and the time at which a mutation is found is the death time of the very first individual of the allele (see crosses on Fig. 1).

The coalescent history of all individuals is recorded in $\mathcal{H}=\left(h_{i}, o_{i}\right)_{i=0}^{B-1}$, where $h_{i}$ is the death time of individual $i$ and $o_{i} \in\{0,1, \ldots, i\}$ is the output of the death event, i.e. the number $j<i$ of the lineage in which lineage $i$ is merged if there is a coalescence, or $o_{i}=i$ if there is a mutation. The total number of alleles is denoted $D=\sum_{i=0}^{B-1} \mathbb{1}_{o_{i}=i}$. Finally, the record of the $B$ birth times $\left(b_{i}\right)$ and death times $\left(h_{i}\right)$, together with boundaries $t=0$ and $t=\infty$, yield a partition of the timeline into $2 B+1$ successive intervals that are denoted $\left(\Delta_{l}\right)_{l=0}^{2 B}$. On any such interval $\Delta_{l}$, the number of lineages remain constant and is denoted $k_{l}$.

\subsection{Density of the full history}

Figure 1 summarizes all notation introduced so far. Note already that, knowing $\mathcal{B}$ and $\mathcal{H}$, i.e. the full sampling and coalescent history, is enough to know the partition $\mathcal{A}$ of individuals into alleles. The density of this full past history $\mathcal{B}, \mathcal{H}$ given $N, S, \mu, g$ is further given by

$$
\mathbb{P}(\mathcal{B}, \mathcal{H} \mid N, S, \mu, g)=\left(\prod_{i=0}^{B-1} \lambda_{b_{i}}^{(b)}\left(\lambda_{h_{i}}^{(c)} \mathbb{1}_{o_{i} \neq i}+\lambda_{h_{i}}^{(d)} \mathbb{1}_{o_{i}=i}\right)\right) \exp \left(-\int_{0}^{\infty}\left(\lambda_{t}^{(b)}+\lambda_{t}^{(c)}+\lambda_{t}^{(d)}\right) d t\right)
$$

The above density belongs to the exponential family, and thus lends itself well to inference via a Gibbs sampling strategy, with priors that belong to other exponential family distributions. In the next Section, I turn to the description of this inference method.

\section{Inference method}

\subsection{Observations and inference strategy}

Data consist in the observation of the sampling times $\mathcal{B}$, together with the partition $\mathcal{A}$ of the set of $B$ individuals into $D$ alleles. I aim at inferring the posterior distribution of $N, S, \mu, g$, which consists, in a Bayesian framework, in sampling from,

$$
\mathbb{P}(N, S, \mu, g \mid \mathcal{A}, \mathcal{B})=\int_{\mathcal{H}} \mathbb{P}(N, S, \mu, g, \mathcal{H} \mid \mathcal{A}, \mathcal{B})
$$


sampling and coalescent history

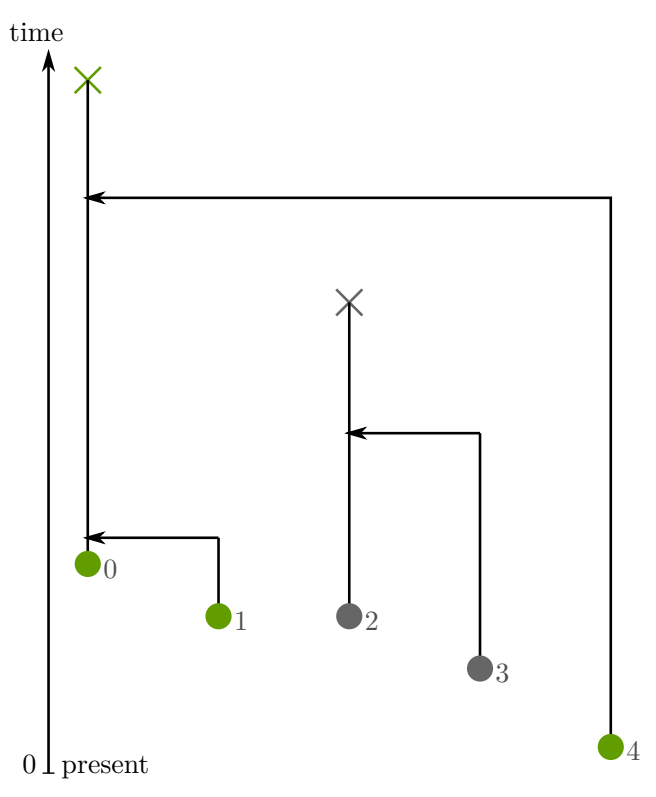

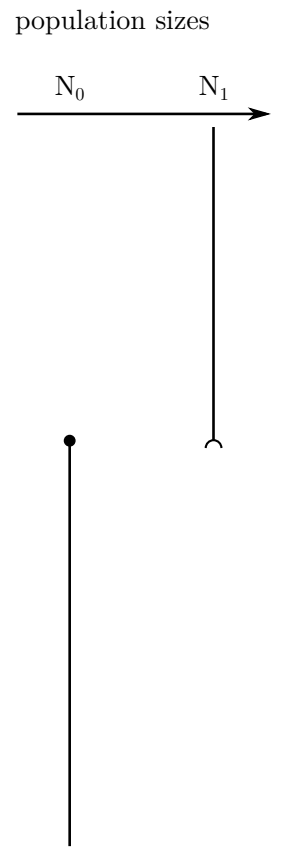

sampling intensities

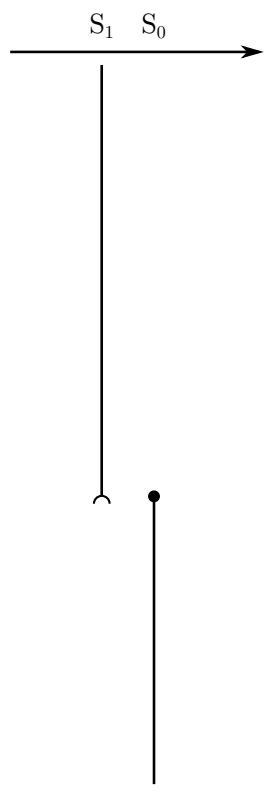

mutation rate generation time
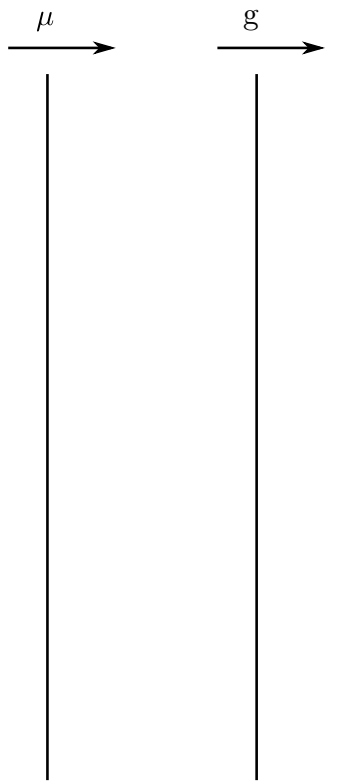

Figure 1: Model notation. Time is oriented from the present towards the past. To the left, individuals, represented as circles at their sampling time, are numbered in decreasing sampling times order and are colored according to the allele they belong to. Past coalescent events are represented with arrows, differentiation events are represented with crosses. The past coalescent history leads to the allele partition $\mathcal{A}=\{\{0,1,4\},\{2,3\}\}$. To the right, the parameters of the model that we are interested in inferring: the piecewise-constant past effective population sizes $N$, the piecewise-constant past sampling intensities $S$, the constant mutation rate $\mu$, and the constant generation time $g$.

where the right-hand side is augmented using the past coalescent history.

I take a Gibbs sampling approach to design a MCMC which converges to the stationary distribution of the augmented target distribution $\mathbb{P}(N, S, \mu, g, \mathcal{H} \mid \mathcal{A}, \mathcal{B})$. To do so, I derive efficient ways to alternatively sample from the following conditional laws,

$$
\begin{aligned}
& \mathbb{P}\left(N_{j} \mid N_{-j}, S, \mu, g, \mathcal{B}, \mathcal{H}\right) \\
& \mathbb{P}\left(S_{j} \mid N, S_{-j}, \mu, g, \mathcal{B}, \mathcal{H}\right) \\
& \mathbb{P}(\mu \mid N, S, g, \mathcal{B}, \mathcal{H}) \\
& \mathbb{P}(g \mid N, S, \mu, \mathcal{B}, \mathcal{H}) \\
& \mathbb{P}\left(H_{i}, O_{i} \mid N, S, \mu, g, \mathcal{A}, \mathcal{B}, H_{-i}, O_{-i}\right),
\end{aligned}
$$

where $N_{-j}, S_{-j}$ denote the effective population sizes and sampling intensities over all intervals other than the one numbered $j$, and $\left(H_{-i}, O_{-i}\right)$ denotes the death information of all individuals other than the one numbered $i$. Remark here that, on the first three lines, $\mathcal{A}$ disappeared from the conditioning because $\mathcal{A}, \mathcal{B}, \mathcal{H}=\mathcal{B}, \mathcal{H}$, i.e. knowing the sampling times and the coalescent history is enough to know the allele partition.

Designing an efficient Gibbs sampler in this context relies on the optimization of two critical steps: (i) one needs to derive the posterior distribution of the parameters conditioned on the augmented data; and (ii) one needs to efficiently perform a data augmentation step, i.e. simulate the past history $\mathcal{H}$ conditioned on the observed data and parameter values. 


\subsection{Prior conjugacy properties for parameters}

\subsubsection{Effective population size}

Recall that $N_{j}$ is a priori independent on $N_{-j}, S, \mu, g$ and is distributed according to a Generalized Inverse Gaussian distribution denoted $\mathcal{G} \mathcal{I} \mathcal{G}(\lambda, \chi, \psi)$. The following will justify this choice of prior. The GIG distribution belongs to the exponential family and is characterized by its density, usually parameterized as,

$$
\mathbb{P}\left(N_{j}\right) \propto N_{j}^{\lambda-1} \exp \left(-\frac{1}{2}\left(\chi N_{j}^{-1}+\psi N_{j}\right)\right)
$$

Its posterior is thus given by,

$$
\begin{aligned}
\mathbb{P}\left(N_{j} \mid N_{-j}, S, \mu, g, \mathcal{B}, \mathcal{H}\right) \propto & \mathbb{P}\left(N_{j}\right) \mathbb{P}(\mathcal{B}, \mathcal{H} \mid N, S, \mu, g) \\
\propto & N_{j}^{\lambda-1} \exp \left(-\frac{1}{2}\left(\chi N_{j}^{-1}+\psi N_{j}\right)\right) \\
& N_{j}^{\sum_{i=0}^{B-1} \mathbb{1}_{b_{i} \in \Delta_{j}^{(N)}}-\mathbb{1}_{o_{i} \neq i} \mathbb{1}_{h_{i} \in \Delta_{j}^{(N)}}} \\
& \exp \left(-N_{j}^{-1} g^{-1} \sum_{l=0}^{2 B}\left(\begin{array}{c}
k_{l} \\
2
\end{array}\right)\left|\Delta_{l} \cap \Delta_{j}^{(N)}\right|-N_{j} \sum_{k=0}^{p^{\prime}-1} S_{k}\left|\Delta_{k}^{(S)} \cap \Delta_{j}^{(N)}\right|\right),
\end{aligned}
$$

where the last line is obtained by substituting the density of $\mathcal{B}, \mathcal{H}$ using Equation (2.4), before dropping out all terms which do not depend on $N_{j}$.

This proves that the prior and posterior are conjugate distributions, with

$$
\begin{aligned}
& N_{j} \mid N_{-j}, S, \mu, g, \mathcal{B}, \mathcal{H} \\
& \sim \mathcal{G} \mathcal{I} \mathcal{G}\left(\lambda+B\left(\Delta_{j}^{(N)}\right)-C\left(\Delta_{j}^{(N)}\right), \chi+g^{-1} \sum_{l=0}^{2 B} k_{l}\left(k_{l}-1\right)\left|\Delta_{l} \cap \Delta_{j}^{(N)}\right|, \psi+2 \sum_{k=0}^{p^{\prime}-1} S_{k}\left|\Delta_{k}^{(S)} \cap \Delta_{j}^{(N)}\right|\right)
\end{aligned}
$$

where $C\left(\Delta_{j}^{(N)}\right)$ and $B\left(\Delta_{j}^{(N)}\right)$ are respectively the number of coalescent and sampling events happening over interval $\Delta_{j}^{(N)}$.

The choice of a conjugate prior will help (i) simplify the Gibbs sampling process, and (ii) provide a better intuitive understanding of the factors that influence the distribution of $N$.

\subsubsection{Sampling intensity}

Recall that $S_{j}$ is a priori independent on $N, S_{-j}, \mu, g$ and that $S_{j} \sim \Gamma(\alpha, \beta)$. Its posterior is thus given by,

$$
\begin{aligned}
\mathbb{P}\left(S_{j} \mid N, S_{-j}, \mu, g, \mathcal{B}, \mathcal{H}\right) & \propto \mathbb{P}\left(S_{j}\right) \mathbb{P}(\mathcal{B}, \mathcal{H} \mid N, S, \mu, g) \\
& \propto S_{j}^{\alpha-1} \exp \left(-\beta S_{j}\right) S_{j}^{\sum_{i=0}^{B-1} \mathbb{1}_{b_{i} \in \Delta_{j}^{(S)}}} \exp \left(-S_{j} \sum_{k=0}^{p-1} N_{k}\left|\Delta_{k}^{(N)} \cap \Delta_{j}^{(S)}\right|\right)
\end{aligned}
$$

where the last line is obtained again by substituting the density of $\mathcal{B}, \mathcal{H}$ using Equation 2.4 , before dropping out all terms which do not depend on $S_{j}$. 
This shows that the prior and posterior are conjugate distributions, with

$$
S_{j} \mid N, S_{-j}, \mu, g, \mathcal{B}, \mathcal{H} \sim \Gamma\left(\alpha+B\left(\Delta_{j}^{(S)}\right), \beta+\sum_{k=0}^{p-1} N_{k}\left|\Delta_{k}^{(N)} \cap \Delta_{j}^{(S)}\right|\right) .
$$

\subsubsection{Mutation rate}

Recall that, a priori, $\mu \sim \Gamma(\alpha, \beta)$. Following the same strategy as above, its posterior is given by,

$$
\begin{aligned}
\mathbb{P}(\mu \mid N, S, g, \mathcal{B}, \mathcal{H}) & \propto \mathbb{P}(\mu, \mathcal{B}, \mathcal{H} \mid N, S, g) \\
& \propto \mathbb{P}(\mu) \mathbb{P}(\mathcal{B}, \mathcal{H} \mid N, S, \mu, g) \\
& \propto \mu^{\alpha-1} \exp (-\beta \mu) \mu^{D} \exp \left(-\mu \sum_{l=0}^{2 B} k_{l}\left|\Delta_{l}\right|\right) .
\end{aligned}
$$

We conclude that the prior and posterior of $\mu$ are conjugate distributions, with,

$$
\mu \mid N, S, g, \mathcal{B}, \mathcal{H} \sim \Gamma\left(\alpha+D, \beta+\sum_{l=0}^{2 B} k_{l}\left|\Delta_{l}\right|\right) .
$$

\subsubsection{Generation time}

Last, recall that $g$ is a priori distributed according to an Inverse-Gamma distribution denoted $\Gamma^{-1}(\alpha, \beta)$. Its posterior is given by,

$$
\begin{aligned}
\mathbb{P}(g \mid N, S, \mu, \mathcal{B}, \mathcal{H}) \propto & \mathbb{P}(g) \mathbb{P}(\mathcal{B}, \mathcal{H} \mid N, S, \mu) \\
\propto & g^{-(\alpha+1)} \exp \left(-\beta g^{-1}\right) \\
& g^{-\sum_{i=0}^{B-1} \mathbb{1}_{o_{i} \neq i}} \\
& \exp \left(-g^{-1} \sum_{l=0}^{2 B} \sum_{j=0}^{p-1}\left(\begin{array}{c}
k_{l} \\
2
\end{array}\right) N_{j}^{-1}\left|\Delta_{l} \cap \Delta_{j}^{(N)}\right|\right)
\end{aligned}
$$

which means that the posterior is

$$
g \mid N, S, \mu, \mathcal{B}, \mathcal{H} \sim \Gamma^{-1}\left(\alpha+B-D, \beta+\sum_{l=0}^{2 B} \sum_{j=0}^{p-1}\left(\begin{array}{c}
k_{l} \\
2
\end{array}\right) N_{j}^{-1}\left|\Delta_{l} \cap \Delta_{j}^{(N)}\right|\right)
$$

This ends the description of the four conjugate priors used for $N, S, \mu, g$. They will be used in the final Gibbs sampler to quickly update the posterior of these variables of interest, provided $\mathcal{B}, \mathcal{H}$ are observed.

\subsection{Data augmentation with the past coalescent history}

Under the assumption of an infinite alleles model with constant effective population size $N$ and constant mutation rate $\mu$, the distribution of the past history of a sample of $n$ genes taken at a single point in time can be efficiently sampled using the equivalence with the Hoppe's urn process (Durrett 2008). Yet, when sequences are heterochronous 
- i.e. have been sampled through time instead of at a single point in time - and when the population size is not constant anymore, an alternative strategy is needed.

Recall that $H_{i} \in \mathbb{R}^{+}$is the death time of a focal individual $i$, and that $O_{i} \in\{0,1, \ldots, i\}$ is the death output. Death can happen either through coalescence with other lineages $\left(O_{i}=j<i\right)$, or through mutation $\left(O_{i}=i\right)$. We aim here at sampling death information $\left(H_{i}, O_{i}\right)$ of each sequence in turn, conditioned on everything else, i.e. when $N, S, \mu, g, \mathcal{A}, \mathcal{B}, H_{-i}, O_{-i}$ are fixed.

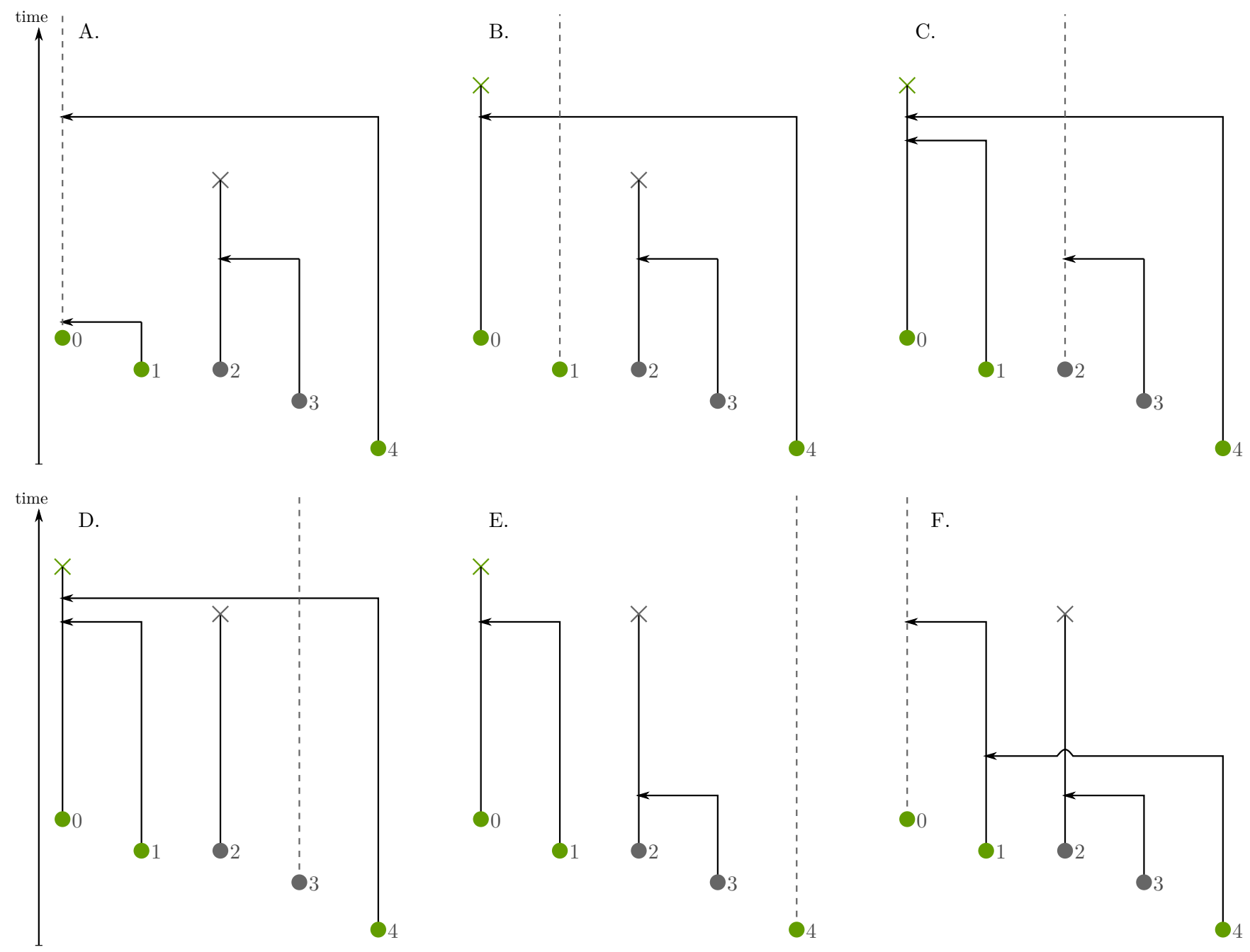

Figure 2: Gibbs sampling approach for simulating the past history of a sample given the allele partition. A-F, Each leaf is considered in turn, and its time of extinction is sampled given the rest of the coalescent history is fixed.

In a standard coalescent process, one can draw $\left(H_{i}, O_{i}\right)$ from left to right: if a focal lineage $i$ sees $k_{t}$ other lineages already drawn to the left, at time $t$, it coalesces with one of them at rate $k_{t}\left(N_{t} g\right)^{-1}$, or finds a mutation at rate $\mu$. Yet, when imposing our conditioning, only a fraction of these events leads to the known allele partition $\mathcal{A}$ and is compatible with the known coalescent history $\left(H_{-i}, O_{-i}\right)$. In particular, the allele partition and past coalescent history excluding $i$ reveal that (i) lineage $i$ dies through a coalescent event if and only if it can coalesce with an other lineage to the left, and (ii) lineage $i$ cannot die before being sampled, nor before reaching the very last coalescence of other lineages with itself, i.e. $H_{i} \geq m_{i}:=\max \left(\left\{b_{i}\right\} \cup\left\{H_{j}, j>i\right.\right.$ such that $\left.\left.O_{j}=i\right\}\right)$.

A first strategy to draw $\left(H_{i}, O_{i}\right)$ conditioned on everything else would thus consist in drawing $\left(H_{i}, O_{i}\right)$ without conditioning, while subsequently rejecting simulations which outcome is incompatible with $\mathcal{A}, \mathcal{O}_{-i}, \mathcal{H}_{-i}$. I take here 
the following alternative approach to avoid rejecting too many simulations. On all intervals $\Delta_{l}=\left(t_{l}, t_{l+1}\right)$ where the total number of lineages $k_{l}$ remains constant and where $t_{l} \geq m_{i}$, the probability that $H_{i}$ falls within the interval conditioned on everything else is computed,

$$
\begin{aligned}
\mathbb{P}\left(H_{i} \in \Delta_{l} \mid \mathcal{A}, \mathcal{B}, H_{-i}, O_{-i}\right) & \propto \mathbb{P}\left(H_{i} \in \Delta_{l}, \mathcal{A} \mid \mathcal{B}, H_{-i}, O_{-i}\right) \\
& =\mathbb{P}\left(H_{i} \in \Delta_{l} \mid \mathcal{B}, H_{-i}, O_{-i}\right) \mathbb{P}\left(\mathcal{A} \mid \mathcal{B}, H, O_{-i}\right) \\
& =\mathbb{P}\left(H_{i}>t_{l}, H_{i}<t_{l+1} \mid \mathcal{B}, H_{-i}, O_{-i}\right) \sum_{O_{i}} \mathbb{P}\left(O_{i}, \mathcal{A} \mid \mathcal{B}, H, O_{-i}\right) \\
& =\mathbb{P}\left(H_{i}>t_{l} \mid \mathcal{B}, H_{-i}, O_{-i}\right) \mathbb{P}\left(H_{i}<t_{l+1} \mid \mathcal{B}, H_{-i}, O_{-i}, H_{i}>t_{l}\right) \frac{N g \mu \mathbb{1}_{o_{i}=i}+k_{a}^{<i} \mathbb{1}_{o_{i} \neq i}}{N g \mu+k_{l}} \\
& =\mathbb{P}\left(H_{i}>t_{l} \mid \mathcal{B}, H_{-i}, O_{-i}\right)\left(1-e^{-\left(\mu+k(N g)^{-1}\right)\left(t_{l+1}-t_{l}\right)}\right) \frac{N g \mu \mathbb{1}_{o_{i}=i}+k_{a}^{<i} \mathbb{1}_{o_{i} \neq i}}{N g \mu+k_{l}} \\
& =: w_{l},
\end{aligned}
$$

where $k_{a}^{<i}$ denotes the number of living lineages to the left of $i$ belonging to the same allele $a$ as $i$.

The above formula is used to recursively compute from bottom to top the weights $w_{l}$ associated to all intervals $\Delta_{l}$ above $m_{i}$. Once these have been computed, we have access to, and can sample from, $\mathbb{P}\left(H_{i} \in \Delta_{l} \mid \mathcal{A}, \mathcal{B}, H_{-i}, O_{-i}\right)=$ $w_{l} / \sum_{k} w_{k}$. Note in addition that, if lineage $i$ satisfies $o_{i} \neq i$, then only intervals from time $m_{i}$ up to time $M_{i}:=\max H_{-i}$ matter, since it must coalesce before the mutation is found. If lineage $i$ dies through a mutation, i.e. $o_{i}=i$, then intervals from time $m_{i}=\max H_{-i}$ up to $\infty$ must be weighted, since the lineage cannot die before everybody else has coalesced into itself.

Once the interval on which the death event happens has been drawn, it remains to draw from $\mathbb{P}\left(H_{i} \in d t \mid H_{i} \in\right.$ $\left.\Delta_{l}\right)$, which corresponds to an exponential distribution with rate $\left(\mu+k_{l}(N g)^{-1}\right)$ conditioned on happening on $\Delta_{l}$. Further, $O_{i}=i$ if the lineage must die through a mutation, or $O_{i}$ is a uniformly chosen lineage $j<i$, in the same allele as lineage $i$, living on interval $\Delta_{l}$. The procedure for drawing $\left(H_{i}, O_{i}\right)$ is summarized in Algorithm 1 and illustrated in Figure 2 .

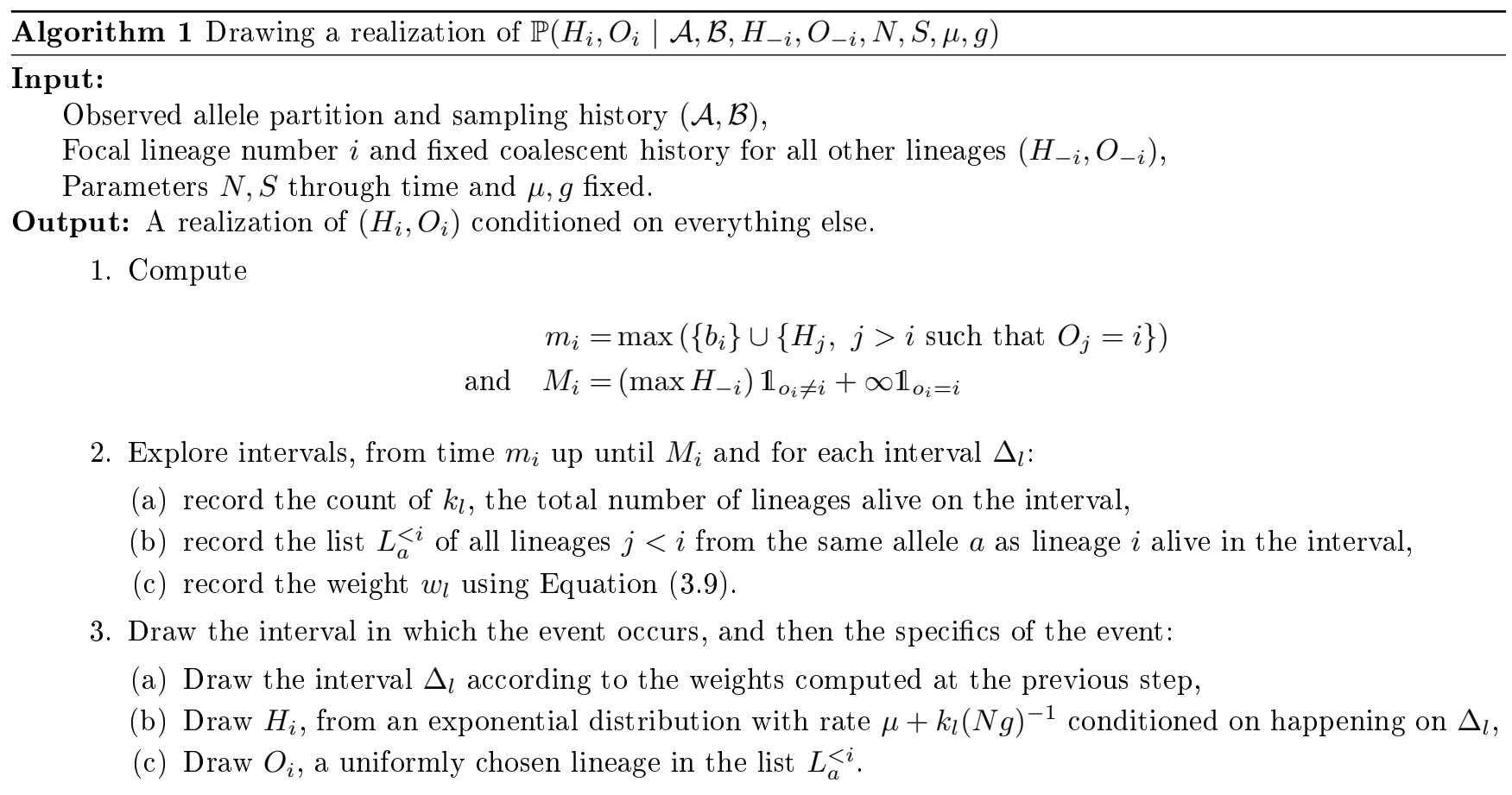




\subsection{Summary of the Gibbs sampler}

The final Gibbs sampler is a simple MCMC that is initialized using the priors of $N, S, \mu, g$, before relying on repeated updates of the four variables $N, S, \mu, g, \mathcal{H}$, using their conditional probabilities. Algorithm 2 summarizes these steps.

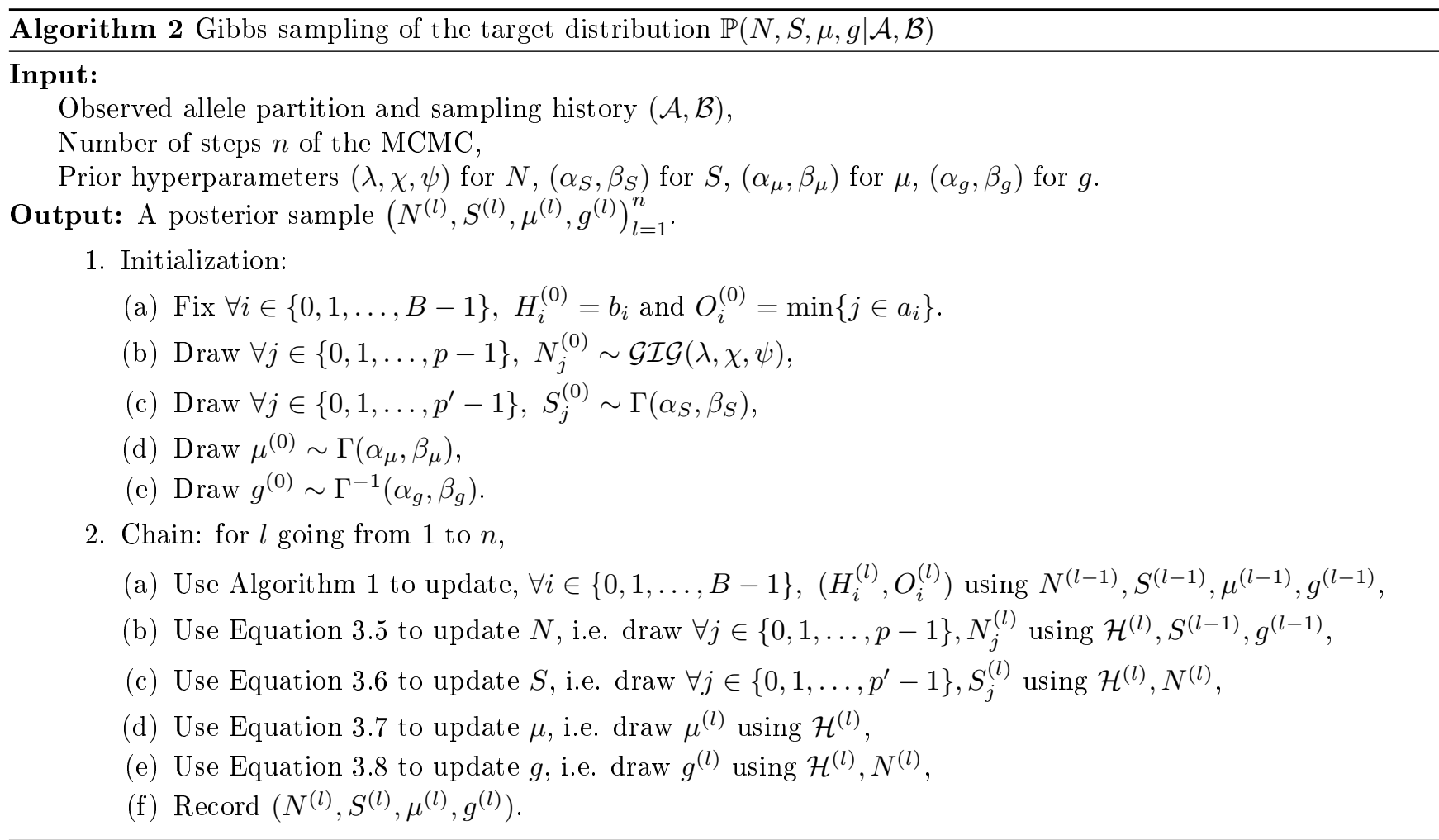

In the next Section, I validate the behaviour of this MCMC on simulated datasets before applying it to empirical datasets in Section 5 .

\section{Numerical validation of the method}

\subsection{Past coalescent history}

I first aim to validate the procedure described in Section 3.3 and the implementation of Algorithm 1. To do so, I wrapped Algorithm 1 in a minimalist Gibbs sampler aiming at sampling from $\mathbb{P}(\mathcal{H} \mid \mathcal{A}, \mathcal{B}, N, S, \mu, g)$. I fix $\mathcal{B}, \mathcal{A}$ as well as all parameters of the model $N, S, \mu, g$. I then use a simplified version of the MCMC described as Algorithm 2. where all updates concerning $N, S, \mu, g$ are skipped. To draw one observation of $\mathcal{H}$, I performed $n=50$ complete cycles of leaf updates, and kept only the last state reached by the MCMC.

I compare the distribution obtained using this procedure with the distribution of $\mathcal{H}$ obtained by a naive rejection algorithm, consisting in simulating the coalescent process backwards in time, while rejecting outcomes that do not satisfy $\mathcal{A}$. The distributions are compared based on summary statistics computed on $10^{4}$ samples drawn in both distributions: (i) the proportion of samples having a mutation in successive death events, as well as (ii) the distribution of death times. Note that the dataset must be small, for the rejection algorithm very quickly becomes computationally too intensive to be used. Figure 3 illustrates the perfect agreement between both distributions, 
on a toy dataset with $N=10, g=0.1, \mu=1.5$, and two alleles respectively joining individuals sampled at times $(0,0.2,0.5)$ and $(0.3,0.7)$.
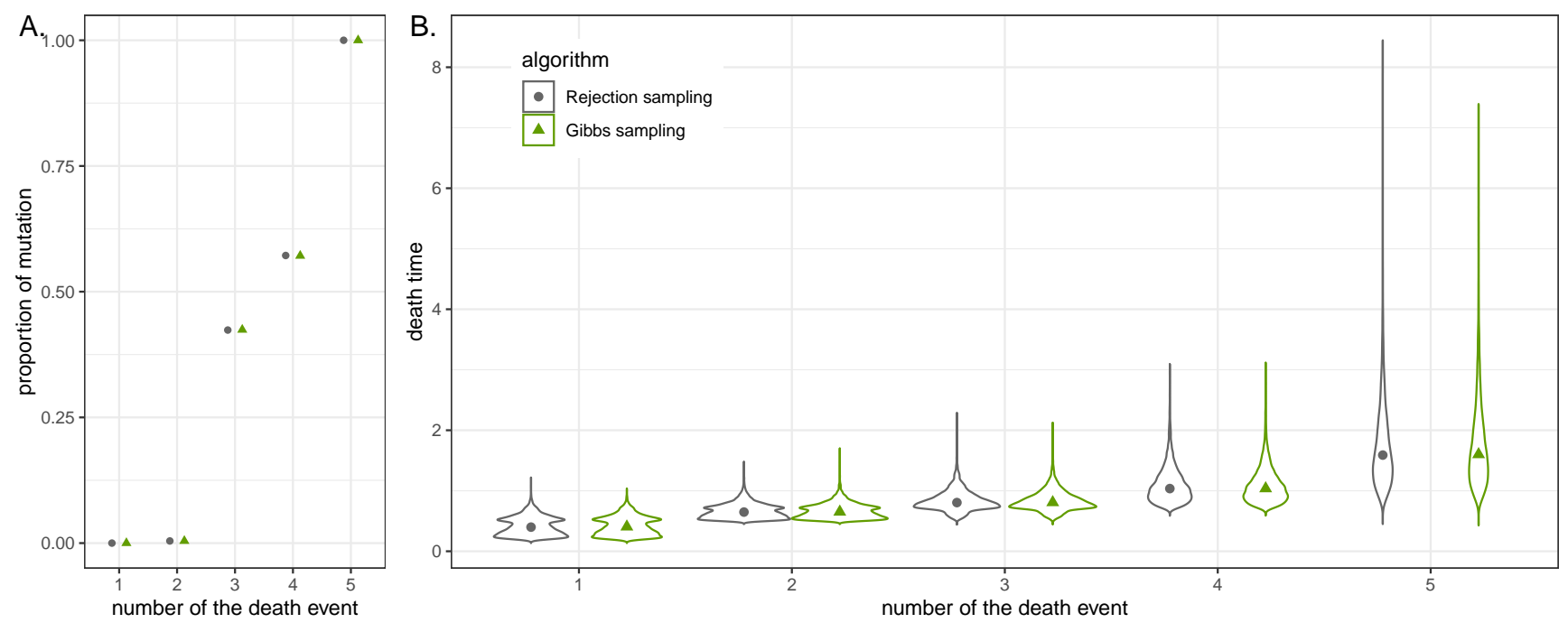

Figure 3: Comparison of the distribution of $\mathcal{H}$ conditioned on $\mathcal{A}$ obtained using a naive rejection algorithm or a custom Gibbs sampler relying on Algorithm 11. The number of the death event in x-axis refers to an order by increasing death time. A. Proportions of mutations in each death event. B. Distributions of death times.

\subsection{Simulation-based calibration}

The MCMC implementation of Algorithm 2 is further validated against simulated data using the Simulation-Based Calibration (SBC) method described by Talts et al. (2018) and summarized hereafter.

First, priors are fixed as follows, with hyperparameter values ensuring that the number of samples remains relatively small. The effective population size is piecewise-constant over $p=2$ intervals, with $N_{0}, N_{1} \sim \mathcal{G I} \mathcal{G}(\lambda=$ $4, \chi=0, \psi=0.08)$ respectively over intervals $(0,20)$ and $(20,+\infty)$. The sampling intensity is piecewise-constant over $p^{\prime}=3$ intervals, with $S_{0}, S_{1}$ having a $\Gamma(4,1000)$ prior respectively over intervals $(0,10)$ and $(10,40)$ and $S_{3}=0$ on $(40,+\infty)$. The mutation rate and generation time are respectively assigned a prior $\mu \sim \Gamma(4,400)$ and $g \sim \Gamma^{-1}(10,10)$.

Second, $10^{4}$ parameter sets are sampled from these distributions and for each parameter set, the sampling history $\mathcal{B}$ as well as the allele partition $\mathcal{A}$ are sampled according to the model.

Third, for each simulated dataset, the posterior distribution of $N, S, \mu, g$ conditioned on $\mathcal{A}, \mathcal{B}$ is sampled using the Gibbs sampler described as Algorithm 2, while using the same priors that were used for the simulation. I ran the MCMC for a total of $10^{4}$ steps, discarded a burn-in of $10^{3}$ steps at the beginning and recorded one state every 100 steps over the remaining steps.

Finally, Figure $4 \mathrm{~A}$ shows the proportion of datasets $p_{\alpha}$ for which a credible interval with level $\alpha$ of the posterior distribution contains the true simulated data, for 9 values of $\alpha$ evenly spaced on $(0,1)$. The good match between $p_{\alpha}$ and $\alpha$ indicates that the MCMC correctly samples the posterior distribution. This is further confirmed in Figure $4 \mathrm{~B}$, showing the histogram of the rank statistic associated with the $10^{4}$ experiments. Here, the rank statistic associated to one experiment refers to the number of samples from the posterior being less than the true value. Under the null hypothesis that we are sampling the true posterior distribution, the histogram of rank statistics should be uniform, as illustrated in Figure $4 \mathrm{~B}$ (Talts et al. 2018). 

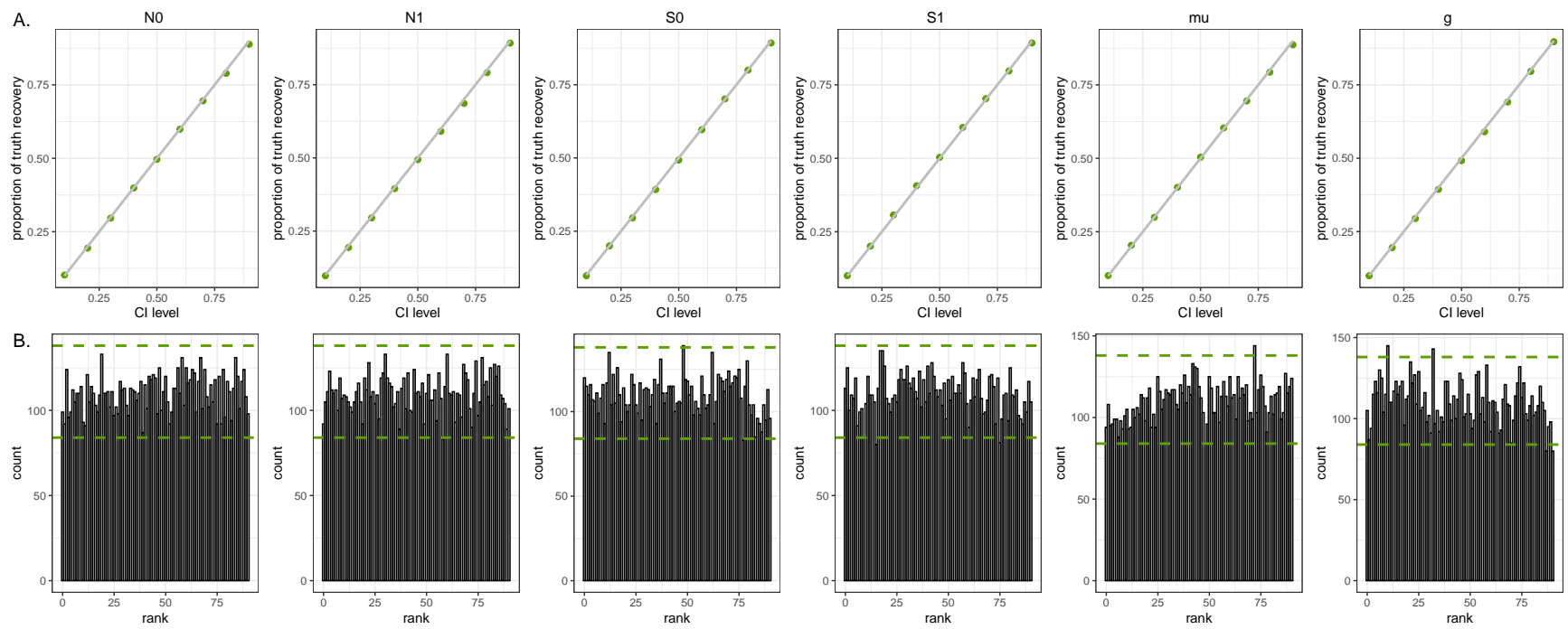

Figure 4: Results of the SBC analysis described in the main text, validating the Gibbs sampler. A. Proportion of datasets which $100 \alpha \%$ posterior credible interval recovers the true parameter, for different values of $\alpha$. B. Histogram of rank statistics. Horizontal dashed lines indicate the $99 \%$ CI of the bar heights if the histogram is uniform.

\subsection{Running time assessment}

I now turn to an assessment of the running time of the method on realistic datasets. I simulated datasets using a timeline cut into $p=p^{\prime}=5$ intervals with varying $N$ and $S$ values, while fixing the same hyperparameters on all intervals, so as to get datasets with total sample size $B$ regularly spaced on a log scale between 10 and 2500 . On each of these, I ran $10^{4}$ steps of the Gibbs sampler, discarded the first $10^{3}$ steps, and recorded the running time and posterior samples.

Let us focus first on the running time of each of the different updates. Since for each of $B$ sequences, the update of the death event requires to compute the weights associated to a number of intervals of the order of $B$, the update of the coalescent history is expected to scale in $O\left(B^{2}\right)$ and to be the bottleneck of the MCMC. Figure $5 \mathrm{~A}$ presents estimates of the running time depending on $B$, using the code released along this article on a laptop. It confirms that the update of the coalescent history - and so, a step in the MCMC - scales in $O\left(B^{2}\right)$.

Running a MCMC moreover requires to perform these updates repeatedly during a certain number of steps, in order to (i) escape the burn-in phase of the MCMC; and (ii) collect enough samples from the posterior to characterize it. When the samples collected through time are highly correlated, it is said that the chain is mixing poorly, and more steps are typically required. In order to provide a rough idea of the expected mixing behaviour on simulated datasets, I computed estimates of the effective sample size of $\left(N_{j}\right)_{j=0}^{p-1},\left(S_{j}\right)_{j=0}^{p^{\prime}-1}, \mu, g$. The results are shown in Figure $5 \mathrm{~B}$. Combined with the running time assessment, it conveys the idea that the current implementation, without further approximation or numerical optimization will likely not be useful to process more than $\sim 10^{4}$ sequences.

Having in mind the rough behaviour of the method, I illustrate its use in the next Section on empirical datasets encompassing $\sim 10^{3}$ sequences. 

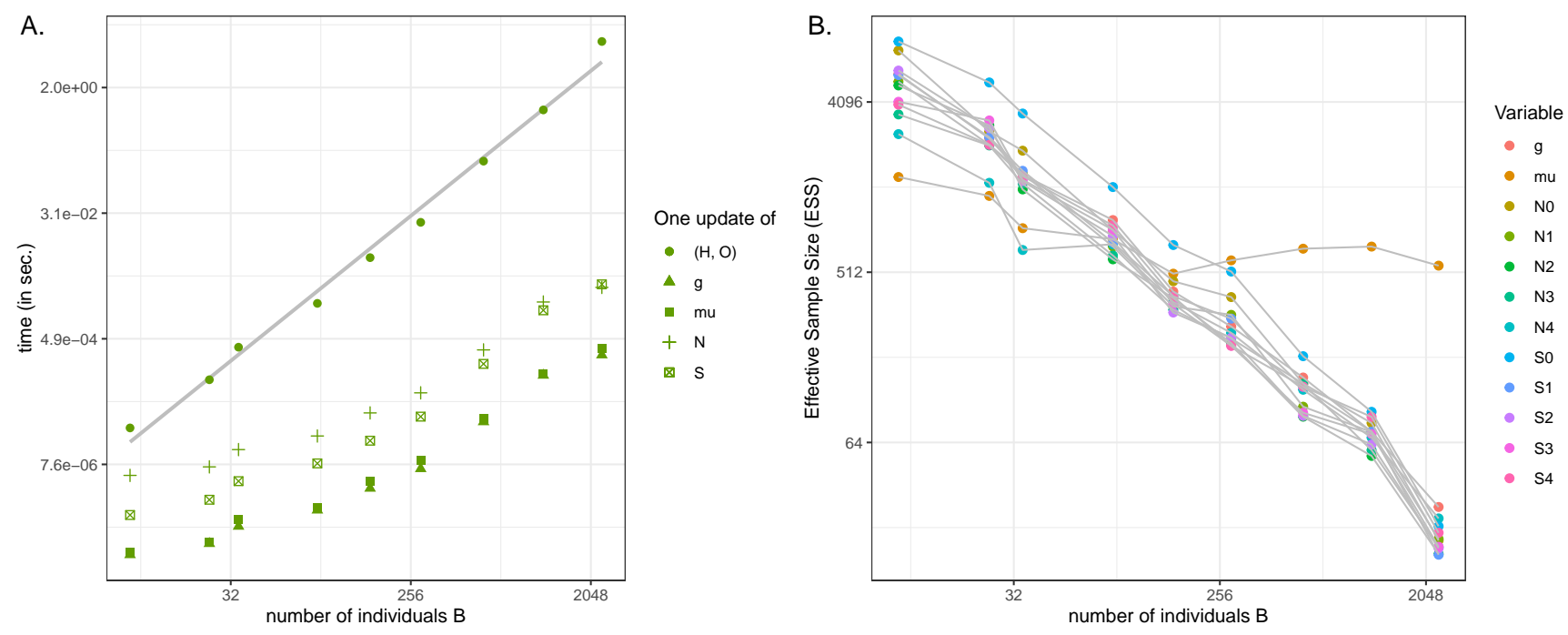

Figure 5: Estimating the running time of the method on simulated datasets. A. The running time of one update of each of the four variables shows that the update of the coalescent history is the bottleneck, that scales in $O\left(B^{2}\right)$. B. The ESS of $\mu, g$ and each of the piecewise-constant values of $S$ and $N$ as a function of the dataset size suggests that reasonable (i.e. $>100$ ) ESS values for datasets up to $B \sim 10^{3}$ can be obtained using $\sim 10^{4}$ MCMC steps.

\section{Empirical application}

\subsection{Data collection and preprocessing}

Sequences collected in Switzerland (CH), Germany (DE), France (FR) and Italy (IT) between December 1 st 2019 and June 1st 2020 have been downloaded on the GISAID website on the 7th of June 2021, while requiring the three options of (i) complete sequences, (ii) high coverage sequences, and (iii) complete collection date. I additionally downloaded GISAID reference genome Wuhan/WIV04/2019 (accession id EPI_ISL_402124) for use in the data preprocessing steps. All people involved in sequence data collection are acknowledged in Supp. Mat. D,

Additional removal of sequences was performed on the basis of either one of these two criteria being fulfilled, (i) sequences were not extending from position 250 to 29700 of the reference genome, (ii) the proportion of ambiguously resolved bases was higher than 10\%. The remaining 1284 sequences from CH (1673 in DE, 1919 in FR, 1314 in IT) were further classified into 627 alleles (886 in DE, 1166 in FR, 750 in IT) using a custom pipeline available as part of the provided code and detailed in Supp. Mat. $\mathrm{A}$.

\section{$5.2 \quad$ MCMC specifications}

The timeline of the analysis is fixed for $N$ and $S$. It extends from the 1st of June 2020 to the 13th of January 2020, cut into successive intervals of 4 weeks each. I assume that $\mu$ and $g$ are known from other studies and are not the focus of the inference. The mutation rate $\mu$ is fixed to 0.065 mutations per genome per day, corresponding to $8 \times 10^{-4}$ mutations per nucleotide per year, and the generation time $g$ is fixed to 5 days.

Finally, hyperparameters values for $N$ and $S$ are chosen so as to not be too informative, using a quick backof-the-envelope reasoning around Equations (3.5) and (3.6). We imagine what could happen over a time period with few data, as happens in the beginning of the dataset. If the order of magnitude of $N$ is approximately $10^{4}$, and we roughly believe that one out of $5 \times 10^{3}$ individuals is sequenced in reality, because each individual 
lives for 5 days in the model, it corresponds to sequencing one out of $2.5 \times 10^{4}$ individuals, i.e. $S \sim 4 \times 10^{-5}$. If we now imagine observing this situation over a time period $\Delta \sim 10$ days, we would observe on expectation 4 births. Using Equation 3.5 helps fix the prior for $\left(N_{j}\right)_{j=0}^{p-1}$ values, which are $\mathcal{G} \mathcal{I} \mathcal{G}$ distributed with hyperparameters $(\lambda, \chi, \psi)=\left(4,0,8 \times 10^{-4}\right)$. Then, using Equation 3.6$)$ helps fix the prior for $\left(S_{j}\right)_{j=0}^{p^{\prime}-1}$ values, which are Gamma distributed with hyperparameters $\left(\alpha_{S}, \beta_{S}\right)=\left(4,10^{5}\right)$.

I ran the Gibbs sampler for $10^{4}$ steps, discarded the first $10^{3}$ steps as burn-in and used the remaining $9 \times 10^{3}$ steps for posterior inference. The code provided along with this article generates the traces and auto-correlation functions of all parameters. These are inspected visually and the ESS values of all parameters are higher than 100.

\subsection{Results}

The output of the Gibbs sampler on each country is a posterior sample of $\left(N_{j}\right)_{j=0}^{p-1}$ and $\left(S_{j}\right)_{j=0}^{p^{\prime}-1}$ values through time over the fixed timeline. Figure6 6 illustrates the input data (to the left) together with the output posteriors of $N$ and $S$ (to the right). In particular, the trajectories of $N$ and $S$ tell a similar story in the four countries. The outbreak slowly started in early 2020 and reached its peak around March-April 2020, before quickly decreasing in May 2020. France appear on this Figure to have experienced the longest outbreak. In all four countries, the sampling intensity increased prior to the peak of the epidemic and slowly decreased thereafter. 

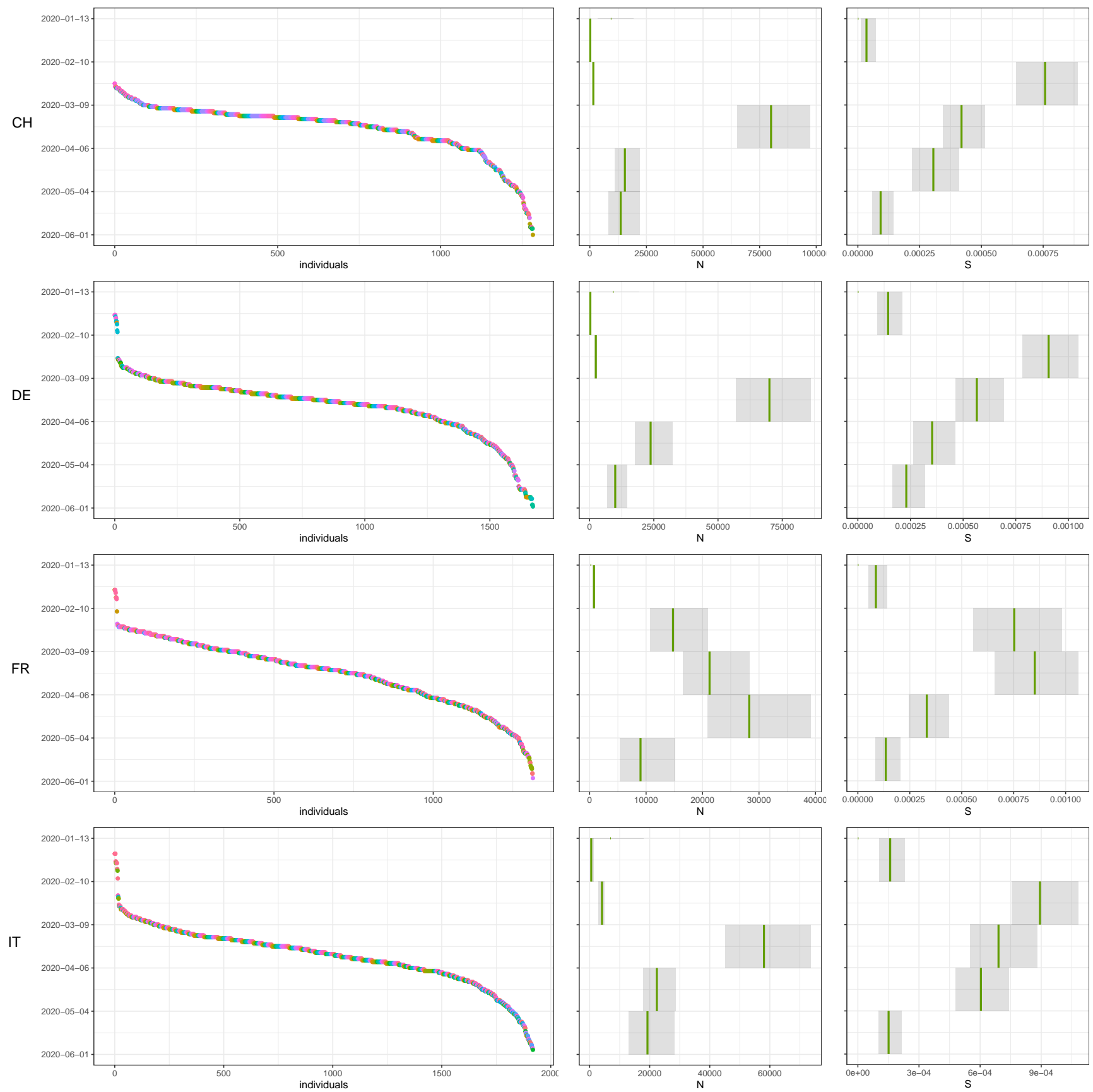

Figure 6: Results of the inference on SARS-CoV-2 data in four European countries during the first wave of the epidemic. CH: Switzerland, DE: Germany, FR: France, IT: Italy. First panel to the left, the raw data consists in an allele partition of sequences sampled through time, where different colors correspond to different alleles. Second and third panels, the posterior sample of $N, S$, with the median shown in green and a $95 \%$ posterior interval shown in gray. 


\section{Discussion}

In this manuscript, I have presented a new Bayesian inference method relying on a Gibbs sampler to sample the posterior distributions of effective population sizes and sampling intensities through time, from the knowledge of an allele partition of sampled-through-time sequences. It relies on a coalescent framework under the infinite alleles model from population genetics, with constant mutation rate, constant generation time, and piecewise-constant effective population sizes and sampling intensities through time. Applying the method to SARS-CoV-2 sequences sampled throughout the first wave of the outbreak in Europe allows us to obtain estimates of effective population sizes, sampling intensities and mutation rate from genetic data only.

Inferred dynamics on empirical data In studies relying on a coalescent model, the usage is to focus on the inferred patterns of change through time rather than on the parameter values per se. The rationale explaining this is that values might be affected in complicated ways by various model misspecifications, among which, for example, having particular distributions of offspring numbers at reproduction, having population structure not taken into account, having a different generation time or mutation rate, or having different priors on $N$ and $S$. Yet, as long as these model misspecifications do not change through time, on can trust the dynamics of the effective population size $N_{t}$ to reflect the dynamics of the true population size. Although I have followed this convention so far throughout the manuscript, one can notice here that the orders of magnitude of inferred effective values seem nevertheless to roughly match what is known from the case count record only (shown in Supp. Mat. B).

In terms of dynamics as well, the patterns of effective population sizes appear compatible with what is known about the first wave of the outbreak in these countries. The number of infected individuals starts increasing exponentially early in 2020, reached a peak in March-April, before decreasing in response to policy measures taken - different versions of a lockdown have been implemented in the four countries around this time. Interestingly, the sampling intensity, on the other hand, starts increasing earlier during the epidemic, when the research effort started growing around SARS-CoV-2 genetics but the case counts where not so high yet. It then decreased again following the peak of the outbreak.

Opening future modeling opportunities with allele data Overall, the results on empirical data illustrates the use and applicability of the method on large real-world datasets. Yet, the current model formulation still lacks a few realistic ingredients before it can be used to learn new aspects of an epidemic.

First and foremost, it does not take into account population structure, a feature that is likely to be present in the empirical dataset and violates the model assumptions. Further work is needed to properly incorporate different demes characterized by different population sizes and sampling intensities, exchanging sequences through migrations among demes. This will likely be the subject of future work aiming to infer population structure and population dynamics using the allele partition. Integrating over the hidden coalescent history will be complicated a bit by migrations between demes, but could be envisioned within a closely related inference framework.

Second, it could be interesting to use smoothing priors for $N$ and $S$ to ensure that these two functions of time do not show huge steps from a time period to the next. This will as well be the focus of future developments of the method, that could build on related work in phylodynamics (Karcher et al. 2020, Parag et al. 2021). It would seem especially interesting for $N$ to root smoothing priors on mechanistic assumptions of population dynamics, such as considered e.g. in other epidemiological models (Cori et al. 2013).

Last, the boundaries of the intervals on which $N$ and $S$ remain constant could be unknown, with or without 
prior distribution. This would allow the timeline to be informed by the data, and could lead as well, in case it is stochastic and averaged over the posterior, to smoother $N$ and $S$ trajectories. This could build on related work in a phylodynamic context under a birth-death model (Stadler 2011).

Further theoretical work is also required before this kind of model can be applied to larger - already available - datasets. Indeed, while the initial hope of bringing back into fashion the infinite allele model was to be able to process very large genetic datasets, it is in the end not realistic to use the current implementation of the method with more than $\sim 10^{4}$ sequences. At least four directions can be envisioned to improve on this objective in the future: (i) trying to optimize the sampling step of the coalescent history, which is the current bottleneck of the computation, so that it scales closer to $O(B)$ than $O\left(B^{2}\right)$, possibly using well designed approximations; (ii) turning to a maximum likelihood framework, possibly relying on an expectation-maximization algorithm to either completely bypass the need for posterior sampling through MCMC, or at least use it to drastically speed-up the burn-in of the MCMC; (iii) turning to a variational Bayes method properly designed to sample the posterior in our model; and (iv) optimizing the implementation of Algorithms 1 and 2 where the most straightforward idea would be to parallelize MCMC chains for example.

When is the use of a simplified mutation process pertinent ? A natural question arises when thinking about the difference between this method and currently used coalescent-based method in phylodynamics, namely How do these compare in terms of statistical power? Or to rephrase it in more technical terms: what signal do we loose by forgetting about the coalescent history above the first mutation?

The answer will likely depend on the mutation rate and on the temporal scale that one is interested in studying. In the limit of very high mutation rate compared to the temporal scale under study, only singletons are observed, bearing no useful signal, while in the limit of very low mutation rate, only one allele is observed, again bearing no useful signal to infer $N$ and $S$.

In between, there is a setting with an intermediate mutation rate, such that alleles extend for some time across the focal time-frame, providing signal to reconstruct $N$ and $S$. However, even in this optimal setting for the method, data is being discarded so that all signal on the internal branches linking different alleles is lost as compared to coalescent-based methods integrating over the full unknown tree. When does the trade-off between computation time and precision turn in favor of using a simpler infinite alleles model ? Quantifying this more precisely on simulations would be a valuable contribution.

Moreover, when one is not interested in estimating $\mu$, the allele partition could be chosen so as to tend to an optimal setting as described above. In principle, the allele partition of the set of sequences could be obtained by applying any another equivalence relation, e.g. being similar only on a given subsequence, or having a similar amino-acid sequence. These could be used to decrease the number of alleles in the dataset.

In between the two above-mentioned extremes of (i) using an infinite alleles model or (ii) using a finite site model with a substitution model, lies also the opportunity to revive another assumption from population genetics, namely the infinite sites model. Under this model, each mutation hits a new site along the sequence, and thus a more precise phylogenetic history between sequences can be reconstructed. An Importance Sampler algorithm has been proposed by Stephens and Donnelly (2000) for simulating the past history under a coalescent with an infinite sites model. A more thorough comparison of this inference framework against another inference method relying on the infinite sites model could as well be a relevant contribution to the field.

Finally, this manuscript also opens the way to develop better approximations aiming at taking into accounts more sequences in scenarios with high numbers of duplicates (Boskova and Stadler 2020). This line of research could benefit from the joint use of different mutation models clearly distinguished in distinct parts of the evolutionary 
tree of sequences, while still relying on a unique underlying population dynamics model, such as e.g. a coalescent model with discrete population size shifts.

Conclusion Bringing back into fashion old population genetics simplifications of the mutation process and incorporating them into modern statistical frameworks could play a key role in better surveying and understanding population demographics and structure from molecular data. I hope that this work will participate in a current trend towards adapting computer-intensive phylodynamics methods for use with datasets characterized by low genetic diversity such as the current SARS-CoV-2 outbreak.

\section{Acknowledgments}

This work was supported by an ETH Zürich Postdoctoral Fellowship. I thank the cEvo group at the D-BSSE department for interesting discussions on phylodynamics methods.

\section{References}

Barido-Sottani, J., T. G. Vaughan, and T. Stadler. 2020. A multitype birth-death model for Bayesian inference of lineage-specific birth and death rates. Systematic Biology 69:973-986.

Beaulieu, J. M. and B. C. O'Meara. 2016. Detecting hidden diversification shifts in models of trait-dependent speciation and extinction. Systematic Biology 65:583-601.

Beerli, P. and J. Felsenstein. 1999. Maximum-likelihood estimation of migration rates and effective population numbers in two populations using a coalescent approach. Genetics 152:763-773.

Boskova, V. and T. Stadler. 2020. PIQMEE: Bayesian phylodynamic method for analysis of large data sets with duplicate sequences. Molecular Biology and Evolution 37:3061-3075.

Cori, A., N. M. Ferguson, C. Fraser, and S. Cauchemez. 2013. A new framework and software to estimate timevarying reproduction numbers during epidemics. American Journal of Epidemiology 178:1505-1512.

Drummond, A. J., G. K. Nicholls, A. G. Rodrigo, and W. Solomon. 2002. Estimating mutation parameters, population history and genealogy simultaneously from temporally spaced sequence data. Genetics 161:1307-1320.

Durrett, R. 2008. Probability models for DNA sequence evolution. Springer.

Etienne, R. S., B. Haegeman, T. Stadler, T. Aze, P. N. Pearson, A. Purvis, and A. B. Phillimore. 2012. Diversitydependence brings molecular phylogenies closer to agreement with the fossil record. Proceedings of the Royal Society B: Biological Sciences 279:1300-1309.

Ewens, W. J. 1972. The sampling theory of selectively neutral alleles. Theoretical Population Biology 3:87-112.

Ewing, G., G. Nicholls, and A. Rodrigo. 2004. Using temporally spaced sequences to simultaneously estimate migration rates, mutation rate and population sizes in measurably evolving populations. Genetics 168:2407-2420.

Gonzalez-Reiche, A. S., M. M. Hernandez, M. J. Sullivan, B. Ciferri, H. Alshammary, A. Obla, S. Fabre, G. Kleiner, J. Polanco, Z. Khan, et al. 2020. Introductions and early spread of SARS-CoV-2 in the New York city area. Science 369:297-301. 
Gupta, A., M. Manceau, T. Vaughan, M. Khammash, and T. Stadler. 2020. The probability distribution of the reconstructed phylogenetic tree with occurrence data. Journal of Theoretical Biology 488:110115.

Hadfield, J., C. Megill, S. M. Bell, J. Huddleston, B. Potter, C. Callender, P. Sagulenko, T. Bedford, and R. A. Neher. 2018. Nextstrain: real-time tracking of pathogen evolution. Bioinformatics 34:4121-4123.

Hein, J., M. Schierup, and C. Wiuf. 2004. Gene genealogies, variation and evolution: a primer in coalescent theory. Oxford university press.

Hörmann, W. and J. Leydold. 2014. Generating generalized inverse gaussian random variates. Statistics and Computing 24:547-557.

Hudson, R. R. 1983. Properties of a neutral allele model with intragenic recombination. Theoretical Population Biology 23:183-201.

Karcher, M. D., L. M. Carvalho, M. A. Suchard, G. Dudas, and V. N. Minin. 2020. Estimating effective population size changes from preferentially sampled genetic sequences. PLoS Computational Biology 16:-1007774.

Kendall, D. G. 1948. On the generalized ‘birth-and-death’ process. Ann. Math. Stat. 19:1-15.

Kim, K., R. Omori, and K. Ito. 2017. Inferring epidemiological dynamics of infectious diseases using Tajima's D statistic on nucleotide sequences of pathogens. Epidemics 21:21-29.

Kingman, J. F. C. 1982. The coalescent. Stochastic processes and their applications 13:235-248.

Kuhner, M. K., J. Yamato, and J. Felsenstein. 1998. Maximum likelihood estimation of population growth rates based on the coalescent. Genetics 149:429-434.

Lanave, C., G. Preparata, C. Sacone, and G. Serio. 1984. A new method for calculating evolutionary substitution rates. Journal of Molecular Evolution 20:86-93.

Lartillot, N. 2006. Conjugate Gibbs sampling for Bayesian phylogenetic models. Journal of Computational Biology $13: 1701-1722$.

Lartillot, N. and H. Philippe. 2004. A Bayesian mixture model for across-site heterogeneities in the amino-acid replacement process. Molecular Biology and Evolution 21:1095-1109.

Lemey, P., S. Hong, V. Hill, G. Baele, C. Poletto, V. Colizza, Á. O’Toole, J. T. McCrone, K. G. Andersen, M. Worobey, M. I. Nelson, A. Rambaut, and M. A. Suchard. 2020. Accommodating individual travel history, global mobility, and unsampled diversity in phylogeography: a SARS-CoV-2 case study. bioRxiv .

Lepage, T., D. Bryant, H. Philippe, and N. Lartillot. 2007. A general comparison of relaxed molecular clock models. Molecular Biology and Evolution 24:2669-2680.

Leventhal, G. E., H. F. Günthard, S. Bonhoeffer, and T. Stadler. 2013. Using an epidemiological model for phylogenetic inference reveals density dependence in HIV transmission. Molecular Biology and Evolution 31:6-17.

Li, Q., X. Guan, P. Wu, X. Wang, L. Zhou, Y. Tong, R. Ren, K. S. M. Leung, E. H. Y. Lau, J. Y. Wong, et al. 2020. Early transmission dynamics in wuhan, china, of novel coronavirus-infected pneumonia. The New England Journal of Medicine 382:1199-1207.

Maddison, W. P., P. E. Midford, and S. P. Otto. 2007. Estimating a binary character's effect on speciation and extinction. Systematic Biology 56:701-710. 
Maliet, O., F. Hartig, and H. Morlon. 2019. A model with many small shifts for estimating species-specific diversification rates. Nature Ecology \& Evolution 3:1086-1092.

Manceau, M., A. Gupta, T. Vaughan, and T. Stadler. 2021. The probability distribution of the ancestral population size conditioned on the reconstructed phylogenetic tree with occurrence data. Journal of Theoretical Biology 509:110400.

McDonald, J. H. and M. Kreitman. 1991. Adaptive protein evolution at the Adh locus in Drosophila. Nature $351: 652-654$.

Morlon, H., T. L. Parsons, and J. B. Plotkin. 2011. Reconciling molecular phylogenies with the fossil record. P. Natl. Acad. Sci. USA 108:16327-16332.

Müller, N. F., D. A. Rasmussen, and T. Stadler. 2017. The structured coalescent and its approximations. Molecular Biology and Evolution 34:2970-2981.

Nee, S., R. M. May, and P. H. Harvey. 1994. The reconstructed evolutionary process. Philosophical Transactions of the Royal Society of London B: Biological Sciences 344:305-311.

Novembre, J., T. Johnson, K. Bryc, Z. Kutalik, A. R. Boyko, A. Auton, A. Indap, K. S. King, S. Bergmann, M. R. Nelson, et al. 2008. Genes mirror geography within Europe. Nature 456:98-101.

Parag, K. V., L. du Plessis, and O. G. Pybus. 2020. Jointly inferring the dynamics of population size and sampling intensity from molecular sequences. Molecular Biology and Evolution 37:2414-2429.

Parag, K. V., O. G. Pybus, and C.-H. Wu. 2021. Are skyline plot-based demographic estimates overly dependent on smoothing prior assumptions? Systematic Biology .

Pybus, O. G., A. J. Drummond, T. Nakano, B. H. Robertson, and A. Rambaut. 2003. The epidemiology and iatrogenic transmission of hepatitis $\mathrm{C}$ virus in Egypt: a Bayesian coalescent approach. Molecular Biology and Evolution 20:381-387.

Pybus, O. G. and P. H. Harvey. 2000. Testing macro-evolutionary models using incomplete molecular phylogenies. P. Roy. Soc. Lond. B. Bio. 267:2267-2272.

Rasmussen, D. A., O. Ratmann, and K. Koelle. 2011. Inference for nonlinear epidemiological models using genealogies and time series. PLoS Computational Biology 7:-1002136.

Skoglund, P., P. Sjödin, T. Skoglund, M. Lascoux, and M. Jakobsson. 2014. Investigating population history using temporal genetic differentiation. Molecular Biology and Evolution 31:2516-2527.

Stadler, T. 2010. Sampling-through-time in birth-death trees. Journal of Theoretical Biology 267:396-404.

Stadler, T. 2011. Mammalian phylogeny reveals recent diversification rate shifts. P. Natl. Acad. Sci. USA 108:61876192.

Stadler, T., D. Kühnert, S. Bonhoeffer, and A. J. Drummond. 2013. Birth-death skyline plot reveals temporal changes of epidemic spread in HIV and hepatitis C virus (HCV). Proceedings of the National Academy of Sciences 110:228-233.

Stephens, M. and P. Donnelly. 2000. Inference in molecular population genetics. Journal of the Royal Statistical Society: Series B (Statistical Methodology) 62:605-635. 
Talts, S., M. Betancourt, D. Simpson, A. Vehtari, and A. Gelman. 2018. Validating Bayesian inference algorithms with simulation-based calibration. arXiv:1804.06788 [stat] ArXiv: 1804.06788.

Tavaré, S. 2004. Part I: Ancestral inference in population genetics. Pages 1-188 in Lectures on probability theory and statistics. Springer.

Vaughan, T. G., D. Kühnert, A. Popinga, D. Welch, and A. J. Drummond. 2014. Efficient Bayesian inference under the structured coalescent. Bioinformatics 30:2272-2279.

Vaughan, T. G., G. E. Leventhal, D. A. Rasmussen, A. J. Drummond, D. Welch, and T. Stadler. 2019. Estimating epidemic incidence and prevalence from genomic data. Molecular Biology and Evolution 36:1804-1816.

Vaughan, T. G., J. Sciré, S. A. Nadeau, and T. Stadler. 2020. Estimates of outbreak-specific SARS-CoV-2 epidemiological parameters from genomic data. medRxiv .

Volz, E. M., S. L. K. Pond, M. J. Ward, A. J. L. Brown, and S. D. Frost. 2009. Phylodynamics of infectious disease epidemics. Genetics 183:1421-1430. 


\section{A Details on the numerical method}

\section{Pipeline for creating the allele partition}

Creating the allele partition is a central step in the method, for this will be the raw data taken as input by the Gibbs sampler. To build it, I relied on the following pipeline:

1. cut the master reference sequence from position 250 to 29700 , and put this one as the first element of a list of reference sequences.

2. initialize an empty list of alleles.

3. Then iterate, for each other sequence, the following steps,

(a) look for a pattern close to the 30 first nucleotides of the master reference into the first 500 nucleotides of each sequence, to get the beginning of the window, and discard the very few sequences where the beginning could not be found.

(b) keep as the focal sequence the 29450 nucleotides following the beginning of the window.

(c) record the collection of snps differing in the focal sequence as compared to the reference sequence.

- if it is smaller than 100 snps long, we consider it to be the compressed representation of the sequence against this reference.

- it not, compare to the next reference sequence in the list.

(d) if no reference sequence is less than 100 snps different than the sequence, it is likely to have a feature of its own (typically, a gap). Add this sequence to the list of reference sequences.

(e) Look for the same compressed representation of the sequence in the list of alleles and add the sampling date of this sequence to the list of sampling dates of the allele.

This pipeline is implemented in the script raw_to_datasets.ml, available as part of the code associated to this article.

\section{MCMC output analysis}

MCMC samples output by the Ocaml code are then analyzed using scripts written in the $R$ programming language. Post-processing steps rely in particular on the following packages to work,

- the very versatile ggplot2 and cowplot to produce figures,

- LaplacesDemon to compute ESS values using traces of scalar values,

- forecast to compute ACF or PACF using traces of scalar values,

The $\mathrm{R}$ post-processing scripts are also available as part of the code released along this article. 
bioRxiv preprint doi: https://doi.org/10.1101/2021.07.21.452479; this version posted July 22, 2021. The copyright holder for this preprint (which

was not certified by peer review) is the author/funder, who has granted bioRxiv a license to display the preprint in perpetuity. It is made available under aCC-BY 4.0 International license.

\section{Generation of random variables}

Random variables distributed according to a $\mathcal{G} \mathcal{I} \mathcal{G}$ distribution are sampled using a personal implementation of Hörmann and Leydold (2014)'s algorithm in the programming language Ocaml. It is naive translation of the very handy R package GIGrvg by the same authors.

\section{B Case count data in the four countries}

Case count numbers in the four countries of interest have been downloaded from the WHO website on the 16th of June 2021. I plot here the number of samples, number of sequences, and sampling fraction through time over the time frame of the first wave of the outbreak, for comparison with the order of magnitudes of $N$ and $S$ presented in the main text.

Note here that the sequencing fraction plotted below corresponds to the number of sequences divided by the sum of the number of sequences and number of samples. Indeed, the number of sequences in the early time period is sometimes higher than the number of samples, and I thus considered that the sequences were not included in the case count.

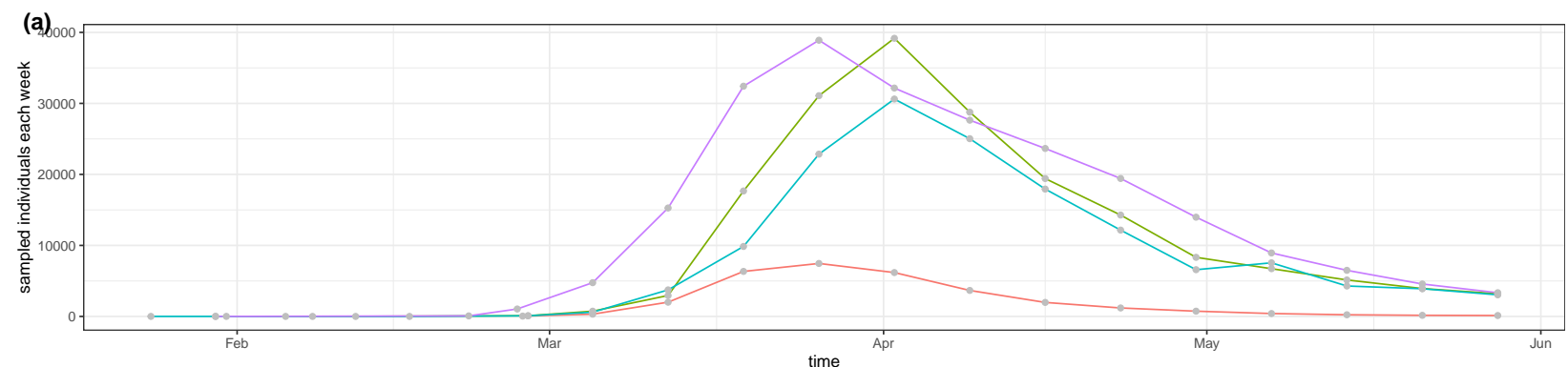

region

$-\mathrm{CH}$

- DE

- FP
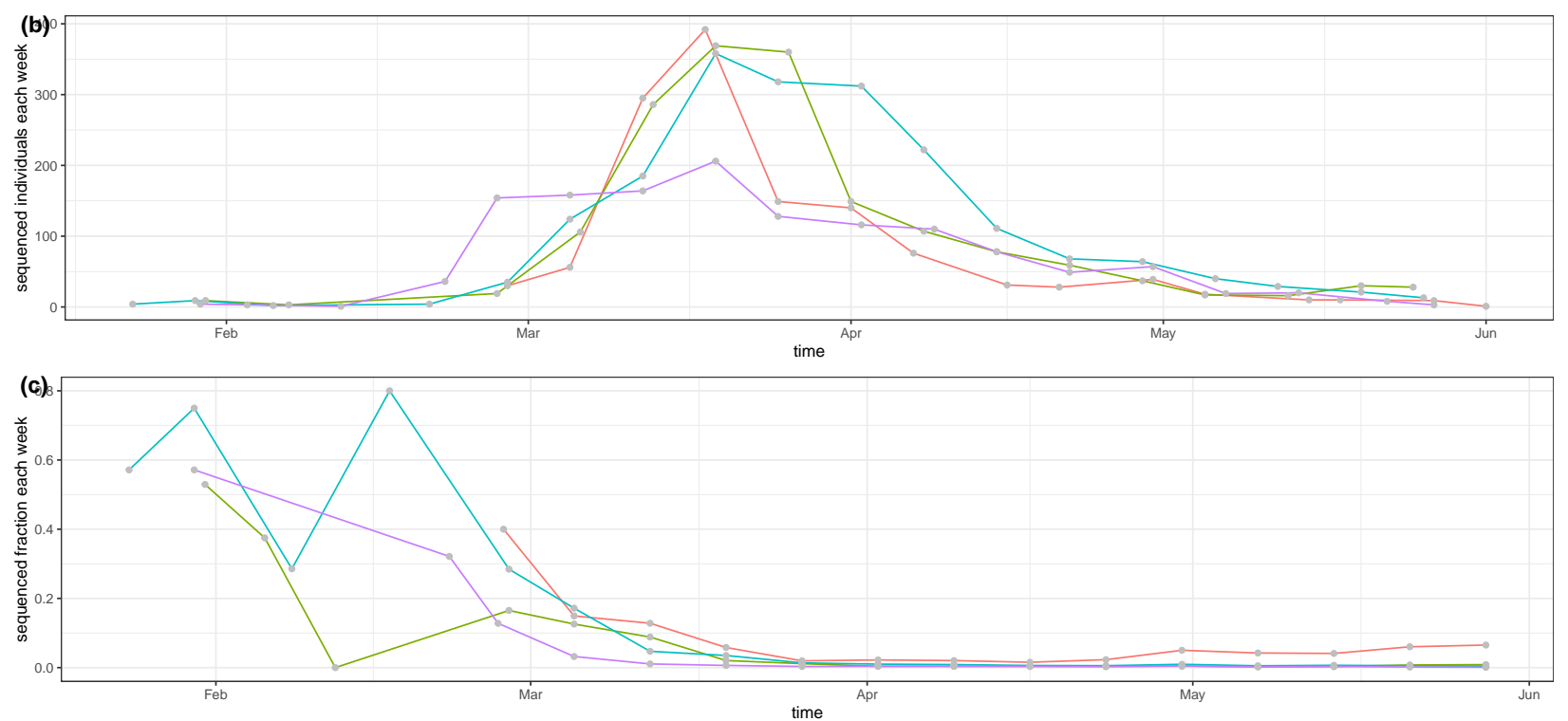

Figure 7: Information on the number of infected, and the number of sequences, sampled through time in $\mathrm{CH}, \mathrm{DE}$, FR, and IT. 


\section{Gibbs sampler code documentation}

This Section aims at making the code released along this article more easily comprehensible, by shortly presenting in plain text the strategy to store different data, together with key functions to manipulate the data.

\section{Format of key quantities}

By default, all lists are ordered in time ascending order (that is, first element on top of the list at present time 0).

listS or listN list of ordered $\left(t_{j}, S_{j}\right)$, where $S_{j}$ is valid on $\left[t_{j}, t_{j+1}\right)$.

an allele or a lineage an ordered list of either $\left(b_{i}\right)$ belonging to the same allele/lineage, if the individuals are not numbered, or an ordered list of $\left(n_{i}\right)$ if the individuals have been numbered.

alleles or lineages a list of (ordered lists of $\left(b_{i}\right)$ ) or a list of (ordered lists of $\left(n_{i}\right)$ ) depending again on whether individuals are numbered or not.

array_individuals an array of information about individuals, with element number $i$ referring to individual number $i$. Each element is a tuple $\left(b_{i}, h_{i}, o_{i}, a_{i}\right)$ where $b_{i}$ is the birth time, $d_{i}$ is the death time, $o_{i}$ is the number of the individual into which this individual coalesces (or $o_{i}=i$ if there is a mutation), and $a_{i}$ is the ID number of the allele this individual belongs to.

array_alleles an array of information about alleles. Each element number $a$ is the list of ID numbers of all individuals belonging to allele $a$.

samp_history an ordered list of $\left(b_{i}, i\right)$ where $i$ is the ID number of the newly born individual at time $b_{i}$.

coal_history an ordered list of $\left(h_{i}, i, o_{i}\right)$ where $i$ is the ID number of the individual dying at time $h_{i}$ by coalescence into lineage $o_{i}$ (or by a mutation if $o_{i}=i$ ).

all_events a list of all events ordered in time ascending order, with lots of other interesting quantities attached to the interval between this event and the following, such as : the number of lineages alive, the current values of $N$, the current value of $S$, the total rate at which an event happens on this interval for a given individual, etc...

intervals the ordered in DESCENDING order list of $\left(t_{s}, t_{e}, k, k_{a}^{<i}, \tau, w\right)$ where $t_{s}$ is the time of start, $t_{e}$ is the end time, $k$ is the total number of lineages alive on the interval, $k_{a}^{<i}$ is the number of individuals from allele $a$, to the left of individual $i$, being alive on the interval, $\tau$ is the total rate at which death happens and $w$ is the weight of the interval, i.e. the probability that the death event of the focal individual falls in this interval, conditioned on $\mathcal{A}$. Note that the reason it is in descending order is that it is built by reading the list of all_events in ascending order, and the next steps consisting in drawing the interval does not require any specific order.

\section{Roles of some key functions}

Here is now an overview of some of the key operations we need to perform for Gibbs sampling steps.

simulation if needed to get samp_history first using sim_sampling_events.

And then to get alleles using sim_coal. 
pre-processing we build the array_individuals and array_alleles from the alleles and samp_history.

Gibbs sampling We need to consider in turn the following operations,

- Updating the death time of individual number $i$ using update_past_coal:

requires to first build the weighted intervals with get_intervals,

before drawing an interval with find_back_interval,

simulating the death time within the interval and finally erasing the old time and inserting the new at a correct place in all_events using replace_coal.

- Updating the $\left(N_{j}\right)$ values using update_listn, which explores the list of all_events, and modifies in place the $N_{j}$ values.

- Updating the $\left(S_{j}\right)$ values using update_listS, working similarly as above.

- Updating $\mu$ using update_mu.

\section{Acknowledgements for data collection}

I am grateful to the following list of authors, who have contributed to the collection of SARS-CoV-2 sequences that I downloaded on GISAID. In the four tables below, you will find the authors that took part in the collection effort in, respectively, Switzerland, Germany, France and Italy over the time period I have been interested in. 
bioRxiv preprint doi: https://doi.org/10.1101/2021.07.21.452479; this version posted July 22, 2021. The copyright holder for this preprint (which was not certified by peer review) is the author/funder, who has granted bioRxiv a license to display the preprint in perpetuity. It is made available under aCC-BY 4.0 International license.

We gratefully acknowledge the following Authors from the Originating laboratories responsible for obtaining the specimens, as well as the Submitting laboratories where the genome data were generated and shared via GISAID, on which this research is based.

All Submitters of data may be contacted directly via www.gisaid.org

Authors are sorted alphabetically.

Accession ID
Originating Laboratory

Accession ID
Originating Laboratory

Accession ID
Originating Laboratory Authors

see above Viollier $A G$

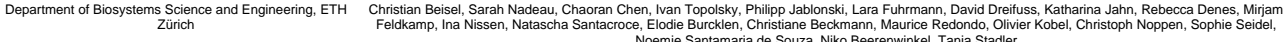

EPI_ISL_1130784

Department of Dermatology

Switzerland Department of Biosystems Science and Engineering, ETH Zürich

EPI ISL 1130824, EPL_ISL_1130961 Viollier AG Department of Biosystems Science and Engineering, ETH

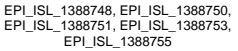

University Hospital Basel, Clinical Virology

University Hospital Basel, Clinical Bacteriology

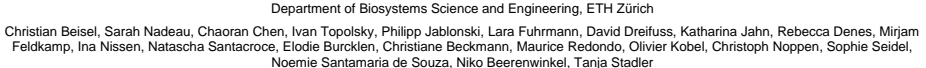

\section{EPI_ISL_2270090}

Synlab Suisse SA Clinical Bacteriology
Laboratory of genomics and metagenomics EPI_ISL_2367311 PSVS

Tim Roloff, Madlen Stange, Helena MB Seth-Smith, Alfredo Mari, Karoline Leuzzinger, Julia Bielicki, Manuel Battegay, Hans Hirsch, Adrian Egli

EPI_ISL_2367353, EPI_ISL_2367356, EPI_ISL_2367357, EPI_ISL_2367358, EPI_ISL_2367359, EPI_ISL_2367360, EPI_ISL_23

see above
EPI_ISL_2367369
EPL_ISL_2367371

EPI_ISL_2367372

EPI_ISL_2367375, EPI_SL_2367376

CHUV

EMS LE FOYER

ADMED

GHOL

LA SOURCE

2367361, EPI ISL 2367362, EPI ISL_236756

Tim Roloff, Madlen Stange, Helena MB Seth-Smith, Aliredo Mari, Karoline Leuzinger, Julia Bielicki, Manuel Battegay, Hans Hirsch, Adrian Egli

EPI_ISL_2367377, EPI_ISL_2367378,

EPI_ISL_2367381

EPI_ISL_2367384, EPI_ISL_2367385

EPI_ISL_2367386, EPL_SL_2367387

EPI_ISL_2367388, EPI_ISL_2367389 EPI_ISL_2367390

EPI_ISL_2367391, EPI_SL_2367392

EPI_ISL_2367393

EPI_ISL_2367394

ISL_2367396, EPI_ISL_2367397

EPI_ISL_2367398

EPI_ISL_2367399

EPI_ISL_2367400

EPI_ISL_2367401, EPI_ISL_2367402

EPI_ISL_2367403

EPI_ISL_2367404

EPI_ISL_2367405

EPI_ISL_2367406

EPI_ISL_2367407

EPI_ISL_2367408, EPI_ISL_2367409,
EPI_ISL_2367410

EPI_ISL_2367411, EPI_ISL_2367412

EPI_ISL_2367413

CHUV

VIDYMED EPALINGES

CHUV

PSVJ

CHUV

Polyanalytic SA

SYNLAB

Polyanalytic SA

GHOL

CHUV
Polyanalytic SA

Polyanalytic SA
SYNLAB

GHOL

VIOLLIER MORGES SA

EHNV

CHUV

PSVJ

EHC MORGES

CHUV

LA SOURCE

EHC MORGES

CHUV

Polyanalytic $S A$

GHOL

CHU

EPI ISL_2367416, EPIISL_2367417,
EPI ISL_2367418, EPI ISL_2367419

EPI_ISL_2367420

EPI_ISL_2367426

EPIISL 2367427, EPIISL_2367428,
EPIISL_2367430, EPIISL-2367431,
EPI ISL 2367432, EPIISL 2367433

EPI_ISL_2367434, EPI_ISL_2367435,

VIDYMED EPALINGES

CHUV

Polyanalytic SA

CHUV
Laboratory of genomics and metagenomics

Laboratory of genomics and metagenomics

Laboratory of genomics and metagenomics

Laboratory of genomics and metagenomics

Laboratory of genomics and metagenomics

Laboratory of genomics and metagenomics

Laboratory of genomics and metagenomics Laboratory of genomics and metagenomics Laboratory of genomics and metagenomics Laboratory of genomics and metagenomics Laboratory of genomics and metagenomics Laboratory of genomics and metagenomics Laboratory of genomics and metagenomics Laboratory of genomics and metagenomics Laboratory of genomics and metagenomics Labortory of genomiss and metagenom Laboratory of genomics and metagenomics Labor Laboratory of genomics and metagenomics Labratory genomics and me agnomics Laboratory or genomics and melagenomics Laboratory of genomics and metagenomics Laboratory or genomics and melagenomics Laboratory of genomics and metagenomics Laboratory of genomics and metagenomics Laboratory of genomics and metagenomics Laboratory of genomics and metagenomics

Laboratory of genomics and metagenomics Laboratory of genomics and metagenomics Laboratory of genomics and metagenomics Laboratory of genomics and metagenomics

Laboratory of genomics and nelagenomics Laboratory of genomics and metagenomic Laboratory of genomics and metagenomics

Laboratory of genomics and metagenomics Trestan Pillonel, Damien Jacot, Sébastien Aeby, Gilbert Greub, Claire Bertelli IISL_2367366, EPI_ISL_2367367, EPI_ISL_2367368

Trestan Pillonel, Damien Jacot, Sébastien Aeby, Gilbert Greub, Claire Bertell Trestan Pillonel, Damien Jacot, Sébastien Aeby, Gilbert Greub, Claire Bertell Trestan Pillonel, Damien Jacot, Sébastien Aeby, Gilbert Greub, Claire Bertell Trestan Pillonel, Damien Jacot, Sébastien Aeby, Gilbert Greub, Claire Bertelli Trestan Pillonel, Damien Jacot, Sébastien Aeby, Gilbert Greub, Claire Bertell Trestan Pillonel, Damien Jacot, Sébastien Aeby, Gilbert Greub, Claire Bertelli

Trestan Pillonel, Damien Jacot, Sébastien Aeby, Gilbert Greub, Claire Bertell Trestan Pillonel, Damien Jacot, Sébastien Aeby, Gilbert Greub, Claire Bertell Trestan Pillonel, Damien Jacot, Sébastien Aeby, Gilbert Greub, Claire Bertelli Trestan Pillonel, Damien Jacot, Sébastien Aeby, Gilbert Greub, Claire Bertell Trestan Pillonel, Damien Jacot, Sébastien Aeby, Gilbert Greub, Claire Bertelli Trestan Pillonel, Damien Jacot, Sébastien Aeby, Gilbert Greub, Claire Bertelli Trestan Pillonel, Damien Jacot, Sébastien Aeby, Gilbert Greub, Claire Bertelli Trestan Pillonel, Damien Jacot, Sébastien Aeby, Gilbert Greub, Claire Bertell Trestan Pillonel Damien Jacot, Sébastien Aeby, Gillbert Greub, Claire Bertell Trestan Pill Trestan Pillo Trestan Pllo Trestan Pllonel, Dan Jaco,, Sebastien Aeby, Giben Greab, Claire Bentel

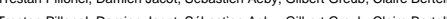
Trestan Pillonel, Damien Jacot, Sebastien Aeby, Gilbert Greub, Claire Bertell Trestan Pillonel, Damien Jacot, Sébastien Aeby, Gilbert Greub, Claire Bertell Trestan Pillonel, Damien Jacot, Sebastien Aeby, Gilbert Greub, Claire Bertel Trestan Pillonel, Damien Jacot, Sébastien Aeby, Gilbert Greub, Claire Bertell Trestan Pillonel, Damien Jacot, Sébastien Aeby, Gilbert Greub, Claire Bertell Trestan Pillonel, Damien Jacot, Sébastien Aeby, Gilbert Greub, Claire Bertell Trestan Pillonel, Damien Jacot, Sébastien Aeby, Gilbert Greub, Claire Bertelli

Trestan Pillonel, Damien Jacot, Sébastien Aeby, Gilbert Greub, Claire Bertell Trestan Pillonel, Damien Jacot, Sébastien Aeby, Gilbert Greub, Claire Bertelli Trestan Pillonel, Damien Jacot, Sébastien Aeby, Gilbert Greub, Claire Bertell Trestan Pillonel, Damien Jacot, Sébastien Aeby, Gilbert Greub, Claire Bertelli

Trestan Pillonel, Damien Jacot, Sébastien Aeby, Gilbert Greub, Claire Bertell Trestan Pillonel, Damien Jacot, Sébastien Aeby, Gilbert Greub, Claire Bertelli Trestan Pillonel, Damien Jacot, Sébastien Aeby, Gilbert Greub, Claire Bertelli

Trestan Pillonel, Damien Jacot, Sébastien Aeby, Gilbert Greub, Claire Bertelli 
bioRxiv preprint doi: https://doi.org/10.1101/2021.07.21.452479; this version posted July 22, 2021. The copyright holder for this preprint (which was not certified by peer review) is the author/funder, who has granted bioRxiv a license to display the preprint in perpetuity. It is made available under aCC-BY 4.0 International license.

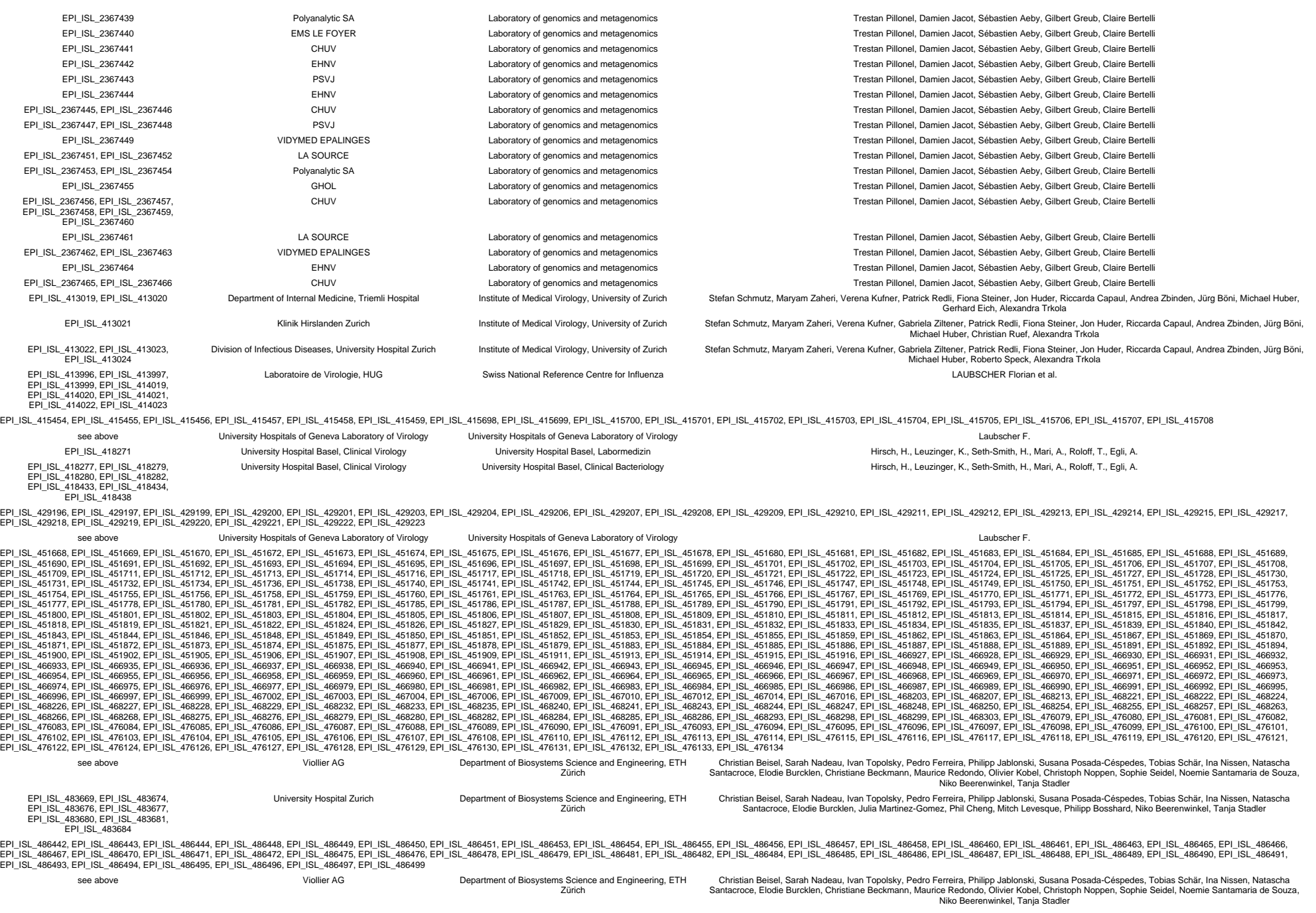


bioRxiv preprint doi: https://doi.org/10.1101/2021.07.21.452479; this version posted July 22, 2021. The copyright holder for this preprint (which was not certified by peer review) is the author/funder, who has granted bioRxiv a license to display the preprint in perpetuity. It is made available under aCC-BY 4.0 International license.

\begin{tabular}{|c|c|c|}
\hline EPI_ISL_508864 & $\begin{array}{l}\text { Division of Infectious Diseases and Hospital Epidemiology, } \\
\text { University Hospital Zürich }\end{array}$ & Institute of Medical Virology, University of Zurich \\
\hline EPI_ISL_508865 & $\begin{array}{l}\text { Division of Infectious Diseases and Hospital Epidemiology, } \\
\text { University Hospital Zürich }\end{array}$ & Institute of Medical Virology, University of Zurich \\
\hline EPI_ISL_508866 & $\begin{array}{l}\text { Division of Infectious Diseases and Hospital Epidemiology, } \\
\text { University Hospital Zürich }\end{array}$ & Institute of Medical Virology, University of Zurich \\
\hline EPI_ISL_508867 & $\begin{array}{l}\text { Division of Infectious Diseases and Hospital Epidemiology, } \\
\text { University Hospital Zürich }\end{array}$ & Institute of Medical Virology, University of Zurich \\
\hline EPI_ISL_508868 & $\begin{array}{l}\text { Division of Infectious Diseases and Hospital Epidemiology, } \\
\text { University Hospital Zürich }\end{array}$ & Institute of Medical Virology, University of Zurich \\
\hline EPI_ISL_508869 & $\begin{array}{l}\text { Division of Infectious Diseases and Hospital Epidemiology, } \\
\text { University Hospital Zürich }\end{array}$ & Institute of Medical Virology, University of Zurich \\
\hline EPI_ISL_508870 & $\begin{array}{l}\text { Division of Infectious Diseases and Hospital Epidemiology, } \\
\text { University Hospital Zürich }\end{array}$ & Institute of Medical Virology, University of Zurich \\
\hline EPI_ISL_509222 & $\begin{array}{l}\text { Division of Infectious Diseases and Hospital Epidemiology, } \\
\text { University Hospital Zürich }\end{array}$ & Institute of Medical Virology, University of Zurich \\
\hline EPI_ISL_524474 & Department of Infectious Diseases, Cantonal Hospital Baden & Institute of Medical Virology, University of Zurich \\
\hline EPI_SL_524475 & Division of Infectious Diseases, University Hospital Zürich & Institute of Medical Virology, University of Zurich \\
\hline EPI_ISL_524476 & Bülach Hospital & Institute of Medical Virology, University of Zurich \\
\hline EPI_SL_524477 & Division of Infectious Diseases, University Hospital Zürich & Institute of Medical Virology, University of Zurich \\
\hline EPI_ISL_524478 & Cantonal Hospital Winterthur & Institute of Medical Virology, University of Zurich \\
\hline EPI_ISL_524479 & Klinik Hirslanden Zürich & Institute of Medical Virology, University of Zurich \\
\hline _524480, EPI_ISL_524481 & Department of Infectious Diseases, Cantonal Hospital Baden & Institute of Medical Virology, University of Zurich \\
\hline EPI_ISL_524482 & University Hospital Zürich & Institute of Medical Virology, University of Zurich \\
\hline EPI_ISL_524483 & Division of Infectious Diseases, University Hospital Zürich & Institute of Medical Virology, University of Zurich \\
\hline EPI_ISL_524484 & Hospital Schwyz & Institute of Medical Virology, University of Zurich \\
\hline EPI_ISL_524485 & Division of Infectious Diseases, University Hospital Zürich & Institute of Medical Virology, University of Zurich \\
\hline EPI_ISL_524782 & University Hospital Zürich & Institute of Medical Virology, University of Zurich \\
\hline
\end{tabular}

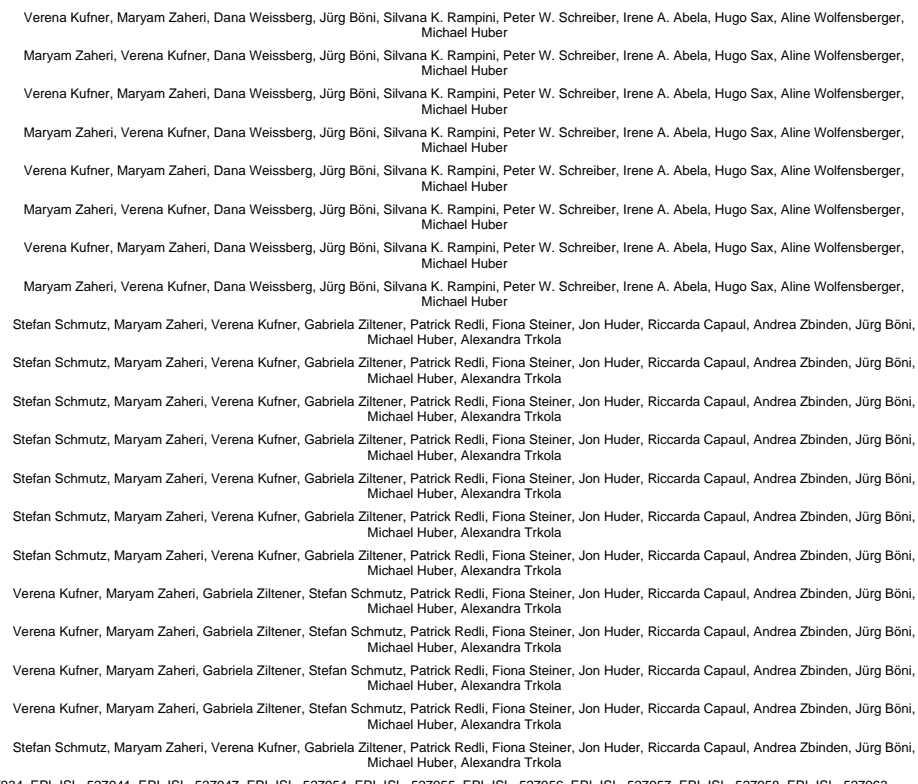
Stefan Schmutz, Maryam Zaheri, Verena Kưner, Gabriela Ziltener, Patrick Redli, Fiona Steiner, Jon Huder, Riccarda Capaul, Andrea Zbinden, Jürg Böni,

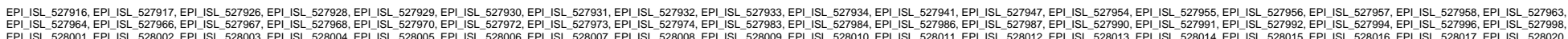

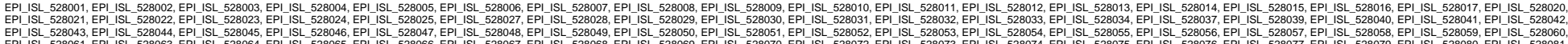

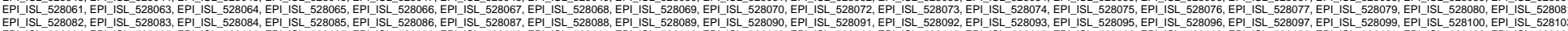

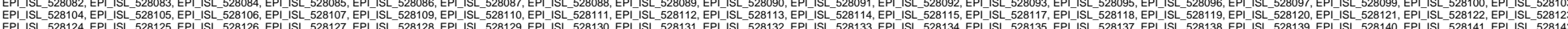

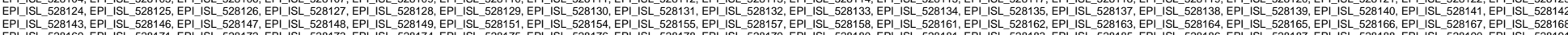

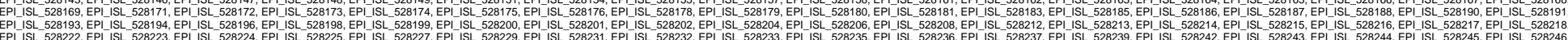

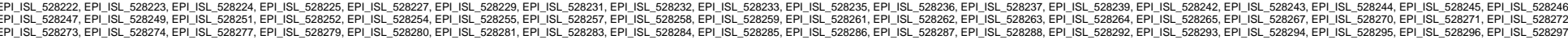

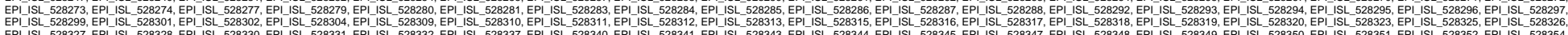

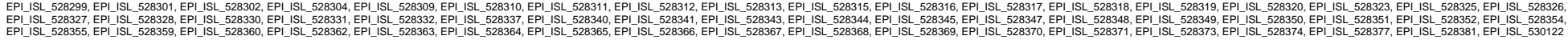
see above University Hospital Basel, Clinical Virology University Hospital Basel, Clinical Bacteriology

Madlen Stange, Alredo Mari, Tim Roloff, Helena MB Seth-Smith, Michael Schweitzer, Myrta Brunner, Karoline Leuzinger, Kirstine K. Soegaard, Alexander
Gensch, Sarah Tschudin-Sutter, Simon Fuchs, Julia Bielicki, Hans Pargger, Martin Siegemund, Christian Nickel, Roland Bingisser, Michael Osthoff,
Stetano Bassetti, Rita Schneider-Sliwa, Manuel Battegay, Hans Hirsch, Adrian Egli

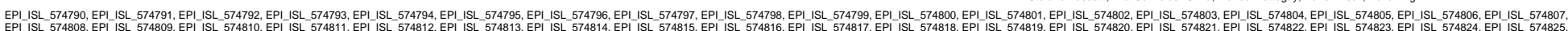

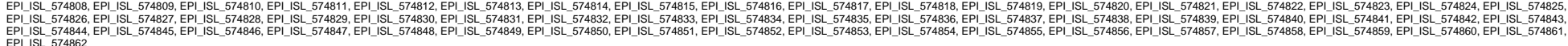

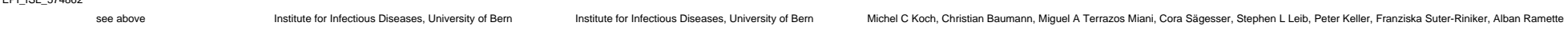

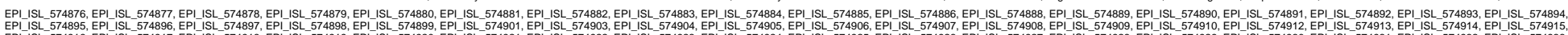

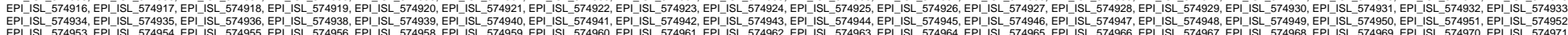

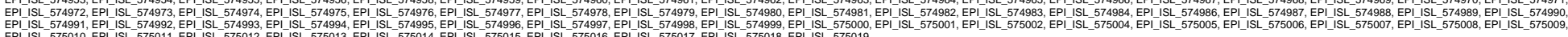


bioRxiv preprint doi: https://doi.org/10.1101/2021.07.21.452479; this version posted July 22, 2021. The copyright holder for this preprint (which was not certified by peer review) is the author/funder, who has granted bioRxiv a license to display the preprint in perpetuity. It is made available under aCC-BY 4.0 International license.

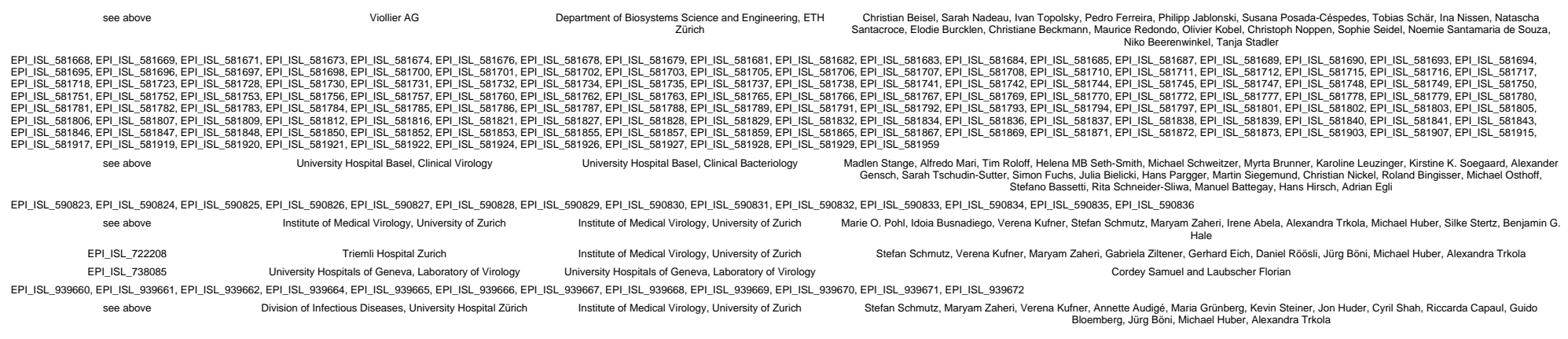


bioRxiv preprint doi: https://doi.org/10.1101/2021.07.21.452479; this version posted July 22, 2021. The copyright holder for this preprint (which was not certified by peer review) is the author/funder, who has granted bioRxiv a license to display the preprint in perpetuity. It is made available under aCC-BY 4.0 International license.

We gratefully acknowledge the following Authors from the Originating laboratories responsible for obtaining the specimens, as well as the Submitting laboratories where the genome data were generated and shared via GISAID, on which this research is based.

All Submitters of data may be contacted directly via www.gisaid.org

Authors are sorted alphabetically.

\begin{tabular}{|c|c|c|c|}
\hline Accession ID & Originating Laboratory & Submitting Laboratory & Authors \\
\hline \multicolumn{4}{|c|}{ EPI_SLL_1143986, EPI_ISL_1143989, EPI_ISL_1143990, EPI_ISL_1143991, EPI_ISL_1143992, EPI_ISL_1143994, EPI_ISL_1143996, EPI_ISL_1144003, EPI_ISL_1144006, EPI_ISL_1144015, EPI_ISL_1144017, EPI_ISL_1144115, EPI_ISL_1144118 } \\
\hline see above & $\begin{array}{l}\text { Bayerisches Landesamt für Gesundheit und } \\
\text { Lebensmittelsicherheit (LGL) }\end{array}$ & Robert Koch Institute & unknown \\
\hline EPI_ISL_1145037 & Sonic - MVZ Medizinisches Labor Bremen GmbH & Robert Koch Institute & unknown \\
\hline $\begin{array}{l}\text { EPI_ISL_1181176, EPI_ISL_1181177, } \\
\text { EPI_ISL_1181178, EP_IISL_1181179, }\end{array}$ & MVZ Dr. Eberhard \& Partner Dortmund & Bielefeld University & David Brandt, Tobias Busche, Markus Haak, Jörn Kalinowski, Levin-Joe Klages, Alexander Sczyrba, Marina Simunovic, Svenja Vinke \\
\hline EPI_ISL_1751474 & $\begin{array}{l}\text { Max von Pettenkofer Institute, Virology, National Reference } \\
\text { Center for Retroviruses, LMU Munich }\end{array}$ & $\begin{array}{l}\text { Laboratory for Functional Genome Analysis; Dept. Genomics; } \\
\text { Gene Center of the LMU Munich }\end{array}$ & Max Muenchhoff; Stefan Krebs; Alexander Graf; Oliver Keppler; Helmut Blum \\
\hline 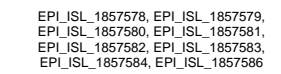 & $\begin{array}{l}\text { Robert Koch Institute, ZBS1 Highly Pathogenic Viruses, Berlin, } \\
\text { Germany }\end{array}$ & $\begin{array}{l}\text { Robert Koch Institute, ZBS1 Highly Pathogenic Viruses, Berlin, } \\
\text { Germany }\end{array}$ & Annika Brinkmann, Steven Uddin, Janine Michel, Andreas Nitsche \\
\hline EPI_ISL_2466314 & $\begin{array}{l}\text { Public Health Microbiology Unit, Bavarian Health and Food } \\
\text { Safety Authority }\end{array}$ & $\begin{array}{l}\text { Public Health Microbiology Unit, Bavarian Health and Food } \\
\text { Safety Authority }\end{array}$ & $\begin{array}{l}\text { Jungnick,S., Hobmaier,B., Mautner,L., Hoyos,M., Haase,M., Baiker,A., Lahne,H., Eberle,U., Wimmer,C., Hepner,S., Sprenger,A., Berger,C., Dangel,A., } \\
\text { Wildner,M., Liebl,B., Ackermann,N., Sing,A., Fingerle,V. }\end{array}$ \\
\hline EPI_ISL_406862 & $\begin{array}{l}\text { Charité Universitätsmedizin Berlin, Institute of Virology; Institut } \\
\text { für Mikrobiologie der Bundeswehr, Munich }\end{array}$ & Charité Universitätsmedizin Berlin, Institute of Virology & Victor M Corman, Julia Schneider, Talitha Veith, Barbara Mühlemann, Markus Antwerpen, Christian Drosten, Roman Wölfel \\
\hline EPI_ISL_412912 & State Health Office Baden-Württemberg & Charite Universitatsmedizin Berlin, Institute of Virology & $\begin{array}{c}\text { Victor M Corman, Julia Schneider, Barbara Muhlemann, Talitha Veith, Jörn Beheim-Schwarzbach, Terry Jones, Rainer Oehme, Silke Fischer, Christian } \\
\text { Drosten }\end{array}$ \\
\hline $\begin{array}{l}\text { EPIIISL_413488, EPI_ISL_414497, } \\
\text { EPIISL-414489, EPIISL-414499, } \\
\text { EPI_ISL_414505, EPP_ISL-414508, }\end{array}$ & $\begin{array}{l}\text { Center of Medical Microbiology, Virology, and Hospital } \\
\text { Hygiene, University of Duesseldorf }\end{array}$ & $\begin{array}{l}\text { Center of Medical Microbiology, Virology, and Hospital } \\
\text { Hygiene, University of Duesseldorf }\end{array}$ & $\begin{array}{l}\text { Ortwin Adams, Marcel Andree, Alexander Dilthey, Torsten Feldt, Sandra Hauka, Torsten Houwaart, Björn-Erik Jensen, Detlef Kindgen-Milles, Malte Kohns } \\
\text { Vasconcelos, Klaus Prefter, Tina Sentf, Daniel Strelow, Jörg Timm, Andreas Walker, Tobias Wienemann }\end{array}$ \\
\hline EPI_ISL_414520, EPI_ISL_414521 & Bundeswehr Institute of Microbiology & Bundeswehr Institute of Microbiology & Mathias $\mathrm{C}$ Walter, Markus $\mathrm{H}$ Antwerpen and Roman Wölfel \\
\hline \multicolumn{4}{|c|}{ 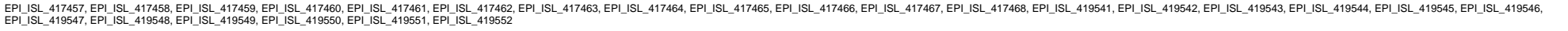 } \\
\hline see above & $\begin{array}{l}\text { Center of Medical Microbiology, Virology, and Hospital } \\
\text { Hygiene, University of Duesseldorf }\end{array}$ & $\begin{array}{l}\text { Center of Medical Microbiology, Virology, and Hospital } \\
\text { Hygiene, University of Duesseldorf }\end{array}$ & $\begin{array}{l}\text { Ortwin Adams, Marcel Andree, Alexander Dithey, Torsten Feldt, Sandra Hauka, Torsten Houwaart, Bïrn-Erik Jensen, Detlef Kindgen-Milles, Malte Kohns } \\
\text { Vasconcelos, Klaus Pfeffer, Tina Senff, Daniel Strelow, Jörg Timm, Andreas Walker, Tobias Wienemann }\end{array}$ \\
\hline 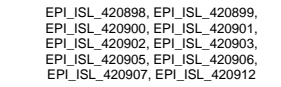 & $\begin{array}{l}\text { Max von Pettenkofer Institute, Virology, National Reference } \\
\text { Center for Retroviruses, LMU Munich }\end{array}$ & $\begin{array}{l}\text { Laboratory for Functional Genome Analysis, Dept. Genomics, } \\
\text { Gene Center of the LMU Munich }\end{array}$ & Max Muenchhoff, Stefan Krebs, Alexander Grat, Ashok Varadharajan, Oliver Keppler, Helmut Blum \\
\hline $\begin{array}{l}\text { EPI_ISL_425121, EPI_ISL_425122, } \\
\text { EPI_ISL-425123, EPP_ISL-425124, } \\
\text { EPIIIL-425125, EPI_IIL-425126, } \\
\text { EPIIISL_425127, EPI_ISL_425128 }\end{array}$ & $\begin{array}{l}\text { Center of Medical Microbiology, Virology, and Hospital } \\
\text { Hygiene, University of Duesseldorf }\end{array}$ & $\begin{array}{l}\text { Center of Medical Microbiology, Virology, and Hospital } \\
\text { Hygiene, University of Duesseldorf }\end{array}$ & $\begin{array}{l}\text { Ortwin Adams, Marcel Andree, Alexander Dilthey, Torsten Feldt, Sandra Hauka, Torsten Houwaart, Björn-Erik Jensen, Detlef Kindgen-Milles, Malte Kohns } \\
\text { Vasconcelos, Klaus Pfefter, Tina Senff, Daniel Strelow, Jörg Timm, Andreas Walker, Tobias Wienemann }\end{array}$ \\
\hline EPI_ISL_425130, EPI_ISL_425131, & $\begin{array}{l}\text { Center of Medical Microbiology, Virology, and Hospital } \\
\text { Hygiene, University of Duesseldorf }\end{array}$ & $\begin{array}{l}\text { Center of Medical Microbiology, Virology, and Hospital } \\
\text { Hygiene, University of Duesseldorf }\end{array}$ & $\begin{array}{l}\text { Ortwin Adams, Marcel Andree, Alexander Dithey, Torsten Feldt, Sandra Hauka, Torsten Houwaart, Bjorn-Erik Jensen, Detlef Kindgen-Milles, Malte Kohns } \\
\text { Vasconcelos, Klaus Pfeffer, Tina Senff, Daniel Strelow, Jorg Timm, Andreas Walker, Tobias Wienemann }\end{array}$ \\
\hline EPL_ISL_425138, EPL_SL_425139 & $\begin{array}{l}\text { Center of Medical Microbiology, Virology, and Hospital } \\
\text { Hygiene, University of Duesseldorf }\end{array}$ & $\begin{array}{l}\text { Center of Medical Microbiology, Virology, and Hospital } \\
\text { Hygiene, University of Duesseldorf }\end{array}$ & $\begin{array}{l}\text { Ortwin Adams, Marcel Andree, Alexander Dilthey, Torsten Feldt, Sandra Hauka, Torsten Houwaart, Björn-Erik Jensen, Detlef Kindgen-Milles, Malte Kohns } \\
\text { Vasconcelos, Klaus Pfeffer, Tina Senff, DDaniel Strelow, Jörg Timm,Andreas Walker, Tobias Wienemann }\end{array}$ \\
\hline \multicolumn{4}{|c|}{ 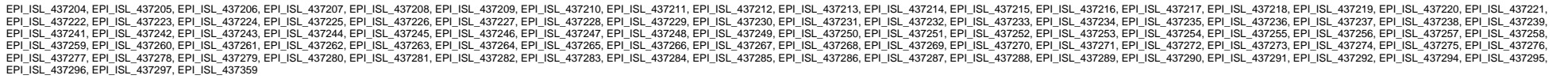 } \\
\hline see above & $\begin{array}{l}\text { Max von Pettenkofer Institute, Virology, National Reference } \\
\text { Center for Retroviruses, LMU München }\end{array}$ & $\begin{array}{l}\text { Laboratory for Functional Genome Analysis, Dept. Genomics, } \\
\text { Gene Center of the LMU Munich }\end{array}$ & Max Muenchhoff, Stefan Krebs, Alexander Graf, Oliver Keppler, Helmut Blum \\
\hline $\begin{array}{l}\text { EPIISL_450198, EPI_ISL_450199, } \\
\text { EPI_ISL-450200, EPI_ISL-450203, } \\
\text { EPIISL-450200, EPIISL-45020, } \\
\text { EPI_ISL_450208, EPI_ISL_450209 }\end{array}$ & Department of Virology & Department of Virology & 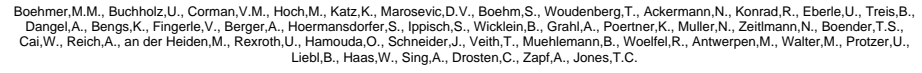 \\
\hline EPI_ISL_450413 & $\begin{array}{l}\text { Center for Diagnostics, Institute of Medical Microbiology, } \\
\text { Virology and Hygiene }\end{array}$ & University Medical Center Hamburg-Eppendorf & Huang,J., Pfefferle,S. and Fischer,N. \\
\hline $\begin{array}{l}\text { EPI_ISL_451937, EPI_ISL_451940, } \\
\text { EPI_ISL-451941, EPI_ISL_451944, } \\
\text { EPI_ISL_451945, EPIIIL_452103, } \\
\text { EPI_ISL_452104 }\end{array}$ & $\begin{array}{l}\text { Max von Pettenkofer Institute, Virology, National Reference } \\
\text { Center for Retroviruses, LMU München }\end{array}$ & $\begin{array}{l}\text { Laboratory for Functional Genome Analysis, Dept. Genomics, } \\
\text { Gene Center of the LMU Munich }\end{array}$ & Max Muenchhoff, Stefan Krebs, Alexander Graf, Oliver Keppler, Helmut Blum \\
\hline $\begin{array}{l}\text { EPI_ISL_452218, EPI_ISL_452219, } \\
\text { EPI_ISL_452220, EPI_ISL_452221, } \\
\text { EPI_ISL_452222, EPI_ISL_452223 }\end{array}$ & Goethe University Hospital Frankfurt & $\begin{array}{c}\text { Institute for Medical Virology, Goethe University Hospital } \\
\text { Frankfurt }\end{array}$ & $\begin{array}{c}\text { Tuna Toptan, Sebastian Hoehl, Sandra Westhaus, Denisa Bojkova, Annemarie Berger, Björn Rotter, Klaus Hoffmeier, Jindrich Cinatl, Sandra Ciesek, and } \\
\text { Marek Widera }\end{array}$ \\
\hline $\begin{array}{l}\text { EPIISL_457750, EPI_ISL_459962, } \\
\text { EPI_ISL_459963, EPI_ISL-459964 }\end{array}$ & Centogene AG & Centogene AG & Bauer, Dr. Krishna Kumar Kandaswamy \\
\hline
\end{tabular}


bioRxiv preprint doi: https://doi.org/10.1101/2021.07.21.452479; this version posted July 22, 2021. The copyright holder for this preprint (which was not certified by peer review) is the author/funder, who has granted bioRxiv a license to display the preprint in perpetuity. It is made available under aCC-BY 4.0 International license.

EPI_ISL_463008 Institute of Molecular Virology, University Münster Institute of Molecular Virology, University Münster Angeles Mecate Zambrano, Linda Brunotte, Stephan Ludwig, Joachim Kühn, Alexander Mellmann

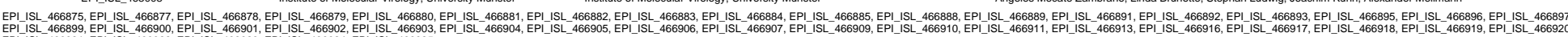

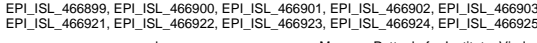

$\begin{array}{ccc}\text { see above } & \text { Max von Pettenkofer Institute, Virology, National Reference } \\ \text { Center for Retroviruses, LMU München } & \text { Laboratory for Functional Genome Analysis, Dept. Genomics, } \\ \text { Gene Center of the LMU Munich }\end{array}$

EPI_ISL_476705

EPI_ISL_481253, EPI ISL_481256,

EPIISL 485809

EPI_ISL_485810

Robert Koch Institute, National Reference center for Influenza
Berlin, Germany

Institut tür Virologie und Epidemiologie der Vin
Universitătsklinikum Tübingen

Virologie und Epidemiologie der Viru
Universitatatsklininum Tübingen

Heinrich Pette Institute, Leibniz Institute for Experimental

Robert Koch Institute, Bioinformatics MF1, Berlin, Germany NGS Competence Center Tübingen, Institut tür Medizinische
Mikrobiologie und Hygiene, Universititatsklininum Tübingen NGS Competence Center Tübingen, Institut tür Medizinische
Mikrobiologie und Hygiene, Universitatitsklinikum Tübingen

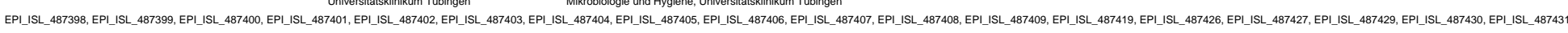
see above Labor Kneißler GmbH \& Co. KG Heinrich Pette Institute, Leibniz Institute for Experimental

EPI ISL 490205, EPIISL 490206
EPI ISL 490207. EPI ISL-490200 München Klinik Schwabing

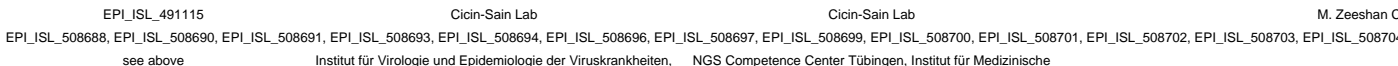
MGZ Medical Genetics Center Thomas Günther, Adam Grundhoff, Manja Czech-Sioli, Nicole Fischer, Matthias Ottinger, Melanie M. Brinkmann

Marianne Wedde, Oliver Drechsel, Andrea Thuermer, Rene Kmiecinski, Ralf Duerrwald, Thorsten Wolf, Stephan Fuchs, Max v. Kleist Angelov at al. EPI ISL 491115

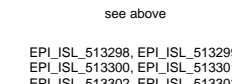
Institut tür Virologie und Epidemiologie der Viruskrankheiten,
Universitattsklinikum Tübingen $\begin{gathered}\text { NGS Competence Center Tübingen, Institut tür Medizinische } \\ \text { Mikrobiologie und Hygiene, Universitätsklinikum Tübingen }\end{gathered}$ Dieter A. Wolf, Elke Holinski-Feder

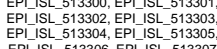
Department of Infection Prevention and Infectious Diseases,
University Hospital Regensburg Angel Angelov

FPI ISL 516629, EPI ISL 516630, EPI ISL 516631, EPI।ISL 516632, EPI ISL 516633, EPI ISL 516634, EPI ISL 516635, EPI ISL 516636, EPI ISL 516637, EPI ISL 516638, EPI ISL 516639, EPI।ISL 516640, EPI ISL 516641, EPI ISL 516642, EPI ISL 516644, EPI ISL 516645 see above Charite Universitatsmedizin Berlin, Institut fur Virologie/Labor Charite Universitatsmedizin Berlin, Institut fur Virologie/Labor
Berlin

EPL_ISL_522407 Department of Infection Prevention and Infectious Diseases, Department of Infection Prevention and Infectious Diseases,
University Hospital Regensburg Victor M Corman, Barbara Muhlemann, Jörn Beheim-Schwarzbach, Julia Schneider, Talitha Veith, Terry Jones, Christian Drosten Fritsch,J., Holzmann, T., Schneider-Brachert,W.

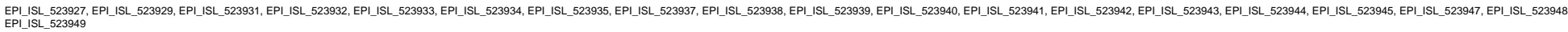
see above EPI_ISL_523950 Center of Medical Microbiology, Virology, and Hospital
Hygiene, University of Duesseldorf Center of Medical Microbiology, Virology, and Hospital
Hygiene, University of Duesseldorf Institute of Clinical Microbiology and Hygiene, University
Hospital Regensburg Center of Medical Microbiology, Virology, and Hospital
Hygiene, University of Duesseldorf (a)

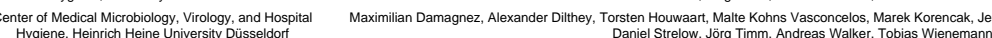
stitute of Clinical Microbiology and Hygiene, Universily

PI_ISL_525472, EPI_ISL_525473 Institute for Virology, University Hospital Duesseldorf, Med
Faculty, Heinrich-Heine-University Duesseldorf ical Microbiology and Hyg
Hospital Regensburg

Hiergeist, A.

EPI_ISL_572330, EPI_ISL_572331 Medizinische Klinik Innere Medizin I, Universiätätsklinikum
Tübingen for Virology, University Hospital Duesseldorf, Maximilian Damagnez, Vere
Antoch, Johannes Bode, Edwi Verena Keitel, Bjöm Jensen, Nadine Lübke, Lis
dwin Bölke, Saskiai Elben, Torsten Feldt, Joh
Annemarie Mohring, Jennifer Neubert, Hein

EPI_ISL_581478, EPI_ISL_581479,
EPIISL-581480, EPI_ISL-581481, NGS Competence Center Tübingen, Institut tür Medizinische
Mikrobiologie und Hygiene, Universitätsklinikum Tübingen Angel Angelo

\section{EPI_ISL_581484, EPI_ISL-581485}

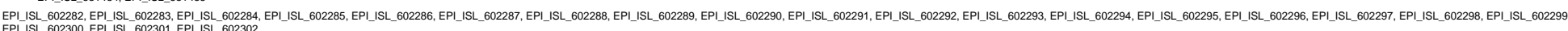

Bielefeld University

David Brandt, Tobias Busche, Markus Haak, Jörn Kalinowski, Levin-Joe Klages, Christiane Scherer, Alexander Sczyrba, Marina Simunovic, Svenja Vinke

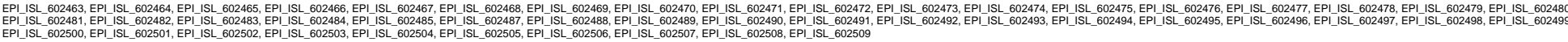
see above $\quad$ Institute for Virology, University Hospital Essen Center of Medical Microbiology, Virology, and Hospital
Hygiene, University of Duesseldorf

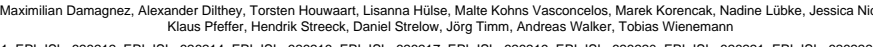
EPI_ISL_602518, EPL_ISL_602519, EPPIIS see above

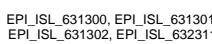
Institute for Virology, University Hospital Essen Center of Medical Microbiology, Virology, and Hospital
Hygiene, University of Duesseldorf Olympia E. Anastasiou, Ulf Dittmer, Maximilian Damagnez, Alexander Dithey, Torsten Houwaart, Lisanna Hülse, Malte Kohnn Vasconcelos, Nadine Lübke,
Jessica Nicolai, Klaus Pfeffer, Daniel Strelow, Jörg Timm, Andreas Walker, Tobias Wienemann MVZ DIAMEDIS Diagnostische Medizin Sennestadt GmbH Bielefeld University David Brandt, Tobias Busche, Markus Haak, Jörn Kalinowski, Levin-Joe Klages, Christiane Scherer, Alexander Sczyrba, Marina Simunovic, Svenja Vinke

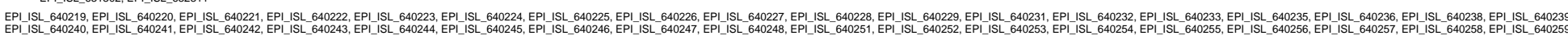

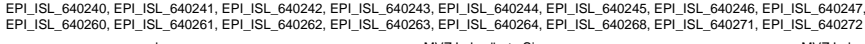

EPI_ISL_707943, EPI_ISL_707947, EPI_ISL_707948, EPI_ISL_707949, EPI_ISL_707950, EPI_ISL_707951, EPI_ISL_707954, EPI_ISL_707956, EPI_ISL_707959, EPI_ISL_707964, EPI_ISL_707966, EPI_ISL_707968, EPI_ISL_708003 
bioRxiv preprint doi: https://doi.org/10.1101/2021.07.21.452479; this version posted July 22, 2021. The copyright holder for this preprint (which was not certified by peer review) is the author/funder, who has granted bioRxiv a license to display the preprint in perpetuity. It is made available under aCC-BY 4.0 International license.

See above
Virology, Universitätsklinikum des Saarlandes Institute for Virology, University Hospital Essen
Epigenetics, Saarland University Medical Microbiology, Virology, and Host
Kathrin Kattler, Markus Vogelgesang, Stefan Lohse, Sascha Tierling, Sigrun Smola, Jörn Walter Dittmer, Maximilian Damagnez, Alexander Dithey, Torsten Houwaart, Lisanna Hülse, Malte Kohns Vasconcelos, Nadine Lübke,
Jessica Nicolai, Klaus Pfeffer, Daniel Strelow, Jorg Timm, Andreas Walker, Tobias Wienemann

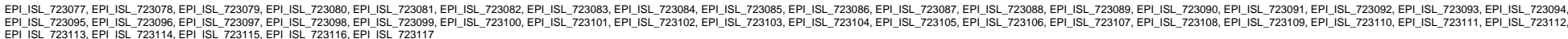

see above

EPI_ISL_728288

EPI_ISL 728292, EPI_ISL_728293,
EPI_ISL-728294, EPI_ISL_728296,

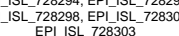

EPISL 728346

EPL_ISL_729461, EPI_ISL_729465
Institute of Medical Genetics and Applied Genomics

Jena University Hospital, Institute for Infectious Diseases and
Infection Control

Jena University Hospital, Institute for Infectious Diseases and
Infection Control

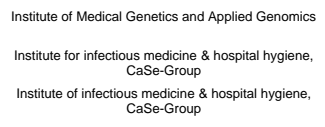

Institue of medical Microbiology and hospital Hygiene A. Krumbholz, Labor Dr. Krause und Kollegen MVZ GmbH,
Institute of medical Microbiology and hospital Hygiene Charité Universitätsmedizin Berlin, Institut für Virologie
Caspar Gross, Tina Ganzenmüller,

Spott, Riccardo; Marquet, Mike; Pletz, Matthias W.; Brandt, Christian

Spott, Riccardo; Marquet, Mike; Pletz, Matthias W.; Brandt, Christian

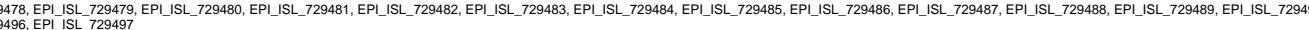

Prot. Dr. Achim Kaasch, Aljoscha Tersteegen

Victor M Corman, Barbara Mühlemann, Jörn Beheim-Schwarzbach, Talitha Veith, Julia Schneider, Terry Jones, Christian Drosten
EPI_ISL 729473, EPL_72949,, EPI_ISL_72929
see above
see above
Charité Universitätsmedizin Berlin, Institut tür Virologie/Labor
Berlin
$\begin{gathered}\text { A. Krumbholz, Labor Dr. Krause und Kollegen MVZ GmbH, } \\ \text { Kiel } \\ \text { Charité Universitätsmedizin Berlin, Institut tür Virologie/Labor } \\ \text { Berlin }\end{gathered}$
Charité Universitätsmedizin Berlin, Institut tür Virologie
Charité Universitätsmedizin Berlin, Institut tür Virologie
Victor M Corman, Barbara Mühlemann, Jörn Beheim-Schwarzbach, Talitha Veith, Julia Schneider, Terry Jones, Christian Drosten
Victor M Corman, Barbara Mühlemann, Jörn Beheim-Schwarzbach, Talitha Veith, Julia Schneider, Terry Jones, Christian Drosten
Victor M Corman, Barbara Mühlemann, Jörn Beheim-Schwarzbach, Talitha Veith, Julia Schneider, Terry Jones, Christian Drosten
EPI_ISL_729499
Charité Universitätsmedizin Berlin, Institut tür Virologie

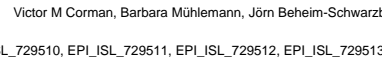

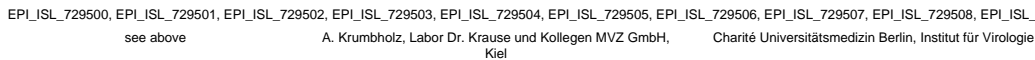
EPI_ISL_729514
Berlin, Institut für Virologie/Labor
Berlin
Charité Universitätsmedizin Berlin, Institut tür Virologie
Victor M Corman, Barbara Mühlemann, Jörn Beheim-Schwarzbach, Talitha Veith, Julia Schneider, Terry Jones, Christian Drosten
Victor M Corman, Barbara Mühlemann, Jörn Beheim-Schwarzbach, Talitha Veith, Julia Schneider, Terry Jones, Christian Drosten
EPI_ISL_729515, EPI_ISL_729516, EPI_ISL_729517, EPI_ISL_729518, EPI_ISL_729519, EPI_ISL_729520, EPI_ISL_729521, EPI_ISL_729522, EPI_ISL_729523, EPI_ISL_729524, EPI_ISL_729525, EPI_ISL_729526, EPI_ISL_729527, EPI_ISL_729528 see above A. Krumbholz, Labor Dr. Krause und Kollegen MVZ GmbH, Charité Universitätsmedizin Berlin, Institut tür Virologie Victor M Corman, Barbara Mühlemann, Jörn Beheim-Schwarzbach, Talitha Veith, Julia Schneider, Terry Jones, Christian Drosten
EPI_ISL_729529, EPI_ISL_729530,
EPI_ISL_729531,EP_ISL_729533,
EPI_ISL_729534- Charité Universitätsmedizin Berlin, Institut tür Virologie/Labor
Berlin
Chariée Universitätsmedizin Berlin, Institut tür Virologie
Victor M Corman, Barbara Mühlemann, Jörn Beheim-Schwarzbach, Talitha Veith, Julia Schneider, Terry Jones, Christian Drosten
EPI_ISL_729535, EPI_ISL_729536, EPI_ISL_729537, EPI_ISL_729538, EPI_ISL_729539, EPI_ISL_729540, EPI_ISL_729541, EPI_ISL_729542, EPI_ISL_729543, EPI_ISL_729544, EPI_ISL_729545, EPI_ISL_729546, EPI_ISL_729547 see above A. Krumbholz, Labor Dr. Krause und Kollegen MVZ GmbH, Charité Universitätsmedizin Berlin, Institut für Virologie $\quad$ Viel $\quad$ Victor M Corman, Barbara Mühlemann, Jörn Beheim-Schwarzbach, Talitha Veith, Julia Schneider, Terry Jones, Christian Drosten
EPI_ISL_729548 Charité Universitätsmedizin Berlin, Institut tür Virologie/Labor
Charité Universitätsmedizin Berlin, Institut tür Virologie
PIISL_729549, EPI_ISL_729550,
A. Krumbholz, Labor Dr. Krause und Kollegen MVZ GmbH,
Kiel
Charité Universitätsmedizin Berlin, Institut tür Virologie Victor M Corman, Barbara Mühlemann, Jörn Beheim-Schwarzbach, Talitha Veith, Julia Schneider, Terry Jones, Christian Drosten Bundeswehr Institute of Microbiology EPI_ISL_732533, EPI_ISL_732538 Bundeswehr Institute of Microbiology
EPI_ISL_732541, EPI_ISL_732542, EPI_ISL_732543, EPI_ISL_732544, EPI_ISL_732545, EPI_ISL_732546, EPI_ISL_732547, EPI_ISL_732548, EPI_ISL_732549, EPI_ISL_732550, see above Bundeswehr Institute of Microbiology
Bundeswehr Institute of Microbiology Bundeswehr Institute of Microbiology Victor M Corman, Barbara Mühlemann, Jörn Beheim-Schwarzbach, Talitha Veith, Julia Schneider, Terry Jones, Christian Drosten Elham Khatamzas, Markus Antwerpen, Mathias Walter, Alexandra Rehn, Sabine Zange, Enrico Georgi, Michael von Bergwelt-Baildon, Roman Wölfel

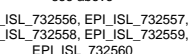 EPI_ISL_732560
Bundeswehr Institute of Microbiology Bundeswehr Institute of Microbiology

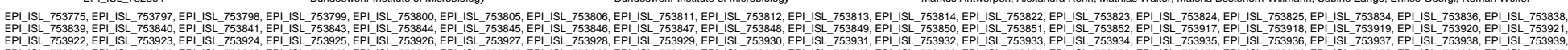

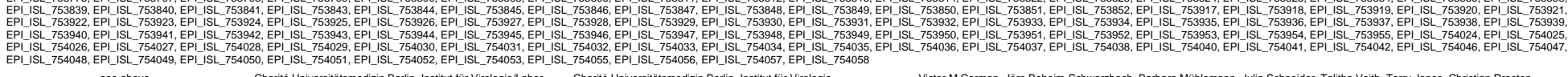 see above Charité Universitätsmedizin Berlin, Institut tür Virologie/Labor
Berlin
Jena University Hospital, Institute for Infectious Diseases and
Infection Control
Charité Universitätsmedizin Berlin, Institut für Virologie Victor M Corman, Jörn Beheim-Schwarzbach, Barbara Mühlemann, Julia Schneider, Talitha Veith, Terry Jones, Christian Drosten Institute of infectious medicine \& hospital hygiene,
CaSe-Group Spott, Riccardo; Marquet, Mike; Pletz, Matthias W.; Brandt, Christian

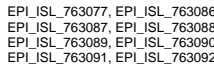

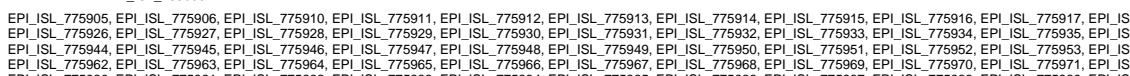

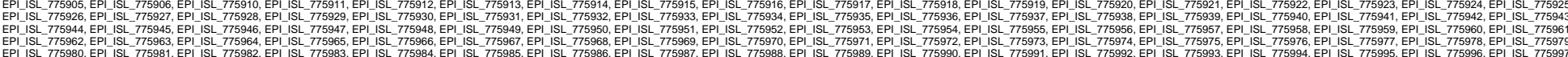

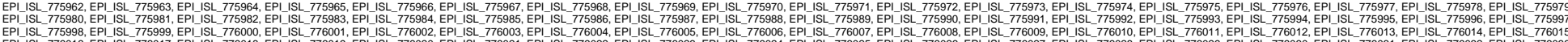

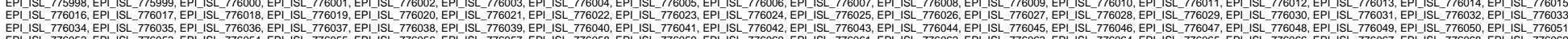

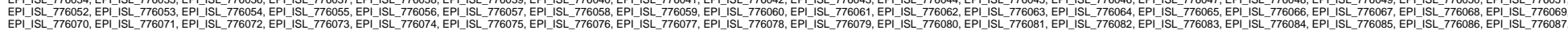


bioRxiv preprint doi: https://doi.org/10.1101/2021.07.21.452479; this version posted July 22, 2021. The copyright holder for this preprint (which was not certified by peer review) is the author/funder, who has granted bioRxiv a license to display the preprint in perpetuity. It is made available under aCC-BY 4.0 International license.

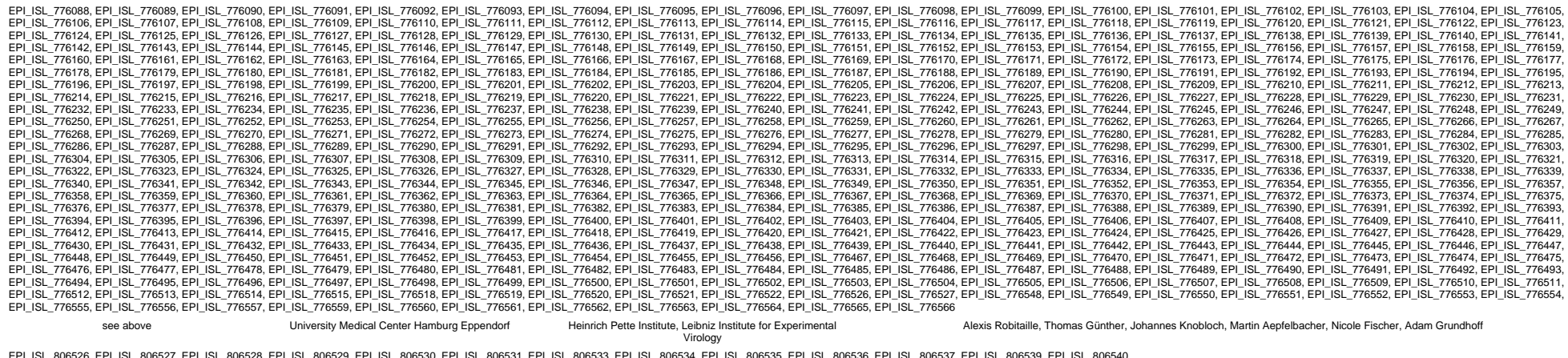

EPI_ISL_806526, EP__ISL_806527, EPI_ISL_806528, EPL_ISL_806529, EPI_ISL_806530, EPL_ISL_806531, EPI_ISL_806533, EP__ISL_806534, EPI_ISL_806535, EP__ISL_806536, EPI_ISL_806537, EPI_ISL_806539, EPI_ISL_806540

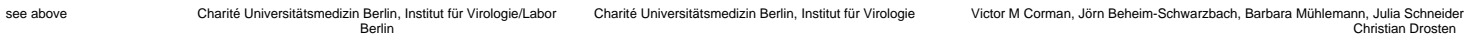

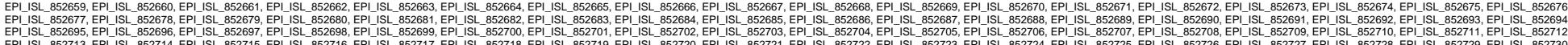

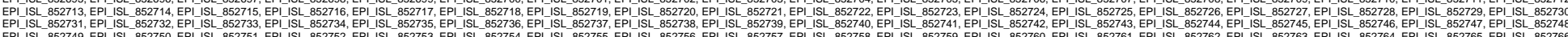

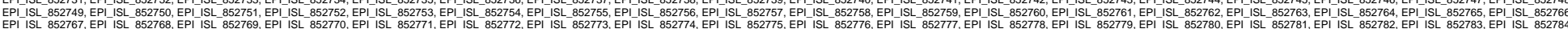

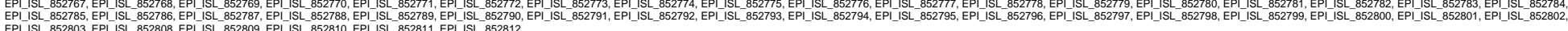
Institute of Virology, Medical Center, University of Freiburg, Institute of Virology, Clinial Virus Genomics, Medical Center,
Uneriversity of Freiburg. Freiburg, Germany EPI ISL $883156 \quad$ UK Tübingen, Medical Microbiology Lars Steinbrück, Jasper Götting EPI_ISL_883158, EPI ISL 883159, EPI_ISL_883160, EPI_ISL 883161, EPIIISL_883162, EPIISLL883163, EPI_ISL_883164, EPI_ISL_883165, EPI_ISL_883166, EPI_ISL_883167, EPIIISL_883168, EPIIISL_883169, EPI_ISL_883170, EPI_ISL_883171 see above Hannover Medical School, Institute of Virology Lars Steinbrück, Jasper Götting

EPI_ISL_883176, EPI_ISL_883177, EPI_ISL_883178, EPI_ISL_883179, EPI_ISL_883180, EPI_ISL_883181, EPI_ISL_883182, EPL_ISL_883183, EPI_ISL_883184, EPI_ISL_883185, EPI_ISL_883186, EPI_ISL_883187, EPI_ISL_883188, EPI_ISL_883189, EPI_ISL_883191, EPI_ISL_883192 see above UK Tübingen, Medical Microbiology Hannover Medical School, Institute of Virology Lars Steinbrück, Jasper Götting

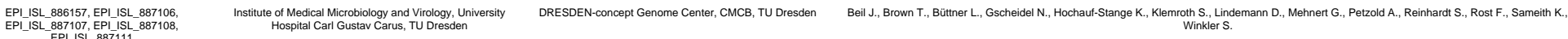

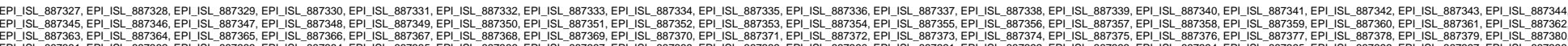

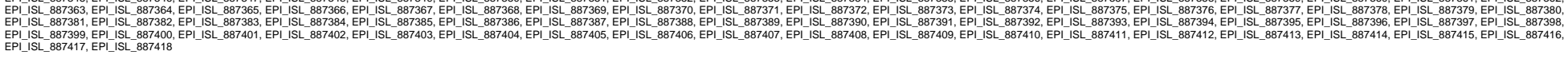
see above Protzer Lab

EPI_ISL_964878, EPI_ISL_964879 Institute of Virology Ulm University Medical Center Prof. Dr.
Thomas Stamminger Protzer Lab, Gagneur Lab, Robert Koch Institut Ulrike Protzer, Dieter Hoffmann, Eva Schulte, Andrea Theumer, Oliver Drechsel, Max von Kleist,Aleksandar Radonic,Stephan Fuchs, Alexander Karollus,
Julien Gagneur Münch Lab / Ulm University Medical Center Kirchnoff Lab / Thomas Stamminger, Helmut Blum, Stefan Krebs, Alexander Grat, Rüdiger Gross, Janis Müller, Carina Conzelmann, Jan Münch, Frank Kirchhofft,
Konstantin Sparrer
Uum University Medical Center Sparrer Lab / Um University
Medical Center Blum Lab / LMU Munich

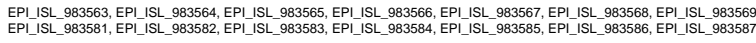

$$
\begin{array}{ccc}
\text { Institute of Virology, University Hospital, University of Bonn } & \text { Institute of Virology, University Hospital, University of Bonn } \\
\text { and German Center or Infection Research (DZIF), } & \text { and German Center for Infection Research (DZIF), } \\
\text { Bonn-Cologne, Bonn, Germany } & \text { Bonn-Cologne, Bonn, Germany }
\end{array}
$$


bioRxiv preprint doi: https://doi.org/10.1101/2021.07.21.452479; this version posted July 22, 2021. The copyright holder for this preprint (which was not certified by peer review) is the author/funder, who has granted bioRxiv a license to display the preprint in perpetuity. It is made available under aCC-BY 4.0 International license.

We gratefully acknowledge the following Authors from the Originating laboratories responsible for obtaining the specimens, as well as the Submitting laboratories where the genome data were generated and shared via GISAID, on which this research is based.

All Submitters of data may be contacted directly via www.gisaid.org

Authors are sorted alphabetically.

Accession ID

ISL_1015004, EPI_ISL_1015006, EPI_ISL_1015007, EPI ISL_10riginating Laboratory

$\begin{array}{ll} & \end{array}$

EPI_ISL_1015060, EPI_ISL_1015061, EPIISL-10 101504

EPIISL 1015111,EP_ISL_1015095,

$\begin{array}{lll} & \\ \end{array}$

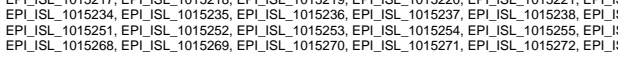
see above

EPIISL_1296382, EPI_ISL_1296384,
EPI_ISL_1296392, EPI_ISL_1296406

EPI_ISL_1301441

$$
\begin{aligned}
& \text { Department of Virology, Pitié-Salpêtrière hospital } \\
& \text { Hôpital Bichat Claude Bernard, Laboratoire de Virologie } \\
& \text { Department of Infectious and Tropical Diseases, Bichat } \\
& \text { Claude Bernard Hospital, Paris }
\end{aligned}
$$
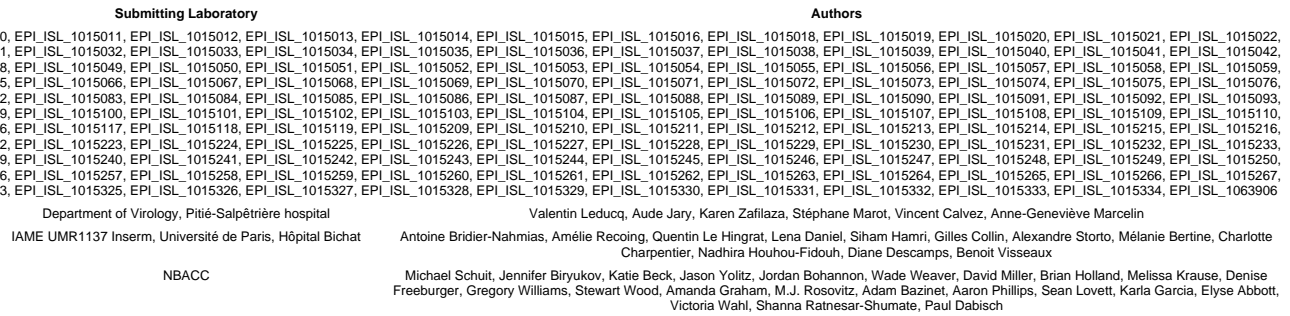

Michael Schuit, Jennifer Biryukov, Katie Beck, Jason Yolitz, Jordan Bohannon, Wade Weaver, David Miller, Brian Holland, Melissa Krause, Denise
Freeburger, Gregory Williams, Stewart Wood, Amanda G Granam, M.J. Rosovitz, Adam Bazinet, Aaron Phillips, Sean Lovett, Karla Garcia, Elyse Abbott,
Victoria Wahl, Shann Ratesar-Shumate, Paw Dabisch

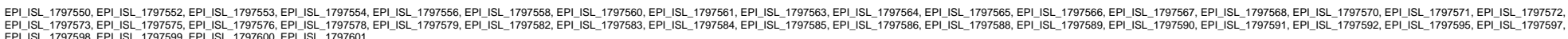
EPI_ISL-1797573, EPI_ISL-1797575, EPI_ISL_1797576, EPI_ISL_179757

$$
\text { see above Medical Center, Aircraft Carrier }
$$

EPI ISL 1910396

EPIISL_406596, EPI_ISL_406597

EPI_ISL_408430

EPI_ISL_408431

EPI_ISL_410486

EPI_ISL_410720

EPI_ISL_410984

EPI_ISL_411218

EPI_ISL_411219, EPI_ISL_411220

EPI_ISL_414600, EPI_ISL_414623

EPI_ISL_414624

EPI_ISL_414625

EPI_ISL_414626

EPI ISL 414627, EPIISL 414628,
EPI ISL 414629, EPI ISL 414630

EPI ISL 414631. EPI ISL 414632

EPI_ISL_414633

EPI_ISL_414634, EPI_ISL_414635,

EPL_ISL_415649

EPI_ISL_415650

EPI_ISL_415651, EPI_ISL_415652
Centre Hospitalier Universitaire Clermont-Ferrand Department of Infectious and Tropical Diseases, Bichat
Claude Bernard Hospital, Paris Department of Infectious and Tropical Diseases, Bichat
Claude Bernard Hospital, Paris Sorbonne Université, Inserm et Assistance Publique-Hôpitaux
de Paris (Pitié Salpétrière) CNR Virus des Infections Respiratoires - France SUD Department of Infectious and Tropical Diseases, Bichat
Claude Bernard Hospital, Paris Department of Infectious and Tropical Diseases, Bichat
Claude Bernard Hospital, Paris Department of Infectious and Tropical Diseases, Bichat
Claude Bernard Hospital, Paris Department of Infectious and Tropical Diseases, Bichat
Claude Bernard Hospital, Paris Laboratoire de Virologie Institut de Virologie - INSERM U
1109 Hôpitaux Universitaires de Strashosrarg Centre Hositalier Universitaire de Rouen Laboratoire de
Virologie Centre Hospitalier Régional Universitaire de Nantes
Laboratoire de Virologie unknown

Centre Hospitalier Compiègne Laboratoire de Biologie Hôpital Robert Debré Laboratoire de Virologie Centre Hospitalier René Dubois Laboratoire de Microbiologie
Bât A Centre Hospitalier Compiègne Laboratoire de Biologie unknown

Hôpital Instruction des Armées - BEGIN unknown
IRBA, 2MI

CHU Clermont-Ferrand, service de virologie National Reference Center for Viruses of Respiratory
Intections, Institut Pasteur, Paris National Reference Center for Viruses of Respiratory
Infections, Institut Pasteur, Paris National Reference Center for Viruses of Respiratory
Infections, Institut Pasteur, Paris CNR Virus des Infections Respiratoires - France SUD National Reference Center for Viruses of Respiratory National Reference Center for Viruses of Respiratory
Infections, Institut Pasteur, Paris Virpath, CIRI U111, UCBL1, INSERM, CNRS, Laboratoire Virpath, CIRI U111, UCBL1, INSERM, CNRS,
ENS Lyon Laboratoire Virpath, CIRI U111, UCBL1, INSERM, CNRS
ENS Lyon National Reference Center for Viruses of Respiratory National Reference Center for Viruses of Respiratory
Infections, Institut Pasteur. Paris National Reference Center for Viruses of Respiratory
Infections, Institut Pasteur, Paris National Reference Center for Viruses of Respiratory
Infections, Institut Pasteur, Paris Infections, Institut Pasteur, Paris
National Reference Center for Viruses of Respiratory
Infections, Institut Pasteur, Paris National Reference Center for Viruses of Respiratory National Reference Center for Viruses of Respiratory
Infections, Institut Pasteur, Paris National Reference Center for Viruses of Respiratory
Infections, Institut Pasteur, Paris National Reference Center for Viruses of Respiratory
Infections, Institut Pasteur, Paris National Reference Center for Viruses of Respiratory
Infections, Institut Pasteur, Paris National Reference Center for Viruses of Respiratory
Infections, Institut Pasteur, Paris Franck de Laval, Hervé Chaudet, Constance Lacrosse, Joffrey Marchi, Aissata Dia, Gaëtan Texier, Olivier Gorgé, Bakridine Mmadi Mrenda, Vanessa
Marbac, Flavie Letois, Anthony Levasseur, Jacques Cobola, Flora Nolent, Fabien Dutasta, Frédéric Janvier, Meynard Jean-Baptiste, Vincent Pommier de Bisseux Maxime, Mirand Audrey, Combes Patricia, Henquell Cécile Mélanie Albert, Marion Barbet, Sylvie Behillil, Méline Bizard, Angela Brisebarre, Flora Donati, Vincent Enouf, Maud Vanpeene, Sylvie van der Werf, Yazdan Mélanie Albert, Marion Barbet, Sylvie Behillil, Méline Bizard, Angela Brisebarre, Flora Donati, Vincent Enout, Maud Vanpeene, Sylvie van der Wert, Yazdan Mélanie Albert, Marion Barbet, Sylvie Behillil, Méline Bizard, Angela Brisebarre, Flora Donati, Vincent Enout, Maud Vanpeene, Sylvie van der Wert, Sonia
Burrel, Anne-Geneviève Marcelin, Vincent Calvez, David Boutolleau, Elise Klément, Valérie Pourcher, Eric Caumes. Bal, Antonin; Destras, Gregory; Gaymard, Alexandre; Bouscambert-Duchamp, Maude; Cheynet, Valérie; Brengel-Pesce, Karen; Morfin-Sherpa, Florence; Mélanie Albert, Marion Barbet, Sylvie Behillil, Méline Bizard, Angela Brisebarre, Flora Donati, Vincent Enouf, Maud Vanpeene, Sylvie van der Wert, Yazdan Mélanie Albert, Marion Barbet, Sylvie Behillil, Méline Bizard, Angela Brisebarre, Flora Donati, Vincent Enout, Maud Vanpeene, Sylvie van der Werf, Yazdan Olivier Terrier, Aurélien Traversier, Julien Fouret, Yazdan Ya

Olivier Terrier, Aurélien Traversier, Julien Fouret, Yazdan Yazdanpanah, Xavier Lescure, Alexandre Gaymard, Bruno Lina, Manuel Rosa-Calatrava Mélnie Albert, Marion Barbet, Sylvie Behillil, Méline Bizard, Angela Brisebarre, Flora Donati Vincent Enouf, Maud Vanpeene, Sylvie van der Werf, Samira

Ménie Albert, Marion Barbet, Sylvie Behillili, Méline Bizard, Angela Brisebarre, Flora Donati Vincent Enout, Maud Vanpeene, Sylvie van der Wert, Marianne

Mélnie Albert, Marion Barbet, Sylvie Behilili, Méline Bizard, Angela Brisebarre, Flora Donati Vincent Enout, Maud Vanpeene, Sylvie van der Wert Mélnie Albert, Marion Barbet, Sylvie Behilili, Méline Bizard, Angela Brisebarre, Flora Donati Vincent Enout, Maud Vanpeene, Sylvie van der Werr, Raulin Mélnie Albert, Marion Barbet, Sylvie Behilili, Méline Bizard, Angela Brisebarre, Flora Donati Vincent Enout, Maud Vanpeene, Sylvie van der Werf, Laurent Mélnie Albert, Marion Barbet, Sylvie Behillil, Méline Bizard, Angela Brisebarre, Flora Donati Vincent Enoư, Maud Vanpeene, Sylvie van der Wert, Pascale Mélnie Albert, Marion Barbet, Sylvie Behilili, Méline Bizard, Angela Brisebarre, Flora Donati Vincent Enout, Maud Vanpeene, Sylvie van der Wert, Raulin Mélnie Albert, Marion Barbet, Sylvie Behilili, Méline Bizard, Angela Brisebarre, Flora Donati Vincent Enout, Maud Vanpeene, Sylvie van der Werf Mélnie Albert, Marion Barbet, Sylvie Behillil, Méline Bizard, Angela Brisebarre, Flora Donati Vincent Enout, Maud Vanpeene, Sylvie van der Wert, Christine Mélnie Albert, Marion Barbet, Sylvie Behilili, Méline Bizard, Angela Brisebarre, Flora Donati Vincent Enout, Maud Vanpeene, Sylvie van der Werf 
bioRxiv preprint doi: https://doi.org/10.1101/2021.07.21.452479; this version posted July 22, 2021. The copyright holder for this preprint (which was not certified by peer review) is the author/funder, who has granted bioRxiv a license to display the preprint in perpetuity. It is made available under aCC-BY 4.0 International license.

EPI_ISL_415654

EPI_ISL_416493

EPI_ISL_416494

EPI_ISL_416495, EPI ISL_416496 EPI ISL 416498

EPI_ISL_416499, EPI_ISL_416500

EPI_ISL_416501

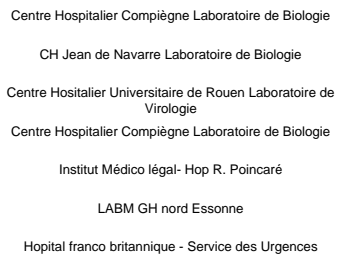

Hopital franco britannique - Service des Urgences

CISL_416505, EPL_ISL_416506, EPI_ISL_416507,
CHRU Pontchaillou - Laboratoire de Virologie CNR Virus des Infections Respiratoires - France SUD Institut des Agents Infectieux (IAI) Hospices Civils de Lyon Centre Hospitalier de Valence

Institut des Agents Infectieux (IAI) Hospices Civils de Lyon CHU Gabriel Montpied

Institut des Agents Infectieux (IAI) Hospices Civils de Lyon

Centre Hospitalier de Bourg en Bresse

Institut des Agents Infectieux (IAI) Hospices Civils de Lyon

Institut des Agents Infectieux (IAI), Hospices Civils de Lyon

Centre Hospitalier de Macon

Institut des Agents Infectieux (IAI), Hospices Civils de Lyon

Centre Hospitalier de Bourg en Bresse

Centre Hospitalier Compiègne Laboratoire de Biologie CHU - Hôpital Cavale Blanche - Labo. de Virologie

Centre Hospitalier Compiègne Laboratoire de Biologie

CHRU Bretonneau - Serv. Bacterio-Virol.

Centre Hospitalier Compiègne Laboratoire de Biologie EHPAD - Résidences les Cèdres

Centre Hospitalier Compiègne Laboratoire de Biologie

Hopital franco britannique - Laboratoire

Clinique AVERAY LA BROUSTE, Med. Polyvalente

Centre Hospitalier Compiègne Laboratoire de Biologie

Service des Urgences

LABM GH nord Essonne

Cabinet médical

Centre Hospitalier Compiègne Laboratoire de Biologie
National Reference Center for Viruses of Respiratory
Infections, Institut Pasteur, Paris National Reference Center for Viruses of Respiratory
Infections. Institut Pasteur, Paris National Reference Center for Viruses of Respiratory
Infections, Institut Pasteur, Paris National Reference Center for Viruses of Respiratory National Reference Center for Viruses of Respiratory
Infections, Institut Pasteur, Paris National Reference Center for Viruses of Respiratory
Intections, Institut Pasteur, Paris National Reference Center for Viruses of Respiratory
Infections, Institut Pasteur, Paris National Reference Center for Virususes of RespirasL National Reference Center for Viruses of Respiratory
Infections, Institut Pasteur, Paris CNR Virus des Infections Respiratoires - France SUD CNR Virus des Infections Respiratoires - France SUD CNR Virus des Infections Respiratoires - France SUD

CNR Virus des Infections Respiratoires - France SUD CNR Virus des Infections Respiratoires - France SUD CNR Virus des Infections Respiratoires - France SUD CNR Virus des Infections Respiratoires - France SUD

CNR Virus des Infections Respiratoires - France SUD CNR Virus des Infections Respiratoires - France SUD CNR Virus des Infections Respiratoires - France SUD CNR Virus des Infections Respiratoires - France SUD CNR Virus des Infections Respiratoires - France SUD National Reference Center for Viruses of Respiratory
Infections, Institut Pasteur, Paris National Reference Center for Viruses of Respiratory
Infections, Institut Pasteur, Paris National Reference Center for Viruses of Respiratory
Infections, Institut Pasteur, Paris National Reference Center for Viruses of Respiratory
Infections, Institut Pasteur, Paris National Reference Center for Viruses of Respiratory National Reference Center for Viruses of Respiratory
Infections. Institut Pasteur, Paris National Reference Center for Viruses of Respiratory
Infections, Institut Pasteur, Paris National Reference Center for Viruses of Respiratory
Infections, Institut Pasteur, Paris National Reference Center for Viruses of Respirator Infections, Institut Pasteur, Paris
National Reference Center for Viruses of Respiratory
Infections, Institut Pasteur, Paris National Reference Center for Viruses of Respiratory
Intections, Institutut Pasteur, Paris National Reference Center for Viruses of Respiratory
Infections, Institut Pasteur, Paris National Reference Center for Viruses of Respiratory
Infections, Institut Pasteur, Paris National Reference Center for Viruses of Respiratory
Mélnie Albert, Marion Barbet, Sylvie Behilili, Méline Bizard, Angela Brisebarre, Flora Donati Vincent Enout, Maud Vanpeene, Sylvie van der Werf, Raulin Mélnie Albert, Marion Barbet, Sylvie Behilili, Méline Bizard, Angela Brisebarre, Flora Donati, Etienne Simon-Lorière, Vincent Enout, Maud Vanpeene, Sylvie Mélnie Albert, Marion Barbet, Sylvie Behilli, Méline Bizard, Angela Brisebarre, Flora Donati, Etienne Simon-Lorière, Vincent Enouf, Maud Vanpeene, Sylvie
van der Werf, Jean-Christophe Plantier Mélnie Albert, Marion Barbet, Sylvie Behillil, Méline Bizard, Angela Brisebarre, Flora Donati, Etienne Simon-Lorière, Vincent Enoưt, Maud Vanpeene, Sylvie Mélnie Albert, Marion Barbet, Sylvie Behillil, Méline Bizard, Angela Brisebarre, Flora Donati, Etienne Simon-Lorière, Vincent Enouf, Maud Vanpeene, Sylvie Mélnie Albert, Marion Barbet, Sylvie Behillil, Méline Bizard, Angela Brisebarre, Flora Donati, Etienne Simon-Lorière, Vincent Enout, Maud Vanpeene, Sylvie Mélnie Albert, Marion Barbet, Sylvie Behillil, Méline Bizard, Angela Brisebarre, Flora Donati, Etienne Simon-Lorière, Vincent Enout, Maud Vanpeene, Sylvie 511, EPI_ISL_416512, EPI_ISL_416513

Mélnie Albert, Marion Barbet, Sylvie Behillil, Méline Bizard, Angela Brisebarre, Flora Donati, Etienne Simon-Lorière, Vincent Enout, Maud Vanpeene, Sylvie Bal, Antonin; Destras, Gregory; Gaymard, Alexandre; Bouscambert-Duchamp, Maude; Cheynet, Valérie; Brengel-Pesce, Karen; Mortin-Sherpa, Florence; Bal, Antonin; Destras, Gregory; Gaymard, Alexandre; Bouscambert-Duchamp, Maude; Cheynet, Valérie; Brengel-Pesce, Karen; Mortin-Sherpa, Florence Bal, Antonin; Destras, Gregory; Gaymard, Alexandre; Bouscambert-Duchamp, Maude; Cheynet, Valérie; Brengel-Pesce, Karen; Mortin-Sherpa, Florence;
Valette, Martine; Josset, Laurence; Lina, Bruno.

Bal, Antonin; Destras, Gregory; Gaymard, Alexandre; Bouscambert-Duchamp, Maude; Cheynet, Valérie; Brengel-Pesce, Karen; Mortin-Sherpa, Florence;
Valette, Martine; Josset, Laurence; Lina, Bruno. Bal, Antonin; Destras, Gregory; Gaymard, Alexandre; Bouscambert-Duchamp, Maude; Cheynet, Valérie; Brengel-Pesce, Karen; Mortin-Sherpa, Florence Bal, Antonin; Destras, Gregory; Gaymard, Alexandre; Bouscambert-Duchamp, Maude; Cheynet, Valérie; Brengel-Pesce, Karen; Mortin-Sherpa, Florence; Bal, Antonin; Destras, Gregory; Gaymard, Alexandre; Bouscambert-Duchamp, Maude; Cheynet, Valérie; Brengel-Pesce, Karen; Mortin-Sherpa, Florence; Bal, Antonin; Destras, Gregory; Gaymard, Alexandre; Bouscambert-Duchamp, Maude; Cheynet, Valérie; Brengel-Pesce, Karen; Mortin-Sherpa, Florence;
Valette, Martine; Josset, Laurence; Lina, Bruno. Antonin Bal, Gregory Destras, Gwendolyne Burfin, Solenne Brun, Carine Moustaud, Raphaelle Lamy, Alexandre Gaymard, Maude Bouscambert-Duchamp.
Florence Morfin-Sherpa, Martine Valette, Laurence Josset, Bruno Lina Antonin Bal, Gregory Destras, Gwendolyne Burfin, Solenne Brun, Carine Moustaud, Raphaelle Lamy, Alexandre Gaymard, Maude Bouscambert-Duchamp,
Florence Morfin-Sherpa, Martine Valette, Laurence Josset, Bruno Lina Antonin Bal, Gregory Destras, Gwendolyne Burfin, Solenne Brun, Carine Moustaud, Raphaelle Lamy, Alexandre Gaymard, Maude Bouscambert-Duchamp,
Florence Morfin-Sherpa, Martine Valette, Laurence Josset, Bruno Lina Florence Morfin-Sherpa, Martine Valette, Laurence Josset, Bruno Lina
Antonin Bal, Gregory Destras, Gwendolyne Burfin, Solenne Brun, Carine Moustaud, Raphaelle Lamy, Alexandre Gaymard, Maude Bouscambert-Duchamp,
Florence Morfin-Sherpa, Martine Valette, Laurence Josset, Bruno Lina Mélanie Albert, Marion Barbet, Sylvie Behillili, Méline Bizard, Angela Brisebarre, Flora Donati, Fabiana Gambaro, Etienne Simon-Lorière, Vincent Enout, Mélanie Albert, Marion Barbet, Sylvie Behilili, Méline Bizard, Angela Brisebarre, Flora Donati, Fabiana Gambaro, Etienne Simon-Lorière, Vincent Enout, Mélanie Albert, Marion Barbet, Sylvie Behilili, Méline Bizard, Angela Brisebarre, Flora Donati, Fabiana Gambaro, Etienne Simon-Lorière, Vincent Enout, Mélanie Albert, Marion Barbet, Sylvie Behillil, Méline Bizard, Angela Brisebarre, Flora Donatit, Fabiana Gambaro, Etienne Simon-Lorière, Vincent Enouf, Mélanie Albert, Marion Barbet, Sylvie Behillil, Méline Bizard, Angela Brisebarre, Flora Donati, Fabiana Gambaro, Etienne Simon-Lorière, Vincent Enouf,

Mélanie Albert, Marion Barbet, Sylvie Behilli, Méline Bizard, Angela Brisebarre, Flora Donati, Etienne Simon-Lorière, Vincent Enout, Maud Vanpeene, Mélanie Albert, Marion Barbet, Sylvie Behilli, Méline Bizard, Angela Brisebarre, Flora Donati, Etienne Simon-Lorière, Vincent Enout, Maud Vanpeene,
Sylvie van der Wert, Raulin Olivia Mélanie Albert, Marion Barbet, Sylvie Behillil, Méline Bizard, Angela Brisebarre, Flora Donati, Etienne Simon-Lorière, Vincent Enout, Maud Vanpeene,
Sylvie van der Werf, Marianne Asso Bonnet Mélanie Albert, Marion Barbet, Sylvie Behillit, Méline Bizard, Angela Brisebarre, Flora Donati, Etienne Simon-Lorière, Vincent Enout, Maud Vanpeene, Mélanie Albert, Marion Barbet, Sylvie Behilli, Méline Bizard, Angela Brisebarre, Flora Donati, Etienne Simon-Lorière, Vincent Enouf, Maud Vanpeene, Mélanie Albert, Marion Barbet, Sylvie Behilli, Méline Bizard, Angela Brisebarre, Flora Donati, Etienne Simon-Lorière, Vincent Enout, Maud Vanpeene,
Sylvie van der Werf, Boubkeur Mélanie Albert, Marion Barbet, Sylvie Behillil, Méline Bizard, Angela Brisebarre, Flora Donati, Etienne Simon-Lorière, Vincent Enout, Maud Vanpeene,
Sylvie van der Wert, Christine Lambert Mélanie Albert, Marion Barbet, Sylvie Behilili, Méline Bizard, Angela Brisebarre, Flora Donati, Etienne Simon-Lorière, Vincent Enout, Maud Vanpeene, Mélanie Albert, Marion Barbet, Sylvie Behillit, Méline Bizard, Angela Brisebarre, Flora Donati, Etienne Simon-Lorière, Vincent Enout, Maud Vanpeene, 
bioRxiv preprint doi: https://doi.org/10.1101/2021.07.21.452479; this version posted July 22, 2021. The copyright holder for this preprint (which was not certified by peer review) is the author/funder, who has granted bioRxiv a license to display the preprint in perpetuity. It is made available under aCC-BY 4.0 International license.

\section{EPI_ISL_418240 \\ EPI_ISL_418412 \\ EPI_ISL_418413 \\ EPI_ISL_418414 \\ EPI_ISL_418416 \\ EPI_ISL_418417}

EPI_ISL_418418, EPI_ISL_418419

EPI_ISL_418420, EPI_ISL_41842

EPIIISL-418422, EPIIISL-418423 EPI_ISL_418426

EPI_ISL_418427

EPI_ISL_418428

EPIISL 418429, EPIISL 4 418430
EPIISL 418431, EPIISL 418432 EPI_ISL_419168

EPI_ISL_419169, EPI_ISL_419170,
EPI__SL_419171, EPIISL-419172,

EPI_ISL_419174, EPI_ISL_419175,
EPI_ISL_419176

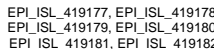

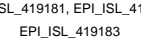

EPI_ISL_419184

EPI_SSL_419185, EPI_ISL_419186

EPI_SL_419187, EPI_ISL_419188

EPI_ISL_420038

EPI_ISL_420039, EPI_ISL_420040

EPI_ISL_420041

EPI_ISL_420042

EPI_ISL_420043

EPI_ISL_420044

EPI_ISL_420045

EPI_ISL_420046, EPI_ISL_420047 EPI_ISL_420048

EPI_ISL_420049, EPI_ISL_420050

EPI_ISL_420051

EPI_ISL_420052

EPI_ISL_420053

EPI_ISL_420055
LABM GH nord Essonne

Centre Hospitalier des Vals d'Ardeche

Centre Hospitalier de Macon

Centre Hospitalier de Valence

GH Les Portes du Sud

Centre Hospitalier de Valence

Centre Hospitalier Saint Joseph Saint Luc

Institut des Agents Infectieux (IAI), Hospices Civils de Lyon

Centre Hospitalier de Bourg en Bresse

Hopital Privé de l'Est Lyonnais

Centre Hospitalier Lucien Hussel

Institut des Agents Infectieux (IAI), Hospices Civils de Lyon

Centre Hospitalier de Valence

Institut des Agents Infectieux (IAI), Hospices Civils de Lyon

Centre Hospitalier de Macon

Institut des Agents Infectieux (IAI), Hospices Civils de Lyon

Centre Hospitalier de Bourg en Bresse

Institut des Agents Infectieux (IAI), Hospices Civils de Lyon

Centre Hospitalier de Bourg en Bresse

Centre Hospitalier de Macon

Sentinelles network

L'Air du Temps

CH Compiègne Laboratoire de Biologie

Service de Biologie clinique

CMIP

CH Jean de Navarre Laboratoire de Biologie

Sentinelles network

Résidence Villa Caroline

Service de Biologie Médicale - BP 125

CH Compiègne Laboratoire de Biologie

Résidence Eleusis

Résidence les Marines

CH Jean de Navarre Laboratoire de Biologie

Sentinelles network
National Reference Center for Viruses of Respiratory
Infections, Institut Pasteur, Paris

CNR Virus des Infections Respiratoires - France SUD

CNR Virus des Infections Respiratoires - France SUD

CNR Virus des Infections Respiratoires - France SUD

CNR Virus des Infections Respiratoires - France SUD

CNR Virus des Infections Respiratoires - France SUD

CNR Virus des Infections Respiratoires - France SUD

CNR Virus des Infections Respiratoires - France SUD

CNR Virus des Infections Respiratoires - France SUD

CNR Virus des Infections Respiratoires - France SUD

CNR Virus des Infections Respiratoires - France SUD

CNR Virus des Infections Respiratoires - France SUD

CNR Virus des Infections Respiratoires - France SUD

CNR Virus des Infections Respiratoires - France SUD

CNR Virus des Infections Respiratoires - France SUD

CNR Virus des Infections Respiratoires - France SUD

CNR Virus des Infections Respiratoires - France SUD

CNR Virus des Infections Respiratoires - France SUD

CNR Virus des Infections Respiratoires - France SUD

CNR Virus des Infections Respiratoires - France SUD

National Reference Center for Viruses of Respiratory
Infections, Institut Pasteur, Paris National Reference Center for Viruses of Respiratory

National Reference Center for Viruses of Respiratorn
Infections, Institut Pasteur, Paris

National Reference Center for Viruses of Respiratory
Infections, Institut Pasteur, Paris

National Reference Center for Viruses of Respiratory
Infections, Institut Pasteur, Paris

National Reference Center for Viruses of Respiratory

National Reference Center for Viruses of Respiratory
Infections, Institut Pasteur. Paris

National Reference Center for Viruses of Respiratory
Infections, Institut Pasteur, Paris

National Reference Center for Viruses of Respiratory
Infections, Institut Pasteur, Paris

National Reference Center for Viruses of Respiratory
Infections. Institut Pasteur, Paris

National Reference Center for Viruses of Respiratory
Infections, Institut Pasteur, Paris

National Reference Center for Viruses of Respiratory
Infections, Institut Pasteur, Paris

National Reference Center for Viruses of Respiratory
Infections, Institut Pasteur, Paris

National Reference Center for Viruses of Respiratory
Infections, Institut Pasteur, Paris

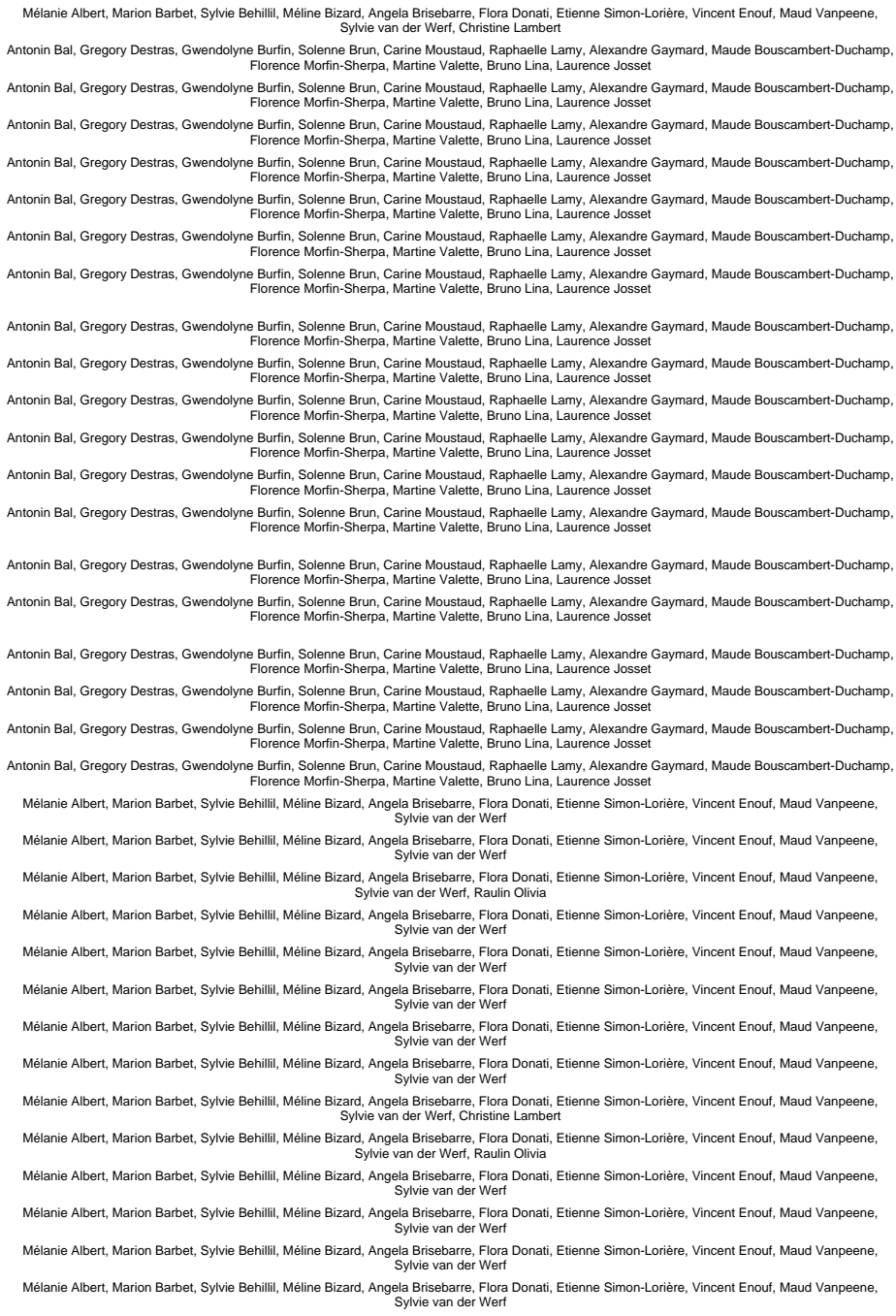


bioRxiv preprint doi: https://doi.org/10.1101/2021.07.21.452479; this version posted July 22, 2021. The copyright holder for this preprint (which was not certified by peer review) is the author/funder, who has granted bioRxiv a license to display the preprint in perpetuity. It is made available under aCC-BY 4.0 International license.

\begin{tabular}{|c|c|c|}
\hline EPI_ISL_420056, EPI_SL__420057 & CH Compiègne Laboratoire de Biologie & $\begin{array}{l}\text { National Reference Center for Viruses of Respiratory } \\
\text { Infections, Institut Pasteur, Paris }\end{array}$ \\
\hline $\begin{array}{l}\text { EPI_ISL_420058, EPI_ISL_420059, } \\
\text { EPI_ISL_420060 }\end{array}$ & Service de Biologie Médicale - BP 125 & $\begin{array}{l}\text { National Reference Center for Viruses of Respiratory } \\
\text { Infections, Institut Pasteur, Paris }\end{array}$ \\
\hline EPI_ISL_420061 & CMIP & $\begin{array}{l}\text { National Reference Center for Viruses of Respiratory } \\
\text { Infections, Institut Pasteur, Paris }\end{array}$ \\
\hline EPI_ISL_420063 & Labo BM - Site de Juvisy - Hopital Général & $\begin{array}{l}\text { National Reference Center for Viruses of Respiratory } \\
\text { Infections, Institut Pasteur, Paris }\end{array}$ \\
\hline EPI_ISL_420064 & Service de Biologie Médicale - BP 125 & $\begin{array}{l}\text { National Reference Center for Viruses of Respiratory } \\
\text { Intections, Institut Pasteur, Paris }\end{array}$ \\
\hline $\begin{array}{l}\text { EPI_ISL_420604, EPI_ISL_420605, } \\
\text { EPI_ISL-420606, EPI_ISL-420607, } \\
\text { EPIISL-42060, EPIISL-420609, } \\
\text { EPI_ISL_420610, EPI_ISL_420611 }\end{array}$ & Institut des Agents Infectieux (IAI), Hospices Civils de Lyon & CNR Virus des Infections Respiratoires - France SUD \\
\hline EPI_ISL_420613, EPI_ISL_420614 & Centre Hospitalier de Macon & CNR Virus des Infections Respiratoires - France SUD \\
\hline EPI_ISL_420615, EPI_ISL_420616 & nstitut des Agents Infectieux (IA|), Hospices Civils de Lyon & CNR Virus des Infections Respiratoires - France SUD \\
\hline EPI_ISL_420617 & Centre Hospitalier Saint Joseph Saint Luc & CNR Virus des Infections Respiratoires - France SUD \\
\hline EPI_ISL_420618, EPI_ISL_420619 & Institut des Agents Infectieux (IAI), Hospices Civils de Lyon & CNR Virus des Infections Respiratoires - France SUD \\
\hline EPI_ISL_420620 & Centre Hospitalier de Bourg en Bresse & CNR Virus des Infections Respiratoires - France SUD \\
\hline $\begin{array}{l}\text { EPI_ISL_420621, EPI_ISL_420622, } \\
\text { EPI_ISL_420623, EPIISL_420624, } \\
\text { EPI_ISL_420625 }\end{array}$ & nstitut des Agents Infectieux (IAI), Hospices Civils de Lyon & CNR Virus des Infections Respiratoires - France SUD \\
\hline EPI_ISL_421500 & CH Compiègne Laboratoire de Biologie & $\begin{array}{l}\text { National Reference Center for Viruses of Respiratory } \\
\text { Intections, Institut Pasteur, Paris }\end{array}$ \\
\hline EPI_ISL_421501 & Service de Biologie Médicale - BP 125 & $\begin{array}{l}\text { National Reference Center for Viruses of Respiratory } \\
\text { Infections, Institut Pasteur, Paris }\end{array}$ \\
\hline EPI_ISL_421502, EPI_ISL_421503 & Parc des Dames & $\begin{array}{l}\text { National Reference Center for Viruses of Respiratory } \\
\text { Infections, Institut Pasteur, Paris }\end{array}$ \\
\hline EPI_ISL_421504, EPLISL_421505, & Service de Biologie Médicale - BP 125 & $\begin{array}{l}\text { National Reference Center for Viruses of Respiratory } \\
\text { Infections, Institut Pasteur, Paris }\end{array}$ \\
\hline EPI_ISL_421507, EPI_ISL_421508 & Le Château de Seine-Port & $\begin{array}{l}\text { National Reference Center for Viruses of Respiratory } \\
\text { Infections, Institut Pasteur, Paris }\end{array}$ \\
\hline $\begin{array}{l}\text { EPI_ISL_421509, EPI_ISL_421510, } \\
\text { EPI_ISL_421511 }\end{array}$ & CH Compiègne Laboratoire de Biologie & $\begin{array}{l}\text { National Reference Center for Viruses of Respiratory } \\
\text { Infections, Institut Pasteur, Paris }\end{array}$ \\
\hline EPI_ISL_421512 & Service de Biologie Médicale - BP 125 & $\begin{array}{l}\text { National Reference Center for Viruses of Respiratory } \\
\text { Infections, Institut Pasteur, Paris }\end{array}$ \\
\hline EPI_ISL_421513 & Service de Biologie clinique & $\begin{array}{l}\text { National Reference Center for Viruses of Respiratory } \\
\text { Infections, Institut Pasteur, Paris }\end{array}$ \\
\hline EPI_ISL_421514 & Sentinelles netwo & $\begin{array}{l}\text { National Reference Center for Viruses of Respiratory } \\
\text { Infections, Institut Pasteur, Paris }\end{array}$ \\
\hline EPI_ISL_428347 & Service de Biologie Médicale - BP 125 & $\begin{array}{l}\text { National Reference Center for Viruses of Respiratory } \\
\text { Infections, Institut Pasteur, Paris }\end{array}$ \\
\hline EPI_ISL_428348 & Maison de Santé du Val d'Ormois & $\begin{array}{l}\text { National Reference Center for Viruses of Respiratory } \\
\text { Infections, Institut Pasteur, Paris }\end{array}$ \\
\hline EPI_ISL_428349 & Service de Biologie Médicale - BP 125 & $\begin{array}{l}\text { National Reference Center for Viruses of Respiratory } \\
\text { Infections, Institut Pasteur, Paris }\end{array}$ \\
\hline EPI_ISL_428350 & CH Jean de Navarre Laboratoire de Biolog & $\begin{array}{l}\text { National Reference Center for Viruses of Respiratory } \\
\text { Infections, Institut Pasteur, Paris }\end{array}$ \\
\hline EPI_ISL_428351, EPI_ISL_428352 & GH Nord Essonne Service de Biologie clinique & $\begin{array}{l}\text { National Reference Center for Viruses of Respiratory } \\
\text { Infections, Institut Pasteur, Paris }\end{array}$ \\
\hline EPI_ISL_428353 & CH Compiègne Laboratoire de Biologie & $\begin{array}{l}\text { National Reference Center for Viruses of Respiratory } \\
\text { Infections, Institut Pasteur, Paris }\end{array}$ \\
\hline EPI_ISL_428354 & LABM GH nord Essonne de Longjumeau - BP 125 & $\begin{array}{l}\text { National Reference Center for Viruses of Respiratory } \\
\text { Infections, Institut Pasteur, Paris }\end{array}$ \\
\hline $\begin{array}{l}\text { EPI_ISL_428355, EPI_ISL_428356, } \\
\text { EPI_ISL_428357 }\end{array}$ & Institut Médico légal- Hop R. Poincaré & $\begin{array}{l}\text { National Reference Center ro Viruses of Respiratory } \\
\text { Infections, Institut Pasteur, Paris }\end{array}$ \\
\hline EPI_ISL_428358 & CH Jeanne de Navarre Laboratoire de Biologi & $\begin{array}{l}\text { National Reference Center for Viruses of Respiratory } \\
\text { Infections, Institut Pasteur, Paris }\end{array}$ \\
\hline EPI_ISL_428359, EPI_ISL_428360 & CH Compiègne Laboratoire de Biologie & $\begin{array}{l}\text { National Reference Center ro Viruses of Respiratory } \\
\text { Infections, Institut Pasteur, Paris }\end{array}$ \\
\hline EPI_ISL_428361 & LABM GH nord Essonne de Longjumeau - BP 125 & $\begin{array}{l}\text { National Reference Center for Viruses of Respiratory } \\
\text { Infections, Institut Pasteur, Paris }\end{array}$ \\
\hline EPI_ISL_428363 & GH Nord Essonne Service de Biologie cliniqu & $\begin{array}{l}\text { National Reference Center for Viruses of Respiratory } \\
\text { Infections, Institut Pasteur, Paris }\end{array}$ \\
\hline PI_ISL_428365 & LABM GH nord Essonne de Longjumeau - BP 125 & $\begin{array}{l}\text { National Reference Center for Viruses of Respiratory } \\
\text { Infections, Institut Pasteur, Paris }\end{array}$ \\
\hline
\end{tabular}

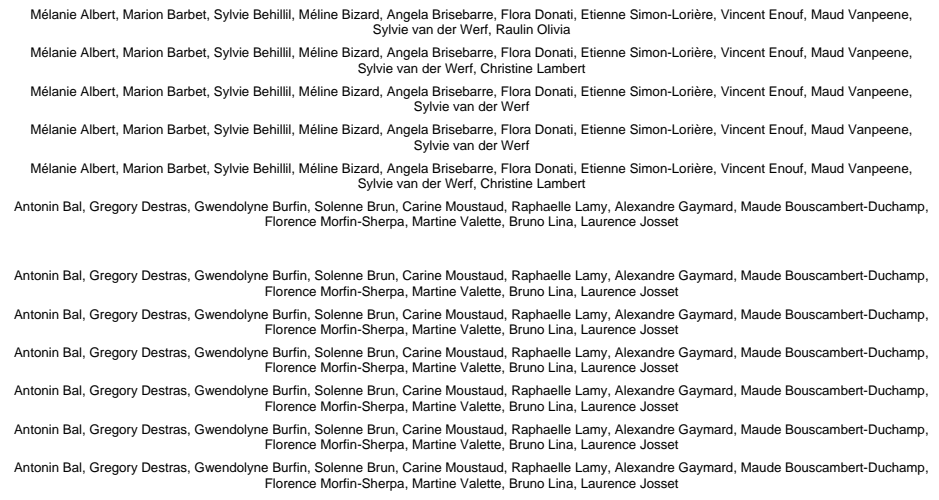
Mélanie Albert, Marion Barbet, Sylvie Behillil, Méline Bizard, Angela a risiebarre, Flora Donati, Etienne Simon-Lorière, Vincent Enouf, Maud Vanpeene, Mélanie Albert, Marion Barbet, Sylvie Behillil, Méline Bizard, Angela Brisebarre, Flora Donati, Etienne Simon-Lorière, Vincent Enout, Maud Vanpeene,
Sylvie van der Wert, Christine Lambert Antonin Bal, Gregory Destras, Gwendolyne Burfin, Solenne Brun, Carine Moustaud, Raphaelle Lamy, Alexandre Gaymard, Maude Bouscambert-Duchamp,
Florence Morfin-Sherpa, Martine Valette, Bruno Lina, Laurence Josset

Antonin Bal, Gregory Destras, Gwendolyne Burfin, Solenne Brun, Carine Moustaud, Raphaelle Lamy, Alexandre Gaymard, Maude Bouscambert-Duchamp,
Florence Morfin-Sherpa, Martine Valette, Bruno Lina, Laurence Josset Antonin Bal, Gregory Destras, Gwendolyne Burfin, Solenne Brun, Carine Moustaud, Raphaelle Lamy, Alexandre Gaymard, Maude Bouscambert-Duchamp,
Florence Morfin-Sherpa, Martine Valette, Bruno Lina, Laurence Josset Antonin Bal, Gregory Destras, Gwendolyne Burfin, Solenne Brun, Carine Moustaud, Raphaelle Lamy, Alexandre Gaymard, Maude Bouscambert-Duchamp,
Florence Morfin-Sherpa, Martine Valette, Bruno Lina, Laurence Josset

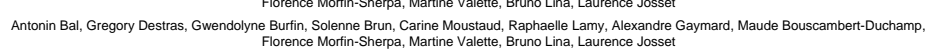
Antonin Bal, Gregory Destras, Gwendolyne Burfin, Solenne Brun, Carine Moustaud, Raphaelle Lamy, Alexandre Gaymard, Maude Bouscambert-Duchamp.
Florence Morfin-Sherpa, Martine Valette, Bruno Lina, Laurence Josset Antonin Bal, Gregory Destras, Gwendolyne Burtin, Solenne Brun, Carine Moustaud, Raphaelle Lamy, Alexandre Gaymard, Maude Bouscambert-Duchamp,
Florence Morfin-Sherpa, Martine Valette, Bruno Lina, Laurence Josset

Mélanie Albert, Marion Barbet, Sylvie Behilli, Méline Bizard, Angela Brisebarre, Flora Donati, Etienne Simon-Lorière, Vincent Enouf, Maud Vanpeene,

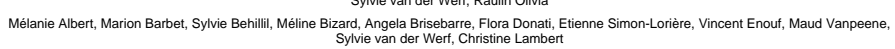
Mélanie Albert, Marion Barbet, Sylvie Behillil, Méline Bizard, Angela Brisebarre, Flora Donati, Etienne Simon-Lorière, Vincent Enouf, Maud Vanpeene, Mélanie Albert, Marion Barbet, Sylvie Behilli, Méline Bizard, Angela Brisebarre, Flora Donati, Etienne Simon-Lorière, Vincent Enout, Maud Vanpeene,
Sylvie van der Wert, Christine Lambert Mélanie Albert, Marion Barbet, Sylvie Behilili, Méline Bizard, Angela Brisebarre, Flora Donati, Etienne Simon-Lorière, Vincent Enouf, Maud Vanpeene, Mélanie Albert, Marion Barbet, Sylvie Behillil, Méline Bizard, Angela Brisebarre, Flora Donati, Etienne Simon-Lorière, Vincent Enouf, Maud Vanpeene,
Sylvie van der Wert, Raulin Olivia Mélanie Albert, Marion Barbet, Sylvie Behillil, Méline Bizard, Angela Brisebarre, Flora Donati, Etienne Simon-Lorière, Vincent Enout, Maud Vanpeene,
Sylvie van der Wert, Christine Lambert Mélanie Albert, Marion Barbet, Sylvie Behilili, Méline Bizard, Angela Brisebarre, Flora Donati, Etienne Simon-Lorière, Vincent Enout, Maud Vanpeene,
Sylvie van der Wert, Christine Lambert Mélanie Albert, Marion Barbet, Sylvie Behilili, Méline Bizard, Angela Brisebarre, Flora Donati, Etienne Simon-Lorière, Vincent Enout, Maud Vanpeene, Mélanie Albert, Marion Barbet, Sylvie Behilili, Méline Bizard, Angela Brisebarre, Flora Donati, Etienne Simon-Lorière, Vincent Enout, Maud Vanpeene, Mélanie Albert, Marion Barbet, Sylvie Behilli, Méline Bizard, Angela Brisebarre, Flora Donati, Etienne Simon-Lorière, Vincent Enouf, Maud Vanpeene, Mélanie Albert, Marion Barbet, Sylvie Behillil, Méline Bizard, Angela Brisebarre, Flora Donati, Etienne Simon-Lorière, Vincent Enout, Maud Vanpeene, Mélanie Albert, Marion Barbet, Sylvie Behillil, Méline Bizard, Angela Brisebarre, Flora Donati, Etienne Simon-Lorière, Vincent Enout, Maud Vanpeene, Mélanie Albert, Marion Barbet, Sylvie Behillil, Méline Bizard, Angela Brisebarre, Flora Donati, Etienne Simon-Lorière, Vincent Enouf, Maud Vanpeene, Mélanie Albert, Marion Barbet, Sylvie Behillil, Méline Bizard, Angela a risisearre, Flora Donati, Etienne Simon-Lorière, Vincent Enouf, Maud Vanpeene, Mélanie Albert, Marion Barbet, Sylvie Behilili, Méline Bizard, Angela Brisebarre, Flora Donati, Etienne Simon-Lorière, Vincent Enouf, Maud Vanpeene, Mélanie Albert, Marion Barbet, Sylvie Behilili, Méline Bizard, Angela Brisebarre, Flora Donati, Etienne Simon-Lorière, Vincent Enouf, Maud Vanpeene, Mélanie Albert, Marion Barbet, Sylvie Behilili, Méline Bizard, Angela Brisebarre, Flora Donati, Etienne Simon-Lorière, Vincent Enout, Maud Vanpeene, Mélanie Albert, Marion Barbet, Sylvie Behilili, Méline Bizard, Angela Brisebarre, Flora Donati, Etienne Simon-Lorière, Vincent Enout, Maud Vanpeene, Mélanie Albert, Marion Barbet, Sylvie Behillil, Méline Bizard, Angela a risisearre, Flora Donati, Etienne Simon-Lorière, Vincent Enouf, Maud Vanpeene, Mélanie Albert, Marion Barbet, Sylvie Behilili, Méline Bizard, Angela Brisebarre, Flora Donati, Etienne Simon-Lorière, Vincent Enouf, Maud Vanpeene, Mélanie Albert, Marion Barbet, Sylvie Behilili, Méline Bizard, Angela Brisebarre, Flora Donati, Etienne Simon-Lorière, Vincent Enout, Maud Vanpeene, 
bioRxiv preprint doi: https://doi.org/10.1101/2021.07.21.452479; this version posted July 22, 2021. The copyright holder for this preprint (which was not certified by peer review) is the author/funder, who has granted bioRxiv a license to display the preprint in perpetuity. It is made available under aCC-BY 4.0 International license.

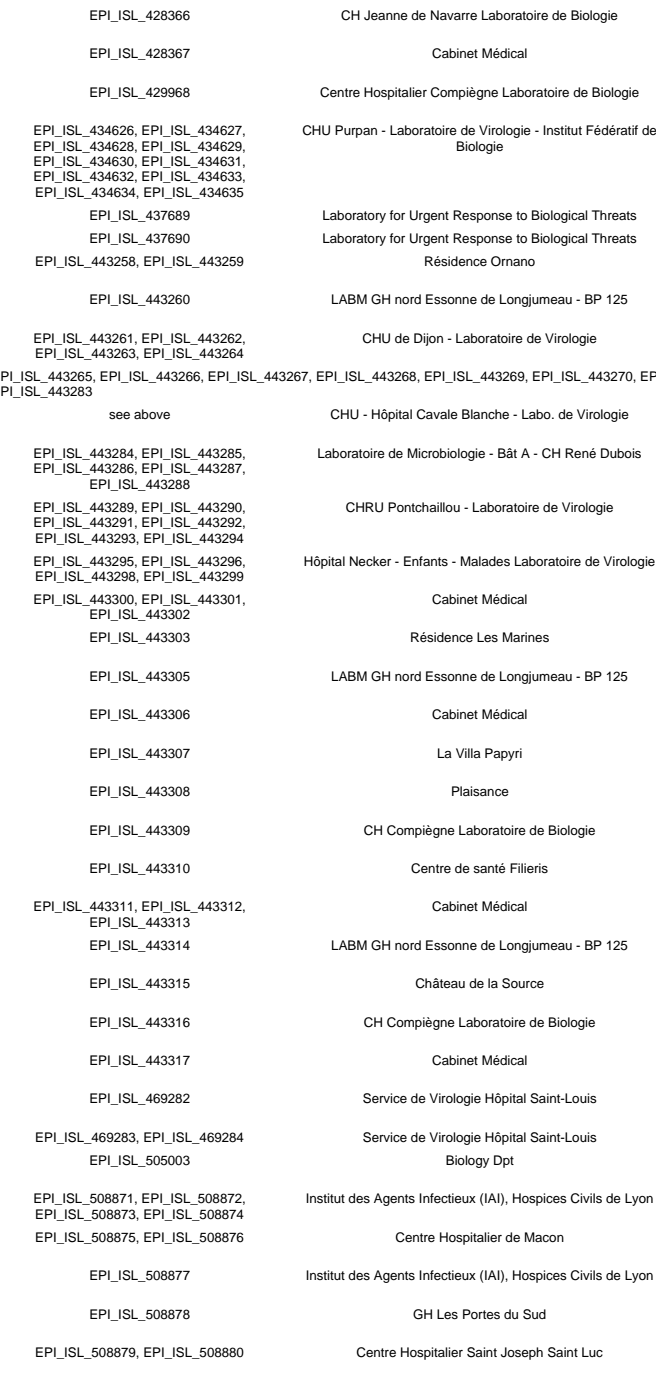

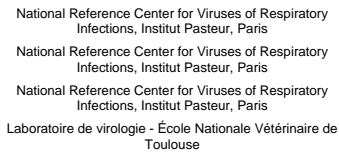
Laboratoire de virologie - École Nationale Vétérinaire de
Toulouse

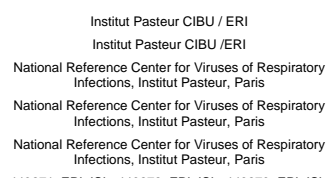
SLL_43271, EP__ISL_443272, EPI_SLL_443273, EPL_ISL_.

National Reterence Center for Viruses of Respiratory
Initections. Instutut Pasteur. Paris

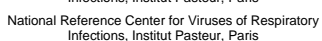
National Reterence Center for Viruses of Respiratory
Intections, Institut Pasteur, Paris National Referencec Center for Viruses of Respiratory
Infections, Institut Pasteur, Paris National Reference Center for Viruses of Respiratory
Intections, Institut Pasteur, Paris National Reference Center for Viruses of Respiratory
Intections, Institut Pasteur, Paris

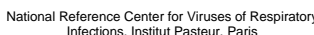

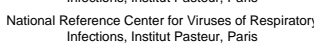
National Reterence Center for Viruses of Resspiratoy
Infections. Institut Pasteur. Paris National Reterence Center tor Viruses of Respiratory
Intections, nstititu Pasteur, paris National Reterence Center for Viruses of Respiratory
Intections, Institut Pasteur. Paris

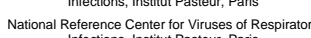
National Referencec Center for Viruses of Respiratory
Intections, Institut Pasteur, Paris National Reterence Center for Viruses of Respiratory
Intections, Institut Pasteur, Paris National Reterence Center tor Viruses of Respiratory
Intections, Institut Pasteur, paris National Reference Center for Viruses of Respirator
Intections, Institut Pasteur, Paris

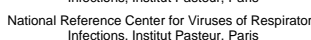
Laboratory of Cell Biloggy of viral infection, Unit
INSERM-U944 Laboratory Cell Biology of Viral Infection-INSERM unit 944 Microbiology and Infections Diseases

CNR Virus des Infections Respiratatires - France SUD CNR Virus des Infections Respiratatores - France SUD CNR Virus des Infections Respiratoires - France SUD CNR Virus des Infections Respiratoires - France SUD CNR Virus des Infections Respiratoires - France SUD
Mélanie Albert, Marion Barbet, Sylvie Behillil, Méline Bizard, Angela Brisebarre, Flora Donati, Etienne Simon-Lorière, Vincent Enout, Maud Vanpeene, Mélanie Albert, Marion Barbet, Sylvie Behillil, Méline Bizard, Angela Brisebarre, Flora Donati, Etienne Simon-Lorière, Vincent Enout, Maud Vanpeene, Mélanie Albert, Marion Barbet, Sylvie Behillili, Méline Bizard, Angela Brisebarre, Flora Donati, Fabiana Gambaro, Etienne Simon-Lorière, Vincent Enouf,
Maud Vanpeene, Sylvie van der Wert, Raulin Olivia Guillaume Croville, Jean-Luc Guérin, Jacques Izopet

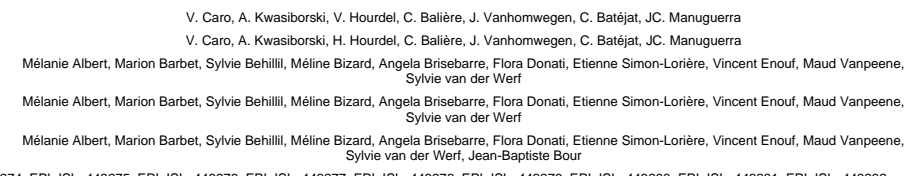
274, EPI_ISL_443275, EPI_ISL_443276, EPI_ISL_443277, EPI_ISL_443278, EPI_ISL_443279, EPI_ISL_443280, EPI_ISL_443281, EPI_ISL_443282, Mélanie Albert, Marion Barbet, Sylvie Behillil, Méline Bizard, Angela Brisebarre, Flora Donati, Etienne Simon-Lorière, Vincent Enouf, Maud Vanpeene, Mélanie Albert, Marion Barbet, Sylvie Behilili, Méline Bizard, Angela Brisebarre, Flora Donati, Etienne Simon-Lorière, Vincent Enout, Maud Vanpeene, Mélanie Albert, Marion Barbet, Sylvie Behillil, Méline Bizard, Angela Brisebarre, Flora Donati, Etienne Simon-Lorière, Vincent Enouf, Maud Vanpeene,
Sylvie van der Wert, Gisèle Lagathu Mélanie Albert, Marion Barbet, Sylvie Behillil, Méline Bizard, Angela Brisebarre, Flora Donati, EEienne Simon-Lorière, Vincent Enouf, Maud Vanpeene, Mélanie Albert, Marion Barbet, Sylvie Behillil, Méline Bizard, Angela Brisebarre, Flora Donati, Etienne Simon-Lorière, Vincent Enouf, Maud Vanpeene, Mélanie Albert, Marion Barbet, Sylvie Behilili, Méline Bizard, Angela Brisebarre, Flora Donati, Etienne Simon-Lorière, Vincent Enout, Maud Vanpeene, Mélanie Albert, Marion Barbet, Sylvie Behilli, Méline Bizard, Angela Brisebarre, Flora Donati, Etienne Simon-Lorière, Vincent Enout, Maud Vanpeene, Mélanie Albert, Marion Barbet, Sylvie Behillil, Méline Bizard, Angela a risisearre, Flora Donati, Etienne Simon-Lorière, Vincent Enouf, Maud Vanpeene, Mélanie Albert, Marion Barbet, Sylvie Behillil, Méline Bizard, Angela Brisebarre, Flora Donati, Etienne Simon-Lorière, Vincent Enout, Maud Vanpeene, Mélanie Albert, Marion Barbet, Sylvie Behilili, Méline Bizard, Angela Brisebarre, Flora Donati, Etienne Simon-Lorière, Vincent Enout, Maud Vanpeene, Mélanie Albert, Marion Barbet, Sylvie Behilili, Méline Bizard, Angela Brisebarre, Flora Donati, Etienne Simon-Lorière, Vincent Enout, Maud Vanpeene, Mélanie Albert, Marion Barbet, Sylvie Behilli, Méline Bizard, Angela Brisebarre, Flora Donati, Etienne Simon-Lorière, Vincent Enouf, Maud Vanpeene, Mélanie Albert, Marion Barbet, Sylvie Behilli, Méline Bizard, Angela Brisisearre, Flora Donati, Etienne Simon-Lorière, Vincent Enouf, Maud Vanpeene, Mélanie Albert, Marion Barbet, Sylvie Behilili, Méline Bizard, Angela Brisebarre, Flora Donati, Etienne Simon-Lorière, Vincent Enout, Maud Vanpeene, Mélanie Albert, Marion Barbet, Sylvie Behillil, Méline Bizard, Angela Brisebarre, Flora Donati, Etienne Simon-Lorière, Vincent Enout, Maud Vanpeene, Mélanie Albert, Marion Barbet, Sylvie Behilli, Méline Bizard, Angela Brisebarre, Flora Donati, Etienne Simon-Lorière, Vincent Enouf, Maud Vanpeene,
Sylvie van der Wert, Olivia Raulin Mélanie Albert, Marion Barbet, Sylvie Behillit, Méline Bizard, Angela drisebarre, Flora Donati, Etienne Simon-Lorière, Vincent Enouf, Maud Vanpeene, Laurent Meertens, Lucie Bonnet-Madin, Constance Delaugerre, Ali Amara

Laurent Meertens, Lucie Bonnet-Madin, Séverine Mercier-Delarue, Maud SALMONA, Constance Delaugerre, Ali Amara Emmanuelle Billon-Denis, Audrey Ferrier-Rembert, Annabelle Garnier, Laurence Cheutin, Clarisse Vigne, Emilie Tessier, Jessica Denis, Olivier Gorgé,
Flora Nolent, Isabelle Drouet, Noémie Verguet, Olivier Ferraris, Jean-Nicolas Tournier Antonin Bal, Gregory Destras, Gwendolyne Burfin, Solenne Brun, Carine Moustaud, Raphaelle Lamy, Alexandre Gaymard, Maude Bouscambert-Duchamp.

Antonin Bal, Gregory Destras, Gwendolyne Burfin, Solenne Brun, Carine Moustaud, Raphaelle Lamy, Alexandre Gaymard, Maude Bouscambert-Duchamp, Antonin Bal, Gregory Destras, Gwendolyne Burfin, Solenne Brun, Marine Moustaud, Raphaelle Lamy, Alexandre Gaymard, Maude Bouscambert-Duchamp,
Florence Morfin-Sherpa, Martine Valette, Bruno Lina, Laurence Josset Antonin Bal, Gregory Destras, Gwendolyne Burfin, Solenne Brun, Carine Moustaud, Raphaelle Lamy, Alexandre Gaymard, Maude Bouscambert-Duchamp,
Florence Morfin-Sherpa, Martine Valette, Bruno Lina, Laurence Josset Antonin Bal, Gregory Destras, Gwendolyne Burfin, Solenne Brun, Carine Moustaud, Raphaelle Lamy, Alexandre Gaymard, Maude Bouscambert-Duchamp, 
bioRxiv preprint doi: https://doi.org/10.1101/2021.07.21.452479; this version posted July 22, 2021. The copyright holder for this preprint (which was not certified by peer review) is the author/funder, who has granted bioRxiv a license to display the preprint in perpetuity. It is made available under aCC-BY 4.0 International license.

EPI_ISL_508881

Centre Hospitalier de Valence
Florence Morfin-Sherpa, Martine Valette, Bruno Lina, Laurence Josset CNR Virus des Infections Respiratoires - France SUD Antonin Bal, Gregory Destras, Gwendolyne Burfin, Solenne Brun, Carine Moustaud, Raphaelle Lamy, Alexandre Gaymard, Maude Bouscambert-Duchamp,
Florence Morfin-Sherpa, Martine Valette, Bruno Lina, Laurence Josset

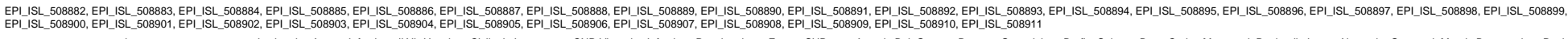
Institut des Agents Infectieux (IAI), Hospices Civils de Lyo CNR Virus des Infections Respiratoires - France SUD Antonin Bal, Gregory Destras, Gwendolyne Burfin, Solenne Brun, Carine Moustaud, Raphaelle Lamy, Alexandre Garn
Florence Morfin-Sherpa, Martine Valette, Bruno Lina, Laurence Josset

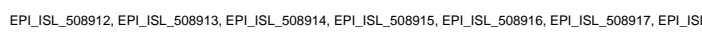
see above CNR Virus des Infections Respiratoires - France SUD 508918, EPI_ISL_508921, EPI_ISL_508922, EPI_ISL_508_ CNR Virus des Infections Respiratoires - France SUD CNR Virus des Infections Respiratoires - France SUD

CNR Virus des Infections Respiratoires - France SUD EPI_ISL 508932 Centre Hospitalier de Villefranche EPI_ISL_508933

EPI_ISL_508934, EPIIISL_508935, EPI_ISL_508936 EPI_ISL_508938

EPI_ISL_508939, EPI_ISL_508940
EPI_ISL_508942 EPI_ISL_508943 EPI_ISL_508944 EPI_ISL_508945 EPI_ISL_508946 EPI_ISL_508947 EPL_ISL_508948 EPI_ISL_508949, EPI_ISL_508950 EPI_ISL_508951 EPI_ISL_508952

EPIISL_508953, EPIISL_508954,
EPI_ISL-508955, EPIIISL508956, EPISL 508958

EPI_ISL_508959, EPI_ISL_508960

EPI_ISL_508961, EPI_ISL_508962,
EPI_ISL_508963, EPIIISL-508964, EPIILL 508966

EPI_ISL_508967 EPI_ISL_508968

EPI_ISL 508969, EPI_ISL 508970,
EPI_ISL_508972, EPIIISL-508973, EPI_ISL_508975

EPI_ISL_508976, EPI_ISL_508977 EPI_ISL_508978

EPIISLL 508979, EPIIISL 508980 EPI'ISL-508981, EPI-ISL-508982,
EPI_ISL-508983, EPIISL-508984,

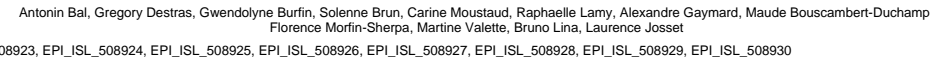
Antonin Bal, Gregory Destras, Gwendolyne Burfin, Solenne Brun, Carine Moustaud, Raphaelle Lamy, Alexandre G
Florence Morfin-Sherpa, Martine Valette, Bruno Lina, Laurence Josset Furfin, Solenne Brun, Carine Moustaud, Raphaelle Lamy, Alexandre $G$ CNR Virus des Infections Respiratoires - France SUD Centre hospitalier Métropole Savoie CNR Virus des Infections Respiratoires - France SUD Centre Hospitalier de Bourg en Bresse CNR Virus des Infections Respiratoires - France SUD Centre Hospitalier de Macon Centre Hospitalier de Bourg en Bresse

CNR Virus des Infections Respiratoires - France SUD Centre Hospitalier de Macon

Centre Hospitalier Lucien Hussel

CNR Virus des Infections Respiratoires - France SUD Centre Hospitalier de Macon CNR Virus des Infections Respiratoires - France SUD Centre Hospitalier de Macon CNR Virus des Infections Respiratoires - France SUD Centre Hospitalier Alpes Leman Centre Hospitalier Saint Joseph Saint Luc CNR Virus des Infections Respiratoires - France SUD

Centre Hospitalier Pierre Oudol CNR Virus des Infections Respiratoires - France SUD Centre Hospitalier de Bourg en Bresse CNR Virus des Infections Respiratoires - France SUD Centre Hospitalier Pierre Oudot CNR Virus des Infections Respiratoires - France SUD Centre Hospitalier de Villefranche CNR Virus des Infections Respiratoires - France SUD
CNR Virus des Infections Respiratoires - France SUD CNR Virus des Infections Respiratoires - France SUD CNR Virus des Infections Respiratoires - France SUD CNR Virus des Infections Respiratoires - France SUD CNR Virus des Infections Respiratoires - France SUD CNR Virus des Infections Respiratoires - France SUD CNR Virus des Infections Respiratoires - France SUD CNR Virus des Infections Respiratoires - France SUD CNR Virus des Infections Respiratoires - France SUD CNR Virus des Infections Respiratoires - France SUD CNR Virus des Infections Respiratoires - France SUD CNR Virus des Infections Respiratoires - France SUD CNR Virus des Infections Respiratoires - France SUD CNR Virus des Infections Respiratoires - France SUD CNR Virus des Infections Respiratoires - France SUD CNR Virus des Infections Respiratoires - France SUD CNR Virus des Infections Respiratoires - France SUD CNR Virus des Infections Respiratoires - France SUD CNR Virus des Infections Respiratoires - France SUD CNR Virus des Infections Respiratoires - France SUD CNR Virus des Infections Respiratoires - France SUD CNR Virus des Infections Respiratoires - France SUD CNR Virus des Infections Respiratoires - France SUD CNR Virus des Infections Respiratoires - France SUD CNR Virus des Infections Respiratoires - France SUD CNR Virus des Infections Respiratoires - France SUD Antonin Bal, Gregory Destras, Gwendolyne Burtin, Solenne Brun, Carine Moustaud, Raphaelle Lamy, Alexandre Gaymard, Maude Bouscambert-Duchamp, Antonin Bal, Gregory Destras, Gwendolyne Burfin, Solenne Brun, Carine Moustaud, Raphaelle Lamy, Alexandre Gaymard, Maude Bouscambert-Duchamp.
Florence Morfin-Sherpa, Martine Valette, Bruno Lina, Laurence Josset Antonin Bal, Gregory Destras, Gwendolyne Burfin, Solenne Brun, Carine Moustaud, Raphaelle Lamy, Alexandre Gaymard, Maude Bouscambert-Duchamp, Antonin Bal, Gregory Destras, Gwendolyne Burfin, Solenne Brun, Carine Moustaud, Raphaelle, Lamy, Alexandre Gaymard, Maude Bouscambert-Duchamp
Florence Morfin-Sherpa, Martine Valette, Bruno Lina, Laurence Josset Antonin Bal, Gregory Destras, Gwendolyne Burfin, Solenne Brun, Carine Moustaud, Raphaelle Lamy, Alexandre Gaymard, Maude Bouscambert-Duchamp, Antonin Bal, Gregory Destras, Gwendolyne Burfin, Solenne Brun, Carine Moustaud, Raphaelle Lamy, Alexandre Gaymard, Maude Bouscambert-Duchamp, Antonin Bal, Gregory Destras, Gwendolyne Burfin, Solenne Brun, Carine Moustaud, Raphaelle Lamy, Alexandre Gaymard, Maude Bouscambert-Duchamp, Antonin Bal, Gregory Destras, Gwendolyne Burfin, Solenne Brun, Carine Moustaud, Raphaelle Lamy, Alexandre Gaymard, Maude Bouscambert-Duchamp, Antonin Bal, Gregory Destras, Gwendolyne Burfin, Solenne Brun, Carine Moustaud, Raphaelle Lamy, Alexandre Gaymard, Maude Bouscambert-Duchamp,
Florence Morfin-Sherpa, Martine Valette, Bruno Lina, Laurence Josset Antonin Bal, Gregory Destras, Gwendolyne Burfin, Solenne Brun, Carine Moustaud, Raphaelle Lamy, Alexandre Gaymard, Maude Bouscambert-Duchamp, Antonin Bal, Gregory Destras, Gwendolyne Burfin, Solenne Brun, Carine Moustaud, Raphaelle Lamy, Alexandre Gaymard, Maude Bouscambert-Duchamp, Antonin Bal, Gregory Destras, Gwendolyne Burfin, Solenne Brun, Carine Moustaud, Raphaelle Lamy, Alexandre Gaymard, Maude Bouscambert-Duchamp. Antonin Bal, Gregory Destras, Gwendolyne Burfin, Solenne Brun, Carine Moustaud, Raphaelle Lamy, Alexandre Gaymard, Maude Bouscambert-Duchamp Antonin Bal, Gregory Destras, Gwendolyne Burfin, Solenne Brun, Carine Moustaud, Raphaelle Lamy, Alexandre Gaymard, Maude Bouscambert-Duchamp, Antonin Bal, Gregory Destras, Gwendolyne Burfin, Solenne Brun, Carine Moustaud, Raphaelle Lamy, Alexandre Gaymard, Maude Bouscambert-Duchamp. Antonin Bal, Gregory Destras, Gwendolyne Burfin, Solenne Brun, Carine Moustaud, Raphaelle Lamy, Alexandre Gaymard, Maude Bouscambert-Duchame,

Antonin Bal, Gregory Destras, Gwendolyne Burfin, Solenne Brun, Carine Moustaud, Raphaeelle Lamy, Alexandre Gaymard, Maude Bouscambert-Duchamp,
Florence Morfin-Sherpa, Martine Valette, Bruno Lina, Laurence Josset Antonin Bal, Gregory Destras, Gwendolyne Burfin, Solenne Brun, Carine Moustaud, Raphaelle Lamy, Alexandre Gaymard, Maude Bouscambert-Duchamp,
Florence Morfin-Sherpa, Martine Valette, Bruno Lina, Laurence Josset Antonin Bal, Gregory Destras, Gwendolyne Burfin, Solenne Brun, Carine Moustaud, Raphaelle Lamy, Alexandre Gaymard, Maude Bouscambert-Duchamp

Antonin Bal, Gregory Destras, Gwendolyne Burfin, Solenne Brun, Carine Moustaud, Raphaelle Lamy, Alexandre Gaymard, Maude Bouscambert-Duchamp, Antonin Bal, Gregory Destras, Gwendolyne Burfin, Solenne Brun, Carine Moustaud, Raphaelle Lamy, Alexandre Gaymard, Maude Bouscambert-Duchamp,
Florence Morfin-Sherpa, Martine Valette, Bruno Lina, Laurence Josset Antonin Bal, Gregory Destras, Gwendolyne Burfin, Solenne Brun, Carine Moustaud, Raphaelle Lamy, Alexandre Gaymard, Maude Bouscambert-Duchamp, Florence Morfin-Sherpa, Martine Valette, Bruno Lina, Laurence Josset yne Burfin, Solenne Brun, Carine Moustaud, Raphaelle Lamy, Alexandre Gaymard, Maude Bouscambert-Duchamp,
Florence Morfin-Sherpa, Martine Valette, Bruno Lina, Laurence Josset

Antonin Bal, Gregory Destras, Gwendolyne Burtin, Solenne Brun, Carine Moustaud, Raphaelle Lamy, Alexandre Gaymard, Maude Bouscambert-Duchamp
Florence Morfin-Sherpa, Martine Valette, Bruno Lina, Laurence Josset Antonin Bal, Gregory Destras, Gwendolyne Burfin, Solenne Brun, Carine Moustaud, Raphaelle Lamy, Alexandre Gaymard, Maude Bouscambert-Duchamp,
Florence Morfin-Sherpa, Martine Valette, Bruno Lina, Laurence Josset Antonin Bal, Gregory Destras, Gwendolyne Burfin, Solenne Brun, Carine Moustaud, Raphaelle Lamy, Alexandre Gaymard, Maude Bouscambert-Duchamp Burfin, Solenne Brun, Carine Moustaud, Raphaelle Lamy, Alexandre Gaymard, Maude Bouscambert-Duchamp, 
bioRxiv preprint doi: https://doi.org/10.1101/2021.07.21.452479; this version posted July 22, 2021. The copyright holder for this preprint (which was not certified by peer review) is the author/funder, who has granted bioRxiv a license to display the preprint in perpetuity. It is made available under aCC-BY 4.0 International license.

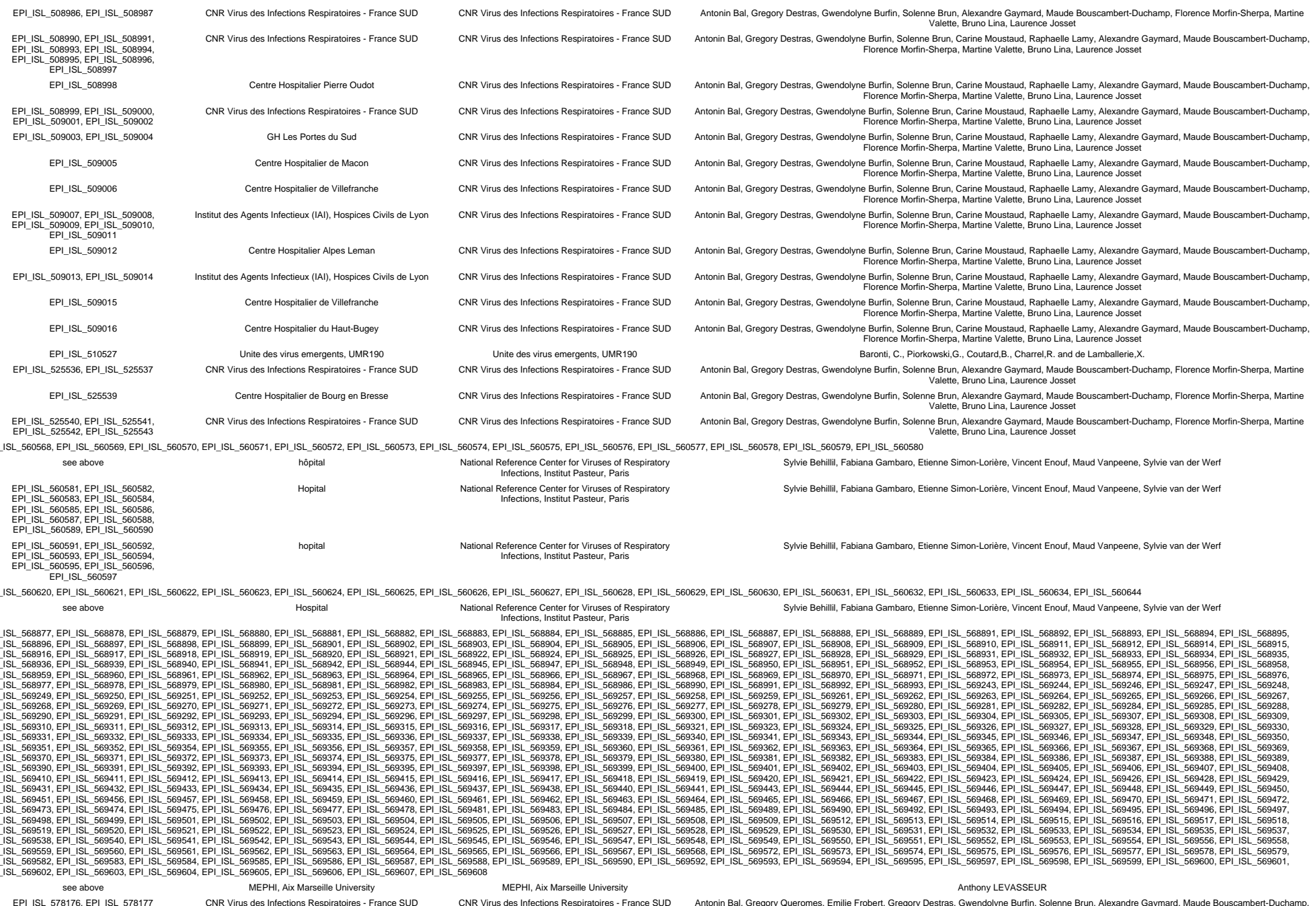


bioRxiv preprint doi: https://doi.org/10.1101/2021.07.21.452479; this version posted July 22, 2021. The copyright holder for this preprint (which was not certified by peer review) is the author/funder, who has granted bioRxiv a license to display the preprint in perpetuity. It is made available under aCC-BY 4.0 International license.

EPI_ISL_614281 CHRU Pontchaillou - Laboratoire de Virologie 2, rue Henri
Guilloux
083, EPLISL_629084, EPI_ISL629085, EPI_ISL_629086, Laboratoire du Centre Hospitalier Annecy Genevois

Laboratoire de virologie, CHU de Grenoble - CS 10217 -
38043 Grenoble cedex 9 Laboratoire de viriologie, CHU de Grenoble - CS 10217 -
38043 Grenoble cedex 10 Laboratoire de virologie, CHU de Grenoble - CS 10217 -
38043 Grenoble cedex 11 Laboratoire de virologie, CHU de Grenoble - CS 10217 -
38043 Grenoble cedex 12 Laboratoire de virologie, CHU de Grenoble - CS 10217 -
38043 Grenoble cedex 13 Laboratoire de virologie, CHU de Grenoble - CS 10217 -
38003 Grenoble cedex 14 Laboratoire de virologie, CHU de Grenoble - CS 10217 .
38043 Grenoble cedex 15 Laboratoire de virologie, CHU de Grenoble - CS 10217 -
38043 Grenoble cedex 16 Laboratoire de virologie, CHU de Grenoble - CS 10217 -
38043 Grenoble cedex 17 Laboratoire de virologie, CHU de Grenoble - CS 10217 Laboratoire de virologie, CHU de Grenoble - CS 10217 -
38043 Grenoble cedex 19 Laboratoire de virologie, CHU de Grenoble - CS 10217 -
38043 Grenoble cedex 20 Laboratoire de virologie, CHU de Grenoble - CS 10217 -
38043 Grenoble cedex 21 Laboratoire de virologie, CHU de Grenoble - CS 10217 -
38043 Grenoble cedex 22 Laboratoire de virologie, CHU de Grenoble - CS 10217 Laboratoire de virologie, CHU de Grenoble - CS 10217 -
38043 Grenoble cedex 24 Laboratoire de virologie, CHU de Grenoble - CS 10217 -
38043 Grenoble cedex 25 Laboratoire de virologie, CHU de Grenoble - CS 10217 -
38043 Grenoble cedex 26 Laboratoire de virologie, CHU de Grenoble - CS 10217 Laboratoire de virologie, CHU de Grenoble - CS 10217 -
38043 Grenoble cedex 28 Laboratoire de virologie, CHU de Grenoble - CS 10217 -
38043 Grenoble cedex 29 CNR Virus des Infections Respiratoires - France SUD Centre Hospitalier Pierre Oudo

CNR Virus des Infections Respiratoires - France SUD Centre Hospitalier Pierre Oudot

Centre Hospitalier de Bourg en Bresse Centre Hospitalier Pierre Oudot

CNR Virus des Infections Respiratoires - France SUD Centre Hospitalier Pierre Oudot

CNR Virus des Infections Respiratoires - France SUD CHU de Nice - Hôpital Archet 2 $\mathrm{CHU}$ de Nice - Hôpital Archet 8 National Reference Center for Viruses of Respiratory
Infections, Institut Pasteur, Paris SL_629088, EPI_ISL_629089, EPI_ISL_629090, EPI_ISL__
CNR Virus des Infections Respiratoires - France SU CNR Virus des Infections Respiratoires - France SUD CNR Virus des Infections Respiratoires - France SUD CNR Virus des Infections Respiratoires - France SUD CNR Virus des Infections Respiratoires - France SUD CNR Virus des Infections Respiratoires - France SUD CNR Virus des Infections Respiratoires - France SUD CNR Virus des Infections Respiratoires - France SUD CNR Virus des Infections Respiratoires - France SUD CNR Virus des Infections Respiratoires - France SUD CNR Virus des Infections Respiratoires - France SUD CNR Virus des Infections Respiratoires - France SUD CNR Virus des Infections Respiratoires - France SUD CNR Virus des Infections Respiratoires - France SUD CNR Virus des Infections Respiratoires - France SUD CNR Virus des Infections Respiratoires - France SUD CNR Virus des Infections Respiratoires - France SUD CNR Virus des Infections Respiratoires - France SUD CNR Virus des Infections Respiratoires - France SUD CNR Virus des Infections Respiratoires - France SUD CNR Virus des Infections Respiratoires - France SUD CNR Virus des Infections Respiratoires - France SUD CNR Virus des Infections Respiratoires - France SUD CNR Virus des Infections Respiratoires - France SUD CNR Virus des Infections Respiratoires - France SUD CNR Virus des Infections Respiratoires - France SUD CNR Virus des Infections Respiratoires - France SUD CNR Virus des Infections Respiratoires - France SUD CNR Virus des Infections Respiratoires - France SUD CNR Virus des Infections Respiratoires - France SUD CNR Virus des Infections Respiratoires - France SUD CNR Virus des Infections Respiratoires - France SUD CNR Virus des Infections Respiratoires - France SUD CNR Virus des Infections Respiratoires - France SUD
Florence Morfin-Sherpa, Martine Valette, Bruno Lina, Laurence Josset

Marion Barbet, Sylvie Behilili, Méline Bizard, Angela Brisebarre, Camille Capel, Etienne Simon-Lorière, Vincent Enout, Maud Vanpeene, Sylvie van der
Wert, Gisèle Lagathu EPI_ISL_629092, EPI_ISL_629093, EPI_ISL_629094, EPI_ISL_629095, EPI_ISL_629096, EPI_ISL_629097, EPL_ISL_629098, EPI_ISL_629099, Antonin Bal, Gregory Destras, Gwendolyne Burfin, Hadrien Règue, Quentin Semanas, Martine Valette, Bruno Lina, Hélène Petitprez, Bruno Chanzy Antonin Bal, Gregory Destras, Gwendolyne Burtin, Hadrien Règue, Quentin Semanas, Martine Valette, Bruno Lina, Sylvie Larrat, Laurence Josset Antonin Bal, Gregory Destras, Gwendolyne Burtin, Hadrien Règue, Quentin Semanas, Martine Valette, Bruno Lina, Sylvie Larrat, Laurence Josset Antonin Bal, Gregory Destras, Gwendolyne Burtin, Hadrien Règue, Quentin Semanas, Martine Valette, Bruno Lina, Sylvie Larrat, Laurence Josset Antonin Bal, Gregory Destras, Gwendolyne Burtin, Hadrien Règue, Quentin Semanas, Martine Valette, Bruno Lina, Sylvie Larrat, Laurence Josset Antonin Bal, Gregory Destras, Gwendolyne Burtin, Hadrien Règue, Quentin Semanas, Martine Valette, Bruno Lina, Sylvie Larrat, Laurence Josset Antonin Bal, Gregory Destras, Gwendolyne Burtin, Hadrien Règue, Quentin Semanas, Martine Valette, Bruno Lina, Sylvie Larrat, Laurence Josset Antonin Bal, Gregory Destras, Gwendolyne Burtin, Hadrien Règue, Quentin Semanas, Martine Valette, Bruno Lina, Sylvie Larrat, Laurence Josset Antonin Bal, Gregory Destras, Gwendolyne Burtin, Hadrien Règue, Quentin Semanas, Martine Valette, Bruno Lina, Sylvie Larrat, Laurence Josset Antonin Bal, Gregory Destras, Gwendolyne Burtin, Hadrien Règue, Quentin Semanas, Martine Valette, Bruno Lina, Sylvie Larrat, Laurence Josse Antonin Bal, Gregory Destras, Gwendolyne Burtin, Hadrien Règue, Quentin Semanas, Martine Valette, Bruno Lina, Sylvie Larrat, Laurence Josset Antonin Bal, Gregory Destras, Gwendolyne Burtin, Hadrien Règue, Quentin Semanas, Martine Valette, Bruno Lina, Sylvie Larrat, Laurence Josset Antonin Bal, Gregory Destras, Gwendolyne Burtin, Hadrien Règue, Quentin Semanas, Martine Valette, Bruno Lina, Sylvie Larrat, Laurence Josset Antonin Bal, Gregory Destras, Gwendolyne Burfin, Hadrien Règue, Quentin Semanas, Martine Valette, Bruno Lina, Sylvie Larrat, Laurence Josset Antonin Bal, Gregory Destras, Gwendolyne Burtin, Hadrien Règue, Quentin Semanas, Martine Valette, Bruno Lina, Sylvie Larrat, Laurence Josset Antonin Bal, Gregory Destras, Gwendolyne Burtin, Hadrien Règue, Quentin Semanas, Martine Valette, Bruno Lina, Sylvie Larrat, Laurence Josset Antonin Bal, Gregory Destras, Gwendolyne Burtin, Hadrien Règue, Quentin Semanas, Martine Valette, Bruno Lina, Sylvie Larrat, Laurence Josset Antonin Bal, Gregory Destras, Gwendolyne Burtin, Hadrien Règue, Quentin Semanas, Martine Valette, Bruno Lina, Sylvie Larrat, Laurence Jossel Antonin Bal, Gregory Destras, Gwendolyne Burtin, Hadrien Règue, Quentin Semanas, Martine Valette, Bruno Lina, Sylvie Larrat, Laurence Jossel Antonin Bal, Gregory Destras, Gwendolyne Burtin, Hadrien Règue, Quentin Semanas, Martine Valette, Bruno Lina, Sylvie Larrat, Laurence Josset Antonin Bal, Gregory Destras, Gwendolyne Burtin, Hadrien Règue, Quentin Semanas, Martine Valette, Bruno Lina, Sylvie Larrat, Laurence Josset Antonin Bal, Gregory Destras, Gwendolyne Burtin, Hadrien Règue, Quentin Semanas, Martine Valette, Bruno Lina, Sylvie Larrat, Laurence Josset Antonin Bal, Gregory Destras, Gwendolyne Burfin, Hadrien Règue, Alexandre Gaymard, Maude Bouscambert-Duchamp, Florence Morfin-Sherpa, Martine Antonin Bal, Gregory Destras, Gwendolyne Burfin, Hadrien Règue, Alexandre Gaymard, Maude Bouscambert-Duchamp, Florence Mortin-Sherpa, Martine Antonin Bal, Gregory Destras, Gwendolyne Burfin, Hadrien Règue, Alexandre Gaymard, Maude Bouscambert-Duchamp, Florence Mortin-Sherpa, Martine Antonin Bal, Gregory Destras, Gwendolyne Burfin, Hadrien Règue, Alexandre Gaymard, Maude Bouscambert-Duchamp, Florence Mortin-Sherpa, Martine
Valette, Bruno Lina, Laurence Josset Antonin Bal, Gregory Destras, Gwendolyne Burfin, Hadrien Règue, Alexandre Gaymard, Maude Bouscambert-Duchamp, Florence Mortin-Sherpa, Martine
Valette, Bruno Lina, Laurence Josset Antonin Bal, Gregory Destras, Gwendolyne Burfin, Hadrien Règue, Alexandre Gaymard, Maude Bouscambert-Duchamp, Florence Mortin-Sherpa, Martin Antonin Bal, Gregory Destras, Gwendolyne Burfin, Hadrien Règue, Alexandre Gaymard, Maude Bouscambert-Duchamp, Florence Mortin-Sherpa, Martine Antonin Bal, Gregory Destras, Gwendolyne Burfin, Hadrien Règue, Alexandre Gaymard, Maude Bouscambert-Duchamp, Florence Mortin-Sherpa, Martine Antonin Bal, Gregory Destras, Gwendolyne Burfin, Hadrien Règue, Alexandre Gaymard, Maude Bouscambert-Duchamp, Florence Morfin-Sherpa, Martine Antonin Bal, Géraldine Gonfrier, Gregory Destras, Gwendolyne Burfin, Hadrien Règue, Quentin Semanas, Martine Valette, Bruno Lina, Valérie Antonin Bal, Géraldine Gonfrier, Gregory Destras, Gwendolyne Burfin, Hadrien Règue, Quentin Semanas, Martine Valette, Bruno Lina, Valérie 
bioRxiv preprint doi: https://doi.org/10.1101/2021.07.21.452479; this version posted July 22, 2021. The copyright holder for this preprint (which was not certified by peer review) is the author/funder, who has granted bioRxiv a license to display the preprint in perpetuity. It is made available under aCC-BY 4.0 International license.

$\begin{array}{lll}\text { EPI_ISL_641522 } & \text { CHU de Nice - Hôpital Archet } 3 & \text { CNR Virus des Infections Respiratoires - France SUD } \\ \text { EPI_ISL_641523 } & \text { CHU de Nice - Hôpital Archet } 4 & \text { CNR Virus des Infections Respiratoires - France SUD } \\ \text { EPI_ISL_641524 } & \text { CHU de Nice - Hôpital Archet } 5 & \text { CNR Virus des Infections Respiratoires - France SUD } \\ \text { EPI_ISL_641525 } & \text { CHU de Nice - Hôpital Archet } 6 & \text { CNR Virus des Infections Respiratoires - France SUD } \\ \text { EPI_ISL_641526 } & \text { CHU de Nice - Hôpital Archet 7 } & \text { CNR Virus des Infections Respiratoires - France SUD } \\ \text { EPI_ISL_641527 } & \text { CHU de Nice - Hôpital Archet 9 } & \text { CNR Virus des Infections Respiratoires - France SUD } \\ \text { EPI_ISL_641528 } & \text { CHU de Nice - Hôpital Archet 10 } & \text { CNR Virus des Infections Respiratoires - France SUD } \\ \text { EPI_ISL_641529 } & \text { CHU de Nice - Hôpital Archet 11 } & \text { CNR Virus des Infections Respiratoires - France SUD } \\ \text { EPI_ISL_641530 } & \text { CHU de Nice - Hôpital Archet 12 } & \text { CNR Virus des Infections Respiratoires - France SUD } \\ \text { EPI_ISL_641531 } & \text { CHU de Nice - Hôpital Archet 13 } & \text { CNR Virus des Infections Respiratoires - France SUD } \\ \text { EPI_ISL_641532 } & \text { CHU de Nice - Hôpital Archet 14 } & \text { CNR Virus des Infections Respiratoires - France SUD } \\ \text { EPI_ISL_641533 } & \text { CHU de Nice - Hôpital Archet 15 } & \text { CNR Virus des Infections Respiratoires - France SUD } \\ \text { EPI_ISL_641534 } & \text { CHU de Nice - Hôpital Archet 16 } & \text { CNR Virus des Infections Respiratoires - France SUD }\end{array}$$$
\text { CHU de Nice - Hôpital Archet } 16
$$

EPI_ISL_641535, EPI_ISL_641536, EPI_ISL_641537, EPI_ISL_641538, EPI_ISL_641539, EPI_ISL_64154_C

$$
\text { see above }
$$

EPIIISL_641546, EPI_ISL_641547,
EPIISL_641548, EP_ISL_641549, EPL_ISL_641550
ISL_641551, EPI_ISL_64155

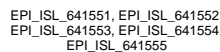
EPI_ISL_641556

EPI_ISL 644403, EPI ISL 644404,
EPIISL-644405, EPI_ISL_644406,

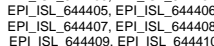

EPI_ISL6644673, EPI_ISL6464674,

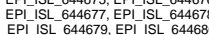

EPI_ISL_644681, EPI_ISL_644682, EPI_ISL_644683, EPI_ISL_644684, EPI_ISL_644685, EPI_ISL_644686, EPI_ISL_644687, EPI_ISL_644688, EPI_ISL_644689, EPI_ISL_64

$$
\text { see above }
$$

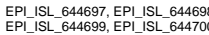

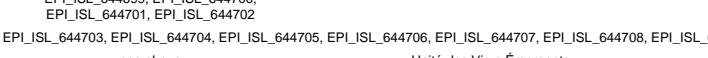

$$
\text { see above }
$$

$$
\text { CHU Clermont-Ferrand }
$$

$$
\text { CHU Toulouse }
$$

MEPHI, Aix Marseille University

CHU de Limoges

$$
\text { CHU Montpellier }
$$

CHU Nimes

$$
\text { Unité des Virus Émergents }
$$

$$
\text { CHU Bordeaux }
$$$$
\text { CHU de Nice }
$$$$
\text { CHU de Limoges }
$$

EPI_ISL 645174, EPI_ISL_645175,

EPIISL-645178, EPI-ISL-645179
EPIISL-645180,
EPI_ISL645182, EPI_ISL-645183

EPI ISL 645184, EPI ISL_645185,
EPI_ISL_645186, EPI_ISL_645187

EPI_ISL-645188, EPIIISL_645189,

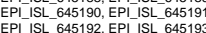

PPIIISL_645192, EPIIISL_645193,
PPIISL_645194, EPI ISL_645195,
EPI ISL_645196

CHU de Saint-Étienne Hôpital Nord CNR Virus des Infections Respiratoires - France SUD CHU Clermont-Ferrand

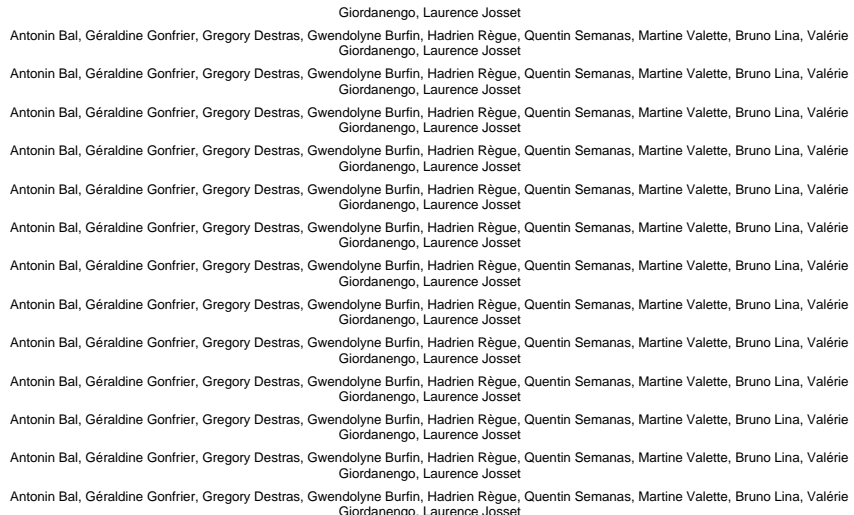
444, EPI_ISL_641545 CNR Virus des Infections Respiratoires - France SUD CNR Virus des Infections Respiratoires - France SUD CNR Virus des Infections Respiratoires - France SUD

CNR Virus des Infections Respiratoires - France SUD MEPHI, Aix Marseille University Antonin Bal, Gregory Destras, Gwendolyne Burfin, Hadrien Règue, Quentin Semanas, Martine Valette, Bruno Lina, Issam Bechri, Manon Vogrig, Marine
Delorme, Bruno Pozzetto, Thomas Bourlet, Sylvie Gonzalo, Sylvie Pillet, Laurence Josset Antonin Bal, Gregory Destras, Gwendolyne Burtin, Hadrien Règue, Quentin Semanas, Martine Valette, Bruno Lina, Christine Archimbaud, Amélie Brebion,
Hélene Chabrolles, Martine Chambon, Audrey Mirand, Christel Regagnon, Maxime Bisseux, Patricia Combes, Cécile Henquell, Laurence Josset Antonin Bal, Gregory Destras, Gwendolyne Burfin, Hadrien Règue, Quentin Semanas, Martine Valette, Bruno Lina, Jean Michel Mansuy, Laurence Josset Antonin Bal, Gregory Destras, Gwendolyne Burfin, Hadrien Règue, Quentin Semanas, Martine Valette, Bruno Lina, Michel Segondy, Vincent Foulongne,
Laurence Josset Anthony LEVASSEUR

Antonin Bal, Gregory Destras, Gwendolyne Burfin, Hadrien Règue, Quentin Semanas, Martine Valette, Bruno Lina, Sylvie Rogez, Laurence Josset

EPI_ISL_645197, EPI_ISL_645198, EPI_ISL_645199, EPI_ISL_645200, EPI_ISL_645201, EPI_ISL_645202, EPI_ISL_645203, EPI_ISL_645204, EPI_ISL_645205, EPI_ISL_645206, EPI_ISL_645207, EPI_ISL_645208, EPI_ISL_645209 
bioRxiv preprint doi: https://doi.org/10.1101/2021.07.21.452479; this version posted July 22, 2021. The copyright holder for this preprint (which was not certified by peer review) is the author/funder, who has granted bioRxiv a license to display the preprint in perpetuity. It is made available under aCC-BY 4.0 International license.

\begin{tabular}{|c|c|c|}
\hline see above & CHU Nimes & CNR Virus des Infections Respiratoires - France SUD \\
\hline $\begin{array}{l}\text { EPL_ISL_645212, EPIISL_645213, } \\
\text { EPIISL_645214 }\end{array}$ & Unité des Virus Émergents & CNR Virus des Infections Respiratc \\
\hline
\end{tabular}

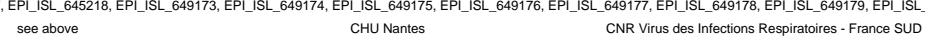

EPI_ISL 649188

Unité des Virus Émergents

EPLISL 649942, EPIISL_649943, E

$$
\text { see above }
$$

CNR Virus des Infections Respiratoires - France SUD

CNR Virus des Infections Respiratoires - France SUD
Antonin Bal, Gregory Destras, Gwendolyne Burfin, Hadrien Règue, Quentin Semanas, Martine Valette, Bruno Lina, Jean-Philippe Lavigne, Stephan Robin, Antonin Bal, Gregory Destras, Gwendolyne Burfin, Hadrien Règue, Quentin Semanas, Martine Valette, Bruno Lina, Laetitia Ninove, Léa Luciani, Antoine
Nougairede, Laurence Josset Antonin Bal, Gregory Destras, Gwendolyne Burfin, Hadrien Règue, Quentin Semanas,, Martine Valette, Bruno Lina, Agnès Beby-Defaux, Magali Garcia,
Clémentt Jousselin, Nicolas Lévếque, Laurence Josset Clément Jousselin, Nicolas Lévêque, Laurence Josset
180, EPI_ISL_649181, EPI_ISL_649182, EPI_ISL_649183, EPI_ISL_649184, EPI_ISL_649185, EPI_SL_649186, EPI_ISL_649187 Antonin Bal, Louise Castain, Gregory Destras, Gwendolyne Burfin, Hadrien Règue, Quentin Semanas, Martine Valette, Bruno Lina, Celine Bressollette, Antonin Bal, Gregory Destras, Gwendolyne Burfin, Hadrien Règue, Quentin Semanas, Martine Valette, Bruno Lina, Laetitia Ninove, Léa Luciani, Antoine 49951, EPI_ISL_649952, EPI_ISL_649953

Antonin Bal, Gregory Destras, Gwendolyne Burfin, Hadrien Règue, Quentin Semanas, Martine Valette, Bruno Lina, Issam Bechri, Manon Vogrig, Marine
Delorme, Bruno Pozzetto, Thomas Bourlet, Sylvie Gonzalo, Sylvie Pillet, Laurence Josset 649960, EPI_ISL_649961, EPI_ISL_649962, EPI_ISL_649963, EPI_ISL_649964, EPL_ISL_649965, EPI_ISL_649966, EPI_ISL_649967, EPI_ISL_649968, EPI_ISL_649969, EPL_ISL_649970, EPIISL_649971 see above CHU Bordeaux CNR Virus des Infections Respiratoires - France SUD Antonin Bal, Gregory Destras, Gwendolyne Burtin, Hadrien Règue, Quentin Semanas, Martine Valette, Bruno Lina, 1 Isabelle Garrigue, Marie-Edith Laton, Pascale Trimoulet, Laurence Josset

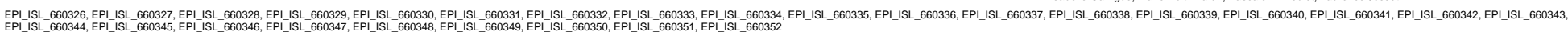

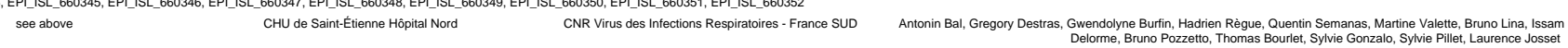
see above CHU Clermont-Ferrand EPI_ISL_660372 CHU Bordeaux

EPI_ISL660373, EPI_ISL_660374,
EPI_ISL_660375, EPIIISL_660376 EPI_ISL 6600432

CHU Toulouse

CHU de Saint-Étienne Hôpital Nord

CHU Toulouse
CNR Virus des Infections Respiratoires - France SUD

CNR Virus des Infections Respiratoires - France SUD

CNR Virus des Infections Respiratoires - France SUD

CNR Virus des Infections Respiratoires - France SUD

CNR Virus des Infections Respiratoires - France SUD
Antonin Bal, Gregory Destras, Gwendolyne Burtin, Hadrien Règue, Quentin Semanas, Martine Valette, Bruno Lina, Christine Archimbaud, Amélie Brebion
Héléne Chabrolles, Martine Chambon, Audrey Mirand, Christel Regagnon, Maxime Bisseux, Patricia Combes, Cécile Henquell, Laurence Josset Antonin Bal, Gregory Destras, Gwendolyne Burfin, Hadrien Règue, Quentin Semanas, Martine Valette, Bruno Lina, Pantxika Bellecave, Camille Ciccone,
Isabelle Garrigue, Mariie-Edith Lafon, Pascale Trimoulet, Laurence Josset Antonin Bal, Gregory Destras, Gwendolyne Burfin, Hadrien Règue, Quentin Semanas, Martine Valette, Bruno Lina, Jean Michel Mansuy, Laurence Josse Antonin Bal, Gregory Destras, Gwendolyne Burtin, Hadrien Règue, Quentin Semanas, Martine Valette, Bruno Lina, Issam Bechri, Manon Vogrig, Marine
Delorme, Bruno Pozzetto, Thomas Bourlet, Sylvie Gonzalo, Sylvie Pillet, Laurence Josset Antonin Bal, Gregory Destras, Gwendolyne Burfin, Hadrien Règue, Quentin Semanas, Martine Valette, Bruno Lina, Jean Michel Mansuy, Laurence Josse

EPI_ISL 660665, EPIISLL660666,
EPIISL 660667, EPIISL-660668
EPI_ISL_660670, EPI_ISL_660671

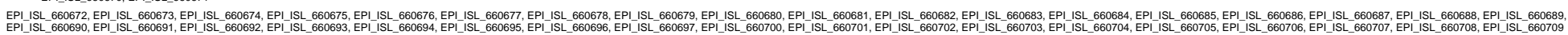

CNR Virus des Infections Respiratoires - France SUD

see above CHU Montpellier

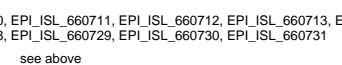

$$
\text { see above }
$$
Antonin Bal, Gregory Destras, Gwendolyne Burfin, Hadrien Règue, Quentin Semanas

EPI_ISL660710, EPI_SL_66071,
EPI_ISL_660728, EPI_ISL_660729,
see above

CHU Nimes

Unité des Virus Émergents
CNR Virus des Infections Respiratoires - France SUD

CNR Virus des Infections Respiratoires - France SUD Antonin Bal, Gregory Destras, Gwendolyne Burfin, Hadrien Règue, Quentin Semanas, Martine Valette, Bruno Lina, Jean-Philippe Lavigne, Stephan Robin
Maxence Lotellier, Marie-Josée Carles, Laurence Josset Antonin Bal, Gregory Destras, Gwendolyne Burfin, Hadrien Règue, Quentin Semanas, Martine Valette, Bruno Lina, Laetitia Ninove, Léa Luciani, Antoine

EPI_ISL 660732, EPI_ISL 660733
EPIISL 660734, EPIIISL 660735,
EPIIISL 660736, EPIIISL 660737

EPI_ISL 660736, EPI_ISL_660737,
EPIISL-660738, EPIISL 660739,
EPI_ISL_660740,EPI_ISL_660741

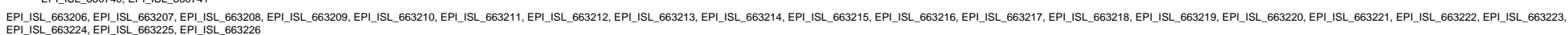

See above
EPI_ISL_663227, EPI_ISL_663228, EPI_ISL_663229, EPI_ISL_663230, EPI_ISL_663231,

CNR Virus des Infections Respiratoires - France SUD Antonin Bal, Gregory Destras, Gwendolyne Burfin, Hadrien Règue, Que CNR Virus Antonin Bal, Gregory Destras, Gwendolyne Burfin, Hadrien Règue, Quentin Semanas, Martine Valette, Bruno Lina, Agnès Beby-Defaux, Magali Garcia
Clément Jousselin, Nicolas Lévếque, Laurence Josset

$$
\text { see above }
$$

CHU Nìmes CNR Virus des Infections Respiratoires - France SUD

EPI_ISL_663243, EPI_ISL 663244,
EPIIIL-663245, EPIISL_663246,
EPI_ISL_663247, EPI_ISL_663248

CNR Virus des Infections Respiratoires - France SUD Antonin Bal, Gregory Destras, Gwendolyne Burfin, Hadrien Règue, Quentin Semanas, Martine Valette, Br
Maxence Lotellier, Marie-Josée Carles, Laurence Josset

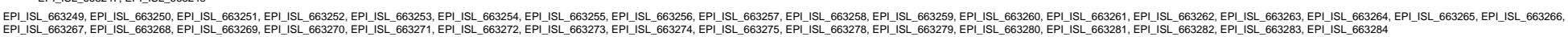
see above CHU Nantes CNR Virus des Infections Respiratoires - France SUD Antonin Bal, Louise Castain, Gregory Destras, Gwendolyne Burfin, Hadrien Règue, Quentin $\begin{gathered}\text { Bressollette, Laurence Josset } \\ \text { S }\end{gathered}$ EPIIISL666654, EPIISL 666656, EPI_ISL_666657, EPIIISL666659
EPI_ISL_666678, EPI_ISL_666679, EPI_ISL_666680, EPI_ISL_666681 see above

EPI_ISL_666683, EPI_ISL_666684,
EPI_ISL_666685, EPI_ISL666686

EPI_ISL 666711, EPIIISL 666712

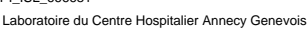

Centre hospitalier Métropole Savoie CHU de Limoges
CNR Virus des Infections Respiratoires - France SUD

CNR Virus des Infections Respiratoires - France SUD

CNR Virus des Infections Respiratoires - France SUD
Antonin Bal, Gregory Destras, Gwendolyne Burfin, Hadrien Règue, Quentin Semanas,

Antonin Bal, Carine Dumollard, Gregory Destras, Gwendolyne Burtin, Hadrien Règue, Quentin Semanas, Martine Valette, Bruno Lina, Jérôme Grosjean
Laurence Josset 
bioRxiv preprint doi: https://doi.org/10.1101/2021.07.21.452479; this version posted July 22, 2021. The copyright holder for this preprint (which was not certified by peer review) is the author/funder, who has granted bioRxiv a license to display the preprint in perpetuity. It is made available under aCC-BY 4.0 International license.

EPL_ISL_666715, EPI_ISL_666716, EPPISL-666717, EPPIISL-666718
EPIIIL-666719, EPIIIL-666720 EPIISL-666721, EPPIILL-666722

EPI_ISL_666870 EPIISL_666870

CHU Nantes

Laboratoire de Virologie, $\mathrm{CHU}$ de Caen, Normandie, France. de Virologie - Institut Fédératif de CHU Purpan - Laboratoire de Virologie - Institut Fédératif de
Biolologie
Antonin Bal, Louise Castain, Gregory Destras, Gwendolyne Burfin, Hadrien Règue, Quentin Semanas, Martine Valette, Bruno Lina, Virginie Ferré, Celine Meriadeg LE GOUIL, Januel VOUTEAU, Juliette ECHE, Estelle LEPERCHOIS, Astrid VABRET Latour J., Ranger N., Dubois M., Carcenac R., Harter A., Boyer P., Tremeaux P., Izopet J.

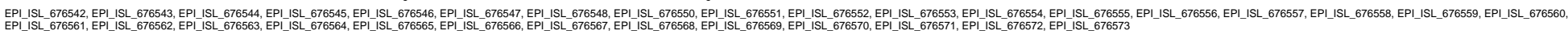

CNR Virus des Intections Respiratoties - France SUD CNR Virus des Infections Respiratioires - France SUD Antonin Bal, Gregory Destras, Gwendolyne Burfin, Solenne Brun, Alexandre Gaymard, Maude Bouscambert-Duchamp, Florence Morfin-Sherpa, Martine

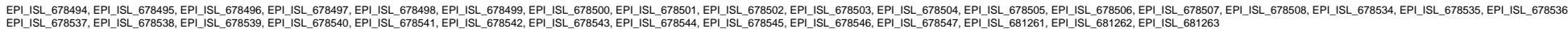
EPI_ISL_683331, EPI_ISL_683332 CNR Virus des Infections Respiratories - France SUD Laboratoire du Centre Hospitalier Annecy Genevois CNR Virus des Infections Respiratoires - France SUD
CNR Virus des Infections Respiratoires - France SUD CNR Virus des Infections Respiratoires - France SUD CNR Virus des Infections Respiratoires - France SUD

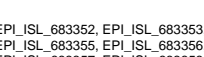

\section{Antonin Bal, Gregory Destras, Gwendolyne Burfin, Solenne Brun, Martine Valette, Bruno Lina, Laurence Josset
Antonin Bal, Gregory Destras, Gwendolyne Burfin, Hadrien Règue, Quentin Semanas, Martine Valette, Bruno Lina, Hélène Petitprez, Bruno Chanzy,} Antonin Bal, Gregory Destras, Gwendolyne Burfin, Quentin Semanas, Martine Valette, Bruno Lina, Laurence Josset

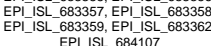
EPIISL_684107

EPIIISL693387, EPIIISL6693388
EPIIISL_693389, EPIIISL 693390 EPI ISL 693391

CHU de Nice - Hôpital Archet 2

EPI_ISL_700348

EPI_ISL_700349

EPI_ISL_700350

EPI_ISL_700351

EPL_ISL_700352

EPI_ISL_700353

EPI_ISL_700354

EPI_ISL_700355

EPI ISL 700356

EPI_ISL_700357

EPI_ISL_700358

EPI_ISL_700359

EPI_ISL_700360

EPI_ISL_700361

EPI_ISL_700362

EPI_ISL_700363

EPI_ISL_700364

EPI_ISL_700365

EPI_ISL_700366

EPI_ISL_700367

EPI_ISL_700368

EPI_ISL_700369

EPI_ISL_700370

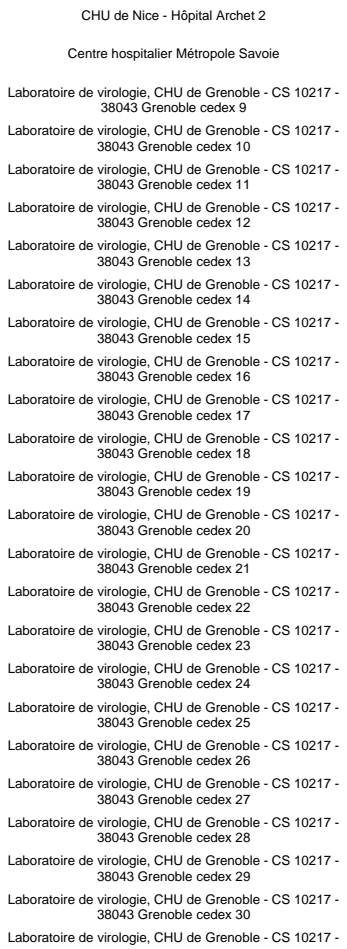

CNR Virus des Infections Respiratoires - France SUD

CNR Virus des Infections Respiratoires - France SUD

CNR Virus des Infections Respiratoires - France SUD

CNR Virus des Infections Respiratoires - France SUD

CNR Virus des Infections Respiratoires - France SUD

CNR Virus des Infections Respiratoires - France SUD

CNR Virus des Infections Respiratoires - France SUD

CNR Virus des Infections Respiratoires - France SUD

CNR Virus des Infections Respiratoires - France SUD

CNR Virus des Infections Respiratoires - France SUD

CNR Virus des Infections Respiratoires - France SUD

CNR Virus des Infections Respiratoires - France SUD

CNR Virus des Infections Respiratoires - France SUD

CNR Virus des Infections Respiratoires - France SUD

CNR Virus des Infections Respiratoires - France SUD

CNR Virus des Infections Respiratoires - France SUD

CNR Virus des Infections Respiratoires - France SUD

CNR Virus des Infections Respiratoires - France SUD

CNR Virus des Infections Respiratoires - France SUD

CNR Virus des Infections Respiratoires - France SUD

CNR Virus des Infections Respiratoires - France SUD CNR Virus des Infections Respiratoires - France SUD

CNR Virus des Infections Respiratoires - France SUD

CNR Virus des Infections Respiratoires - France SUD

CNR Virus des Infections Respiratoires - France SUD
Antonin Bal, Géraldine Gonfrier, Gregory Destras, Gwendolyne Burfin, Hadrien Règue, Quentin Semanas, Martine Valette, Bruno Lina, Valérie Antonin Bal, Carine Dumollard, Gregory Destras, Gwendolyne Burtin, Hadrien Règue, Quentin Semanas, Martine Valette, Bruno Lina, Jérôme Grosjean
Laurence Josset Antonin Bal, Gregory Destras, Gwendolyne Burtin, Hadrien Règue, Quentin Semanas, Martine Valette, Bruno Lina, Sylvie Larrat, Laurence Josset Antonin Bal, Gregory Destras, Gwendolyne Burtin, Hadrien Règue, Quentin Semanas, Martine Valette, Bruno Lina, Sylvie Larrat, Laurence Josset Antonin Bal, Gregory Destras, Gwendolyne Burtin, Hadrien Règue, Quentin Semanas, Martine Valette, Bruno Lina, Sylvie Larrat, Laurence Josse Antonin Bal, Gregory Destras, Gwendolyne Burtin, Hadrien Règue, Quentin Semanas, Martine Valette, Bruno Lina, Sylvie Larrat, Laurence Josset Antonin Bal, Gregory Destras, Gwendolyne Burfin, Hadrien Règue, Quentin Semanas, Martine Valette, Bruno Lina, Sylvie Larrat, Laurence Josset Antonin Bal, Gregory Destras, Gwendolyne Burtin, Hadrien Règue, Quentin Semanas, Martine Valette, Bruno Lina, Sylvie Larrat, Laurence Josse Antonin Bal, Gregory Destras, Gwendolyne Burtin, Hadrien Règue, Quentin Semanas, Martine Valette, Bruno Lina, Sylvie Larrat, Laurence Josset Antonin Bal, Gregory Destras, Gwendolyne Burfin, Hadrien Règue, Quentin Semanas, Martine Valette, Bruno Lina, Sylvie Larrat, Laurence Josset Antonin Bal, Gregory Destras, Gwendolyne Burfin, Hadrien Règue, Quentin Semanas, Martine Valette, Bruno Lina, Sylvie Larrat, Laurence Josset Antonin Bal, Gregory Destras, Gwendolyne Burtin, Hadrien Règue, Quentin Semanas, Martine Valette, Bruno Lina, Sylvie Larrat, Laurence Josset Antonin Bal, Gregory Destras, Gwendolyne Burtin, Hadrien Règue, Quentin Semanas, Martine Valette, Bruno Lina, Sylvie Larrat, Laurence Josset Antonin Bal, Gregory Destras, Gwendolyne Burfin, Hadrien Règue, Quentin Semanas, Martine Valette, Bruno Lina, Sylvie Larrat, Laurence Josset Antonin Bal, Gregory Destras, Gwendolyne Burtin, Hadrien Règue, Quentin Semanas, Martine Valette, Bruno Lina, Sylvie Larrat, Laurence Josset Antonin Bal, Gregory Destras, Gwendolyne Burtin, Hadrien Règue, Quentin Semanas, Martine Valette, Bruno Lina, Sylvie Larrat, Laurence Josset Antonin Bal, Gregory Destras, Gwendolyne Burfin, Hadrien Règue, Quentin Semanas, Martine Valette, Bruno Lina, Sylvie Larrat, Laurence Josse Antonin Bal, Gregory Destras, Gwendolyne Burtin, Hadrien Règue, Quentin Semanas, Martine Valette, Bruno Lina, Sylvie Larrat, Laurence Josset Antonin Bal, Gregory Destras, Gwendolyne Burfin, Hadrien Règue, Quentin Semanas, Martine Valette, Bruno Lina, Sylvie Larrat, Laurence Josse Antonin Bal, Gregory Destras, Gwendolyne Burfin, Hadrien Règue, Quentin Semanas, Martine Valette, Bruno Lina, Sylvie Larrat, Laurence Josset Antonin Bal, Gregory Destras, Gwendolyne Burfin, Hadrien Règue, Quentin Semanas, Martine Valette, Bruno Lina, Sylvie Larrat, Laurence Jossel Antonin Bal, Gregory Destras, Gwendolyne Burtin, Hadrien Règue, Quentin Semanas, Martine Valette, Bruno Lina, Sylvie Larrat, Laurence Josse Antonin Bal, Gregory Destras, Gwendolyne Burtin, Hadrien Règue, Quentin Semanas, Martine Valette, Bruno Lina, Sylvie Larrat, Laurence Josset Antonin Bal, Gregory Destras, Gwendolyne Burtin, Hadrien Règue, Quentin Semanas, Martine Valette, Bruno Lina, Sylvie Larrat, Laurence Josset Antonin Bal, Gregory Destras, Gwendolyne Burfin, Hadrien Règue, Quentin Semanas, Martine Valette, Bruno Lina, Sylvie Larrat, Laurence Josset 
bioRxiv preprint doi: https://doi.org/10.1101/2021.07.21.452479; this version posted July 22, 2021. The copyright holder for this preprint (which was not certified by peer review) is the author/funder, who has granted bioRxiv a license to display the preprint in perpetuity. It is made available under aCC-BY 4.0 International license.

38043 Grenoble cedex 3

$$
\text { CHU Nantes }
$$

CNR Virus des Infections Respiratoires - France SUD Antonin Bal, Louise Castain, Gregory Destras, Gwendolyne Burtin, Hadrien Règue, Quentin Semanas, Martine Valette, Bruno Lina, Virginie Ferré, Celine
Bressollette, Laurence Josset

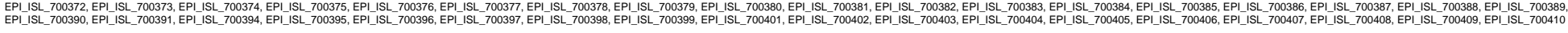
see above

EPI_ISL_707781, EPI_ISL_707782

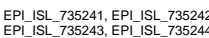

EPI ISL 735245, EPI ISL-735246,
EPI ISL 738241, EPI ISL 738242

EPI_ISL_779254

EPI_ISL_833200

EPI_ISL_860093, EPI_SL_860094 EPI_ISL_896179

$\mathrm{CHU}$ Poitiers

UZ Leuven, National Reference Laboratory for Coronaviruses,
Laboratory Medicine, Leuven, Belgium

Virology, CHU Pitie Salpetriere Charles Foix

Hôpital Bichat Claude Bernard, Laboratoire de Virologie MEPHI, Aix Marseille University MEPHI, Aix Marseille University Laboratoire de Virologie, CHU de Caen, Normandie, France. GRAM2.0, Université de Caen Normandie Laboratoire de
Virologie, CHU de Caen CNR Virus des Infections Respiratoires - France SUD

CNR Virus des Infections Respiratoires - France SUD

KU Leuven, Rega Institute, Clinical and Epidemiological

Virology, CHU Pitie Salpetriere Charles Foix

IAME UMR1 137 Inserm, Université de Paris, Hôpital Bichat Antonin Bal, Carine Dumollard, Gregory Destras, Gwendolyne Burfin, Hadrien Règue, Quentin Semanas, Martine Valette, Bruno Lina, Jerôme Grosjean

Antonin Bal, Gregory Destras, Gwendolyne Burfin, Hadrien Règue, Quentin Semanas, Martine Valette, Bruno Lina, Agnès Beby-Defaux, Magali Garcia, Tony Wawina-Bokalanga, Joan Marti-Carerras, Bert Vanmechelen, Piet Maes

Marot,S., Malet,I,., Leducq,V., Zafilaza,K., Sterlin,D., Planas,D.,Gothland,A., Jary,A., Dorgham,K., Bruel,T., Burrel,S.,Boutolleau,D., Schwartz,O., Antoine Bridier, Amélie Recoing, Quentin Le Hingrat, Lena Daniel, Siham Hamri, Gilles Collin, Alexandre Storto, Mélanie Bertine, Charlotte Charpentier. Anthony Levasseur Meriadeg LE GOUIL, Januel VOUTEAU, Juliette ECHE, Estelle LEPERCHOIS, Astrid VABRET

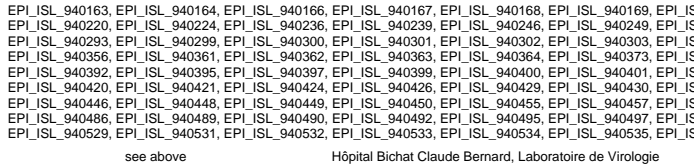

$$
\text { see above }
$$

Hôpital Henri Mondor

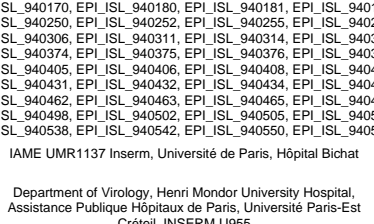

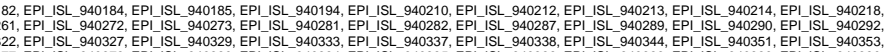

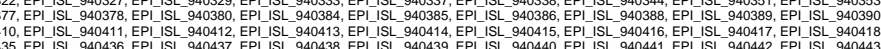

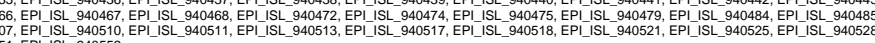
Antoine Bridier-Nahmias, Amélie Recoing, Quentin Le Hingrat, Lena Daniel, Siham Hamri, Gilles Collin, Alexandre Storto, Mélanie Bertine, Charlotte
Charpentier, Nadhira Houhou-Fidouh, Diane Descamps, Benoit Visseaux Cescamps, Benoit Visseaux 
bioRxiv preprint doi: https://doi.org/10.1101/2021.07.21.452479; this version posted July 22, 2021. The copyright holder for this preprint (which was not certified by peer review) is the author/funder, who has granted bioRxiv a license to display the preprint in perpetuity. It is made available under aCC-BY 4.0 International license.

We gratefully acknowledge the following Authors from the Originating laboratories responsible for obtaining the specimens, as well as the Submitting laboratories where the genome data were generated and shared via GISAID, on which this research is based.

All Submitters of data may be contacted directly via www.gisaid.org

Authors are sorted alphabetically.

Accession ID

EPI ISL 1020160, EPIISL_1020161,

EPI-ISL-1020162, EPIIILL 102016, ISL_1020170
Originating Laboratory Istituto Zooprofilattico Sperimentale dell' Umbria e delle
Marche -Togo Rosati Università degli Studi di Perugia
Submitting Laboratory

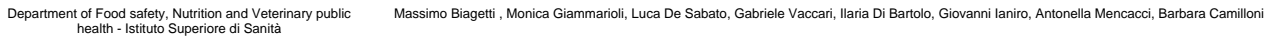

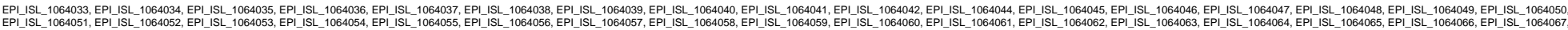

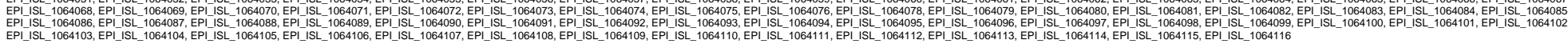

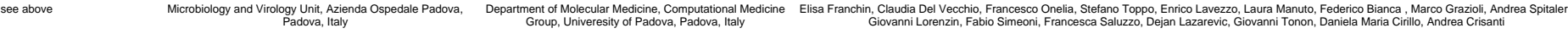

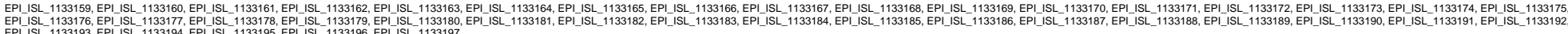

see above Molecular Virology Unit, Microbiology and Virology
Molecular Virology Unit, Microbiology and Virology
Depertment, Fondazione IRCCS Policlinico San Matteo, Pavia Depertment, Fondazione IRCCS Policlinico San Matteo, Pavia

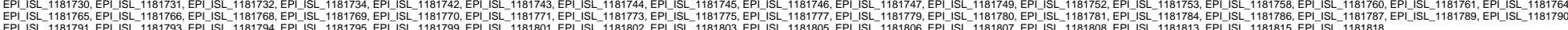
see above

EPI_ISL_1260872, EPI_ISL_1260873

EPI_ISL-1260885, EPI_ISL1260887,
EPIISL-126889, EPP_ISL 1260890,
EPI_ISL_1260891, EPI_ISL-1260892, PIISL 1361596

EPL_ISL_1499504

EPI_ISL_1499572

EPL_ISL_1499593

EPI_ISL_1499594

EPI_ISL_1692721, EPI_ISL_1692723, EPIISL-1692788, EPI_ISL-1692805,

EPIISL_1854981, EPI_ISL_1854982, EPI_SL_2138923

EPI_ISL_2138924

EPIISL_2282167

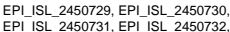
EPI_ISL_2450731, EPI_ISL_2450732, EPI-ISL-245073, EPIISL-2450734,
EPI_ISL_2450735, EPIISL-2450736,
EPI_ISL 2450737
Microbiology and Virology Unit,Azienda Ospedale
Padova,Padova, Italy

ULSS 5 Polesana

ULSS 2 Treviso

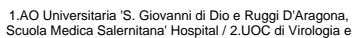

1.AO Universitaria 'S. Giovanni di Dio e Ruggi D'Aragona,
Scuola Medica Salernitana' 'Hospital / 2.UOC di Virologia e
Microbiologia, Universita della Campania 'L. Vanvitelli' 3 .AO Universitaria 'Federico II' Napoli Hospitial ' 4 4.AORR 'San

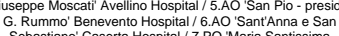
Sebastiano' Caserta Hospital / 7.PO 'Maria Santissima Addolorata' Eboli Hospital/ 8. Biogem Istituto di Ricerche
Genetiche /9. U. O.C. di Genetica Medica edi Laboratorio A.O.R.N., Azienda O. Ospedaliera di Rilievo Nazionale Antonio
Cardarelli, Napoli / 10 . Centro di riferimento Oncologico della Cardarelli, Napoli/ /10. Centroo di riferimento Oncologico
Basilicata (IRCCS-CROB), Rionero in Vulture (PZ)/11.
Presidio Ospedaliero di Agropoli, Agropoli (SA).

\begin{tabular}{|c|c|}
\hline ooratorio di Microbiologia e & \\
\hline $\begin{array}{l}\text { di Microbiologia e Virologia, Università v } \\
\text { San Raffaele, Milano }\end{array}$ & $\begin{array}{l}\text { obiologia e Virologia, Uni } \\
\text { San Raffaele, Milano }\end{array}$ \\
\hline $\begin{array}{l}\text { Laboratorio di Microbiologia e Virologia, Università Vita-Salute } \\
\text { San Raffaele, Milan }\end{array}$ & $\begin{array}{l}\text { biologia e Viriologia, Univer } \\
\text { San Raffaele, Milan }\end{array}$ \\
\hline $\begin{array}{l}\text { Laboratorio di Microbiologia e Virologia, Università Vita-Salute } \\
\text { San Raffaele, Milano }\end{array}$ & $\begin{array}{l}\text { oratorio di Microbiologia e Virologia, Uni } \\
\text { San Raffaele, Milano }\end{array}$ \\
\hline
\end{tabular}

Università Federico II - Dipartimento di scienze mediche Telethon Institute of Genetics and Medicine (TIGEM)
traslazionali - Napoli

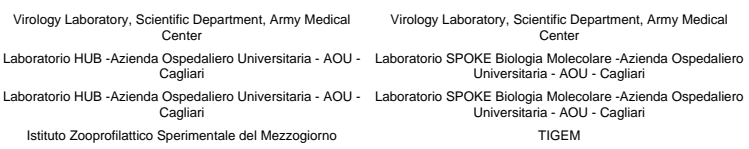

Istituto Zooprofilattico Sperimentale del Mezzogiorno

TIGEM

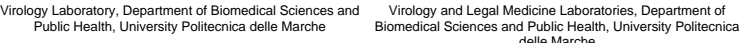

Elisa Franchin, Claudia Del Vecchio,Francesco Onelia,Stefano Toppo, Enrico Lavezzo,Laura Manuto, Federico Bianca ,Marco Grazioli,Andrea Crisanti Adelaide Milani, Alessia Schivo, Annalisa Salviato, Erika Giorgia Quaranta, Luca Tassoni, Ambra Pastori, Edoardo Giussani, Alice Fusaro, Isabella Monne, Adelaide Milani, Alessia Schivo, Annalisa Salviato, Erika Giorgia Quaranta, Luca Tassoni, Ambra Pastori, Edoardo Giussani, Alice Fusaro, Isabella Monne
Calogero Terregino, Antonia Ricci

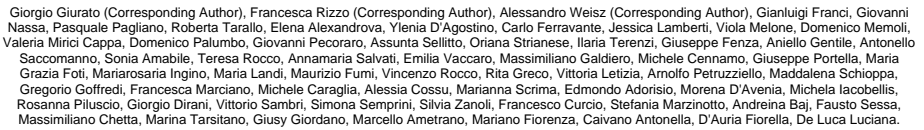

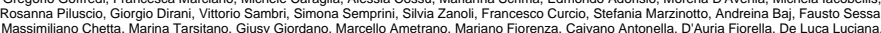

\footnotetext{
Roberto Ferrarese, Roberta Antonia Diotti, Elena Criscuolo, Matteo Castelli, Nicasio Mancini, Massimo Clementi Matteo Castelli, Elena Criscuolo, Roberta Antonia Diotti, Roberto Ferrarese, Nicasio Mancini, Massimo Clementi, Nicola Clementi on behalf of Elena Criscuolo, Roberta Antonia Diotti, Roberto Ferrarese, Matteo Castelli, Massimo Clementi, Nicola Clementi, Nicasio Mancini on behalf of
SARS-CoV-2 ITALIAN RESEARCH ENTERPRISE-(SCIRE) Collaborative Group Nicola Clementi, Matteo Castelli, Elena Criscuolo, Roberta Antonia Diotti, Roberto Ferrarese, Nicasio Mancini, Massimo Clementi, on behalf of
SARS-CoV-2 ITALIAN RESEARCH ENTERPRISE-(SCIRE) Collaborative Group Antonio Grimaldi Patrizia Annunziata Francesco Panariello Teresa Giuliano Michele Cennamo Valentina Bouche Chiara Colantuono Lucio Di Filippo
Mariano Fiorenza Anna Mantredi Marcello Salvi Giuseppe Portella Andrea Ballabio Davide Cacchiarelli Silvia Fillo, Riccardo De Sanctis, Antonella Fortunato, Anella Monte, Anna Anselmo, Vanessa Vera Fain, Francesco Giordani, Giandomenico Cerreto,
Filippo Molinari, Giancarlo Petralito, Florigio Lista Germano Orrù, Alessandra Scano, Sara Fais, Valentina Medda, Miriam Loddo, Riccardo Cappai, Ferdinando Coghe Alessandra Scano, Germano Orrù, Sara Fais, Valentina Medda, Miriam Loddo, Riccardo Cappai, Ferdinando Coghe Antonio Grimaldi Patrizia Annunziata Francesco Panariello Biancamaria Pierri Claudia Tiberio Teresa Giuliano Valentina Bouche Chiara Colantuono Maria Cacchiarelli
}

Sara Caucci, Patrizia Bagnarelli, Stefano Menzo, Federica Alessandrini, Valerio Onofri, Chiara Turchi, Filomena Melchionda, Adriano Tagliabracci 
bioRxiv preprint doi: https://doi.org/10.1101/2021.07.21.452479; this version posted July 22, 2021. The copyright holder for this preprint (which was not certified by peer review) is the author/funder, who has granted bioRxiv a license to display the preprint in perpetuity. It is made available under aCC-BY 4.0 International license.

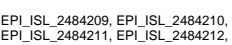

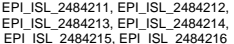

EPI_ISL_410545

EPI_ISL_410546

EPI_ISL_412973

EPI_ISL_412974

EPI_ISL_413489

EPI_ISL_417418

EPI_ISL_417419, EPI_ISL_41742

EPI_ISL_417423

EPL_ISL_417445, EPI_ISL_417447

EPI_ISL_417491

EPI_ISL_417921

EPI_ISL_417922

EPI_ISL_417923

EPI_ISL_418255

EPI_ISL_418256

EPI_ISL_418257

EPI_ISL_418258, EPI_ISL_418259

EPI_ISL_418260

EPI_ISL_419254

EPI_ISL_419255

EPI_ISL_420563

EPI_ISL_420564

EPI_ISL_420565

EPI_ISL_420566, EPI_ISL_420567

EPI_ISL_420568, EPI_ISL_420569
EPI_ISL_420583

EPI_ISL_422437, EPI_ISL_422438

EPI_ISL_424342

EPI_ISL_424343

EPI_ISL_424344

EPI_ISL_428853

EPI_ISL_428854

EPI_ISL_429226, EPI_ISL_429227

EPIIISL4429228, EPI_ISL4429231,
EPI_ISL_429232, EPI_ISL_429235
University of Brescia - Dept. of Molecular and Translational
Medicine

INMI Lazzaro Spallanzani IRCCS

INMI Lazzaro Spallanzani IRCCS

$$
\begin{aligned}
& \text { Department of Infectious Diseases, Istituto Superiore di } \\
& \text { Sanita, Roma, Italy }
\end{aligned}
$$

Department of Infectious Diseases, Istituto Superiore di
Sanitä, Rome, Italy

Laboratorio di Microbiologia e Virologia, Università Vita-Salute

Laboratory of Molecular Virology International Center fro
Genetic Engineering and Biotechnology (ICGEB)

Laboratory of Molecular Virology International Center for
Genetic Engineering and Biotechnology (ICGEB)

Laboratory of Molecular Virology International Center for
Genetic Engineering and Biotechnology (ICGEB)

Laboratory of Infectious Diseases, Department of Biomedi
and Clinical Sciences L. Sacco, University of Milan

Virology Laboratory, Department of Biomedical Sciences an
Public Health, University Politecnica delle Marche

INMI Lazzaro Spallanzani IRCCS

INMI Lazzaro Spallanzani IRCCS

INMI Lazzaro Spallanzani IRCCS

Presidio Ospedaliero "S. Spirito" - PESCARA

Ospedale "San Liberatore" di Atri

Ospedale Civile Giuseppe Mazzini, Teramo

Presidio ospedaliero "Santo Spirito"

Ospedale Civile Giuseppe Mazzini

INMI Lazzaro Spallanzani IRCCS

INMI Lazzaro Spallanzani IRCCS

Ospedale Civile Giuseppe Mazzini

Ospedale Civile Castel Di Sangro

Ospedale Civile Giuseppe Mazzini

Ospedale Regionale San Salvatore

Ospedale Civile Giuseppe Mazzini

ULSS9 Distretto di Bussolengo

INMI Lazzaro Spallanzani IRCCS

INMI Lazzaro Spallanzani IRCcS

INMI Lazzaro Spallanzani IRCCS

Laboratory of Molecular Virology International Center for
Genetic Engineering and Biotechnology (ICGEB)

Laboratory of Molecular Virology International Center for
Genetic Engineering and Biotechnology (ICGEB)

Presidio Ospedaliero Santo Spirito

Ospedale Civile Giuseppe Mazzini
Istituto Zooprofilattico Sperimentale della Lombardia e
dell'Emilia Romagna (IZSLER), Risk Analy Lis and Genomic
Epidemiology Unit

Laboratory of Virology, INMI Lazzaro Spallanzani IRCCS

Laboratory of Virology, INMI Lazzaro Spallanzani IRCCS

Virology Laboratory, Scientitic Department, Army Medical

Virology Laboratory, Scientific Department, Army Medical
Center

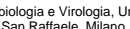

ARGO Open Lab Plattorm for Genome sequencing

ARGO Open Lab Plattorm for Genome sequencing

ARGO Open Lab Plattorm for Genome sequencing

Laboratory of Infectious Diseases, Department of Biomedica
and Clinical Sciences L. Sacco, University of Milan Virology and Legal Medicine Laboratories, Department of
Biomedical Sciences and Public Health, University Politecnica

delle Marche
Laboratory of Virology, INMI Lazzaro Spallanzani IRCCS

Laboratory of Virology, INMI Lazzaro Spallanzani IRCCS

Laboratory of Virology, INMI Lazzaro Spallanzani IRCCS

Istituto Zooprofilattico Sperimentale dell'Abruzzo e Molise "G.
Caporale"

Istituto Zooprofilattico Sperimentale dell'Abruzzo e Molise "G.
Caporale"

Istituto Zooprofilatitico Sperimentale dell'Abruzzo e Molise
"G.Caporale"

Istituto Zooprofilattico Sperimentale dell'Abruzzo e Molise "G.

Istituto Zooprofilattico Sperimentale dell'Abruzzo e Molise "G.

Laboratory of Virology, INMI Lazzaro Spallanzani IRCCS

INMI Lazzaro Spallanzani IRCCS

Istituto Zooprofilattico Sperimentale dell'Abruzzo e Molise "G.
Caporale"

Istituto Zooprofilattico Sperimentale dell'Abruzzo e Molise

Istituto Zooprofilattico Sperimentale dell'Abruzzo e Molise
"G.Caporale"

Istituto Zooprofilatitico Sperimentale dell'Abruzzo e Molise
"G.Caporale"

Istituto Zooprofilatitico Sperimentale dell'Abruzzo e Molise
"G.Caporale"

Istituto Zooprofilattico Sperimentale delle Venezie

Laboratory of Virology, INMI Lazzaro Spallanzani IRCCS

Laboratory of Virology, INMI Lazzaro Spallanzani IRCCS

Laboratory of Virology, INMI Lazzaro Spallanzani IRCCS

ARGO Open Lab Plattorm for Genome Sequencing

ARGO Open Lab Plattorm for Genome sequencing

Istituto Zooprofilattico Sperimentale dell'Abruzzo e Molise "G.

Istituto Zooprofilattico Sperimentatele dell'Abruzzo e Molise "G.
Caporale"
Garuso Arnaldo, Fiorentini Simona, Caccuri Francesca, Messali Serena, Zani Alberto, Marina Morganti, Erika Scaltriti, Stefano Pongolin

Maria R. Capobianchi, Cesare E. M. Gruber, Martina Rueca, Barbara Bartolini, Francesco Messina, Emanuela Giombini, Francesca Colavita, Concetta Maria R. Capobianchi, Cesare E. M. Gruber, Martina Rueca, Fabrizio Carletti, Barbara Bartolini, Francesco Messina, Emanuela Giombini, Francesca nella Marchi, Eleonora Benedetti, Concetta Fabiani, Giovanni Faggioni, Antonella Fortunato, Riccardo De Santis, Silvia
Fillo, Anna Anselmo, Andrea Ciammaruconi, Stefano Palomba, Florigio Lista

Paola Stefanelli, Stefano Fiore, Antonella Marchi, Eleonora Benedetti, Concetta Fabiani, Giovanni Faggioni, Antonella Fortunato, Silvia Fillo, Riccardo De
Santis, Andrea Ciammaruconi, Giancarlo Petralito, Filippo Molinari, Florigio Lista
R.A Diotti, E. Criscuolo, M. Castelli, V. Caputo, R. Ferrarese, M. Sampaolo, E. Boeri, I. Negri, V. Amato, G. Lo Raso, C. Di Resta, R. Burioni, M. Clementi,

R.A Diotti, E. Criscuolo, M. Castelli, V. Caputo, R. Ferrarese, M. Sampaolo, E. Boeri, I. Negri, V. Amato, G. Lo Raso, C. D Licastro D, Rajasekharan S, Dal Monego S, Segat L, D'Agaro P, Marcello A

Licastro D, Rajasekharan S, Dal Monego S, Segat L, D'Agaro P, Marcello A

Licastro D, Rajasekharan, Dal Monego S, Segat L, D'Agaro P, Marcello A

Gianguglielmo Zehender, Alessia Lai, Annalisa Bergna, Luca Meroni, Agostino Riva, Claudia Balotta, Maciej Tarkowski, Arianna Gabrieli, Dario Bagnarelli,P., Caucci,S., Di Sante,L., Menzo,S., Alessandrini,F., Onofri, V., Turchi,C., Tagliabracci,A. Martina Rueca, Barbara Bartolini, Francesco Messina, Cesare E. M. Gruber, Emanuela Giombini, Maria R. Capobianchi, Fabrizio Carletti, Francesca
Colavita, Conceetta Castilletti, Eleonora Lalle, Daniele Lapa, Giuseppe Ippolito.

Cesare E. M. Gruber, Martina Rueca, Barbara Bartolini, Francesco Messina, Emanuela Giombini, Maria R. Capobianchi, Fabrizio Carletti, Francesca

Francesco Messina, Barbara Bartolini, Martina Rueca, Cesare E. M. Gruber, Emanuela Giombini, Maria R. Capobianchi, Fabrizio Carletti, Francesca Lorusso A, Marcacci M, Cammà C, Monaco F, Puglia I, Di Pasquale A, Rinaldi A, Mangone I, Savini G

Lorusso A, Marcacci M, Di Domenico M, Puglia I, Curini V, Ancora M, Di Pasquale A, Rinaldi A, Mangone I, Cammà C, Savini G.

Lorusso A, Marcacci M, Di Domenico M, Puglia I, Curini V, Ancora M, Di Pasquale A, Rinaldi A, Mangone I, Cammà C, Savini G.

Lorusso A, Marcacci M, Di Domenico M, Puglia I, Curini V, Ancora M, Di Pasquale A, Rinaldi A, Mangone I, Cammà C, Savini G.

Lorusso A, Marcacci M, Di Domenico M, Puglia I, Curini V, Ancora M, Di Pasquale A, Rinaldi A, Mangone I, Cammà C, Savini G.

Barbara Bartolini, Martina Rueca, Francesco Messina, Cesare E. M. Gruber, Emanuela Giombini, Maria R. Capobianchi, Fabrizio Carletti, Francesca
Colavita, Concetta Castilletti, Eleonora Lalle, Daniele Lapa, Giuseppe Ippolito. Antonino Di Caro, Cesare E. M. Gruber, Martina Rueca, Barbara Bartolini, Francesco Messina, Emanuela Giombini, Maria R. Capobianchi, Fabrizio
Carletti, Francesca Colavita, Concetta Castilletti, Eleonora Lalle, Daniele Lapa, Giuseppe Ippolito.

Lorusso A, Marcacci M, Di Domenico M, Ancora M, Curini V, Mangone I, Rinaldi A, Di Pasquale A, Cammà C, Puglia I, Savini G

Lorusso A, Marcacci M, Di Domenico M, Ancora M, Curini V, Mangone I, Rinaldi A, Di Pasquale A, Cammà C, Puglia I, Savini G

Lorusso A, Marcacci M, Di Domenico M, Ancora M, Curini V, Mangone I, Rinaldi A, Di Pasquale A, Cammà C, Puglia I, Savini G

Lorusso A, Marcacci M, Di Domenico M, Ancora M, Curini V, Mangone I, Rinaldi A, Di Pasquale A, Cammà C, Puglia I, Savini G

Lorusso A, Marcacci M, Di Domenico M, Ancora M, Curini V, Mangone I, Rinaldi A, Di Pasquale A, Cammà C, Puglia I, Savini G

Adelaide Milani, Alessia Schivo, Annalisa Salviato, Erika Giorgia Quaranta, Ambra Pastori, Bianca Zecchin, Alice Fusaro, Isabella Monne, Calogero Concetta Castilletti, Barbara Bartolini, Martina Rueca, Cesare Erresto Maria Gruber, Francesco Messina, Fabrizizo Carletti, Eleonora Lalle, Licia Bordi,
Giulia Matusali,

Fabrizio Carletti, Barbara Bartolini, Martina Rueca, Cesare Emesto Maria Gruber, Francesco Messina, Eleonora Lalle, Licia Bordi, Giulia Matusal
Francesca Colavita Maria Rosaria Capobianchi, Concetta Castilletit, Francesco Vairo, Giuseppe Ippolito, Antonino Di Caro

Eleonora Lalle, Barbara Bartolini, Martina Rueca, Cesare Ernesto Maria Gruber, Francesco Messina, Fabrizio Carletti, Licia Bordi, Giulia Matusali,
Francesca Colavita, Maria Rosaria Capobianchi, Concetta Castilletti, Francesco Vairo, Giuseppe Ippolito, Antonino Di Caro Licastro D, Rajasekharan S, Dal Monego S, Segat L, D'Agaro P, Marcello A Licastro D, Rajasekharan S, Dal Monego S, Segat L, D'Agaro P, Marcello A

Lorusso A, Marcacci M, Di Domenico M, Ancora M, Curini V, Mangone I, Rinaldi A, Di Pasquale A, Camma C, Puglia I, Savini G Lorusso A, Marcacci M, Di Domenico M, Ancora M, Curini V, Mangone I, Rinaldi A, Di Pasquale A, Camma C, Puglia I, Savini G 
bioRxiv preprint doi: https://doi.org/10.1101/2021.07.21.452479; this version posted July 22, 2021. The copyright holder for this preprint (which was not certified by peer review) is the author/funder, who has granted bioRxiv a license to display the preprint in perpetuity. It is made available under aCC-BY 4.0 International license.

\begin{tabular}{|c|c|}
\hline EPI_ISL_429236 & Ospedale Civile S. Liberatore di Atri \\
\hline EPI_ISL_435145 & Ospedale Civile Giuseppe Mazzini \\
\hline EPIISL_4355146, EPL_ISL_435147 & Villa Serena del Dr. Leonardo Petruzzi \\
\hline EPI_ISL_435148 & Ospedale SS Annunziata \\
\hline EPI_ISL_435149 & SERVIZIO DI GIIENE E SANTTA PUBBLICA ASL Teramo \\
\hline EPI_ISL_435150, EPP_ISL_435151 & Ospedale SS Annunziata \\
\hline EPI_ISL_435152 & $\begin{array}{l}\text { Servizio di giene, Epidemiloggiae Sanità Pubblica (SIESP) } \\
\text { Avezzano }\end{array}$ \\
\hline $\begin{array}{l}\text { EPI_ISL_435153, EPIISL_435154, } \\
\text { EPI_ISL_435155 } \\
\text { EPI_ISL_436718 }\end{array}$ & $\begin{array}{l}\text { SERVIZIO DI IGIENE E SANTTA PUBBLLCA ASL Teramo } \\
\text { Ospedale Regionale San Salvatore }\end{array}$ \\
\hline $\begin{array}{l}\text { EPIISL_436719, EPIISL_436720, } \\
\text { EPI_ISL_436721, EPIIISL-436722 } \\
\text { EPI_ISL_436723 }\end{array}$ & $\begin{array}{l}\text { Ospedale Civile S. Liberatore di Atri } \\
\text { Ospedale Civile Giuseppe Mazzini }\end{array}$ \\
\hline EPIISL_436724 & Ospedale Civile S. Liberatore di Atri \\
\hline EPI_ISL_436725 & RSARP Villa San Giovanni - Gruppo Edos \\
\hline $\begin{array}{l}\text { EPI_ISL_4367266, EPIIISL_436727, } \\
\text { EPI_ISL_436729 } \\
\text { EPI_ISL_436730 }\end{array}$ & $\begin{array}{l}\text { SERVVIZIO DI IGIENE E SANITÀ PUBBLICA ASL Teramo } \\
\text { Servizio di i igiene epidemiologia e sanità pubblica (Siesp) }\end{array}$ \\
\hline EPI_ISL_436731, EPI_ISL_436732 & 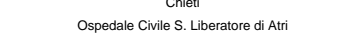 \\
\hline EPI_SL_451298 & Laboratory of Virology, INMI Lazzaro Spallanzani IRCCS \\
\hline EPI_ISL_451299 & Laboratory of Virology, INMI Lazzaro Spallanzani IRCCS \\
\hline EPI_ISL_451300 & Laboratory of Virology, INMI Lazzaro Spallanzani IRCCS \\
\hline EPI_ISL_451301 & Laboratory of Virology, INMI Lazzaro Spallanzani IRCCS \\
\hline EPI_ISL_451302 & Laboratory of Virology, INMI Lazzaro Spallanzani IRCCS \\
\hline EPI_ISL_451303 & \\
\hline EPI_ISL_451304 & Laboratory of Virology, IIMMI Lazzaro Spallanzani IRCCS \\
\hline EPI_ISL_451306 & $\begin{array}{l}\text { Molecular Virology Unit, Fondazione IRCS Policlinico San } \\
\text { Matteo , Pavia }\end{array}$ \\
\hline EPL_ISL_4551307 & $\begin{array}{l}\text { Molecular Virology Unit, Fondazizen IRCCS Policlinico San } \\
\text { Matteo Pavia }\end{array}$ \\
\hline EPI_ISL_451308 & $\begin{array}{l}\text { Molecular Virology Unit, Fondazizen IRCS Policlinico San } \\
\text { Matteo , Pavia }\end{array}$ \\
\hline EPIISL_451309 & $\begin{array}{l}\text { Molecular Virology Unit, Fondazione IRCS Policlinico San } \\
\text { Matteo , Pavia }\end{array}$ \\
\hline EPI_ISL_451961 & 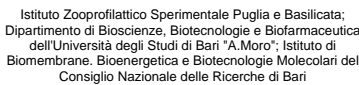 \\
\hline EPI_ISL_451962 & 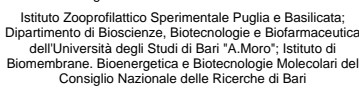 \\
\hline 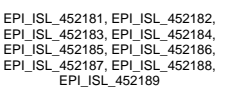 & $\begin{array}{l}\text { Consiggio Nazionale delle Ricerche diE } \\
\text { ULSSg Distretto di Bussolengo }\end{array}$ \\
\hline EPP_ISL_452190, EPD_ISL_452191 & ULSS9 Distretto di San Bonifacio \\
\hline $\begin{array}{l}\text { EPIISL_454733 } \\
\text {-_557699, EP_ISL_457700 }\end{array}$ & $\begin{array}{l}\text { Department of Medical, Biotechnologies University of Siena } \\
\text { Department of Infectious Diseases, Istituto Superiore di } \\
\text { Sanitä, Roma, It thaly }\end{array}$ \\
\hline 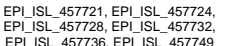 & $\begin{array}{l}\text { Department of Infectious Diseases, Istituto Superiore di } \\
\text { Sanitä, Roma, Italy }\end{array}$ \\
\hline
\end{tabular}

Istituto Zooprofilattico Sperimentale dell'Abruzzo e Molise "G. Caporale"
Istituto Zooprofilatico Sperimentale dell'Abruzzo e Molise
"G.Caporale" Istituto Zooprofilatitico S.perimentale dell'Abruzzo e Molise
"G.Caporale" Istituto Zooprofilattico Sperimentale dell'Abruzzo e Molise Istituto Zooprofilattico $\begin{gathered}\text { Sperimentale dell'Abruzzo e Molise } \\ \text { "G.Caporale" }\end{gathered}$ Istituto Zooprofilattico Sperimentale dell'Abruzzo e Molise
"G.Caporale" Istituto Zooprofilattico Sperimentale dell'Abruzzo e Molise
"G.Caporale" Istituto Zooprofilattico Sperimentale dell'Abruzzo e Molise Istituto Zooprofilatitico Sperimentale dell'Abruzzo e Molise Istituto Zooprofilattico Sperimentale dell'Abruzzo e Molise Istituto Zooprofilattico Sperimentale dell'Abruzzo e Molise
"G.Caporale" Istituto Zooprofilattico Sperimentale dell'Abruzzo e Molise
"G.Caporale" Istituto Zooprofilatitico Sperimentale dell'Abruzzo e Molise "G.Caporale"
Istituto Zooprofilatitico Sperimentale dell'Abruzzo e Molise
"G.Caporale" Istituto Zooprofilattico Sperimentale dell'Abruzzo e Molise
"G.Caporale" Istituto Zooprofilattico Sperimentale dell'Abruzzo e Molise
"G.Caporale" Laboratory of Virology, INMI Lazzaro Spallanzani IRCCS Laboratory of Virology, INMI Lazzaro Spallanzani IRCCS Laboratory of Virology, INMI Lazzaro Spallanzani IRCCS Laboratory of Virology, INMI Lazzaro Spallanzani IRCCS Laboratory of Virology, INMI Lazzaro Spallanzani IRCCS Laboratory of Virology, INMI Lazzaro Spallanzani IRCCS Laboratory of Virology, INMI Lazzaro Spallanzani IRCCS Labort of Virolog. INMI Lazzaro Spallanzi IRCCS

Laboratory of Virology, INMI Lazzaro Spallanzani IRCCS Laboratory of Virology, INMI Lazzaro Spallanzani IRCCS Laboratory of Virology, INMI Lazzaro Spallanzani IRCCS Beaconlab (Bioinformatics Evvlution and Comparative
Genomics lab), Dept of Biosciences, University of Milan Beaconlab (Bioinformatics, Evolution and Comparative
Genomics lab) Dept of Biosciences, University on Milan Istituto Zooprofilattico Sperimentale delle Venezie

Istituto Zooprofilattico Sperimentale delle Venezie Department of Medical, Biotechnologies University of Siena Army Medical and Veterinary Research Center Army Medical and Veterinary Research Center
Lorusso A, Marcacci M. Di Domenico M, Ancora M, Curini V. Mangone I, Rinaldi A, Di Pasquale A, Camma C, Puglia I, Savini G Lorusso A, Marcacci M, Di Domenico M, Ancora M, Curini V, Mangone I, Rinaldi A, Di Pasquale A, Cammà C, Puglia I, Savini G Lorusso A, Marcacci M, Di Domenico M, Ancora M, Curini V, Mangone I, Rinaldi A, Di Pasquale A, Cammà C, Puglia I, Savini G Lorusso A, Marcacci M, Di Domenico M, Ancora M, Curini V, Mangone I, Rinaldi A, Di Pasquale A, Cammà C, Puglia I, Savini C Lorusso A, Marcacci M, Di Domenico M, Ancora M, Curini V, Mangone I, Rinaldi A, Di Pasquale A, Cammà C, Puglia I, Savini G Lorusso A, Marcacci M, Di Domenico M, Ancora M, Curini V, Mangone I, Rinaldi A, Di Pasquale A, Cammà C, Puglia I, Savini G Lorusso A, Marcacci M, Di Domenico M, Ancora M, Curini V, Mangone I, Rinaldi A, Di Pasquale A, Cammà C, Puglia I, Savini G Lorusso A, Marcacci M, Di Domenico M, Ancora M, Curini V, Mangone I, Rinaldi A, Di Pasquale A, Cammà C, Puglia I, Savini G Lorusso A, Marcacci M, Di Domenico M, Ancora M, Curini V, Mangone I, Rinaldi A, Di Pasquale A, Cammà C, Puglia I, Savini G Lorusso A, Marcacci M, Di Domenico M, Ancora M, Curini V, Mangone I, Rinaldi A, Di Pasquale A, Cammà C, Puglia I, Savini G Lorusso A, Marcacci M, Di Domenico M, Ancora M, Curini V, Mangone I, Rinaldi A, Di Pasquale A, Cammà C, Puglia I, Savini G Lorusso A, Marcacci M, Di Domenico M, Ancora M, Curini V, Mangone I, Rinaldi A, Di Pasquale A, Cammà C, Puglia I, Savini G Lorusso A, Marcacci M, Di Domenico M, Ancora M, Curini V, Mangone I, Rinaldi A, Di Pasquale A, Cammà C, Puglia I, Savini G Lorusso A, Marcacci M, Di Domenico M, Ancora M, Curini V, Mangone I, Rinaldi A, Di Pasquale A, Cammà C, Puglia I, Savini G Lorusso A, Marcacci M, Di Domenico M, Ancora M, Curini V, Mangone I, Rinaldi A, Di Pasquale A, Cammà C, Puglia I, Savini G

Lorusso A, Marcacci M, Di Domenico M, Ancora M, Curini V, Mangone I, Rinaldi A, Di Pasquale A, Cammà C, Puglia I, Savini G Cesare E.M. Gruber, Martina Rueca, Barbara Bartolini, Francesco Messina, Antonino Di Caro, Maria R. Capobianchi, Giuseppe Ippolito Martina Rueca, Cesare E.M. Gruber, Barbara Bartolini, Francesco Messina, Antonino Di Caro, Maria R. Capobianchi, Giuseppe Ippolito Cesare E.M. Gruber, Martina Rueca, Barbara Bartolini, Francesco Messina, Antonino Di Caro, Maria R. Capobianchi, Giuseppe Ippolito Martina Rueca, Cesare E.M. Gruber, Barbara Bartolini, Francesco Messina, Antonino Di Caro, Maria R. Capobianchi, Giuseppe Ippolito Cesare E.M. Gruber, Martina Rueca, Barbara Bartolini, Francesco Messina, Antonino Di Caro, Maria R. Capobianchi, Giuseppe Ippolito Martina Rueca, Cesare E.M. Gruber, Barbara Bartolini, Francesco Messina, Antonino Di Caro, Maria R. Capobianchi, Giuseppe Ippolito Cesare E.M. Gruber, Martina Rueca, Barbara Bartolini, Francesco Messina, Antonino Di Caro, Maria R. Capobianchi, Giuseppe Ippolito

Fausto Baldanti, Antonio Piralla, Antonino Di Caro, Cesare E.M. Gruber, Martina Rueca, Barbara Bartolini, Maria R. Capobianchi Antonio Piralla, Fausto Baldanti, Maria R. Capobianchi, Cesare E.M. Gruber, Martina Rueca, Barbara Bartolini, Antonino Di Caro Fausto Baldanti, Antonio Piralla, Cesare E.M. Gruber, Maria R. Capobianchi, Antonino Di Caro, Martina Rueca, Barbara Bartolini Parisi A.,Pesole G., Manzari C., Chiara M.

Parisi A.,Pesole G., Manzari C., Chiara M.

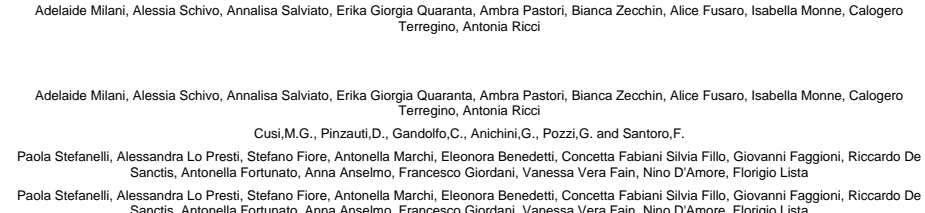
Cusi,M.G., Pinzauti,D., Gandolfo,C., Anichini,G., Pozzi,G. and Santoro,F. Paola Stefanelli, Alessandra Lo Presti, Stefano Fiore, Antonella Marchi, Eleonora Benedetti, Concetta Fabiani Silvia Fillo, Giovanni Faggioni, Riccardo De Paola Stefanelli, Alessandra Lo Presti, Stefano Fiore, Antonella Marchi, Eleonora Benedetti, Concetta Fabiani Silvia Fillo, Giovanni Faggioni, Riccardo De 
bioRxiv preprint doi: https://doi.org/10.1101/2021.07.21.452479; this version posted July 22, 2021. The copyright holder for this preprint (which was not certified by peer review) is the author/funder, who has granted bioRxiv a license to display the preprint in perpetuity. It is made available under aCC-BY 4.0 International license.

\begin{abstract}
EPI_ISL_457825
EPI_ISL_457826

EPI_ISL_458084

EPI_ISL_458085

EPI_ISL_460079

EPI_ISL_460080

EPI_ISL_460081

EPI_ISL_460082

EPI_ISL_460083

EPI_ISL_460084

EPI_ISL_460085

EPI_ISL_460086

EPI_ISL_460087

EPI_ISL_460088

EPI_ISL_460089

EPI_ISL_460090

EPI_ISL_460091

EPL_ISL_460092

EPI_ISL_460093

EPI_ISL_460094

EPI_ISL_460095
\end{abstract}

EPIISL 468914, EPI_ISL_469016,

ISL-469020, EPI ISL-46902
EPIIISL 469022

EPI_ISL_469023

EPI_ISL_477193, EPI_ISL_477194

EPIISL 477195, EPIIISL_477196,

EPIIISL-477199,EPIIIILL-477200

EPI_ISL_477202, EPI_ISL_477203

EPI_ISL_477204

EPI_ISL_479616, EPI_ISL_479617

EPI_ISL 479618, EPI_ISL_479619,
EPI_ISL_479790, EPI_ISL_479791
Army Medical Research Center - Scientific Department

Army Medical Center - Scientific Department

Laboratorio Biologia Molecolare Sars Cov2 - UOC Laboratorlo
Analisi - Servizio Medicina di Laboratorio, Ospedale "San Laboratorio Biologia Molecolare Sars Cov2 - UOC Laboratorio
Analisi - Servizio Medicina di Laboratorio , Ospedale "San Francesco" - ATS- ASSL Nuoro Molecular Virology Unit, Fondazione IRCCS Policlinico San Molecular Virology Unit, Fondazione IRCCS Policlinico San Molecular Virology Unit, Fondazione IRCCS Policlinico San
Matteo , Pavia Molecular Virology Unit, Fondazione IRCCS Policlinico San
Matteo , Pavia Molecular Virology Unit, Fondazione IRCCS Policlinico San
Matteo . Pavia Molecular Virology Unit, Fondazione IRCCS Policlinico San

Molecular Virology Unit, Fondazione IRCCS Policlinico San Molecular Virology Unit, Fondazione IRCCS Policlinico San
Matteo , Pavia Molecular Virology Unit, Fondazione IRCCS Policlinico San Molecular Virology Unit, Fondazione IRCCS Policlinico San

Molecular Virology Unit, Fondazione IRCCS Policlinico San Molecular Virology Unit, Fondazione IRCCS Policlinico San
Matteo, Pavia Molecular Virology Unit, Fondazione IRCCS Policlinico San
Matteo Pavia Molecular Virology Unit, Fondazione IRCCS Policlinico San

Molecular Virology Unit, Fondazione IRCCS Policlinico San Molecular Virology Unit, Fondazione IRCCS Policlinico San Molecular Virology Unit, Fondazione IRCCS Policlinico San
Matteo , Pavia Istituto Zooprofilattico Sperimentale Puglia e Basilicata;
Dipartimento di Bioscienze, Biotecnologie e Biofarmaceutica dell'Università degli Studidi di Bari "A.Moro"; Istituto di
Biomembrane. Bioenergetica e Biotecnologie Molecolari del
Consiglio Nazionale delle Ricerche di Bari iftuto Zooprofilattico Sperimentale Puglia e Basilica

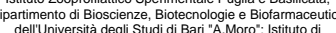
dell"Universita degli Studid di Bari "A.Moro"; Istituto di
Biomembrane. Bioenergetica e Biotecnologie Molecolari del Consiglio Nazionale delle Ricerche di Bari
Istituto Zooprofilattico Sperimentale Puglia e Basilicata;

Istituto Zooprofilattico Sperimentale Puglia e Basilicata;

Istituto Zooprofilattico Sperimentale Puglia e Basilicata; Prof. Massimo Zollo CEINGE TASK-FORCE COVID19 -

Laboratory of Molecular Virology of the International Centre for
Genetic Engineering and Biotechnology (ICGEB) aboratory of Molecular Virology of the International Centre for
Army Medical and Veterinary Research Center

Army Medical and Veterinary Research Center Laboratorio specialistico UOC Ematologia - Ospedale "San
Francesco" - ATS-ASSL Nuoro Laboratorio specialistico UOC Ematologia - Ospedale "San
Francesco" - ATS-ASSL Nuoro Laboratory of Virology, INMI Lazzaro Spallanzani IRCCS Laboratory of Virology, INMI Lazzaro Spallanzani IRCCS Laboratory of Virology, INMI Lazzaro Spallanzani IRCCS Laboratory of Virology, INMI Lazzaro Spallanzani IRCCS Laboratory of Virology, INMI Lazzaro Spallanzani IRCCS Laboratory of Virology, INMI Lazzaro Spallanzani IRCCS Laboratory of Virology, INMI Lazzaro Spallanzani IRCCS Laboratory of Virology, INMI Lazzaro Spallanzani IRCCS Laboratory of Virology, INMI Lazzaro Spallanzani IRCCS Laboratory of Virology, INMI Lazzaro Spallanzani IRCCS Laboratory of Virology, INMI Lazzaro Spallanzani IRCCS Laboratory of Virology, INMI Lazzaro Spallanzani IRCCS Laboratory of Virology, INMI Lazzaro Spallanzani IRCCS Laboratory of Virology, INMI Lazzaro Spallanzani IRCCS Laboratory of Virology, INMI Lazzaro Spallanzani IRCCS Laboratory of Virology, INMI Lazzaro Spallanzani IRCCS Laboratory of Virology, INMI Lazzaro Spallanzani IRCCS Beaconlab (Bioinformatics, Evolution and Comparative
Genomics lab), Dept of Biosciences. University on Milan Beaconlab (Bioinformatics, Evolution and Comparative
Genomics lab). Dept of Biosciences. University on Milan Beaconlab (Bioinformatics, Evolution and Comparative
Genomics lab), Dept of Biosciences, University on Mila Beaconlab (Bioinformatics, Evolution and Comparative

Beaconlab (Bioinformatics, Evolution and Comparative
Genomics lab), Dept of Biosciences, University on Mila Prof. Massimo Zollo CEINGE TASK-FORCE COVID19 Regione Campania

ARGO Open Lab Plattorm for Genome Sequencing ARGO Open Lab Plattorm for Genome Sequencing

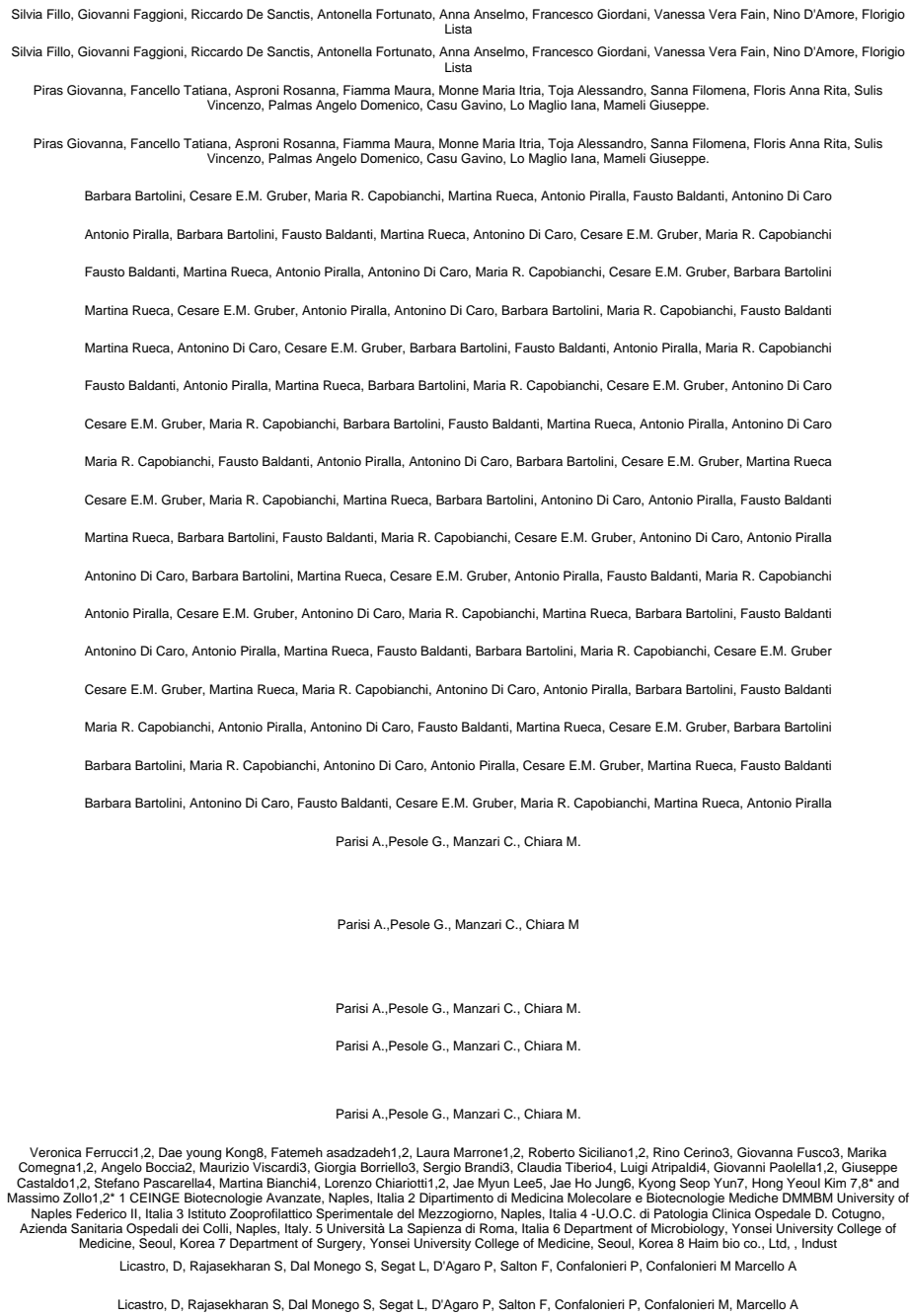


bioRxiv preprint doi: https://doi.org/10.1101/2021.07.21.452479; this version posted July 22, 2021. The copyright holder for this preprint (which was not certified by peer review) is the author/funder, who has granted bioRxiv a license to display the preprint in perpetuity. It is made available under aCC-BY 4.0 International license.

\begin{tabular}{|c|c|c|c|}
\hline EPI_ISL_486646 & $\begin{array}{l}\text { Microbiology, Virology and Biemergency Laboratory-ASST } \\
\text { FBF Sacco }\end{array}$ & $\begin{array}{l}\text { Microbiology, Virology and Biemergency Laboratory-ASST } \\
\text { FBF Sacco }\end{array}$ & Mancon A, Comandatore F, Romeri F, Micheli V, Rimoldi SG \\
\hline EPI_ISL_486650 & $\begin{array}{l}\text { Microbiology, Virology and Biemergency Laboratory-ASST } \\
\text { FBF Sacco }\end{array}$ & $\begin{array}{l}\text { Microbiology, Virology and Biemergency Laboratory-ASST } \\
\text { FBF Sacco }\end{array}$ & Romeri F, Comandatore F, Mancon A, Micheli V, Rimoldi SG \\
\hline EPI_ISL_486651 & $\begin{array}{l}\text { Microbiology, Virology and Biemergency Laboratory-ASST } \\
\text { FBF Sacco }\end{array}$ & $\begin{array}{l}\text { Microbiology, Virology and Biemergency Laboratory-ASST } \\
\text { FBF Sacco }\end{array}$ & Mancon A, Comandatore F, Romeri F, Micheli V, Rimoldi SG \\
\hline EPI_ISL_486652 & $\begin{array}{l}\text { Microbiology, Virology and Biemergency Laboratory-ASST } \\
\text { FBF Sacco }\end{array}$ & $\begin{array}{l}\text { Microbiology, Virology and Biemergency Laboratory-ASST } \\
\text { FBF Sacco }\end{array}$ & Micheli V, Comandatore F, Romeri F, Mancon A, Rimoldi SG \\
\hline EPI_ISL_486653 & $\begin{array}{l}\text { Microbiology, Virology and Biemergency Laboratory-ASST } \\
\text { FBF Sacco }\end{array}$ & $\begin{array}{l}\text { Microbiology, Virology and Biemergency Laboratory-ASST } \\
\text { FBF Sacco }\end{array}$ & Rimoldi SG, Comandatore F, Romeri F, Mancon A, Micheli V \\
\hline EPI_ISL_486655 & $\begin{array}{l}\text { Microbiology, Virology and Biemergency Laboratory-ASST } \\
\text { FBF Sacco }\end{array}$ & $\begin{array}{l}\text { Microbiology, Virology and Biemergency Laboratory-ASST } \\
\text { FBF Sacco }\end{array}$ & Mancon A, Comandatore F, Romeri F, Micheli V, Rimoldi SG \\
\hline EPI_ISL_486657 & $\begin{array}{l}\text { Microbiology, Virology and Biemergency Laboratory-ASST } \\
\text { FBF Sacco }\end{array}$ & $\begin{array}{l}\text { Microbiology, Virology and Biemergency Laboratory-ASST } \\
\text { FBF Sacco }\end{array}$ & Rimoldi SG, Comandatore F, Romeri F, Mancon A, Micheli V \\
\hline EPI_ISL_486658 & $\begin{array}{l}\text { Microbiology, Virology and Biemergency Laboratory-ASST } \\
\text { FBF Sacco }\end{array}$ & $\begin{array}{l}\text { Microbiology, Virology and Biemergency Laboratory-ASST } \\
\text { FBF Sacco }\end{array}$ & Romeri F, Comandatore F, Mancon A, Micheli V, Rimoldi SG \\
\hline EPI_ISL_486659 & $\begin{array}{l}\text { Microbiology, Virology and Biemergency Laboratory-ASST } \\
\text { FBF Sacco }\end{array}$ & $\begin{array}{l}\text { Microbiology, Virology and Biemergency Laboratory-ASST } \\
\text { FBF Sacco }\end{array}$ & Micheli V, Comandatore F, Romeri F, Mancon A, Rimoldi SG \\
\hline EPI_ISL_486660 & $\begin{array}{l}\text { Microbiology, Virology and Biemergency Laboratory-ASST } \\
\text { FBF Sacco }\end{array}$ & $\begin{array}{l}\text { Microbiology, Virology and Biemergency Laboratory-ASST } \\
\text { FBF Sacco }\end{array}$ & Rimoldi SG, Comandatore F, Romeri F, Mancon A, Micheli V \\
\hline EPI_ISL_486662 & $\begin{array}{l}\text { Microbiology, Virology and Biemergency Laboratory-ASST } \\
\text { FBF Sacco }\end{array}$ & $\begin{array}{l}\text { Microbiology, Virology and Biemergency Laboratory-ASST } \\
\text { FBF Sacco }\end{array}$ & Mancon A, Comandatore F, Romeri F, Micheli V, Rimoldi SG \\
\hline EPI_ISL_486663 & $\begin{array}{l}\text { Microbiology, Virology and Biemergency Laboratory-ASST } \\
\text { FBF Sacco }\end{array}$ & $\begin{array}{l}\text { Microbiology, Virology and Biemergency Laboratory-ASST } \\
\text { FBF Sacco }\end{array}$ & Micheli V, Comandatore F, Romeri F, Mancon A, Rimoldi SG \\
\hline EPI_ISL_486664 & $\begin{array}{l}\text { Microbiology, Virology and Biemergency Laboratory-ASST } \\
\text { FBF Sacco }\end{array}$ & $\begin{array}{l}\text { Microbiology, Virology and Biemergency Laboratory-ASST } \\
\text { FBF Sacco }\end{array}$ & Rimoldi SG, Comandatore F, Romeri F, Mancon A, Micheli V \\
\hline EPI_ISL_486665 & $\begin{array}{l}\text { Microbiology, Virology and Biemergency Laboratory-ASST } \\
\text { FBF Sacco }\end{array}$ & $\begin{array}{l}\text { Microbiology, Virology and Biemergency Laboratory-ASST } \\
\text { FBF Sacco }\end{array}$ & Micheli V, Rimoldi SG, Comandatore F, Mancon A, Romeri F \\
\hline EPI_ISL_487276 & $\begin{array}{l}\text { Department of Food Safety, Nutrition and Veterinary public } \\
\text { health, Istituto Superiore di Sanita' }\end{array}$ & $\begin{array}{l}\text { Department of Biomedical, Surgical and Dental Sciences and } \\
\text { Department of Biomedical Sciences for Health }\end{array}$ & Delbue,S., Ferrante,P., Basilico,N., Parapini,S., Binda,S., D'Alessandro,S., Galli,C., Signorini,L., Primache,V., Anselmi,G., Pariani,E. \\
\hline 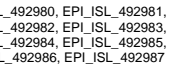 & $\begin{array}{l}\text { IRCCS Sacro Cuore Don Calabria Hospital, Department of } \\
\text { Infectious, Tropical Diseases \& Microbiology }\end{array}$ & University of Verona, Department of Biotechnology & $\begin{array}{l}\text { Antonio Mori, Michela Deiana, Elena Pomari, Chiara Piubelli; Giulia Lopatriello, Luca Marcolungo, Cristina Beltrami, Chiara Degli Esposti, Emanuela } \\
\text { Cosentino, Massimo Delledonne }\end{array}$ \\
\hline EPI_ISL_493328 & INMI Lazzaro Spallanzani IRCCS & INMI Lazzaro Spallanzani IRCCS & Martina Rueca, Cesare E.M. Gruber, Barbara Bartolini, Francesco Messina, Maria R. Capobianchi, Antonino Di Caro \\
\hline EPI_ISL_493329 & INMI Lazzaro Spallanzani IRCCS & INMI Lazzaro Spallanzani IRCCS & Barbara Bartolini, Martina Rueca, Cesare E.M. Gruber, Francesco Messina, Antonino Di Caro, Maria R. Capobianchi \\
\hline EPI_ISL_493330 & INMI Lazzaro Spallanzani IRCCS & INMI Lazzaro Spallanzani IRCCS & Cesare E.M. Gruber, Martina Rueca, Barbara Bartolini, Francesco Messina, Maria R. Capobianchi, Antonino Di Caro \\
\hline EPI_ISL_493331 & INMI Lazzaro Spallanzani IRCCS & INMI Lazzaro Spallanzani IRCCS & Martina Rueca, Cesare E.M. Gruber, Barbara Bartolini, Francesco Messina, Maria R. Capobianchi, Antonino Di Caro \\
\hline EPI_ISL_493332 & Istituto Zooprofilattico Sperimentale del Mezzogiorno & INMI Lazzaro Spallanzani IRCCS & $\begin{array}{l}\text { Cesare E.M. Gruber, Martina Rueca, Barbara Bartolini, Francesco Messina, Antonino Di Caro, Giovanna Fusco, Maurizio Viscardi, Giorgia Borriello, Maria } \\
\text { R. Capobianchi }\end{array}$ \\
\hline EPI_ISL_493333 & Istituto Zooprofilattico Sperimentale del Mezzogiorno & INMI Lazzaro Spallanzani IRCCS & $\begin{array}{l}\text { Barbara Bartolini, Martina Rueca, Cesare E.M. Gruber, Francesco Messina, Antonino Di Caro, Giovanna Fusco, Maurizio Viscardi, Giorgia Borriello, Maria } \\
\text { R. Capobianchi }\end{array}$ \\
\hline EPI_ISL_496482 & $\begin{array}{l}\text { Dept. Infectious, Tropical Diseases \& Microbiology, IRCCS } \\
\text { Sacro Cuore Don Calabria Hospital }\end{array}$ & $\begin{array}{l}\text { 1) Dept. Infectious, Tropical Diseases \& Microbiology, IRCCS } \\
\text { Sacro Cuore Don Calabria Hospital; 2) Centro Piattaforme } \\
\text { Tecrologioge, University of Verona; 3) Dept. Neurosciences, } \\
\text { Biomedicine and Movement Sciences, University of Verona. }\end{array}$ & 1) Antonio Mori, Michela Deiana, Elena Pomari, Chiara Piubelli; 2) Monica Castellucci and Francesca Griggio; 3) Giovanni Malerba \\
\hline EPI_ISL_514432 & $\begin{array}{l}\text { Prof. Massimo Zollo CEINGE TASK-FORCE COVID19 - } \\
\text { Regione Campania }\end{array}$ & $\begin{array}{l}\text { Prof. Massimo Zollo CEINGE TASK-FORCE COVID19 - } \\
\text { Regione Campania }\end{array}$ & 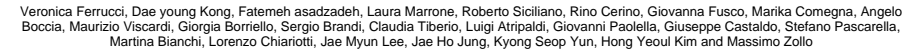 \\
\hline EPI_ISL_514751 & $\begin{array}{l}\text { CoronaNet Lab- TaskForce Regione Campania, CEINGE } \\
\text { Biotecnologie Avanzate, Via G. Salvatore }\end{array}$ & $\begin{array}{l}\text { CoronaNet Lab- TaskForce Regione Campania, CEINGE } \\
\text { Biotecnologie Avanzate, Via G. Salvatore }\end{array}$ & 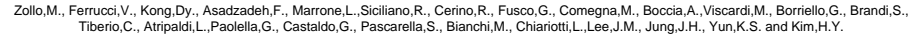 \\
\hline 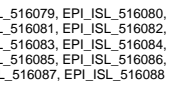 & $\begin{array}{l}\text { Biomedical Sciences and Public Health, Polytechnic University } \\
\text { of Marche }\end{array}$ & $\begin{array}{l}\text { Biomedical Sciences and Public Health, Polytechnic University } \\
\text { of Marche }\end{array}$ & Bagnarelli,P., Caucci,S., Di Sante,L., Menzo,S., Alessandrini,F., Onofri,V., Turchi,C., Melchionda,F., Tagliabracci,A. \\
\hline EPI_ISL_522855 & ULSS9 Distretto di Bussolengo & Istituto Zooprofilattico Sperimentale delle Venezie & $\begin{array}{l}\text { Adelaide Milani, Alessia Schivo, Annalisa Salviato, Erika Giorgia Quaranta, Ambra Pastori, Bianca Zecchin, Alice Fusaro, Isabella Monne, Calogero } \\
\text { Terregino, Antonia Ricci }\end{array}$ \\
\hline EPI_ISL_522856 & ULSS9 Distretto di San Bonifacio & Istituto Zooprofilattico Sperimentale delle Venezie & $\begin{array}{l}\text { Adelaide Milani, Alessia Schivo, Annalisa Salviato, Erika Giorgia Quaranta, Ambra Pastori, Bianca Zecchin, Alice Fusaro, Isabella Monne, Calogero } \\
\text { Terregino, Antonia Ricci }\end{array}$ \\
\hline EPI_ISL_522857 & ULSS9 Scaligera & Istituto Zooprofilattico Sperimentale delle Venezie & $\begin{array}{l}\text { Adelaide Milani, Alessia Schivo, Annalisa Salviato, Erika Giorgia Quaranta, Ambra Pastori, Bianca Zecchin, Alice Fusaro, Isabella Monne, Calogero } \\
\text { Terregino, Antonia Ricci }\end{array}$ \\
\hline EPI_ISL_522858 & ULSS9 Distretto di San Bonifacio & Istituto Zooprofilattico Sperimentale delle Venezie & $\begin{array}{l}\text { Adelaide Milani, Alessia Schivo, Annalisa Salviato, Erika Giorgia Quaranta, Ambra Pastori, Bianca Zecchin, Alice Fusaro, Isabella Monne, Calogero } \\
\text { Terregino, Antonia Ricci }\end{array}$ \\
\hline EPI_ISL_522859 & ULSS9 Scaligera & Istituto Zooprofilattico Sperimentale delle Venezie & $\begin{array}{c}\text { Adelaide Milani, Alessia Schivo, Annalisa Salviato, Erika Giorgia Quaranta, Ambra Pastori, Bianca Zecchin, Alice Fusaro, Isabella Monne, Calogero } \\
\text { Terregino, Antonia Ricci }\end{array}$ \\
\hline 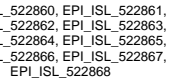 & ULSS9 Distretto di Bussolengo & Istituto Zooprofilattico Sperimentale delle Venezie & $\begin{array}{l}\text { Adelaide Milani, Alessia Schivo, Annalisa Salviato, Erika Giorgia Quaranta, Ambra Pastori, Bianca Zecchin, Alice Fusaro, Isabella Monne, Calogero } \\
\text { Terregino, Antonia Ricci }\end{array}$ \\
\hline
\end{tabular}


bioRxiv preprint doi: https://doi.org/10.1101/2021.07.21.452479; this version posted July 22, 2021. The copyright holder for this preprint (which was not certified by peer review) is the author/funder, who has granted bioRxiv a license to display the preprint in perpetuity. It is made available under aCC-BY 4.0 International license.

EPI_ISL_525572, EPI_ISL_525573, EPI_ISL_525574, EPI_ISL_527380 see above Istituto Zooprofilattico Sperimentale Puglia e Basilicata;
Dipartimento di Bioscienze, Biotecnologie e Biofarmaceutica Dipartimento di Bioscienze, Biotecnologie e Biofarmaceutica
dell'Università degli Studid di Bari "A.Moro"; Istituto di
Biomembrane. Bioenergetica e Biotecnologie Molecoldi

EPI_ISL_528919

EPI_ISL_528920, EPI_ISL_528921

EPI_ISL_528922, EPI_ISL_528924 EPI_ISL_528925

EPI_ISL_528926, EPI_ISL_528927,
EPI_ISL_528928 EPI_ISL_528929

$$
\begin{aligned}
& \text { Ospedale Civile S. Liberatore-Atri } \\
& \text { This }
\end{aligned}
$$

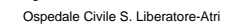

Presidio Ospedaliero "Santo Spirito"-Pescara

Ospedale "Giuseppe Mazzini"-Teramo

Ospedale Regionale San Salvatore-L'Aquila

Ospedale "Giuseppe Mazzini"-Teramo

Ospedale Civile S. Liberatore-Atri
Beaconlab (Bioinformatics, Evolution and Comparative
Genomics lab), Dept of Biosciences, University on Milan

Istitituto Zooprofilattico Sperimentale dell'Abruzzo e Molise
"G.Caporale"
Istitituto Zooprofilattico Sperimentale dell'Abruzzo e Molise
"G.Caporale"
Istititutu Zooprofiliattico Sperimentale dell'Abruzzo e Molise
"G.Caporale"
Istitituto Zooprofilattico Sperimentale dell'Abruzzo e Molise
"G.Caporale"
Istititituto Zooprofilattico Sperimentale dell'Abruzzo e Molise
"G.Caporale"
Istititutu Zooprofilattico Sperimentale dell'Abruzzo e Molise
"G.Caporale"

EPI_SSL_528934, EPI_ISL_528935, EPI_ISL_528936, EPI_ISL_528937, EPI_ISL_528938, EPI_ISL_528939, EPP see above Agenzia di Tutela della Salute di Bergamo

EPI_ISL_528990

Ospedale Civile Maria SS. dello Splendore

EPI_ISL_528991

Ospedale SS Annunziata-Sulmona

EPI_ISL_528993

Ospedale Civile S. Liberatore-Atri

L_528940, EPI_ISL_528941, EPI_ISL_528943, EPI _ISL_52 Istitituto Zooprofilattico Sperimentale dell'Abruzzo e Molise
"G.Caporale"

Istitituto Zooprofilattico Sperimentale dell'Abruzzo e Molise Istitituto Zooprofilattico Sperimentale dell'Abruzzo e Molise
"G.Caporale" Istitituto Zooprofilattico Sperimentale dell'Abruzzo e Molise
"G.Caporale"

EPI_ISL_528994, EPI_ISL_528995, EPI_ISL_528996, EPI_ISL_528997, EPI_ISL_528998, EPI_ISL_528999, EPI_ISL_529000, EPI_ISL_529001, EPI_ISL_529003, EPI_ISL_529004, EPI_ISL_529005

see above

Servizio di igiene epidemiologia e sanità pubblica
(SIESP)-Chieti

Istitituto Zooprofilattico Sperimentale dell'Abruzzo e Molise
"G.Caporale"

Istitituto Zooprofilattico Sperimentale dell'Abruzzo e Molise
"G.Caporale"

Istitituto Zooprofilattico Sperimentale dell'Abruzzo e Molise

Ospedale SS Annunziata-Sulmona

EPI_ISL_529016

Ospedale "Giuseppe Mazzini"-Teramo

EPI_ISL_529018

RSA/RP Villa San Giovanni - Gruppo Edos

Istitituto Zooprofilattico Sperimentale dell'Abruzzo e Molise
"G.Caporale"

Istitituto Zooprofilattico Sperimentale dell'Abruzzo e Molise
"G.Caporale"

Istitituto Zooprofilattico Sperimentale dell'Abruzzo e Molise
"G.Caporale"
Ospedale Civile S. Liberatore-Atri
PPI_ISL_529020, EPI_ISL_529021
Ospedale "Ss. Annunziata"

EPIIL 529026

Ospedale "Giuseppe Mazzini"-Teramo

Lorusso A, Marcacci M, Di Domenico M, Curini V, Ancora M, Cammà C, Rinaldi A, Mangone I, Di Pasquale A, Puglia I, Savini G. Lorusso A, Marcacci M, Di Domenico M, Curini V, Ancora M, Cammà C, Rinaldi A, Mangone I, Di Pasquale A, Puglia I, Savini G. Lorusso A, Marcacci M, Di Domenico M, Curini V, Ancora M, Cammà C, Rinaldi A, Mangone I, Di Pasquale A, Puglia I, Savini G. Lorusso A, Marcacci M, Di Domenico M, Curini V, Ancora M, Cammà C, Rinaldi A, Mangone I, Di Pasquale A, Puglia I, Savini G. Lorusso A, Marcacci M, Di Domenico M, Curini V, Ancora M, Cammà C, Rinaldi A, Mangone I, Di Pasquale A, Puglia I, Savini G. Lorusso A, Marcacci M, Di Domenico M, Curini V, Ancora M, Cammà C, Rinaldi A, Mangone I, Di Pasquale A, Puglia I, Savini G. SL_528945, EPI_ISL_528946, EPI_ISL_528947, EPI_ISL_528948, EPI_ISL_528949 Lorusso A, Marcacci M, Di Domenico M, Curini V, Ancora M, Cammà C, Rinaldi A, Mangone I, Di Pasquale A, Puglia I, Savini G. Lorusso A, Marcacci M, Di Domenico M, Curini V, Ancora M, Cammà C, Rinaldi A, Mangone I, Di Pasquale A, Puglia I, Savini G. Lorusso A, Marcacci M, Di Domenico M, Curini V, Ancora M, Cammà C, Rinaldi A, Mangone I, Di Pasquale A, Puglia I, Savini G. Lorusso A, Marcacci M, Di Domenico M, Curini V, Ancora M, Cammà C, Rinaldi A, Mangone I, Di Pasquale A, Puglia I, Savini G.
Lorusso A, Marcacci M, Di Domenico M, Curini V, Ancora M, Cammà C, Rinaldi A, Mangone I, Di Pasquale A, Puglia I, Savini G. Lorusso A, Marcacci M, Di Domenico M, Curini V, Ancora M, Cammà C, Rinaldi A, Mangone I, Di Pasquale A, Puglia I, Savini G. Lorusso A, Marcacci M, Di Domenico M, Curini V, Ancora M, Cammà C, Rinaldi A, Mangone I, Di Pasquale A, Puglia I, Savini G. Lorusso A, Marcacci M, Di Domenico M, Curini V, Ancora M, Cammà C, Rinaldi A, Mangone I, Di Pasquale A, Puglia I, Savini G. Lorusso A, Marcacci M, Di Domenico M, Curini V, Ancora M, Cammà C, Rinaldi A, Mangone I, Di Pasquale A, Puglia I, Savini G. Lorusso A, Marcacci M, Di Domenico M, Curini V, Ancora M, Cammà C, Rinaldi A, Mangone I, Di Pasquale A, Puglia I, Savini G. Lorusso A, Marcacci M, Di Domenico M, Curini V, Ancora M, Cammà C, Rinaldi A, Mangone I, Di Pasquale A, Puglia I, Savini G. Lorusso A, Marcacci M, Di Domenico M, Curini V, Ancora M, Cammà C, Rinaldi A, Mangone I, Di Pasquale A, Puglia I, Savini G.

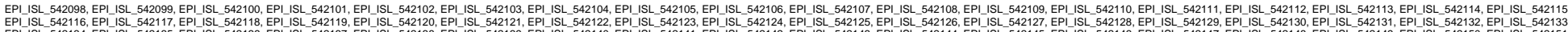

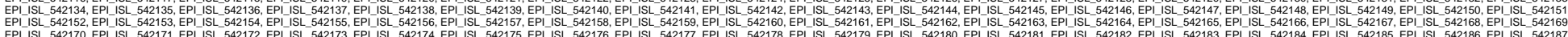

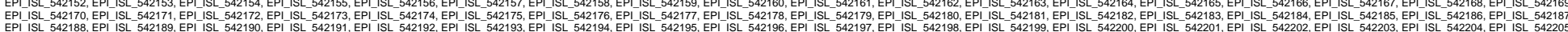

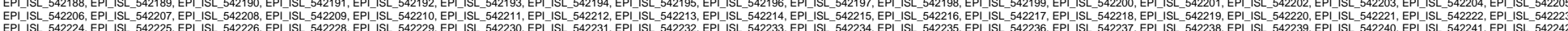

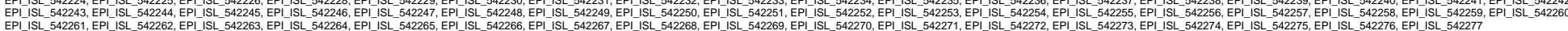
(1) ASST GOM Niguarda

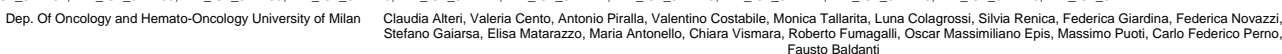

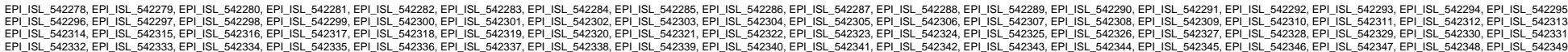

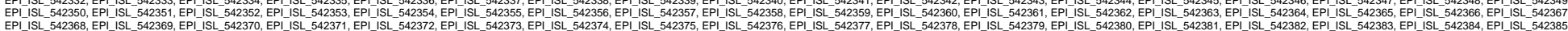

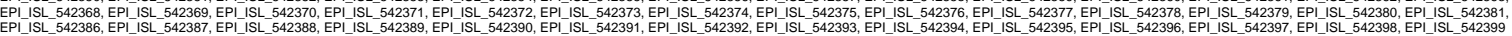
see San Matteo Hospital Pavia

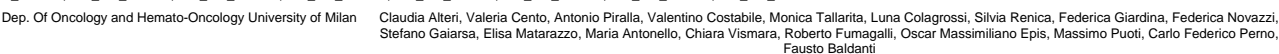

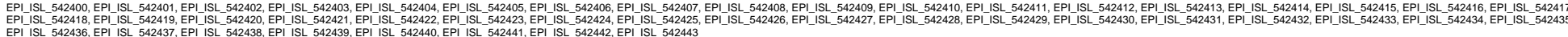


bioRxiv preprint doi: https://doi.org/10.1101/2021.07.21.452479; this version posted July 22, 2021. The copyright holder for this preprint (which was not certified by peer review) is the author/funder, who has granted bioRxiv a license to display the preprint in perpetuity. It is made available under aCC-BY 4.0 International license.

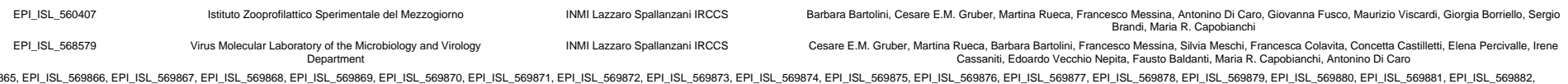

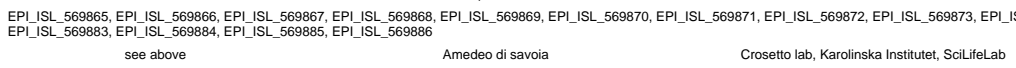
see above
EPI_ISL_572324

EPI_ISL 582123, EPIIISL 583954,
EPIIISL-583955, EPI_ISL_583958,

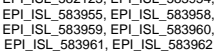

EPI_ISL_584048

EPI_ISL_584049

EPI_ISL_584051

EPI_ISL_584052

EPIISL 591327, EPIISL 591328,
EPI-ISL-591331, EPIISLL 591332,

LISL_591333, EPIIISL-59
EPLISL_591335

EPI_ISL_591335

EPI_ISL6003177

EPI_ISL6603178

EPI_ISL_603179

EPI_ISL_603180

EPI_ISL_603181

EPI_ISL_603182

EPI_ISL_603183

EPI_ISL_603184

EPI_ISL_603185

EPI_ISL_603186

EPI_ISL_603187

EPI_ISL_613560

EPIIISL 613706, EPI ISL_613953,

EPIISL_613955, EPIIIIL-614396
EPI_ISL_614397,EPIIIL-614398,

IIISL_636462, EPI_ISL_636463

EPI_ISL_636464

EPI_ISL_636467, EPI_ISL_636468,
EPI_ISL_636469, EPI_ISL_636470

EPI_ISL_636471, EPIISL_636472,
EPI_ISL 636473

EPI_ISL_636474, EPI_ISL_636475

EPI_ISL_636488

EPI_ISL_637108, EPI_ISL_637109

EPI_ISL_649189

EPI_ISL_653813

EPIISL 653814, EPIIISL653815
EPI_ISL-6538516. EPIISL-653817

EPI_ISL_738147,6PIIISL_738194,
EPI_ISL_738243
Microbiologia e Virologia, Azienda Ospedaliera
Universitaria Senese, Siena, ttaly

Laboratory of Molecular Virology, Department of Biomedical
Surgical and Dental Sciences University of Milano

Laboratory of Molecular Virology, Department of Biomedical
Surgical and Dental Sciences University of Milano

Laboratory of Molecular Virology, Department of Biomedical
Surgical and Dental Sciences University of Milano

Laboratory of Molecular Virology, Department of Biomedical
Surgical and Dental Sciences University of Milano

Dipartimento di Biotecnologie Mediche, University of Sien
IZSM
IZSM
Dipartimento di Biotecnologie Mediche

Laboratory of Molecular Virology, Department of Biomedical,
Surgical and Dental Sciences University of Milano

aboratory of Molecular Virology, Department of Biomedica,
Surgical and Dental Sciences University of Milano

Surgical and Dental Sciences University of Milano
boratory of Molecular Virology, Department of Biomedical
Surgical and Dental Sciences University of Milano

Suratory of Molecular Virology, Department of Biomedical
Sund Dental Sciences University of Milano

Dipartimento di Biotecnologie Mediche, University of Siena

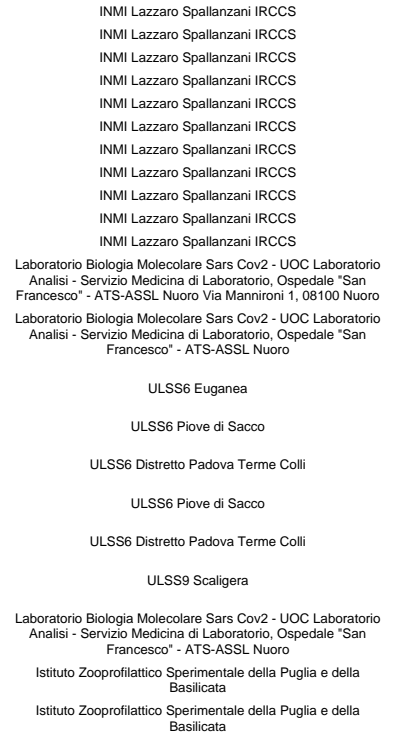

I.R.C.C.S. "S. De Bellis" - Ente Ospedaliero

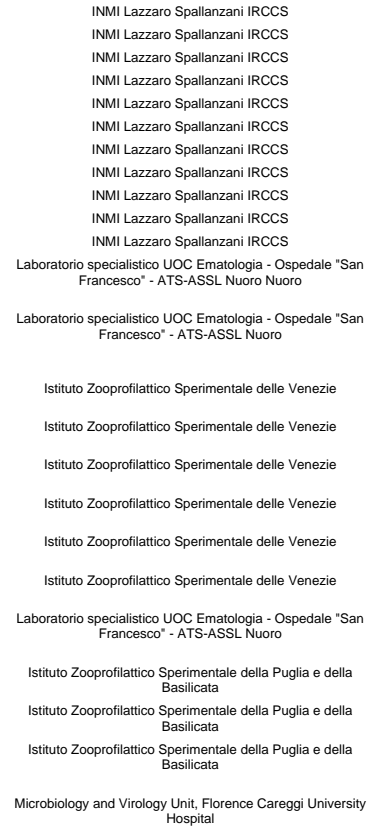

Michele Simonetti, Maria Grazia Milia, Luuk Harbers, Ning Zhang, Anna Sapino, Valeria Ghisetti, Nicola Crosetto Maurizio Viscardi, Lorena Cardillo, Giovanna Fusco
Delbue,S., Modenese,A., Bianchi,M., Fattori,M., D'Alessandro,S., Pariani,E., Basilico,N., Galli,C. and Ferrante,P.

Delbue,S., Modenese,A., Bianchi,M., Fattori,M., D'Alessandro,S.,Pariani,E., Basilico,N., Galli,C. and Ferrante,P.

Delbue,S., Ferrante,P., Basilico,N., Parapini,S., Binda,S., D'Alessandro,S., Galli,C., Signorini,L., Primache,V., Anselmi,G. and Pariani,E

Delbue,S., D'Alessandro,S., Modenese,A., Signorini,L., Parapini,S.,Dolci,M., Binda,S., Primache,V., Taramelli,D., Incorvaia,B. and Ferrante,P.

Cusi,M.G., Pinzauti,D., Gandolfo,C., Anichini,G., Pozzi,G., Santoro,F.
Barbara Bartolini, Francesco Messina, Emanuela Giombini, Martina Rueca, Cesare E.M. Gruber, Simone Lanini, Maria R. Capobianchi, Antonino Di Caro Martina Rueca, Francesco Messina, Cesare E.M. Gruber, Barbara Bartolini, Simone Lanini, Emanuela Giombini, Antonino Di Caro, Maria R. Capobianchi Cesare E.M. Gruber, Barbara Bartolini, Francesco Messina, Martina Rueca, Emanuela Giombini, Simone Lanini, Antonino Di Caro, Maria R. Capobianchi Barbara Bartolini, Cesare E.M. Gruber, Francesco Messina, Simone Lanini, Martina Rueca, Emanuela Giombini, Maria R. Capobianchi, Antonino Di Caro Francesco Messina, Cesare E.M. Gruber, Barbara Bartolini, Martina Rueca, Simone Lanini, Emanuela Giombini, Maria R. Capobianchi, Antonino Di Caro Martina Rueca, Barbara Bartolini, Cesare E.M. Gruber, Francesco Messina, Emanuela Giombini, Simone Laninin, Maria R. Capobianchi, Antonino Di Caro arbara Bartolini, Francesco Messina, Martina Rueca, Cesare E.M. Gruber, Emanuela Giombini, Simone Lanini, Maria R. Capobianchi, Antonino Di Caro Barbara Bartolini, Francesco Messina, Martina Rueca, Cesare E.M. Gruber, Emanuela Giombini, Simone Lanini, Maria R. Capobianchi, Antonino Di Caro
Martina Rueca, Barbara Bartolini, Francesco Messina, Cesare E.M. Gruber, Emanuela Giombini, Simone Lanini, Maria R. Capobianchi, Antonino Di Caro Martina Rueca, Barbara Bartolini, Francesco Messina, Cesare E.M. Gruber, Emanuela Giombini, Simone Lanini, Maria R. Capobianchi, Antonino Di Caro Cesare E.M. Gruber, Martina Rueca, Barbara Bartolini, Francesco Messina, Simone Lanini, Emanuela Giombini, Maria R. Capobianchi, Antonino Di Caro
Erancesco Messina, Martina Rueca, Barbara Bartolini, Cesare E.M. Gruber, Emanuela Giombini, Simone Lanini, Maria R. Capobianchi, Antonino Di Caro Francesco Messina, Martina Rueca, Barbara Bartolini, Cesare E.M. Gruber, Emanuela Giombini, Simone Lanini, Maria R. Capobianchi, Antonino Di Caro
Cesare E.M. Gruber, Martina Rueca, Francesco Messina, Barbara Bartolini, Simone Lanini, Emanuela Giombini, Antonino Di Caro, Maria R. Capobianchi Piras Giovanna, Fancello Tatiana, Asproni Rosanna, Fiamma Maura, Monne Maria Itria, Toja Alessandro, Sanna Filomena, Floris Anna Rita, Sulis Piras Giovanna, Fancello Tatiana, Asproni Rosanna, Fiamma Maura, Monne Maria Itria, Toja Alessandro, Sanna Filomena, Floris Anna Rita, Sulis
Vincenzo, Palmas Angelo Domenico, Casu Gavino, Lo Maglio lana, Mameli Giuseppe

Adelaide Milani, Alessia Schivo, Annalisa Salviato, Erika Giorgia Quaranta, Ambra Pastori, Bianca Zecchin, Alice Fusaro, Isabella Monne, Calogero Adelaide Milani, Alessia Schivo, Annalisa Salviato, Erika Giorgia Quaranta, Ambra Pastori, Bianca Zecchin, Alice Fusaro, Isabella Monne, Calogero Adelaide Milani, Alessia Schivo, Annalisa Salviato, Erika Giorgia Quaranta, Ambra Pastori, Bianca Zecchin, Alice Fusaro, Isabella Monne, Calogero Adelaide Milani, Alessia Schivo, Annalisa Salviato, Erika Giorgia Quaranta, Ambra Pastori, Bianca Zecchin, Alice Fusaro, Isabella Monne, Calogero Adelaide Milani, Alessia Schivo, Annalisa Salviato, Erika Giorgia Quaranta, Ambra Pastori, Bianca Zecchin, Alice Fusaro, Isabella Monne, Calogero Adelaide Milani, Alessia Schivo, Annalisa Salviato, Erika Giorgia Quaranta, Ambra Pastori, Bianca Zecchin, Alice Fusaro, Isabella Monne, Calogero Piras Giovanna, Fancello Tatiana, Asproni Rosanna, Fiamma Maura, Monne Maria ltria, Toja Alessandro, Sanna Filomena, Floris Anna Rita, Sulis
Vincenzo, Palmas Angelo Domenico, Casu Gavino, Lo Maglio lana, Mameli Giuseppe Parisi A., Bianco A., Capozzi L., Del Sambro L., Manzulli V, Rondinone V., Pace L., Galante D., Cipolletta D. Parisi A., Bianco A., Capozzi L., Del Sambro L., Manzulli V, Rondinone V., Pace L., Cipolletta D., Galante D. Parisi A., Bianco A., Capozzi L., Del Sambro L., Lippolis A., Notarnicola M., Cipolletta D., Galante D.

Vincenzo Di Pilato, Marco Coppi, Alberto Antonelli, Simona Pollini, Gian Maria Rossolini 
bioRxiv preprint doi: https://doi.org/10.1101/2021.07.21.452479; this version posted July 22, 2021. The copyright holder for this preprint (which was not certified by peer review) is the author/funder, who has granted bioRxiv a license to display the preprint in perpetuity. It is made available under aCC-BY 4.0 International license.

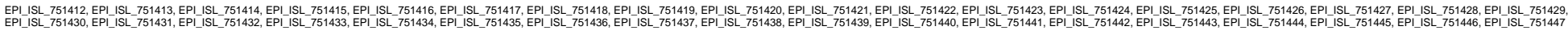

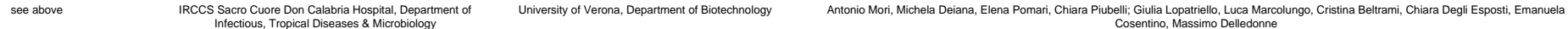
EPL_ISL_767043 EPI_ISL_775259 INT Fondazione Pascale
IN INT Fondazione Pascale Maria Chironna, Anna Sallustio, Daniela Loconsole, Marisa Accogli INT Fondazione Pascale

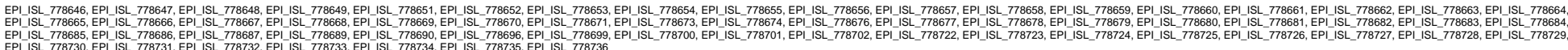
see above Istituto Zooprofilattico Sperimentale del Mezzogiorno

TIGEM

EPIIISL_779704, EPI_ISL_779709,

EPIIISL-779714, EPIIISL-780378,
EPIISL_-780381, EPI_ISL_780413

EPL_ISL_788944, EPL_ISL-788945,

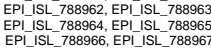
EPI_ISL_794745

\begin{abstract}
Laboratory of Infectious Diseases, Department of Biomed
and Clinical Sciences L. Sacco, University of Milan
\end{abstract}
Ospedale "Di Venere"
Istituto Zooprofilattico Sperimentale della Puglia e della Istrtuto Zooprofilattico Sperimentale della Puglia e della
Laboratory of Infectious Diseases, Department of Biomedical
and Clinical Sciences L. Sacco, University of Milan
Antonio Grimaldi, Patrizia Annunziata, Francesco Panariello, Biancamaria Pierri, Valentina Bouche, Chiara Colantuono, Maria Concetta Cuomo, Denise Di
Concilio, Lucio Di Filippo, Anna Mantredi, Marcello Salvi, Antonio Limone, Pellegrino Cerino, Andrea Ballabio, Davide Cacchiarelli. Alessia Lai, Annalisa Bergna, Carla Della Ventura, Claudia Balotta, Massimo Galli, Gianguglielmo Zehender on behalf of SARS-CoV-2 ITALIAN

lacobellis M, d'Avenia M, Piluscio R, Parisi A, Chiara M, Manzari C, Pesole G

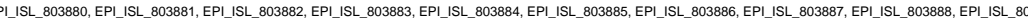

see above Department of Medical Biotechnologies, University of Siena $\begin{array}{r}\text { Laboratory of Infectious Diseases, Department of Biomedica } \\ \text { and Clinical Sciences L. Sacco, University of Milan }\end{array}$

EPL_ISL_812968

Department of Molecular Medicine, University of Padova Department of Molecular Medicine, University of Padova

991, EPI_ISL_803892, EPI_ISL_803893, EPL_ISL_803895

Parisi A., Bianco A., Capozzi L., Del Sambro L., Manzulli V, Rondinone V., Pace L., Cipolletta D., Galante D.

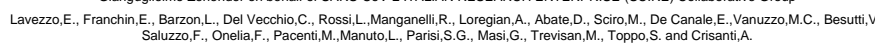

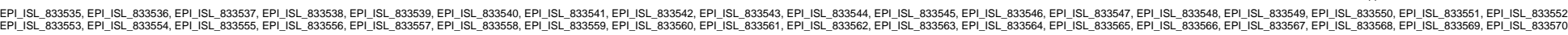

see above Istituto Zooprofilattico Sperimentale del Mezzogiorno

EPI_ISL_855550

EPI_ISL_855552

EPI_ISL_855553

EPI_ISL_855554, EPI_ISL_855555

EPI_ISL_856712, EPI_ISL_856716
EPI ISL 856721

EPIISL 856869

EPI_ISL_856870

EPI_ISL_856871

EPIISL_856872, EPIISL_856873,
EPI_ISL_856874, EPL_ISL_856875 EPI_ISL_856876

EPI_ISL_856877, EPI_ISL_856878

EPI_ISL_856879

EPI_ISL_856880

EPI_ISL_856881

EPI_ISL_856882

EPI_ISL_856883

EPI_ISL_856884
Department of Infectious Diseases, Istituto Superiore di
Sanità, Rome, Italy Department of Infectious Diseases, Istituto Superiore di
Sanita, Rome, Italy; Ospedali Riunnitit Laboratorio Virologia,
Ancona, Italy Department of Infectious Diseases, Istituto Superiore di
Sanità, Rome, Italy Department of Infectious Diseases, Istituto Superiore di
Sanita, Rome Itaty ASST G. OM. Niguarda, sezione Infectious Diseases Unit, Department of Internal Medici
Azienda Ospedaliera-Universitaria di Padova Virology Laboratory, Scientific Department, Army Medical
Center Virology Laboratory, Scientific Department, Army Medical
Center Department of Infectious Diseases, Istituto Superiore di
Sanitä, Roma, traly: AORN dei Colli, UOC Microbiologia Virology Laboratory, Scientific Department, Army Medical Virology Laboratory, Scientific Department, Army Medical
Center Virology Laboratory, Scientific Department, Army Medical
Center Virology Laboratory, Scientific Department, Army Medical
Center Department of Infectious Diseases, Istituto Superiore di
Sanitä, Roma, Italy; Ospedali Riunitit Laboratorio Virologia,

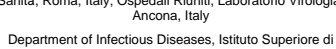
Department of Infectious Diseases, Istituto Superiore
Sanitä, Roma, Italy; Po Cardarelli, Laboratorio Analisi
Microbiologia e Virologia, Campobasso, titaly Virology Laboratory, Scientific Department, Army Medical Virology Laboratory, Scientific Department, Army Medical
Center Department of Infectious Diseases, Istituto Superiore di
Sanità, Roma, Italy; PO Santa Chiara, Microbiologia e
Virologia, Trento, Italy
TIGEM

Istituto Superiore di Sanità (ISS)

Istituto Superiore di Sanità (ISS)

Istituto Superiore di Sanità (ISS)

Istituto Superiore di Sanità (ISS)

Laboratory of Infectious Diseases, Department of Biomedical
and Clinical Sciences L. Sacco, University of Milan Virology Laboratory, Scientitic Virology Laboratory, Scientitic Department, Army Medical
Center Virology Laboratory, Scientific Department, Army Medical
Center Virology Laboratory, Scientific Department, Army Medical Virology Laboratory, Scientific Department, Army Medical
Center Virology Laboratory, Scientific Department, Army Medical Virology Laboratory, Scientitic Department, Army Medical Virology Laboratory, Scientific Department, Army Medical
Center Virology Laboratory, Scientific Department, Army Medical
Center Virology Laboratory, Scientific Department, Army Medical
Center Virology Laboratory, Scientific Department, Army Medical
Center Virology Laboratory, Scientific Department, Army Medical
Center Antonio Grimaldi, Patrizia Annunziata, Francesco Panariello, Biancamaria Pierri, Valentina Bouche, Chiara Colantuono, Maria Concetta Cuomo,
Concilio, Lucio Di Filippo, Anna Mantredi, Marcello Salvi, Antonio Limone, Pellegrino Cerino, Andrea Ballabio, Davide Cacchiarelli. Paola Stefanelli, Angela Di Martino, Alessandra Lo Presti, Stefano Fiore, Gabriele Vaccari, Luca De Sabato, llaria Di Bartolo, Giovanni laniro, Manuela
Marra, Maria Carollo, Marco Crescenzi Paola Stefanelli, Angela Di Martino, Alessandra Lo Presti, Stefano Fiore, Patrizia Bagnarelli, Gabriele Vaccari, Luca De Sabato, llaria Di Bartolo, Giovann

Paola Stefanelli, Angela Di Martino, Alessandra Lo Presti, Stefano Fiore, Gabriele Vaccari, Luca De Sabato, Ilaria Di Bartolo, Giovanni laniro, Manuela
Marra, Maria Carollo, Marco Crescenzi Paola Stefanelli, Angela Di Martino, Alessandra Lo Presti, Stefano Fiore, Carlo Federico Perno, Gabriele Vaccari, Luca De Sabato, llaria Di Bartolo,
Giovanni laniro, Manuela Marra, Maria Carollo, Marco Crescenzi Anna Maria Cattelan, Lolita Sasset, Davide Leoni, Alessia Lai, Annalisa Bergna, Carla Della Ventura, Claudia Balotta, Massimo Galli, Gianguglielmo
Zehender on behalf of SARS-CoV-2 ITALIAN RESEARCH ENTERPRISE-(SCCRE) Collaborative Group Silvia Fillo, Giovanni Faggioni, Riccardo De Sanctis, Antonella Fortunato, Anella Monte, Anna Anselmo, Vanessa Vera Fain, Francesco Giordani, Nino Silvia Fillo, Giovanni Faggioni, Riccardo De Sanctis, Antonella Fortunato, Anella Monte, Anna Anselmo, Vanessa Vera Fain, Francesco Giordani, Nino Paola Stefanelli, Angela Di Martino, Alessandra Lo Presti, Stefano Fiore, Luigi Atripaldi, Silvia Fillo, Giovanni Faggioni, Riccardo De Sanctis, Antonella
Fortunato, Anna Anselmo, Francesco Giordani, Vanessa Vera Fain, Nino D'Amore, Florigio Lista Silvia Fillo, Giovanni Faggioni, Riccardo De Sanctis, Antonella Fortunato, Anella Monte, Anna Anselmo, Vanessa Vera Fain, Francesco Giordani, Nino Silvia Fillo, Giovanni Faggioni, Riccardo De Sanctis, Antonella Fortunato, Anella Monte, Anna Anselmo, Vanessa Vera Fain, Francesco Giordani, Nino
D'Amore, Filippo Molinari, Giancarlo Petralito, Florigio Lista Silvia Fillo, Giovanni Faggioni, Riccardo De Sanctis, Antonella Fortunato, Anella Monte, Anna Anselmo, Vanessa Vera Fain, Francesco Giordani, Nino Silvia Fillo, Giovanni Faggioni, Riccardo De Sanctis, , Antonella arortunato, Anella Monte, Anna Anselmo, Vanessa Vera Fain, Francesco Giordani, Nino
D'Amore, Filippo Molinari, Giancarlo Petrallito, Florigio Lista Paola Stefanelli, Angela Di Martino, Alessandra Lo Presti, Stefano Fiore, Patrizia Bagnarelli, Silvia Fillo, Giovanni Faggioni, Riccardo De Sanctis, Antonella
Fortunato, Anna Anselmo, Francesco Giordani, Vanessa Vera Fain, Nino D'Amore, Florigio Lista

Paola Stefanelli, Angela Di Martino, Alessandra Lo Presti, Stefano Fiore, Massimiliano Scutellà, Silvia Fillo, Giovanni Faggioni, Riccardo De Sanctis,
Antonella Fortunato, Anna Anselmo, Francesco Giordani, Vanessa Vera Fain, Nino D'Amore, Florigio Lista Silvia Fillo, Giovanni Faggioni, Riccardo De Sanctis, Antonella Fortunato, Anella Monte, Anna Anselmo, Vanessa Vera Fain, Francesco Giordani, Nino
D'Amore, Filippo Molinari, Giancarlo Petralito, Florigio Lista Silvia Fillo, Giovanni Faggioni, Riccardo De Sanctis, Antonella Fortunato, Anella Monte, Anna Anselmo, Vanessa Vera Fain, Francesco Giordani, Nino
D'Amore, Filippo Molinari, Giancarlo Petralito, Florigio Lista Paola Stefanelli, Angela Di Martino, Alessandra Lo Presti, Stefano Fiore, Paolo Lanzafame, Silvia Fillo, Giovanni Faggioni, Riccardo De Sanctis, Antonella
Fortunato, Anna Anselmo, Francesco Giordani Vanessa Vera Fain, Nino D'Amore, Florigio Lista 
bioRxiv preprint doi: https://doi.org/10.1101/2021.07.21.452479; this version posted July 22, 2021. The copyright holder for this preprint (which was not certified by peer review) is the author/funder, who has granted bioRxiv a license to display the preprint in perpetuity. It is made available under aCC-BY 4.0 International license.

\begin{abstract}
EPI_ISL_856885
EPI_ISL_856886

EPI_ISL_856887

EPI_ISL_856888

EPI_ISL_856889

EPI_ISL_856890
\end{abstract}

EPI_ISL_856891, EPI_ISL_856892

EPI_ISL_856893, EPI_ISL_856894

EPL_ISL_856895, EPI_ISL_85689

EPI_ISL_856897

EPI_ISL_856898, EPI_ISL_856899

EPI_SL_856900, EPI_ISL_85690

EPI_ISL_856902

EPI_ISL_856903

EPI_ISL_856904

EPI_ISL_856905, EPI_ISL_856906

EPI_ISL_856907

EPI_ISL_856908

EPI_ISL_856909

EPP_ISL 872027, EPI_ISL_872028,

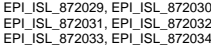

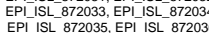

EPI_ISL_875674

EPI_ISL_876042, EPI ISL_876043

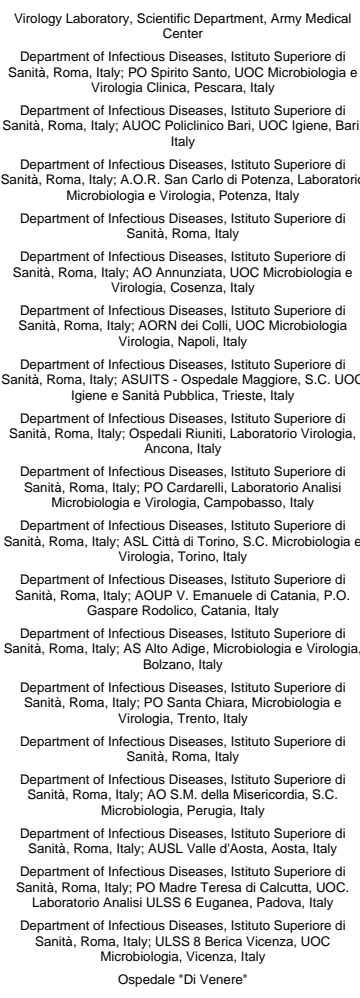

"1.AO Universitaria 'S. Giovanni di Dio e Ruggi D'Aragona
Scuola Medica Salernitana' Hospital / 2. UOC di Virologia Scuola Medica Salernitana' Hospital / 2. UOC di Virologia e
Microbiologia, Università della Campania 'L. Vanvitelli' 3 .AO
Universitaria 'Federico II' Napoli Hospital / 4 4.AORN 'San Giuseppe Moscati' Avellino Hospital / 5.AO 'San Pio - presidio
G. Rummo' Benevento Hospital / 6.AO 'Sant'Anna e San Sebastiano' Caserta Hospital / 7.PO 'Maria Santissima
Addolorata' Eboli Hospsital 8 .8iogem Istituto di Ricerche
Genetiche"

1.AO Universitaria 'S. Giovanni di Dio e Ruggi D'Aragona,
Scuola Medica Salernitana' Hospital / 2 . UOC di Virologia

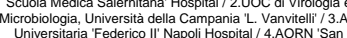

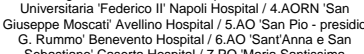
Sebastiano' Caserta Hospital/ 7.PO 'Maria Santissima
Addolorata' Eboli Hosppital 8 8. Biogem Istituto di Ricerche
Virology Laboratory, Scientific Department, Army Medical Center
Virology Laboratory, Scientific Department, Army Medical
Center Virology Laboratory, Scientific Department, Army Medical Virology Laboratory, Scientific Department, Army Medical
Center Virology Laboratory, Scientific Department, Army Medical Virology Laboratory, Scientific Department, Army Medical Virology Laboratory, Scientific Department, Army Medical
Center Virology Laboratory, Scientific Department, Army Medical
Center Virology Laboratory, Scientitic Department, Army Medical
Center

Virology Laboratory, Scientitic Department, Army Medical
Center Virology Laboratory, Scientific Department, Army Medical
Center Virology Laboratory, Scientitic Department, Army Medical
Center Virology Laboratory, Scientific Department, Army Medical

Virology Laboratory, Scientific Department, Army Medical
Center Virology Laboratory, Scientific Department, Army Medical Virology Laboratory, Scientific Department, Army Medical Virology Laboratory, Scientitic Department, Army Medical
Center Virology Laboratory, Scientific Department, Army Medical
Center Virology Laboratory, Scientific Department, Army Medical
Center Beaconlab (Bioinformatics, Evolution and Comparative
Genomics lab), Dept of Biosciences, University on Milan "1. Genome Research Center for Health (CRGS) / 2. oratory of Molecular Medicine and Genomics(LMMGe) /
Center for Research in Pure and Applied Mathematics
(CMMPA)"

1. Genome Research Center for Health (CRGS) / 2 . 1. Genome Research Center for Health (CRGS) $/ 2$.
boratory of Molecular Medicicie and Genomics(LMMGe) /
Center for Research in (ure and Applied Mathematics
(CRMPA)
Silvia Fillo, Giovanni Faggioni, Riccardo De Sanctis, Antonella Fortunato, Anella Monte, Anna Anselmo, Vanessa Vera Fain, Francesco Giordani, Nino
D'Amore, Filippo Molinari, Giancarlo Petralito, Florigio Lista Paola Stefanelli, Angela Di Martino, Alessandra Lo Presti, Stefano Fiore, Paolo Fazii, Silvia Fillo, Giovanni Faggioni, Riccardo De Sanctis, Antonella
Fortunato, Anna Anselmo, Francesco Giordani, Vanessa Vera Fain, Nino D'Amore, Florigio Lista Paola Stefanelli, Angela Di Martino, Alessandra Lo Presti, Stefano Fiore, Maria Chironna, Silvia Fillo, Giovanni Faggioni, Riccardo De Sanctis, Antonella
Fortunato, Anna Anselmo, Francesco Giordani, Yanessa Vera Fain, Nino D'Amore, Florigio Lista Paola Stefanelli, Angela Di Martino, Alessandra Lo Presti, Stefano Fiore, Antonio Picerno, Silvia Fillo, Giovanni Faggioni, Riccardo De Sanctis, Antonella
Fortunato, Anna Anselmo, Francesco Giordani, Vanessa Vera Fain, Nino D'Amore, Florigio Lista Paola Stefanelli, Angela Di Martino, Alessandra Lo Presti, Stefano Fiore, Silvia Fillo, Giovanni Faggioni, Riccardo De Sanctis, Antonella Fortunato, Anna Paola Stefanelli, Angela Di Martino, Alessandra Lo Presti, Stefano Fiore, Cristina Giraldi, Silvia Fillo, Giovanni Faggioni, Riccardo De Sanctis, Antonella
Fortunato, Anna Anselmo, Francesco Giordani, Vanessa Vera Fain, Nino D'Amore, Florigio Lista Paola Stefanelli, Angela Di Martino, Alessandra Lo Presti, Stefano Fiore, Luigi Atripaldi, Silvia Fillo, Giovanni Faggioni, Riccardo De Sanctis, Antonella
Fortunato, Anna Anselmo, Francesco Giordani, Vanessa Vera Fain, Nino D'Amore, Florigio Lista Paola Stefanelli, Angela Di Martino, Alessandra Lo Presti, Stefano Fiore, Pierlantranco D'Agaro, Silvia Fillo, Giovanni Faggioni, Riccardo De Sanctis,
Antonella Fortunato, Anna Anselmo, Francesco Giordani, Vanessa Vera Fain, Nino D'Amore, Florigio Lista Paola Stefanelli, Angela Di Martino, Alessandra Lo Presti, Stefano Fiore, Patrizia Bagnarelli, Silvia Fillo, Giovanni Faggioni, Riccardo De Sanctis, Antonella
Fortunato, Anna Anselmo, Francesco Giordani, Vanessa Vera Fain, Nino D'Amore, Florigio Lista Paola Stefanelli, Angela Di Martino, Alessandra Lo Presti, Stefano Fiore, Massimiliano Scutellà, Silvia Fillo, Giovanni Faggioni, Riccardo De Sanctis,
Antonella Fortunato, Anna Anselmo, Francesco Giordani, Vanessa Vera Fain, Nino D'Amore, Florigio Lista Paola Stefanelli, Angela Di Martino, Alessandra Lo Presti, Stefano Fiore, Valeria Ghisetti, Silvia Fillo, Giovanni Faggioni, Riccardo De Sanctis, Antonella
Fortunato, Anna Anselmo, Francesco Giordani, Vanessa Vera Fain, Nino D'Amore, Florigio Lista Paola Stefanelli, Angela Di Martino, Alessandra Lo Presti, Stetano Fiore, Guido Scalia, Silvia Fillo, Giovanni Faggioni, Riccardo De Sanctis, Antonella
Fortunato, Anna Anselmo, Francesco Giordani, Vanessa Vera Fain, Nino D'Amore, Florigio Lista Paola Stefanelli, Angela Di Martino, Alessandra Lo Presti, Stefano Fiore, Elisabetta Pagani, Silvia Fillo, Giovanni Faggioni, Riccardo De Sanctis, Antonella Paola Stefanelli, Angela Di Martino, Alessandra Lo Presti, Stefano Fiore, Paolo Lanzatame, Silvia Fillo, Giovanni Faggioni, Riccardo De Sanctis, Antonella
Fortunato, Anna Anselmo, Francesco Giordani, Vanessa Vera Fain, Nino D'Amore, Florigio Lista Paola Stefanelli, Angela Di Martino, Alessandra Lo Presti, Stefano Fiore, Silvia Fillo, Giovanni Faggioni, Riccardo De Sanctis, Antonella Fortunato, Anna Paola Stefanelli, Angela Di Martino, Alessandra Lo Presti, Stefano Fiore, Barbara Camilloni, Silvia Fillo, Giovanni Faggioni, Riccardo De Sanctis, Antonella
Fortunato, Anna Anselmo, Francesco Giordani, Vanessa Vera Fain, Nino D'Amore, Florigio Lista Paola Stefanelli, Angela Di Martino, Alessandra Lo Presti, Stefano Fiore, Massimo Di Benedetto, Silvia Fillo, Giovanni Faggioni, Riccardo De Sanctis,
Antonella Fortunato, Anna Anselmo. Francesco Giordani, Vanessa Vera Fain, Nino D'Amore, Florigio Lista Paola Stefanelli, Angela Di Martino, Alessandra Lo Presti, Stefano Fiore, Giacomo Mezzapelle, Silvia Fillo, Giovanni Faggioni, Riccardo De Sanctis,
Antonella Fortunato, Anna Anselmo, Francesco Giordani, Vanessa Vera Fain, Nino D'Amore, Florigio Lista Paola Stefanelli, Angela Di Martino, Alessandra Lo Presti, Stefano Fiore, Mario Rassu, Silvia Fillo, Giovanni Faggioni, Riccardo De Sanctis, Antonella
Fortunato, Anna Anselmo, Francesco Giordani, Vanessa Vera Fain, Nino D'Amore, Florigio Lista lacobellis M, d'Avenia M, Piluscio R, Parisi A, Chiara M, Manzari C, Pesole G

"Giorgio Giurato (Corresponding Author), Francesca Rizzo (Corresponding Author), Alessandro Weisz (Corresponding Author), Gianluigi Franci, Giovann

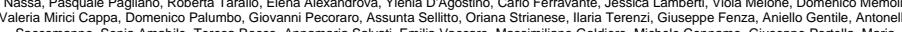

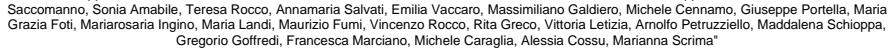

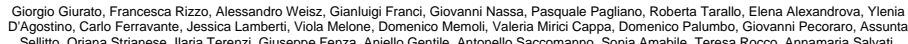
Sellitto, Oriana Strianese, Ilaria Terenzi, Giusepee Fenza, Aniello Gentile, Antonello Saccomanno, Sonia Amabile, Teresa Rocco, Annamaria Salvati,
Emilia Vaccaro, Massimiliano Galdiero, Michele Cennamo, Giuseppe Portella, Maria Grazia Foti, Mariarosaria Ingino, Maria Landi, Maurizio Fumi,
Vincenzo Vincenzo Rocco, Rita Greco, Vittoria Letizia, Arnolfo Petruzziello, Maddalena Schioppa, Gregorio Goffredi, Francesca Marciano, Michele Caraglia, Alessia
Cossu, Marianna Scrima 
bioRxiv preprint doi: https://doi.org/10.1101/2021.07.21.452479; this version posted July 22, 2021. The copyright holder for this preprint (which was not certified by peer review) is the author/funder, who has granted bioRxiv a license to display the preprint in perpetuity. It is made available under aCC-BY 4.0 International license.

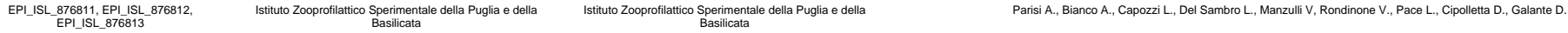

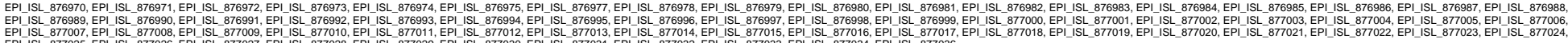

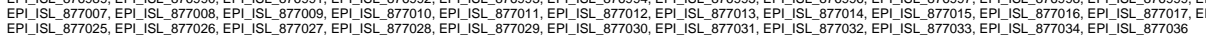
see above

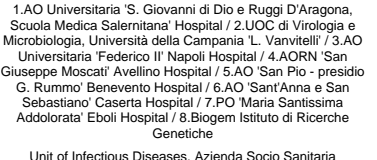
1. Genome Research Center for Health (CRGS) $/ 2$.
Lentory of Molecular Medicine and Genomics (LMMGe)/3.
Center for Research in Pure and Applied Mathematics
(CRMPA)

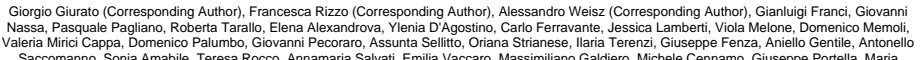

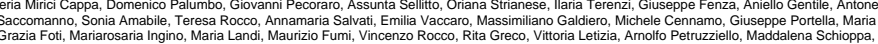
ingino, Maria Landi, Maurizio Fumi, Vincenzo Rocco, Rita Greco, Vittoria Letizia, Arnolfo Petruzz,
Gregorio Goftredi, Francesca Marciano, Michele Caraglia, Alessia Cossu, Marianna Scrima

EPI_ISL_882883

$$
\begin{aligned}
& \text { Unit of Infectious Diseases, Azienda Socio Sanitaria } \\
& \text { Territoriale di Cremona }
\end{aligned}
$$

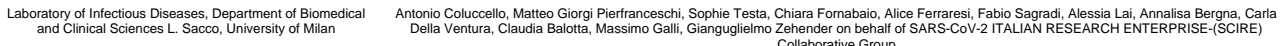

EPI_ISL 883499, EPIISL_887506,
EPI_ISL_887507, EPI_ISL_-894218

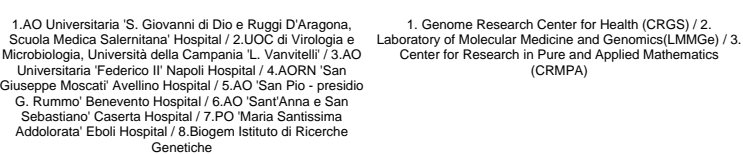

EPI_ISL_918128, EPI_ISL_918412, EPI_ISL_918413, EPI_ISL_918414, EPI_ISL_918415, EPL_ISL_918416, EPI_ISL_918417, EPI_ISL_918418, EPI_ISL_918419, EPI_ISL_918420, EPI_ISL_918421, EPI_ISL_918422

see above

EPIIISL-934419, EPIIISL9934420,
EPI_ISL_934421, EPI_ISL_934423

EPI_ISL_990753 EPI_ISL_954216

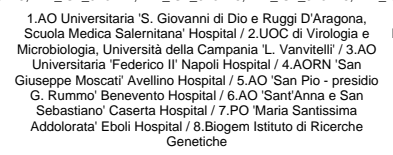

1.AO Universitaria 'S. Giovanni di Dio e Ruggi D'Aragona,
Scuola Medica Salernitana' Hospital / 2. UOC di Virologia e

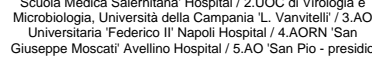

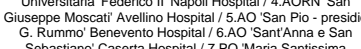
Sebastiano' Caserta Hospital / 7.PO 'Maria Santissima
Addolorata' Eboli Hospital / 8.Biogem Istituto di Ricerche
Genetiche

University of Bari Biomedical Sciences and Human Oncology University of Bari Biomedical Sciences and Human Oncology 1.AO Universitaria 'S. Giovanni di Dio e Ruggi D'Aragona,
Scuola Medica Salernitana' Hospital / 2. UOC di Virologia e Scuola Medica Salernitana' Hospital / 2.UOC di Virologia e
Microbiologia, Universitid della Campania 'L. Vannitell' $/ 3 . A 0$
Universitiaria 'Federico II' Napoli Hospital / 4.AORN 'San Giuseppe Moscati' Avellino Hospital / 5.AO 'San Pio - presid
G. Rummo' Benevento Hospital / 6.AO 'Sant'Ann G. Sebastiano' Caserta Hospital / 7.PO 'Maria Santissima
Addolorata' Eboli Hospitial / 8.8Bogem Istituto di Ricerche
Genetiche

Center for Research in Pure and Applied Mathematics 1. Genome Research Center for Health (CRGS) $/ 2$.
Laboratory of Molecular Medicine and Genomics(LMMGe) / 3 .
Center for Research in Pure and Applied Mathematics 1. Genome Research Center tor Health (CRGS) $/ 2$.
Laboratory of Molecular Medicine and Genomics(LMMGe)
Center for Center for Research in Pure and Applied Mathematics
(CRMPA)

\section{Genome Research Center for Health (CRGS) / 2 os}

Giorg
Nass
Valeria
Saca

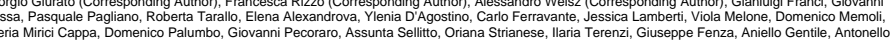
Saccomanno, Sonia Amabile, Teresa Rocco, Annamaria Salvati, Emilia Vaccaro, Massimiliano Galdiero, Michele Cennamo, Giuseppe Portella, Maria
Grazia Fot Gregorio Goffredi, Francescam Marciano, Michele Caraglia, Alessia Cossu, Marianna Scrima

\section{Nalsar}

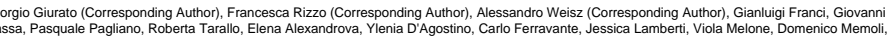
Saccom Mirici Cappa, Domenico Palumbo, Giovanni Pecoraro, Assunta Sellitto, Oriana Strianese, llaria Terenzi, Giuseppe Fenza, Aniello Gentile, Antonelli Saccomanno, Sonia Amabile, Teresa Rocco, Annamaria Salvatit, Emilia Vaccaro, Massimiliano Galdiero, Michele Cennamo, Giuseppe Portella, Maria
Grazia Fotit, Mariarosaraia IIngino, Maria Landi, Maurizio

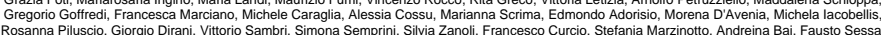

Chironna M., Sallustio A., Loconsole D., Accogli M.

Giorgio Giurato, Francesca Rizzo, Alessandro Weiszz, Gianluigi Franci, Giovanni Nassa, Pasquale Pagliano, Roberta Tarallo, Elena Alexandrova, Ylenia
'Agostino, Carlo Ferravante Jessica Lamberti, Viola Melone, Domenico Memoli, Valeria Mirici Cappa, Domenico Palumbo, Giovanni Pecoraro, Assunta Sellitto, Oriana Strianese Ilaria Terenzi, Giuseppe Fenza, Aniello Gentile, Antonello Saccomanno, Sonia Amabile, Teresa Rocco, Annatria Astrat Emilia Vaccaro, Massimiliano Galdiero, Michele Cennamo, Giuseppe Portella, Maria Grazia Foti, Mariarosaria Ingino, Maria Landi, Maurizio Fumi, Vincenzo Rocco, Rita Greco, Vittoria Letiziza, Arnolfo Petruzziello, Maddalena Schiloppa, Gregorio Gotredi, Francesca Marciano, Michele Caraglia, Alessia
Cossu, Marianna Scrima, Edmondo Adorisio, Morena D Avenia, Michela lacobelili, Rosanna Piluscio, Giorgio Dirani, Vittorio Sambri, Simona Semprini, 